UC-NRLF

|||||||||||||||||||||||||||||||||||||||||||||||||||

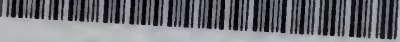

B 4519270 


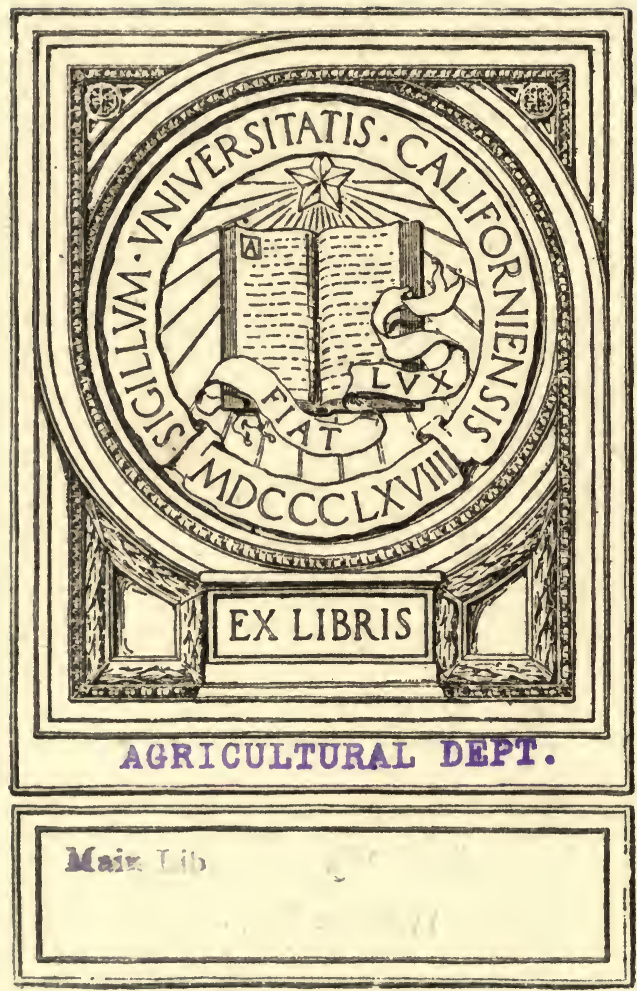








\section{Canada Dept of anriculture.}

\section{PRODUCTION}

AND

THRIF T

\section{Agricultural WAR BOo'K}

Published by direction of Hon. Martin Burrell, Minister of Agriculture, Ottawa, Canada, March, 1916 


\section{TO THE FARMERS OF CANADA}

TO the call for men, and more men, Canada has nobly responded, and 1 every day sees fresh battalions on their willing way to the Empire's battle line. To the unceasing and unselfish work of the women of Canada we all pay a heartfelt tribute, and the patriotic activities of our people in the cities and towns have made life a finer thing than it was before. But those concerned with the production of that which is the life-blood of armies in the field have been no whit behind. The farmers of Canada realizing as perhaps never before the important part that the production of food stuffs plays in such a gigantic struggle, looked upon their calling and responsibilities with deeper respect and broader view, and made strong efforts to give their assistance by increasing production along all possible lines. To what extent, small or great, the appeal made last year was responsible for this, I cannot tell, but in any case I gladly here express my own and the Government's deep appreciation of the fine response made. The results have surpassed expectations. Canada from her abundance can help supply the Empire's needs, and this must be a comforting thought for those upon whom the heavy burden of directing the Empire's affairs has been laid. Gain or no gain the course before the farmers of Canada is as clear as it was last year-they must produce abundantly in order to meet the demands that may be made, and I believe this to be especially true in regard to live stock, the world's supply of which must be particularly affected in this vast struggle. Stress and strain may yet be in store for us all before this tragic conflict is over, but not one of us doubts the issue, and Canadians will do their duty in the highest sense of that great word.

MARTIN BURRELL, Minister of Agriculture. 


\section{THANKSGIVING IN ENGLAND FOR CANADIAN CROPS}

On Thursday last, writes a London correspondent, under date of Oct. 5, a church service such as has never before been held in London was celebrated when the Lord Mayor of London and the sheriffs paid a state visit to the old London church of St. Andrew Undershaft to attend the annual harvest thanksgiving service of the Baltic Exchange and the National Food Stuffs association. The service was noteworthy in being one of thanksgiving for the bountiful Canadian harvest. The Bishop of Willesden, whom you know better under the name of Bishop Perrin, former Bishop of British Columbia, gave the address in this, his parish church in the heart of old London, and to the assembled wheat kings of Britain, told a simple but eloquent record of the work of the Canadian wheat growers on the prairies. He gave a word picture of the great grain-raising areas of western Canada, told of the determination of Canadian farmers, when the question of food supplies for the motherland became acute, to provide all that was required, and their redemption of that promise in the production of a record crop. Also he spoke of the prodigal abundance of gifts of all kinds from Canada to Great Britain.

Many Canadians were present, and after the service they were the guests of Sir Charles Johnston, the lord mayor, who has extensive interests in western Canada. The collection, by the way, was devoted to the work of the churches in Canada as a thank-offering-another noteworthy feature.

The church of St. Andrew Undershaft is neglected by the average visitor to London, as are many of the old city churches, yet it has many points of interest, apart from having a Canadian bishop as its incumbent. Its name means "under the Maypole," as the Maypole which used to be erected there was higher than the church. This Maypole was taken down, as a result of one of the earliest riots against German encroachment on British traders. One May Day in the sixteenth century the apprentices of London assembled there to celebrate the national fête and combined to attack the Germans, with result that many were wounded and some killed. Judgment took form of the hanging of two London apprentices and the dismantling of the Maypole. The church contains the tomb of Stow, the historian, who was the only beggar to hold the royal license to beg, which entitled him to "seek alms of all my loving subjects of London and Westminster." 


\title{
THE WAR AND FINANCE
}

\author{
"The Economic aspects of the War are those on which the outcome \\ largely hinges."
}

\section{FROM THE BUDGET}

\section{SIR THOMAS WHITE, Mínister of Finance.}

Canada's Trade-We have been blessed with a most bountiful harvest, the greatest by far in the history of the Dominion, and this, coupled with the demand for war material, supplies and munitions, has given such stimulation and impetus to trade and industry that, notwithstanding the war, we are experiencing a high degree of prosperity.

Probably the outstanding feature of our national economy during the year has been the extraordinary change that has taken place in our international trade balance. For the fiscal year $1912-13$, it was adverse to the extent of over $\$ 300,000,000$; in $1913-14$ of $\$ 180,000,000$; and in $1914-15$ of $\$ 36,000,000$. For the present fiscal year it seems certain that we shall have a favourable trade balance in the neighbourhood of $\$ 200$,000,000 . That so great a change should have been effected in one year is a striking tribute to the marvellous productivity of the Dominion, and to the capability, industry, and thrift of our people. Our total trade for the year will aggregate approximately $\$ 1,200,000,000$, an increase of nearly $\$ 200,000,000$ in exports, and a slight reduction in imports. This is the largest aggregate trade in the history of the Dominion.

Production-From this viewpoint it is our true policy to augment our financial strength by multiplying our productive exertions, and by exercising a rigid economy that will reduce to the minimum all expenditures upon luxuries and non-essentials. Only in this way shall we be able to make good the loss caused by the withdrawal of so many of our workers from industrial activities, repair the wastage of the war, and find the funds for its continuance. It cannot be too frequently or too earnestly impressed upon our people that the heaviest burdens of the conflict still lie before us, and that industry and thrift are, for those who remain at home, supreme patriotic duties. Upon their faithful fulfilment our success and consequently our national safety may ultimately depend. Apart altogether from these higher grounds, it should be pointed out that, in-so-far as our present prosperity is based upon abnormal prices for our produce and upon the production of war material, it is precarious and transient, and dependent upon the continuance of the war and its conditions. On ordinary business grounds alone, the prudent husbanding of resources, and the wise conservation of profits, are dictated by the plainest considerations of practical wisdom and good sense. 
Cost of the War-Let us assume that our indebtedness on account of this war will reach $\$ 500,000,000$. At 5 per cent. the annual interest will amount to $\$ 25,000,000$. This sum, with a substantial amount added yearly for a sinking fund could, in my opinion, be met, provided strict economy be practised by governments, from the future revenues of the Dominion. In national finance, if debts can be funded, the practical question is that of payment of annual interest. But while this is so, the fact must not be overlooked that debt is debt, a financial obligation and burden upon the body politic, whether owed to investors at home or abroad. In making these observations it is my earnest desire that neither the House nor the country should gather the impression that we underrate the magnitude of the liabilities we are assuming or the gravity of the financial considerations involved in our participation in this great struggle. We believe, however, that the people of Canada desire the Government to put forward the maximum of effort in the cause, and that they will, both for the present and the future, be prepared cheerfully to bear whatever burdens may in consequence be placed upon them.

In this connection I think it opportune to state, on behalf 'of the Government, and as enunciating its settled policy, that, in providing our war expenditure, resort will not be had to taxation upon the farms, personal effects or incomes of those engaged in our great basic industry of agriculture.

Agricultural Credit-The future of Canada rests with the development of its great resources, of which the greatest and most fundamental is agriculture. This development is in turn bound up with the question of increase in population of the productive sort and the facilities afforded it for the application of its intelligence and industry. It is probable that in the straitened financial conditions that may prevail for some years forward the question of capital for the development of agriculture may be of paramount importance, and it is our intention to inquire carefully during the coming recess into this most important subject, with a view, if desirable in the public interest, to supplementing by federal aid existing facilities in this connection. Particularly will the question of establishment of a system whereby loans at reasonable rates repayable on the amortization principle engage the attention of the Government.

Victory-The conflict has developed and extended upon a scale and to an extent far beyond our expectations or imaginings at its inception. Looking backward over its tragic course and reflecting upon its varied fortunes, there has grown in the hearts and minds of all an ever-deepening sense of its increasing gravity and menace to the Empire's safety. But the Empire's courage and the Empire's strength have steadily grown with the growing peril. Never has our national spirit been more high, never our resolve more unshaken, never have we been more supremely confident of ultimate victory than we are to-day. We have taken the measure of our foe, we have estimated the resources of our manhood, and the other elements of Imperial power, and we steadfastly abide the issue in calm consciousness of inherent strength and the eternal justice of our cause. We fight for human progress and for human rights, and we can and shall endure unto the end. 


\title{
THE NATIONAL INCOME AND EXPENDITURE OF THE UNITED KINGDOM
}

\author{
“The Round Table," December, 1915.
}

Neither in peace nor in war does a nation live on money. Its gold and silver coins have, it is true, an intrinsic value of their own, but neither they nor its banknotes, nor its currendy notes, nor its bank deposits are its real wealth. Its real wealth is something quite different. It consists of all those existing things which the efforts and sacrifices of past generations, and of this generation too, have produced, and are from day to day producing. It is from this mass of wealth, which either has been produced in the past or is day by day being produced-i.e., from its capital and income-that a nation's needs, whether in peace or war, can alone be met. There is only one other source, and that a temporary and unstable one-namely, borrowing from other nations, or in other words the sale by foreign nations of their goods for the time being on credit. No inflation of credit, no increase of currency, no financial manipulation will of itself produce a single additional grain of wheat or a single additional cartridge.

It is interesting to compare the figures usually given by statisticians for the value of our capital and income as compared with Germany's, and for the respective expenditure of the two nations, a comparison that gives some remarkable results. Statistical figures of this nature can only be very approximately true, and other difficulties arise, in comparing results as between nations, whose standards of life and ways of living are very different. Nevertheless they form an adequate ground for broad comparisons. Dr. Helfferich, the present German Finance Minister, placed Germany's capital wealth in 1913 at something under $£ 16,000,000,000$. He estimated the United Kingdom's capital wealth at only $£ 12,000,000,000$. But British statisticians make a considerably higher valuation, and usually give for the United Kingdom the same figure as he gives for Germany-namely, $£ 16,000,000,000$. Since, then, the populations are respectively $68,000,000$ and $47,000,000$ our capital wealth per head is considerably greater, a result due no doubt in the main to our much greater holdings of foreign and colonial securities, which are usually said to equal about $£ 4,000,000,000$, though it is probable that they have of recent years largely decreased in value. The comparative figures for income yield still more striking results. For Germany we will take Dr. Helfferich's figures; for the United Kingdom the figures of the Census of Production of 1907, though since that date our wealth must undoubtedly have increased.

$$
\begin{array}{lrr}
\text { Goods and services produced and } & \multicolumn{1}{c}{\text { England }} & \multicolumn{1}{c}{\text { Germany }} \\
\text { received, about............. } & £ 2,150,000,000 & £ 1,960,000,000 \\
\text { Goods and services consumed..... } & 1,800,000,000 & 1,560,000,000 \\
\text { Surplus wealth.............. } & 350,000,000 & 400,000,000
\end{array}
$$

It is vital to grasp how all-important is a nation's annual production of wealth. Whether in peace or war what it lives on is what it produces from day to day. The figures quoted above show that the wealth-i.e., the materials, goods and servicesproduced each year in this country are not much less than one-sixth of the total capital wealth of the country, resulting from the efforts of all past generations. It is true that the great bulk of this annual production is immediately consumed, only something under one-fifth being added to the capital stock. Yet nothing could show more clearly that a nation's true wealth lies in the harmonious employment of the energy, skill, productive capacity, and thrift of its citizens. A nation's production of wealth is not something fixed. It is capable of being indefinitely expanded by the application of increased capital-i.e., by the savings of the nation transformed into additional or improved plant, into labour-saving devices, into increased motive horsepower per man, and, on the other hand, by the greater efficiency of labour, superior management, and the greater co-ordination of the efforts of labour and capital. But, if, owing to extravagance and failure to save the necessary capital, owing to inefficiency of labour, restriction 
of output, or bad organisation, owing to continued friction between capital and labour, a nation's income falls far below what it might be, then all classes will suffer and the nation as a whole fall behind its competitors.

On the side of consumption the growing wealth of a nation and its bad distribution tends to great waste. The growth of luxury diverts the nation's productive powers into supplying unproductive articles. All classes become wasteful in food, drink, clothing, and household economy generally. What this means may be gathered from Sir Robert Giffen's estimate, made some years ago, that 34 per cent. of the national expenditure is on food and drink, 13 per cent. on dress, and 16 per cent. in "house" expenditure, including rent, furniture, light, etc. The rich become wasteful in all their pleasures, motoring, dress, servants, etc. They demand that labour shall be uselessly employed in providing for all their unnecessary wants, and the less rich follow suit as best they can. Take one or two instances of wasteful consumption. Our drink bill in 1913 was over $£ 166,000,000$. All that money could have been productively employed. As it was, it went to employ labour, capital, and ability on the growth of barley and hops, the working of breweries and distilleries, and on the management of countless publichouses. In the end the product of all this great labour and effort had gone down the throats of the people, generally to their great detriment, and nothing remained. Had it been diverted for the betterment of our productive industries-suppose, for instance, that it had been employed in providing better motive power for our industries or in rebuilding our canals or in better clothing, housing, or education of the poorer classesour wealth would have been much greater. Again, when a rich man employs much labour and capital in his unproductive pleasures, in keeping, for instance, too large a number of men-servants or gardeners for pleasure gardens, or when his wife employs many dressmakers, they are diverting the nation's labour and capital from productive to unproductive wealth. Nor is it only the rich who err, though in their case the error is the more glaring and the less pardonable. The poorer classes in this country are perhaps less thrifty than their fellows in any great civilized country except the United States. Unfortunately there are too many millions for whom saving is practically an impossiblility. But, even where it is possible, it is a comparatively rare virtue, as the profits of public-houses, cinemas, theatres, and racecourse "bookies" show. Many social troubles would be remedied if both rich and poor learnt more of the true art of economical living.

\section{THE CAPITAL AND INCOME OF THE BRITISH EMPIRE}

The discussion hitherto has been confined to the financial and economic position of the United Kingdom. But it may be asked:-What about the resources of the British Empire as a whole? It is the British Empire, not the United Kingdom only, which is at war. There is no part of the British Empire that is not vitally concerned in the struggle. Are not the whole resources of the Empire available? And are they not much greater than the resources of the United Kingdom only?

In 1903 Sir Robert Giffen made the following estimate:-

\begin{tabular}{|c|c|c|}
\hline & Capital & Income \\
\hline Canada....... & $£ 1,350,000,000$ & $£ 270,000,000$ \\
\hline Australasia..... & $1,150,000,000$ & $210,000,000$ \\
\hline India.......... & $3,000,000,000$ & $600,000,000$ \\
\hline South Africa......... & $600,000,000$ & $100,000,000$ \\
\hline Remainder of Empire. & $1,200,000,000$ & $200,000,000$ \\
\hline
\end{tabular}

Here indeed is a great addition to the wealth of the United Kingdom alone, and since 1903 the wealth of the rest of the British Empire has been largely increased. Sir Robert Giffen then estimated the income per head of Canada and Australasia at $£ 48$, 
as against $£ 42$ for the United Kingdom. Since then the latter figure has increased to $£ 46$ and it is hardly open to doubt that the figure for Canada and Australasia has increased in proportion. Let us take it however at $£ 50$ per head. If the populations of Canada and Australasia are taken at $8,000,000$ and $6,000,000$ respectively, their annual incomes would then be $£ 400,000,000$ and $£ 300,000,000$ respectively. If Giffen is right in assuming that for a new country the income could be estimated at about one-fifth of the capital, then the capital of Australasia and Canada would be $£ 2,000$,000,000 and $£ 1,500,000,000$ respectively.

In truth, the great wealth of the British Dominions over the seas, while potentially of enormous value, is of use in the present war only insofar as it is employed on its objects. And it can be so employed only to the extent that the different parts of the Empire either meet out of their own resources their own cost of the war, or lend money out of those resources to the British Government, or in other words sell them their exports on credit, just as the United States by lending $£ 100,000,000$ is selling to France and England its goods to that extent on credit.

If the conclusions of this article are right, then the great difficulty of England will be to find the means to pay for her purchases of food, raw materials, and munitions from oversea. What greater help could the Dominions give than to advance her for the time being the money wherewith to buy the food and other materials which she can get from them?

Owing to the great economies in expenditure which she has made, and to her fine harvest, it is probable that Canada, instead of the usual heavy balance of trade against her, will, if her people continue to be economical, have a favourable balance of even up to $\$ 200,000,000$. Of this $\$ 125,000,000$ is required for interest on her external debt. But it is quite possible that she could raise by loan in New York an amount at least equal to the latter sum, in which case she would have her whole surplus available to lend to Great Britain. She will in so doing benefit herself as well. She will be merely foregoing the immediate enjoyment of her profits and building up for herself a reserve abroad which will be very useful to her after the war. It would, of course, serve the same purpose if she were to use her surplus to pay off any indebtedness to England shortly falling due. The more the Dominions were able to lend, the greater naturally would be England's purchases from them of food, munitions, and raw materials-in preference to neutrals. They would thus reap the immediate benefit of their loans.

It is wise therefore not to shut our eyes to the possibilities of the future. Germany has been forced to live on herself. Whether she can continue to do so indefinitely remains to be seen. We on the other hand have based our whole war policy on our ability to maintain our supplies from abroad. Fortunately there is no reason to assume that we shall not always maintain our power to buy a great deal abroad. Our ability to repay in the long run is undoubted, and it is therefore very greatly to the interest of the countries chiefly concerned to sell us their goods even on credit. If, however, these supplies were to be largely cut off, we should have to alter our policy, and try to make ourselves self-sufficient, or nearly so. That the Empire could do so if every part were ready to make the sacrifices required there is little doubt. But it would involve, on the part of the people of Great Britain particularly, efforts and sacrifices far greater even than any hitherto made.

It is therefore a matter of the first importance that we should preserve our credit and our buying power. To that end we must devote our whole energies to increased production and simultaneously to the strictest economy in consumption. And not only we in Great Britain, but the citizens of the Dominions too, so that they may, by giving their assistance not only in men, but in money, lend their decisive aid to help their brothers and ours in the trenches, and to carry the Empire victoriously through this great crisis. 


\section{THE NATION'S NEED}

The following manifesto drawn up and signed by a number of bankers and others in close touch with financial conditions in Great Britain has been given wide publicity throughout that country. The close touch that exists between Canada and Great Britain, particularly in financial matters, renders it almost equally applicable to Canada.

At this time of great national danger it is imperative that every citizen should realize the vastness of the work that Great Britain has to perform and should so act that the full strength of the nation may be put forth. Not only must everyone pull, but, in order that the work may be well within the nation's strength, all must pull together.

The Allied fleets have driven the enemy's ships from the seas, and have established a blockade of the enemy's coasts. The enemy are thus prevented from carrying on their foreign commerce except to a very small extent, their income is seriously curtailed and their financial strength diminished. Moreover, the fleet has enabled both the British people and their Allies to draw abundant supplies of food, of material and of munitions from all parts of the world, to conduct their foreign commerce much as usual, and to maintain their income at a high level. The closure of the Dardanelles and of the Baltic is, indeed, the only remaining impediment to the overseas commerce of the Allies.

On land the Allies have added steadily to their military strength from week to week ever since war began, not only actually but relatively to the enemy. Germany's hopes of victory depended upon a short and swift war. These hopes have been completely dispelled.

In a long war success depends mainly upon the respective financial resources of the combatants, and the consequent power of one of them to maintain, or to add to, its fighting strength when the other's is declining, or is not capable of expansion. It is not in doubt that the financial resources of the Allies, when fully mobilized and wisely controlled, will be vastly greater than the enemy's.

Therefore, the enemy's efforts have been directed to three essential matters:-

(1) To seize victory before the forces of the Allies could be mobilized in overwhelming strength.

(2) To reduce the economic and financial strength of the Allies.

(3) To prevent the Allies from making or purchasing sufficient equipment and ammunition for their ever expanding forces.

The endeavours of the enemy to accomplish these objects have been completely frustrated by the co-ordination of the armies, of the financial resources, of the equipment and of the munitions of the Allied nations. The success of the Allies in defeating the enemy's efforts to cripple them in men, munitions and money before they could assemble their full strength has now brought the war nearer to its final stage. The Allies have assembled new armies of overwhelming strength in France, in Russia, in Italy, and in Great Britain, and everything needed to equip them and to supply them with munitions has been secured, or is in process of manufacture. Indeed, only one thing is now needed to command victory. The only thing remaining to be done is to provide all the money needed to support these great armies of new men, and to pay for the vast quantities of arms and munitions now being manufactured in all parts of the world.

The task of finding the greater part of the immense sums of money needed by the Allies is the special duty of the British people, for they in particular possess the necessary 
financial resources. Their manufacturing power has not been reduced by invasion, their cities have not been destroyed, their ports have not been shut off from the rest of the world, and their income has not been diminished. Indeed, the income of the British people has been maintained at a very high level. Their exports, though not as great as before the War, are greater than they were as recently as 1909 , their income from interest on capital invested abroad has been reduced but little, the earnings of their ships are greater than ever, and their factories are working full time. Moreover, the effect upon the production of the nation of the mobilization of a great army has been largely neutralized by the more vigorous and effective work of the civilian population in general and of the women in particular. Lastly, the average individual income is much in excess of any total hitherto reached. Thus the power of Great Britain to meet her own expenditures and the sums needed by her Allies is very great.

What is it, then, that the country has to do? The Chancellor of the Exchequer has informed the nation that the Government expenditure in the fiscal year will be:-

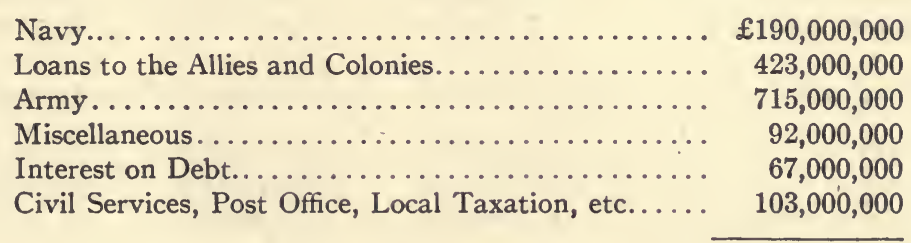

Total............ £1,590,000,000

And that in $1916-17$ the expenditure will reach $£ 5,000,000$ per day, or $£ 1,825,000,000$ per annum.

Therefore, the work that the British people are called upon to perform is to provide out of all their financial resources a sum of nearly $£ 1,600,000,000$ in the current fiscal year, and over $£ 1,800,000,000$ in the next fiscal year. In the current calendar year (1915) the British people will spend about $£ 1,300,000,000$ upon war and government, and next year (1916) will need to spend about $£ 1,800,000,000$ in place of a sum of about $£ 200,000,000$ a year before the war. To raise this vast sum is a stupendous task, and one that will try the mettle of the nation as it has not been tried for a hundred years. Not only has the nation to find this great sum of $£ 1,800,000,000$ in 1916 , but it has to find it with several millions of its most active sons in the fighting line.

No one can realize the vastness of the task before the nation without becoming keenly conscious that it demands the strenuous co-operation of every man and woman, youth and maiden in the country; that the nation's energies must be completely concentrated upon the production of really essential things; and that the production of all non-essentials must be wholly stopped. Moreover, not only must the nation avoid the consumption of all non-essentials, but must even restrict the consumption of essentials to the limits of efficiency. Furthermore, individuals possessing securities marketable abroad must sell them in order to pay for goods and munitions purchased abroad for which no other means of payment can be provided. Lastly, the credit of the nation and of individuals must be employed in order to pay for goods and munitions purchased abroad for which payment cannot be made in goods, services, or securities. Only by all classes, employers and employed alike, adding to, and most carefully husbanding, income, by selling foreign securities and by creating foreign credits, will it be possible to provide the vast sum noeded by the nation and the nation's Allies.

The work of mobilizing the whole of the nation's financial resources must now be undertaken with courage and with vigor.

With everyone anxious "to do his bit," the task of financing the War can and will be accomplished and ultimate victory assured. 


\section{COST OF THE WAR}

A recent estimate states that the warring nations are spending $\$ 70,000,000$ a day.

That Germany's military expenditures are $\$ 18,000,000$ daily.

That Great Britain is now spending monthly $\$ 600,000,000$, France $\$ 501,000,000$, and Russia $\$ 400,000,000$.

That the first two years of hostilities will have cost Great Britain nearly $\$ 12,000,000,000$.

The London Economist gives the following estimate to March 31st:-

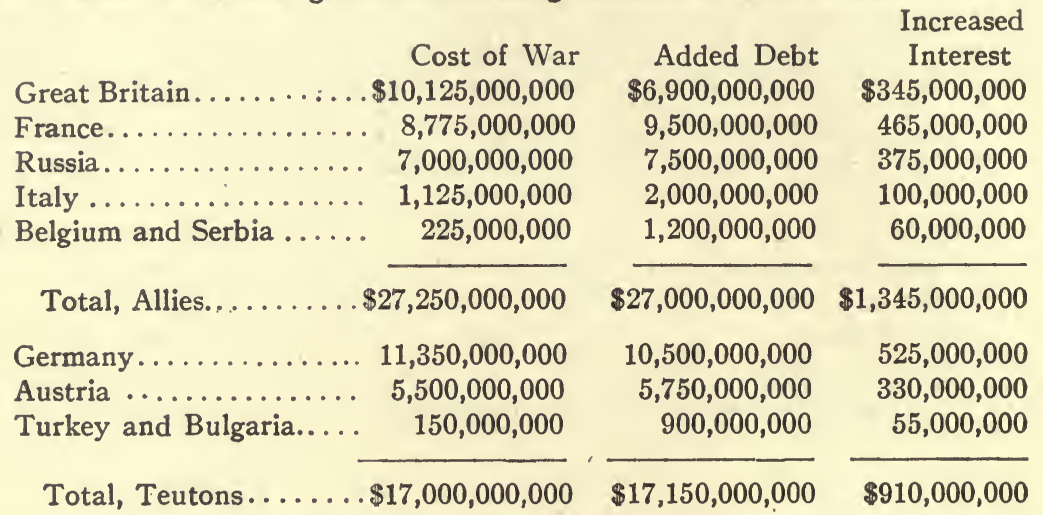

\section{BELLIGERENTS' BORROWINGS}

Up to the close of 1915 the fighting nations had borrowed the colossal sum of thirty billion dollars. Three-fifths of this sum was floated by Great Britain and her Allies. The other two-fifths were from Germany, Austria-Hungary, Bulgaria and Turkey. Of the total borrowings of belligerents and neutrals since the outbreak of war $(\$ 30,184,000,000$ plus $\$ 353,380,000) \$ 800,000,000$ was raised in the United States. It is interesting to observe that German Government bonds to the extent of only $\$ 10,000,000$ were sold in the American Republic, while the Allies' borrowings in that field totalled $\$ 525,000,000$.

The following table summarizes the war loans above referred to:

\section{Allies}

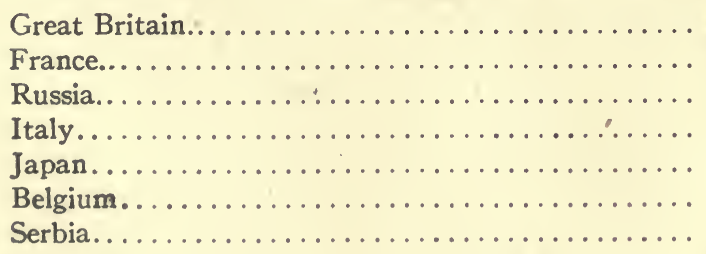

Total. .

\section{Central Powers}

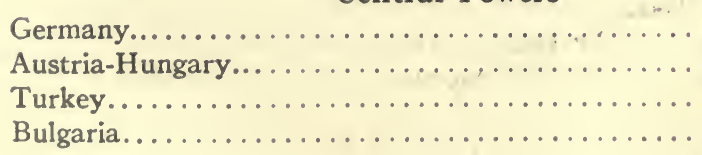

Total.

Total belligerents................... \$30,184,000,000

Neutral countries................. $353,380,000$
$\$ 12,281,000,000$

$\$ 6,265,000,000$ $7,931,000,000$ $3,148,000,000$ $415,000,000$ $26,000,000$ $100,000,000$ $18,000,000$

$\$ 17,903,000,000$

$\$ 9,270,000,000$ $2,731,000,000$ $250,000,000$ $30,000,000$ 


\section{PRODUCE MORE-SAVE MORE}

\section{SIR THOMAS WHITE}

It is true that war is the first business of Canada, until success crowns our cause. But it is nevertheless true that modern war is made by resources; by money; by developed natural resources; by products; by foodstuffs; as well as by men and by munitions. And while war is our first business, it is the imperative duty, I repeat, of every man in Canada to produce all that he can, to work doubly hard while our soldiers are in the trenches, in order that the resources of the country may not only be conserved but increased for the great struggle that lies before us.

The people of Canada can preserve their credit and keep the nation strong for the war by increasing production and exercising a reasonable economy.

"Work harder, save more," is a good motto for war time.

I do not know any other way for Canada to become a lending country than to save more money, produce more and save more; I do not know any way whereby an individual can save money and have it for investment, except by the old fashioned mode of living within his income and saving his profits to the extent that he can. I do not believe there is any magic method. If there is one put forward, prima facie, I disbelieve in it. The way for Canada to become a lending country is for Canada to produce all she can and to save what she can, and by production and saving Canada has been enabled to meet the vicissitudes of the past year as none of us ever expected she would be able to meet them, and by production and saving Canada will in time become a lending nation and be able to find the money for her own works and be able probably to do something more in the way of buying international securities.

\section{TRADE OF CANADA}

\section{Twelve Months Ending January 1914, 1915 and 1916}

1914

$\$ 647,233,510 \quad \$ 470,698,226$
1916

Imports of Merchandise for consumption......................
Exports of Canadian Produce(Merchandise)

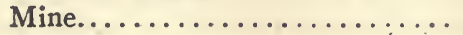

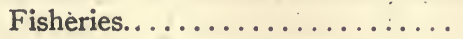

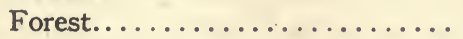

Animal produce...............

Agricultural produce..........

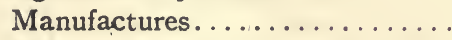

Miscellaneous.............

\begin{tabular}{rrr}
$\$ 59,100,714$ & $\$ 53,084,863$ & $\$ 62,960,628$ \\
$20,988,841$ & $18,661,560$ & $22,407,687$ \\
$42,707,781$ & $41,523,344$ & $51,211,820$ \\
$52,361,474$ & $70,727,132$ & $99,056,115$ \\
$211,322,370$ & $126,262,825$ & $237,964,468$ \\
$55,473,978$ & $71,870,071$ & $190,997,981$ \\
111,122 & 542,920 & $4,666,732$ \\
\hline$\$ 442,066,280$ & $\$ 382,672,715$ & $\$ 669,265,431$
\end{tabular}

Note:-Not including imports and exports of coin and bullion, nor exports of foreign produce. 


\section{CANADA'S FOREIGN INDEBTEDNESS}

\section{Outstanding Canadian Loans in London for the year ended June 30, 1914 and 1915}

\begin{tabular}{|c|c|c|}
\hline \multirow[t]{2}{*}{ 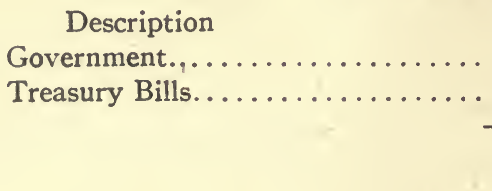 } & $\begin{array}{r}1914 \\
£ 65,956,621 \\
3,000,000\end{array}$ & $\begin{array}{c}1915 \\
£ 72,284,788\end{array}$ \\
\hline & $68,956,621$ & $72,284,788$ \\
\hline \multirow{3}{*}{ 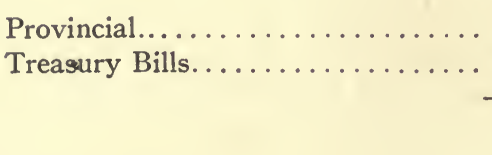 } & $24,202,327$ & $24,202,327$ \\
\hline & $1,625,000$ & 825,000 \\
\hline & $25,827,327$ & $25,027,327$ \\
\hline \multirow{3}{*}{ 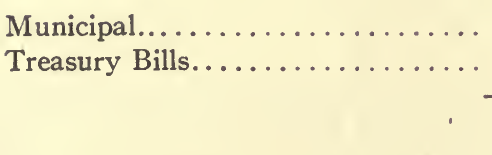 } & $50,876,310$ & $50,809,710$ \\
\hline & $1,610,020$ & 460,000 \\
\hline & $52,486,330$ & $51,269,710$ \\
\hline \multirow{3}{*}{ 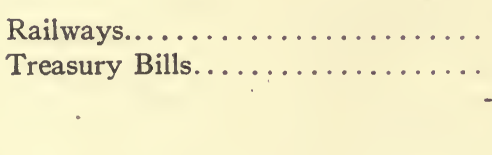 } & $285,788,492$ & $291,793,670$ \\
\hline & $1,260,959$ & 850,000 \\
\hline & $287,049,451$ & $292,643,670$ \\
\hline \multirow{2}{*}{$\begin{array}{l}\text { Industrials. . . . . . . . . . . . . . } \\
\text { Sundries not publicly recorded (esti- } \\
\text { mated) } \ldots \ldots \ldots \ldots \ldots \ldots \ldots \ldots\end{array}$} & $87,098,919$ & $87,096,519$ \\
\hline & $25,000,000$ & $25,000,000$ \\
\hline
\end{tabular}

The only material change in the above figures since 30 th of June last has been the reduction of Treasury Bills afloat in London, from $£ 2,135,000$ to $£ 325,000$.

Including the Dominion Government loan of $\$ 45,000,000$ floated in New York in August last,Canada's indebtedness to the United States is probably in the neighbourhood of $\$ 750,000,000$.

-Sir F. Williams-Taylor, General Manager Bank of Montreal.

"The problem of finance underlies all the other problems. The nation's need in the matter of men and munitions has been, or is in course of being, supplied, but nearly all the money has still to be found with which to maintain the forces and to supply them with arms and equipment in 1916. This is the work that must now be carried on from hour to hour by everyone in the nation with unflagging persistency until victory is secured."-THE STATIST. 


\section{PRODUCTION IN 1915}

"Never before has the true worth of our agricultural production been so impressed upon the mind as a fundamental factor in the industrial and financial situation as at the present moment."

\section{THE FARMERS' RESPONSE TO THE EMPIRE'S CALL}

\section{C. JAMES}

A year ago the Minister of Agriculture determined that the situation should be fully set before the farmers of Canada. With the hearty assistance of the press of Canada this was done. The results were most gratifying. Some seem to think, however, that the wheat crop is the main or only farm production of Canada, and have credited it in 1915 solely to favourable weather. True it is that Providence favoured the grain crops over the larger portion of the West; but if the farmers had not paid more than usual attention to good cultivation and good seed, and had not worked early and late with a larger acreage and in the harvesting of the crops, Canada would to-day be many, many millions of dollars poorer than she is.

The wheat crop of the prairies was worth about $\$ 275,000,000$; a big crop, the biggest ever known in Canada, but after all, only a little if any over one-quarter of the entire farm production of the Dominion.

In addition to the Prairie Provinces, there are six other provinces in Canada, and there are many other products besides wheat. Favourable weather did not prevail all along the line, and yet, every province responded. What of the beef and the bacon, the cheese and the eggs, the fruit and the vegetables?

What about dairying? In Ontario the output was twenty per cent. over 1914, and the market prices were increased ten to twenty percent. Alberta and Saskatchewan also made big increases in dairy production; so did other provinces. In 1910, according to the Dominion Dairy Commissioner, the milk products of Canada were worth approximately $\$ 110,000,000$. It is a safe estimate to put the dairy output of Canada for 1915 at $\$ 150,000,000$. While discussing wheat we should not forget the dairy cow. She has done more for Canada during the past ten years than have our wheat fields, and in view of what is now happening the world over, there is a possibility that the dairy products of Canada in 1916 may exceed wheat in value. The wheat fields reached their maximum yield per acre in 1915 , the dairy cow is only getting into her stride. She is now producing $4,000 \mathrm{lbs}$. or less a year; $10,000 \mathrm{lbs}$. a year is what the dairymen are working for.

Lumping all the farm products together, and deducting the food fed to stock, we estimate that, in 1915, the farms, orchards and gardens of Canada gave a net product of over a billion dollars.

Perhaps the people of Canada have not yet fully realized what the farmers did accomplish last year through hard work, good management, determination, and patriotism. The farm products of all Canada in 1915 exceeded in value the farm products of any previous year by at least $\$ 300,000,000$. It is well for our public men and our writers to know that the increase in the value of the farm products in 1915 was at least three times in value our entire output of war munitions. 


\title{
HOW THE PROVINCES RESPONDED
}

Ontario-The reports received by the Provincial Department of Agriculture indicate that never before was such a genuine effort put forward by the farmers to adopt the best methods of cultivation and the best varieties of seed, in fact to do everything in their power to assure the maximum supply of food stuffs. Aggregrate yields show considerable increases in almost every crop. There is no doubt that the patriotic appeal was one of the most influential factors in this regard.

First let us look for a moment at what the records for Ontario show. Wheat is as you all know one of the fundamental staples and yet it is quite true that this Province during the many years past has been gradually decreasing its wheat acreage. The reasons for this are not hard to find and need not be dwelt upon here. The point I wish to make is that in the year 1915 under the stress of the present war, Ontario increased its wheat area by 40 per cent. and produced a crop 75 per cent. greater in amount than that of the previous year. Furthermore only once in the last thirty years has such a crop of wheat been produced on Ontario farms as that which was produced in 1915. Nor was this accomplished by sacrificing other crops. Oats gave an increased yield of 25 per cent., barley of 15 per cent., hay of 15 per cent., and so I might continue through the list of the different branches of our varied agriculture in like manner. Dairying showed an increase of 25 per cent. and enjoyed by all odds the record year of its history in this Province. Without going into live stock and other important branches, it may suffice to say that the total value of the field crops in 1915 was $\$ 12,000,000$ greater than in 1914 , when we had good crops and high prices, and $\$ 54,000,000$ greater than during an average of 10 years. This is a splendid record for Ontario and shows vitality which promises to keep it the banner Province of the Dominion.

-W. B. Roadhouse, Deputy Minister of Agriculture.

Manitoba-Manitoba's 1915 grain crop stands as a record in the history of the Province. Authentic reports are in many cases astounding. Wheat yields of 30 to 35 bushels per acre for a district are reported from every section, while yields averaging 40 bushels per acre for whole districts are not uncommon. Individual fields on summer fallow, potato land, etc., have gone as high as 60 to 70 bushels. Oats in several districts are said to have averaged 80 to 100 bushels.

These phenomenal yields can be attributed to no single cause, but among the reasons advanced these appear to be most important: First, more land was well prepared in the fall of 1914 than had ever been the case previously. This certainly had a beneficial effect on the crop. Second, a liberal rainfall in the month of June was also advantageous. Third: the wheat crop this year bore a wonderful bloom. Practically every cell of the wheat head was fertilized, and each head filled wonderfully well.

\section{-A. J. McMillan, B.S.A., Deputy Minister of Agriculture.}

\begin{abstract}
Alberta-During the past year our farmers responded to the Empire's call for "More and more production" in a manner that reflects on them great credit. A splendid effort was made, not only to enlarge the area under crop, but to increase live stock and all other productions. This effort, combined with an unusually favourable year, resulted in producing what is perhaps the greatest grain crop ever grown anywhere. Fifty and sixty bushels per acre were quite common, and in not a few localities, seventy and even eighty bushels of wheat per acre were vouched for. The potato area was five thousand acres with a total yield of nine million bushels, thus meeting the deficiency in Eastern Canada. Other root crops showed a very large increase and on the whole the year's harvest was away and beyond all previous records.
\end{abstract}

- Chas. S. Hotchkiss, Publicity Commissioner. 
The farmers of Alberta made a fitting response to the call for increased production during the year 1915. They reaped not only the moral reward of having contributed to the Empire's needs, but they also secured a higher material reward than commonly results from their labour.

\section{-H. A. Craig, Deputy Minister of Agriculture, Alberta.}

British Columbia-This province readily responded to the slogan, resulting on the whole in an increased area in field crops. In crop yields and in the production of live stock an even greater proportionate increase is shown.

\section{-A. B. Tweddle, Assistant Statistician.}

Nova Scotia-Grain and roots fell 20 per cent. short in yield per acre, and only the increased acreage, the result of the "Patriotism and Production" campaign, is responsible for filling the grain bins and the root cellars. The year witnessed a 40 per cent. increase in dairy production.

\section{-M. Cumming, B.A., B.S.A., Secretary for Agriculture.}

New Brunswick-The campaign conducted in the interests of increased production was well received and had considerable effect. Prices for all farm products have been well maintained, and the farmers find themselves in excellent financial condition.

Live stock men were active, and more pure-bred stock changed hands or was imported than in any two recent years.

The farmers of the province have entered upon the second year of the war with the firm determination to do their part until the end. Hundreds of young men have left the farms to join the colours, and the province is facing a labour shortage, but ways and means will be found to meet the demand and keep production up to the standard.

-J. B. DAgGetr, Secretary for Agriculture.

\section{SASKATCHEWAN'S BIG YEAR}

One would naturally expect a Canadian province to increase her production of grain in war time, but the Province of Saskatchewan surpassed itself in 1915. Those interested in Canadian matters, will perhaps recall that 1914 saw Southwest Saskatchewan and Southern Alberta suffering from drought with consequent crop loss, so that the astonishing yields of the 1915 grain crop over the same area possess added interest. It was a common occurrence for oats in Saskatchewan to yield over 100 bushels to the acre, and wheat anywhere from 40 to 60 bushels per acre. At Rosetown for instance, J. G. Carruthers had a fifteen acre field of oats that gave an average yield per acre of 116 bushels. In the same district $H$. Macey grew 110 acres of wheat which yielded him 52 bushels per acre, or 5,720 bushels in all. Going south we find that John Neigel at Prussia, with 420 acres of wheat had an average yield of 47.6 bushels. At Lancer, Ernest Lipsit harvested 570 bushels of wheat from ten acres. At Webb, A. D. Spooner saved 6,776 bushels of wheat off 150 acres. At Rosthern, Seager Wheeler-but most people in the wheat world know what he has done, so it is hardly necessary to mention that this year he again won the World's Championship at Denver for best hard wheat.

According to Provincial Government data, the average yield of wheat per acre in Saskatchewan was 25.2 bushels, while the south-western part of the province gave an average yield of 31 bushels. Dealing with the crop en bloc, we find Saskatchewan produced $173,723,775$ bushels of wheat, most of it of high grade. Oats, too, did exceedingly well, and if we base "the value to producer on the farm" on October-November prices (December prices were better, but not yet compiled) for wheat and oats alone, the Saskatchewan farmer is two hundred million dollars to the good. Throwing the 
whole of this year's crop into the scales, it represents some $\$ 281.25$ for each man, woman and child in the province.

Luxuriant was the only word to describe the growth of grain crops, alfalfa, timothy and other grasses in Western Saskatchewan last year. Foliage in the lower portion of the province is not profuse, but if the Garden of Eden looked as enticing as did Saskatchewan during the past summer, it is difficult to understand why the Garden was forsaken so soon.

\section{ALBERTA'S BIG WHEAT CROP}

Latest provincial estimates place the average wheat yield for Alberta at about 33 bushels per acre: Acreage, 1,563,700; production, 51,355,000. Though all parts of the Province have contributed to the increased average and grand total, it is in the southern part of the province where both the yield and the acreage have been increased.

The large crop is the result of natural and controlled causes combined. When moisture is not too plentiful, it is important that it should be available during the growing season. In 1914 the records of precipitation at the Experimental Farm in Lethbridge for the months of May, June and July show a total of only 3.7 inches. In 1915 the total for the same period of three months was 11.31 . This practically insured a crop as far as moisture was concerned, independent of the use of methods of cultivation for moisture conservation.

At the same time the improvement in yields must be ascribed largely to the summerfallow. A succession of lean years has established the need of summer-fallowing, in the area under the characteristic influence of the Chinook, every other year, or at least once in three years. In the fall of 1915 there was a large area of summer-fallow. There was also such precipitation as made fall ploughing possible on practically all kinds of land, and the country responded actively to the call for increased production. There was little crop to harvest in the autumn of 1914 , so that the land was clear and the farmer was not busy. Yields of a phenomenal kind are reported on summer-fallowed land. The partial failures of the two or three years previous and the rich returns for work on the land in 1915 will no doubt establish better tillage practice in all of the southern part of the province.

Another reason for the heavy yields was the large quantity of heavy yielding varieties of wheat sown-i.e., Marquis. Considerable seed was supplied by the Federal Government. It was obtained from the best supplies available and was of a grade that was satisfactory to the Dominion Department of Agriculture.

-J. McCaIG, Editor of Publications, Edmonton.

\section{A Great Change}

Mr. J. T. Gordon, one of the West's foremost cattle men, and who is also president of the Standard Trusts Co. and a director of other financial institutions, says that "three years ago, the provinces of Alberta, Saskatchewan and Manitoba were importing their horses, a great deal of their fresh meat, I should say 75 per cent. of the hog product, their poultry, their eggs, their cheese, butter and everything that was wanted in large centres for the maintenance and support of the masses. What do we find today? Instead of these provinces importing and sending money into a foreign country where we never got any benefit, as it never came back and circulated, they are exporting every one of the items I have mentioned, with the exception of cheese and mutton. Within two years, we shall be exporters of those products. You will understand now why it is that interest payments have been so well met, up to the present time." 


\section{CANADA'S DAIRY INDUSTRY IN 1915}

\begin{tabular}{ccc} 
Ontario & \multicolumn{2}{c}{ Quantity } \\
& 1914 & 1915 \\
& lbs. & lbs. \\
Cheese output for province....... & $101,900,065$ & $115,500,000$ \\
Creamery output............. & $23,116,104$ & $21,350,000$
\end{tabular}

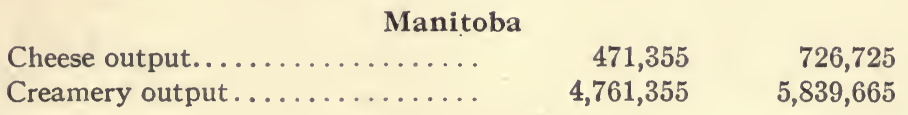

\begin{tabular}{|c|c|c|}
\hline \multicolumn{3}{|c|}{ Saskatchewan } \\
\hline Creamery output: & & \\
\hline Government Creameries....... & $1,398,731$ & $2,283,945$ \\
\hline Independent Creameries....... & No returns & $1,798,413$ \\
\hline
\end{tabular}

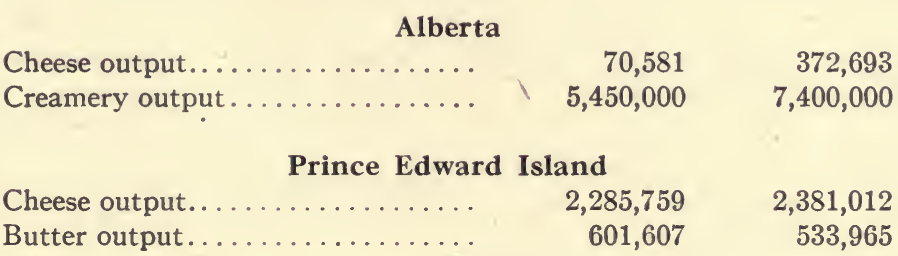

Statistics for Quebec, British Columbia, New Brunswick and Nova Scotia not available.

\section{FIELD CROPS OF CANADA, 1915}

The year 1915 will be memorable for the most abundant grain harvest ever reaped in Canada up to that time. With the prospect of high prices for wheat and other cereals, and responding to appeals for increased production on patriotic grounds, the farmers of Canada took the fullest advantage of their opportunities, with the result that the area sown to wheat for the harvest of 1915 was not only the largest on record in Canada, but exceeded the area sown in the previous year by $1,964,400$ acres, or nearly 18 per cent. Finally, the growing season was uniformly favourable, and the average yields per acre of all the principal cereals in Canada were higher than in any previous year on record. For wheat, the average yield per acre was close upon 29 bushels, or eight bushels more than the previous record of 21 bushels in 1913. The total area estimated to be sown to field crops in Canada for 1915 was $37,063,455$ acres, as compared with $35,102,175$ acres, the sown area, and $33,436,675$ acres, the harvested area, in 1914.

\section{Yield of Grain Crops}

As a result of the returns of the average yield per acre, made after threshing, the total yields of the grain crops in bushels for the season of 1915, compared with 1914, were as follows:- 


\section{Wheat-}

1914.

1915 .

\begin{tabular}{rccc}
\multicolumn{3}{c}{ Yield per } & \\
Area & acre & Total & Value \\
Acres. & bush. & bush. & $\$$
\end{tabular}

$10,293,900 \quad 15.67 \quad 161,280,000 \quad 196,418,000$ $12,986,400 \quad 28.98 \quad 376,303,600 \quad 312,569,400$

Oats-

1914.

$10,061,500$

31.12

$313,078,000$

$151,811,000$

1915

$11,365,000$

45.76

$520,103,000$

$176,894,700$

\section{Barley-}

1914.

1915 .

$1,495,600$

$1,509,350$

24.21

$36,201,000$

$21,557,000$

$53,331,300$

$26,704,700$

Rye-

1914..................

1915 .

111,280

112,300

18.12

21.32

$2,016,800$

$2,394,100$

$1,679,300$

$1,899,900$

\section{Peas-}

$1914 \ldots . \ldots \ldots \ldots \ldots \ldots \ldots \ldots$

1915

$205,550 \quad 17.64$

$196,210 \quad 17.73$

$3,362,500$

$3,478,850$

$4,895,000$ $5,730,700$

\section{Beans-}

1914

1915

$43,830 \quad 18.20$

$43,310 \quad 16.70$

797,500

723,400

$1,844,300$

$2,206,800$

\section{Buckwheat -}

1914.

1915 .

354,400

24.34

343,800

22.88

$8,626,000$

$7,865,900$

$6,213,000$ $5,913,000$

Flax-

1914

$1,084,000$

6.62

806,600

13.18

$7,175,200$

$10,628,000$

$7,368,000$

$15,965,000$

\section{Corn for Husking-}

1914....................

1915

256,000

54.39

$13,924,000$

253,300

56.72

$14,368,000$

$9,808,000$

$10,243,000$

\section{Potatoes -}

1914.

1915

Turnips, Mangolds, etc.-

$1914 \ldots \ldots \ldots \ldots \ldots \ldots \ldots \ldots$

1915

Hay and Clover-

1914.

1915.

\section{Fodder Corn-}

1914

1915 .

\section{Sugar Beets-}

1914.

1915 .

Alfalfa-

1914

1915.
$475,900 \quad 180.02$ $478,600 \quad 130.81$

$85,672,000$ $62,604,000$

$175,000394.30$ $172,700372.21$

$69,003,000$ $64,281,000$

Tons Tons

$7,997,000 \quad 1.28$

$7,875,000$

1.39

$317,000 \quad 10.25$

$343,400 \quad 10.00$

8.98

18,000

7.83

90,315

92,685

2.42

2.83

$10,259,000$

$10,953,000$

$3,251,480$
12,100

$41,598,000$ $35,964,000$

$18,934,000$ $16,560,000$

$145,999,000$

$155,807,000$

$15,949,700$ $3,429,870 \quad 16,999,100$ 
The quality of the grain crops in 1915 , as determined by the weight in lb. per measured bushel, is, with the exception of one or two crops, superior to that of the previous year and is also superior to the average of the last five years.

\section{Yield of Potatoes}

In Ontario the average yield per acre was not more than 92.66 bushels, almost the lowest yield of potatoes on record for the province. In the other provinces the potato yield was also poor, excepting in Alberta and British Columbia.

\section{Value of Field Crops}

The values are estimated from local market prices as returned by the crop-reporting correspondents of the Census and Statistics Office. For all wheat, in 1915, the average price per bushel for the whole of Canada is 39 cents less than that of last year and 8 cents more than that of the quinquennial average. Including the root and fodder crops, the total value of the field crops of Canada in 1915 amounts to $\$ 797,669,500$, comprising grain crops $\$ 568,161,900$, potatoes and sugar beets $\$ 36,739,500$, and fodder crops $\$ 192,768,100$.

\section{Wheat, Oats, Barley and Flax in the Northwest Provinces}

In the three northwest provinces of Manitoba, Saskatchewan, and Alberta, the production of wheat in 1915 is estimated at $342,948,000$ bushels, as compared with $140,958,000$ bushels in 1914 ; of oats at $334,840,600$ bushels, compared with $150,843,000$ bushels; of barley at $35,317,200$ bushels, compared with 19,535,000 bushels, and flax at $10,559,000$ bushels, compared with $7,083,000$ bushels.

The wheat production of 1915 in Manitoba was $96,425,000$ bushels from 3,342,900 acres, in Saskatchewan 195,168,000 bushels from 6,838,100 acres, and in Alberta $51,355,000$ bushels from $1,563,700$ acres.

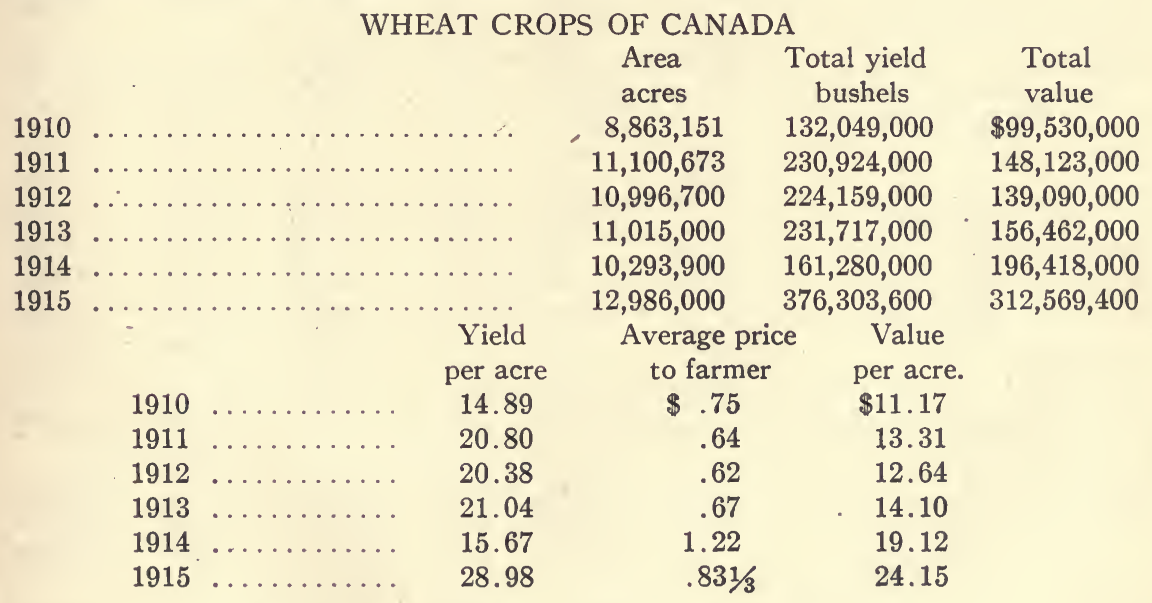

Exportable Surplus of Canadian Wheat, 1915

Based on an estimated yield of $376,303,600$ bushels, the quantity available for export out of the crop of 1915 is placed by the Census and Statistics Office at $264,173,300$ bushels.

The largest quantity of wheat previously exported from Canada in any one fiscal year was $142,574,000$ bushels in 1913-14. The quantity now estimated as available for export is $121,599,200$ bushels in excess of this amount, and represents about 70 per cent. of the total estimated wheat production of Canada in 1915. Moreover, for the first time, the Canadian wheat surplus proves more than sufficient to supply the annual average wheat deficit of the United Kingdom, which, according to official calculations published in the Journal of the English Board of Agriculture for September last, amounts to $215,209,300$ bushels. 


\section{FIELD CROPS OF THE UNITED STATES, 1915}

The Crop Reporting Bureau of the U.S. Department of Agriculture issued (December 15,1915$)$ the following estimates of the acreage production and value of the principal farm crops in the United States for the years 1914 and 1915, as compared with the annual average for the quinquennium 1909-13:-

\begin{tabular}{|c|c|c|c|c|c|c|}
\hline & & & Pro & ction & & \\
\hline Crop & . & Acreage & per & & per & \\
\hline & & & acre & Total & bush. & Total \\
\hline & & 000 acres & bush. & 000 bush. & cents. & $000 \$$ \\
\hline & .1914 & 103,435 & 25.8 & $2,672,804$ & 64.4 & $1,722,070$ \\
\hline & 1915 & 108,321 & 28.2 & $3,054,535$ & 57.5 & $1,755,859$ \\
\hline Average 1909-13. & $\cdots \cdots$ & 104,229 & 26.0 & $2,708,334$ & 56.4 & $1,527,969$ \\
\hline Winter wheat...... & .1914 & 36,0 & 19.0 & 684,990 & 98.6 & 675,623 \\
\hline & 1915 & $-40,4$ & 16.2 & 655,0 & 95.0 & 622,012 \\
\hline Average 1909-13. & $\ldots \ldots$ & & 15.6 & & 88.3 & 382 \\
\hline pring wheat........ & .1914 & 17,533 & 11.8 & & 98.6 & 057 \\
\hline & 1915 & 19,445 & 18.3 & & 86.5 & 290 \\
\hline Average 1909-13. & $\ldots \ldots$ & & 13.1 & & 81.2 & 253 \\
\hline 11 wheat......... & .1914 & 53, & 16.6 & & 98.6 & 680 \\
\hline & 1915 & 59,8 & 16.9 & 1,01 & 92.0 & \\
\hline Average 1909-13. & $\ldots \ldots$ & 47,097 & 14.6 & & 85.7 & 635 \\
\hline ats................... & .1914 & & 29.7 & & 43.8 & \\
\hline & 1915 & & 37.8 & & 36.1 & \\
\hline Average 1909-13. & $\ldots \ldots$ & & 30.3 & & 37.5 & \\
\hline Barley............. & .1914 & & 25.8 & & 54.3 & \\
\hline & 1915 & & 32.0 & & 51.7 & 499 \\
\hline Average 1909-13. & $\ldots \ldots$ & 7,619 & 23.0 & & 59.6 & 364 \\
\hline zye & .1914 & & 16.8 & & 86.5 & 7,018 \\
\hline & 1915 & & 17.2 & & 83.9 & 295 \\
\hline Average 1909-13. & $\ldots \ldots$ & & 15.6 & & 70.8 & 706 \\
\hline Buckwheat.......... & .1914 & 792 & 21.3 & & 76.4 & 892 \\
\hline & 1915 & 806 & 19.6 & & 78.7 & 408 \\
\hline Average 1909-13. & $\ldots \ldots$ & $843^{\circ}$ & 19.7 & & 69.7 & 11,576 \\
\hline laxseed........... & $\ldots 1914$ & 1,645 & 8.4 & & $\$ 126$ & 17,318 \\
\hline & 1915 & & 10.1 & & $\$ 174$ & 24,080 \\
\hline Average $1909-13$ & $\ldots \ldots$ & 2,490 & 7.8 & 19,501 & $\begin{array}{l}\$ 152 \\
\text { cents }\end{array}$ & 29,628 \\
\hline tot & .1914 & & & & 48.7 & \\
\hline & 1915 & & 95.5 & & 61.6 & 104 \\
\hline Average $1909-13$. & $\ldots \ldots$ & 3,677 & 97.0 & 356,627 & 60.5 & 215,893 \\
\hline & & & ton & & ton & \\
\hline av & .1914 & & 1.43 & 70,071 & $\$ 1112$ & \\
\hline & 1915 & & & & $\$ 1070$ & \\
\hline Average 1909-13. & $\ldots \ldots$ & 49,756 & 1.33 & & $\$ 1213$ & 800,670 \\
\hline gar Beets... & .1914 & 483 & 11.6 & 5,585 & $\$ 5.45$ & 30,438 \\
\hline & 1915 & 624 & 10.4 & 6,462 & $\$ 554$ & 35,800 \\
\hline Average 1909-13 & $\cdots$ & 502 & 10.6 & 5,342 & & $\ldots$ \\
\hline rerros & & & bbls. & $\begin{array}{c}000 \text { bbls. } \\
644\end{array}$ & $\begin{array}{r}\text { bush. } \\
\$ 393\end{array}$ & \\
\hline & 1915 & 17.8 & 25.8 & 457 & $\$ 623$ & 2,845 \\
\hline & & & & & & \\
\hline & & & .. & & $\$ 185$ & \\
\hline & 1915 & $\ldots$ & .. & 76,670 & $\$ 204$ & 156,407 \\
\hline
\end{tabular}

The prices in the above table are those paid to farmers on December 1,1915 . 


\section{FIELD CROPS OF ENGLAND AND WALES, 1915}

Statement showing the estimated total produce and yield per acre of the principal field crops in England and Wales for the year 1915, as compared with 1914, and with the annual average of the ten years 1905-14.

\begin{tabular}{|c|c|c|c|c|c|c|c|}
\hline \multirow[t]{2}{*}{ Field crops } & 1914 & 1915 & 1914 & 1915 & 1914 & 1915 & $\begin{array}{c}\text { Average } \\
\text { ten } \\
\text { years } \\
1905-14\end{array}$ \\
\hline & acres & acres & bush. & bush. & $\begin{array}{l}\text { bush. } \\
\text { per ac. }\end{array}$ & $\begin{array}{l}\text { bush. } \\
\text { per ac. }\end{array}$ & $\begin{array}{l}\text { bush. } \\
\text { per ac. }\end{array}$ \\
\hline Wheat....... & $1,807,498$ & $2,170,170$ & $58,456,288$ & $67,925,536$ & 32.34 & 31.30 & 32.02 \\
\hline Barley... & $1,504,771$ & $1,231,714$ & $49,391,584$ & $36,464,552$ & 32.82 & 29.60 & 33.18 \\
\hline Oats........ & $1,929,617$ & $2,088,009$ & $76,429,816$ & $83,617,024$. & 39.61 & 40.05 & 40.22 \\
\hline Beans....... & 284,371 & 257,655 & $8,669,616$ & $7,156,792$ & 30.49 & 27.78 & 30.28 \\
\hline Peas........ & 129,528 & 98,265 & $2,979,096$ & $2,393,808$ & 23.00 & 24.36 & 26.39 \\
\hline Potatoes.... . & 461,621 & 463,399 & $110,249,403$ & $106,702,885$ & 238.93 & 230.35 & 230.35 \\
\hline \multicolumn{8}{|c|}{ Turnips and } \\
\hline Swedes... & $1,042,438$ & 929,224 & $602,594,989$ & $528,933,082$ & 577.92 & 569.41 & 588.22 \\
\hline \multirow{2}{*}{ Mangolds.... } & 431,366 & 412,509 & $354,760,762$ & $350,989,542$ & 822.53 & 850.75 & 870.46 \\
\hline & & & long tons & long tons & $\begin{array}{l}\text { long } \\
\text { cwt. }\end{array}$ & $\begin{array}{l}\text { long } \\
\text { cwt. }\end{array}$ & $\begin{array}{l}\text { long } \\
\text { cwt. }\end{array}$ \\
\hline & & & $2,117,137$ & $2,287,703$ & 27.23 & 29.75 & 28.87 \\
\hline Meadow hay. & $4,785,451$ & $4,651,609$ & $5,148,241$ & $4,299,354$ & 21.52 & 18.49 & 23.25 \\
\hline
\end{tabular}

Note.-The root crops are converted from long tons to bushels at the rate of $60 \mathrm{lb}$. per bushel for potatoes and $50 \mathrm{lb}$. per bushel for turnips, swedes and mangolds.

"It is an imperative duty for our population to fill up, by their labour, the wide gaps caused by the war in the ranks of the tillers of the soil; a pressing obligation devolves upon holders of cultivable land to make every inch of soil produce its maximum to meet the enormous deficit in the world's production and to feed the Allies and countries starved by invasion.

"I repeat that the patriotic farmer's first duty, at this hour in our history, is to unceasingly increase his production; he will thereby contribute to the solution of the problem due to the excessive cost of living, the growth of our national riches and, consequently, to the support of Canadian finances and the triumph of the cause of the Allies in Europe."

-Hon. J. E. Caron, Minister of Agriculture, Quebec. 


\title{
PRODUCTION IS CANADA'S DUTY WHILE EMPIRE IS AT WAR
}

\author{
THE SUCCESS OF 1915 MUST BE REPEATED IN 1916
}

\begin{abstract}
Because modern war is made not only with men and with munitions, but also with money and resources, the policy for Canadians-the war policy and the economic policy-is for all those who cannot go to the front to put forth their best efforts to increase the production and wealth of the country; because this war, in my opinion, is going to be won by superior resources, and the superior resources are unquestionably on the side of the Allies. Apart from the question of financing the huge sums which we must find to do our part in this warapart from that, Canada, if she increases her production proportionately to what she has done this year, will be able easily to sustain the burden of the war. If she can finance, and she can, then the question which arises is that of paying the rapidly increasing interest on an expanding public debt, but when you set off against the interest payments an increased production of one, two or three hundred million dollars per year, the economic position becomes clear. If on the one hand you produce, say, three hundred million dollars of new wealth, and on the other hand you pay out fifteen million dollars in interest, I do not need to tell you, as business men, of the advantage, and how the country is going to get on. You will get on well, because you are increasing your production to such an extent; so that for those who do not go to the front, I would say, give to all the causes-the Patriotic Fund, the Red Cross, all the others-give continually, patriotically and generously, and on an increasing scale, because our army is increasing, and above all, work, produce more, in order that the country may continue to grow stronger for whatever lies before it. I believe the people of Canada will do that, and therefore, that we shall continue to do our share, and more than our share-this is no time to consider shares; we must put forth the maximum effort.
\end{abstract}

-Sir Thomas White, Minister of Finance.

This great war is due directly to ambitious Prussian Militarism. Germany has been able to carry on her land war because of the efficiency both of her industrial life and of her agricultural life. She has not conquered the world mainly because of the efficiency of the British Navy. The defence of civilization now depends upon the staying powers of the Allies and the development of their efficiency. Let the farmers and food producers of Canada once more renew their efforts and see to it that nothing is lacking in the economic use of their labour. The hope of Canada lies largely in the efficiency of her agriculture.

A year ago nearly all were optimists with regard to the length of the war, while many were pessimists with regard to the probable continued demand for all non-perishable foodstuffs. In the opinion of many farmers, patriotism and self-interest did not 
coincide. Patriotism, however, prompted an effort to obtain the maximum return from the land, consistent with economy of production. The returns recently issued give the measure of the results achieved in this patriotic effort, and emphasize the possibility, not only of increased production, but of increased production at a substantial profit.

With the end of the war not yet in sight, patriotism, combined with a better appreciation of the gravity of the situation and strengthened by the prospect of self-interest, should induce all farmers to devote themselves with even greater energy and determination to the task of seeing that the Empire incurs no risk of being confronted with a shortage of food stuffs.-L. S. KLiNck, University of British Columbia, Vancouver, B.C.

The increase of the crops is the basis of all possible future prosperity.

\section{OUR COUNTRY'S NEED}

The Empire may depend upon the farmers of Canada doing their full duty in this great war, if the situation is fully and frankly put before them, and if their part in the work is clearly and officially set out. There need be no flag-waving processions along the highways, no martial music to stimulate patriotism. Just as the facts are presented to them, so will they respond with whatever is most needed-money, production, men.

The world's demands are greater than they were a year ago; the problem is more complicated than usual; but, if the stern requirements of an Empire fighting this, the greatest world conflict, do not cripple our agricultural leadership, and unduly deplete our supply of farm labour, and if Providence shall favour us with normal weather in the coming season, the farmers of Canada will do their full duty and give the country a production that will be most satisfactory; and in so doing they will give as good service at home as will our soldiers at the front.-C. C. JAMEs.

\section{THE FARMER IN 1916}

\section{Professor M. Cumming, Nova Scotia.}

The essence of every communication on agriculture a year ago was production. It made no difference whether it was a professional agriculturist, an editor, a bank president, or a minister of finance, all uttered the same message. Naturally the Minister of Agriculture was the strongest possible supporter of a campaign for bigger crops in 1915. None took a greater interest in this campaign than the Canadian manufacturer, who, seeing his foreign market shut off, recognized that the possibility of the wheels of his factory continuing to turn lay largely with the farmer who could produce real wealth by turning the latent wealth of the soil into wheat and beef and other farm produce, the liquid gold, so necessary to lubricate the machinery of the whole country. The farmer produced and to-day the returns from the farms of Canada constitute a record for the Dominion.

No one at this date knows what the season of 1916 will be. It may be another productive year. It may be a lean year. Granting the uncertainty, does it not seem a matter of paramount importance that every measure should be taken to avert the slightest possibility of a shortage of food supply even should the leanest possible conditions prevail. And do not forget that the farmer of 1916 promises to be confronted with difficulties which will require all his efforts, and perhaps the efforts of those who are dependent upon him, to solve. 
The labour problem on the farm, as a result of enlistment, will be, both in the East and in the West, an acute one. Financial difficulties, especially in the West, have not been wholly solved by this year's big crops. Hay and clover and other important crop seeds will be high. Fertilizers, which are an absolute necessity in the East, have advanced 20 per cent. and more. But despite all of these difficulties the farmer, if he can feel reasonably certain of his market, will do his share. Nevertheless he needs the assistance of the financial men, the bankers, of the country. He needs the aid of those who are in a position to direct the marketing of surplus products of the farm.

One wonders if the commercial men of Canada are giving the farmer the credit he deserves. Just now, we fear that the glamour of the artificial trade in munitions has tended to direct the eyes of the country away from the most important man in the community, the producer of real wealth. In this we may be mistaken. But be that as it may, our message to the farmers of Canada is "Greater production than ever in 1916;" and in presenting this message we urge every citizen of Canada, whether directly engaged in agriculture or not, to give his sympathetic support to those measures which our governments, both Provincial and Federal, as well as other big bodies of men, are making to promote the fundamental industry of Canada-agriculture.

\section{WE MUST HAVE A BIG CROP FOR 1916}

\section{To Arms and To Agriculture-The True Calls of Patriotism-Better Organization Necessary}

In 1916 The WorLd will reap a big harvest. How big it will be, no one can tell as yet. The most able authorities that have expressed opinions doubt if it will be as big a crop as that of 1915 . In Canada, we have farmers, plenty of them, who state that they never saw such crops as those of 1915 in all their lives, and they do not expect ever to see such crops again. But it is of immense import to Canada that our crops should be as big as they were in 1915-bigger, if possible. What are we going to do about it? Able authorities have placed the value of Canada's agricultural production for the past year at about one billion, one hundred million dollars. It is a record. It is a big record per acre, big per capita of our population, and biggest of all per farmer, or per man.

For Canada this crop did wonders. It came amid hard times. It has left Canada prosperous. It came when our leaders in agriculture were impressing us with the plain facts of Canada's position. We had debts upon which the interest totaled up to about one hundred and fifty millions of dollars annually. We were borrowing some two hundred millions more just then. Since that time we have loaned one hundred millions of dollars and are preparing to make another flotation of three hundred millions. And for next year there will be bigger dråins upon our finances, our armies and people will have to be fed; fed and clothed and financed. It is quite true that if we don't produce the foodstuffs that the world needs, other nations may do so. But meanwhile what of the situation at home? What of the financial necessities? Last year's big crop "saved the credit of Canada," according to the statement of Sir Thomas White, Minister of Finance. It will have to be saved over again for the year 1916. Yes, we have got to grow another big crop for next year. The facts are plain and simple. We have got to.

How Canada can do this is a question not easy to answer. Few people expect such cereal crops for next year, the signs that tell of the acreage of wheat, for example, indicate a smaller acreage than that of 1915. Our ablest authorities do not assume that we can even equal our 1915 performance in live stock products, or exports. In butter, cheese, eggs, and possibly in fruit, we may even exceed the records of 1915, big as they are, granted propitious climatic conditions. But the more doubtful the prospects are that we shall equal or surpass the performances of last year, the more urgent the need that every effort should be bent to that task. 
Then there is the labour situation. This year there will be fewer hands to toil, and fewer heads to plan for the food production of Canada. Thousands have gone to the war, for the call to arms has sounded just as insistently in the ears of the farmer, his son and his hired man, as in any others. The farmer is just as willing to go, much more willing than many who have not yet gone and upon whom ties and responsibilities sit more lightly. But still the demands of the farm are inexorable. The farm work must go on, and successfully too, if Canada's credit is to be saved once more, if our military activities are to be financed, if our armies and our own peoples are to be clothed and fed.

What is the solution for all of this complex problem? To-day the organization for recruiting is more complete that it was a year ago. Its pulling power has been intensified. . . There is as much actual need for the inauguration of recruiting plans for agriculture as there is for arms. The worker on the farm, the worker in the munitions factory, can render no bigger or better service to their country than they can render where they are. The time may come when these men may be needed to fill the fighting lines, but they should be amongst the last, not the first, to be called upon. If they are left for the present, they will leave behind them much better economic conditions because they stayed, than could possibly be the case were they to be taken first. And when they do go, the sacrifice will be big, and national prosperity, even efficiency will suffer, and give place to depression, poverty, and want.

These are facts of national significance. They should not be hid behind, nor buried beneath any other facts, the necessity that our young men should answer the call to defend their country not excepted. That we should furnish soldiers is no more important than that we should have the money and the food and munitions, and that soldiers and munition workers and their families should be furnished and financed and fed. We have got to raise a big crop for 1916 .

Hired help on the farms will be a big problem in the year 1916. Plans for recruiting the forces on the farm should be carefully made, and in this business the farmer in the past has been rather remiss. Usually the initial cost to the farmer for his hired help has been rather light. It's up to our farmers to make permanent provision for the employment of married rather than of single men and to give them the preference wherever possible.

It is time that this whole problem received much more common sense consideration than it has in the past. Labour for the farms should be a matter of patriotism, at least second to that of recruits for our army corps at the front.

\section{-From "The Canadian Countryman."}

A military authority has said that any officer can lead his men to fight, but it requires the genius of a General to feed them. There is in this some suggestion of the service rendered the Empire in the grain fields of the Dominion.

\section{PATRIOTIC PRODUCTION}

Wise farmers will make even more extensive preparations for a big crop in 1916 than they did for a big crop in 1915 . It is wholly improbable that all exporting countries will again have such favourable growing conditions and such large surpluses of wheat for export as they have raised this year. Nature is scarcely likely to repeat such a phenomenal universal yield. Some exporting countries, Canada or the United States or India or Argentina, will fall behind, and perhaps several of them will have partial crop failures.

It may be that the belligerent countries of Europe have managed to harvest fair-sized crops this season, but the terrible destruction of life and the withdrawal of 
additional millions of men from the land for the battle-line during the last few months must have a widespread effect in the reduction of next year's European crops. The shortage of European-grown food in 1916 is therefore likely to be a serious factor in the world's grain markets. It is not unlikely that continental Europe will experience famine conditions before next summer is over. In that event the purchases of the Allied nations from exporting countries outside of Europe will be greatly expanded, and prices of wheat and other breadstuffs may easily rule high. There is every reason for saying that the wise Canadian farmer will make all possible preparations to increase his production of foodstuffs in 1916.

The longer the war lasts, the more wil! farm products be needed.

\section{THE SITUATION IN MANITOBA}

\section{George Batho, Manitoba Department of Agriculture.}

The agricultural situation in Manitoba is unprecedented. In 1915, according to our official figures, our wheat yield was 84 per cent. greater than in 1914 , and a very striking increase is also to be noted in oats and barley. But, while this appears very favourable, there are quite a number of less encouraging facts.

The first of these is that in some fields the grain in the middle of January still stands in the stooks. Of just what value it will be when an effort is made to haul and thresh it, even the best farmers do not know at time of writing.

Then there is a comparatively small amount of land prepared for crop. The December, 1915, crop report of this Department presented the following figures:-

\section{Land prepared for Crop}

\begin{tabular}{|c|c|c|}
\hline & 1915 & 1914 \\
\hline Breaking..... & 193,144 & 175,336 \\
\hline Summer Fallow. & $1,094,514$ & $1,208,394$ \\
\hline Fall Ploughing. & $1,509,002$ & $2,733,885$ \\
\hline
\end{tabular}

A very serious shortage of labour on our farms is now felt, and there is every reason to expect this to become more acute as the season advances and recruiting continues. In many cases elderly farmers whose sole dependence is either in their sons or in hired help will, if the sons go to war, be forced to reduce their farming operations during 1916. Seeing that the ability to produce food is probably greater per man in Western Canada than in any other part of the British Empire, and that food is urgently demanded if the war is to be successfully prosecuted, the military authorities might very properly direct their attention to the men of other callings and permit bona fide farmers and farmers' sons as a class to remain at home to produce food. It is to be remembered that one trained farm worker is worth much more than an untrained man who tries to take his place. Many Manitoba farmers are very emphatic in their statement that the enlistment of every experienced farm worker enrolled from now forward will mean a proportionate reduction in the crop grown this season.

If you have never felt the joy of doing something worth while; accomplished something that is of benefit to your fellow man and to posterity, do it in 1916, because of the satisfaction it brings. 


\section{THE CALL OF 1916}

\section{W. E. SCOTT, Deputy Minster of Agriculture, Victoria, B.C.}

The year 1916 still sees us in the midst of a titanic conflict, in which autocracy and despotism are engaged in a death struggle with honour, justice and liberty. Whilst the ultimate outcome must undoubtedly be the triumph of right, our British Empire may yet have to undergo many heavy sacrifices before the bright sunshine of peace breaks through the lowering war clouds.

We are all asking ourselves how we may best serve our Empire. The farmers of Canada have, during the past year, done nobly, and through the disposition of a bountiful Providence, our stock and fields have largely increased their output.

It is, however, our duty not to relax our efforts, but rather to redouble them, so that the Motherland and our Allies may know that they can look to Canada with confidence for the necessary grains and meats to feed their men at the front and their women and children at home.

Through proper organization, a large output has been effected in Canada of munitions of war. Assistance of great importance has been rendered in this way. It is, however, still more important that those of us on the land in Canada who, for one cause or another, may not have the privilege of serving their country at the front, should use every effort to increase production. By so doing, our farmers at home are as surely contributing towards the successful termination of the war as are our brave soldiers in the trenches in Flanders and elsewhere, and our sailors on the high seas.

Shall Great Britain look to us in vain? A thousand times No. Our farmers will not be found wanting. They will grow more grain and raise more stock, and thereby each will do his share towards crushing once and for all, the present nightmare of civilization-Prussian militarism.

Farmers, remember the fate of Belgium, Servia, and Poland. Remember the Lusitania and the martyred Edith Cavell, and there will be no doubt as to what your answer will be. Once more respond to the call for increased production.

\section{PROSPECTS IN WEST}

\section{Favourable Conditions for Crops and Live Stock}

Mr. George Lane of Calgary, perhaps the largest individual farmer and rancher in western Canada, stated in an interview in the press recently that, while the amount of land under summer fallow, ready for the crop of 1916, is less than the prepared area a year ago, the land was so well cultivated in the fall of 1914 and the spring of 1915 , that it is able to hold the present abundant supply of moisture, and really make conditions quite favourable for the crops of the coming season.

In comparison with a year ago, the farmers of the west, Mr. Lane attests, are infinitely better prepared to-day to commence operations on the land when the spring season opens. "They have plenty of everything to start with this year," said he, "lots of good seed, which was so scarce in 1915 , and any amount of good feed for live stock.

"I have never seen the ground in better shape in thirty years to receive the crop than it is now. If we have a good spring season with an early opening, depend upon it, a mighty big crop will go into the ground in all three western Provinces."

Taking all kinds of live stock into consideration, Mr. Lane says that 1915 was the best year in 25 years in western Canada. "For instance," said he, "hogs have been at the unprecedented figure in Calgary of $\$ 8.50$ to $\$ 9$ per cwt., and we have had buyers competing in Alberta for stock, from Vancouver, Seattle, Winnipeg, Minneapolis and Chicago, and we have sent any number of hogs to Toronto." 
Too much emphasis could not be laid upon the importance of the successful crop of 1915 in its relation to the live stock industry of the west. Men who already possess live stock have had at their disposal for months, tons of the very best fodder, in the form of straw and offal from the threshing, while those who have not been large holders of cattle or hogs in the past have been able to get into this business quickly and profitably.

\section{ACREAGE OF FALL WHEAT}

The area sown to fall wheat for next year's harvest is estimated to be $1,100,800$ acres, which is about 15 per cent..less than the area of $1,294,000$ acres sown in 1914 for 1915 . The decrease is principally in Ontario and is due to the heavy rains of August which prevented the working of the soil in time for seeding. The area sown to fall wheat in Ontario is estimated to be 820,600 acres, as compared with $1,043,000$ acres sown in 1914, the decrease being 222,400 acres, or over 21 p.c. In Alberta there is an increase from 230,000 acres in 1914 to 260,500 acres in 1915 , the plus difference representing 13 p.c. In Manitoba there is a decrease from 10,900 to 9,400 acres; in Saskatchewan there is no change from the estimated area of 4,100 acres, and in British Columbia there is a small increase of 200 acres, making 6,200 acres sown to this crop.

\section{Amount of Fall Ploughing}

For all Canada about 53 p.c. of the area intended for next year's crops is reported as ploughed by October 31, as compared with 71 p.c. last year and 54 p.c. in 1913 . In the Northwest the percentages are as follows: Manitoba 36 against 92, Saskatchewan 27 against 77, Alberta 34 against 56.-From Census and Statistics Monthly.

Improved seed and improved stock properly cared for constitute one of the surest means of increasing the returns from the farm.

Is your land yielding a maximum return for the amount of energy, time and money expended upon it?

We know enough of good farming now to double our yields and treble our income, if we would put it in practice. Again we repeat the slogan-"Raise the acre yieldthere the profit lies."

The easy, rational and inexpensive way to secure a yield above the average is by better seed bed, better seed, better rotation, and crop and animal manures.

The higher the yield the greater the cost does not apply to a farming condition wherein the farmer has not begun to get the natural yield of an honestly treated farm.

Our farms are not producing within 50 per cent. on an average of the possible maximum.

The profit is in the excess yield above the average. The farmers who are following the more intelligent method and getting the larger yields are the ones who are making the most money; poor and unintelligent methods are sure to run down the production close to or below the profit point. 


\section{FOOD SUPPLIES OF THE UNITED KINGDOM}

The economic problems that will have to be dealt with on broad lines after the war must necessarily include the question of food supplies; and it is almost certain that the problem of how to increase the productiveness of the Empire, so as to enable it to supply its own meat requirements for military as well as civilian purposes, will occupy a foremost place.

The following table, prepared by R. H. Rew, Assistant Secretary of the British Board of Agriculture, shows the proportions of the food supply of the United Kingdom, contributed by Britain, the Empire and foreign countries respectively. The statistics relate to articles produced more or less in the Kingdom, and are based on an average of the five years 1910-14:-

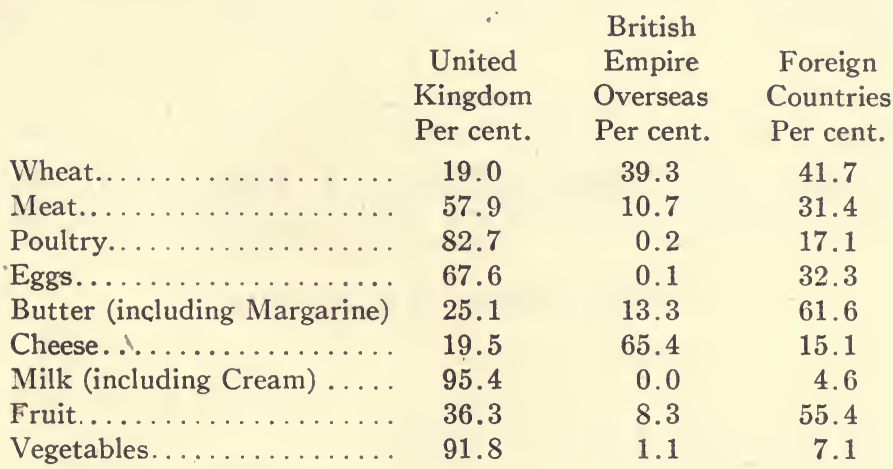

Canada's contribution to the food supplies of the United Kingdom was, on the whole, well maintained in 1915, particularly in view of the great shortage of means of transportation which had to be encountered during the whole period.

It is true that there is a considerable falling off in the quantities of grain credited to Canada, notably in the case of wheat, but it is probable that, as in the past, considerable Canadian shipments made via the United States are attributed to that country, owing to the system adopted by the Board of Trade whereby imports are frequently classified as received from the country whence consigned, and not from the country of actual origin. On the other hand, there were increases, in some cases to a large extent, in receipts of bacon, hams, and cheese. Flour also shows a small increase.

A noteworthy feature is the revival in Canadian exports of butter, the quantity being three times as great as in 1914, while receipts from Canada in 1913 were only 813 cwts.

The high prices of the past year drew forth unexpected but very welcome supplies of Canadian beef, amounting to some 6,280 tons, of which about 3,600 tons came to the United Kingdom, the remainder going direct to the Continent. Had more refrigerated freight been available considerably larger quantities could have been shipped.

In view of Canada's loyalty as a British Dominion it is gratifying to be able to record this new departure, and opportune to express a hope that it may be found practicable to increase materially the contribution thus made to the food supply of the Empire from within its own borders. The Canadian Government is now alive to the desirability of fostering the export trade and putting it upon a permanent footing as soon as possible. 


\title{
MEAT CONSUMPTION IN UNITED KINGDOM
}

The quantity of meat consumed per head of the population in Great Britain and Ireland (including bacon and hams), is given as follows:

$\begin{array}{cccc} & \begin{array}{c}\text { Consumption } \\ \text { per capita } \\ \text { lbs. }\end{array} & \begin{array}{c}\text { Home } \\ \text { Produce } \\ \text { lbs. }\end{array} & \begin{array}{c}\text { Foreign and } \\ \text { Colonial Produce } \\ \text { lbs. }\end{array} \\ 1900-1 \ldots \ldots \ldots \ldots \ldots & 125.0 & 67.8 & 57.2 \\ 1904-5 . \ldots \ldots \ldots \ldots \ldots & 122.0 & 67.1 & 54.9 \\ 1906-7 \ldots \ldots \ldots \ldots \ldots & 118.8 & 63.3 & 55.5 \\ 1907-8 \ldots \ldots \ldots \ldots & 119.5 & 64.1 & 55.4 \\ 1908-9 \ldots \ldots \ldots \ldots & 120.2 & 67.0 & 53.2 \\ 1909-10 \ldots \ldots \ldots \ldots & 114.0 & 64.6 & 49.4 \\ 1910-11 \ldots \ldots \ldots \ldots & 115.2 & 61.2 & 54.0\end{array}$

\section{QUANTITIES OF FARM PRODUCTS IMPORTED BY THE UNITED KINGDOM IN 1914 AND 1915}

\author{
(British Journal of Agriculture.)
}

\begin{tabular}{|c|c|c|}
\hline (c & $\begin{array}{c}1914 \\
\text { wt. } 112 \text { lbs.) }\end{array}$ & $\begin{array}{c}1915 \\
\text { (cwt. } 112 \text { lbs.) }\end{array}$ \\
\hline \multicolumn{3}{|c|}{ Beef, mutton and pork, fresh, refrigerated } \\
\hline 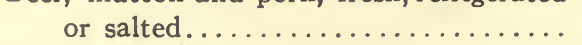 & $16,149,774$ & $14,662,820$ \\
\hline 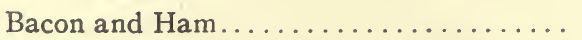 & $5,936,910$ & $8,008,568$ \\
\hline Meat preserved.................. & 995,211 & $2,037,651$ \\
\hline 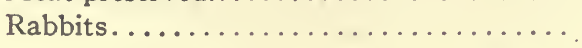 & 505,925 & 603,659 \\
\hline V & $23,587,820$ & $25,312,698$ \\
\hline Poultry (dead) ........... & 223,599 & 156,438 \\
\hline 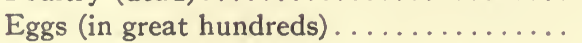 & $17,904,805$ & $10,247,960$ \\
\hline
\end{tabular}

Chilled Beef imports, which represent the better class of trade, show a marked decline since 1913, the maximum year. The main sources of supply are Argentina, Uruguay, and the United States. Imports from the United States, which had previously declined, revived in 1915 .

Frozen Beef imports, on the other hand, show a marked increase. The supply comes from Argentina, Uruguay, Australia, New Zealand and the United States. The United States dropped out for several years previous to 1913. Imports from Uruguay are rapidly increasing.

Mutton-Nearly all the imported mutton is frozen and comes chiefly from New Zealand, Australia, Argentina and Uruguay. Imports decreased in 1915. A small quantity of fresh mutton is imported from Holland.

Pork-Frozen pork is imported from the U.S. and fresh pork from Holland. Imports decreased in 1915.

Bacon and Ham-Bacon imports in 1915 were the largest recorded. Imports from Denmark declined, and increased from the United States and Canada.

Poultry (dead)-Received chiefly from Russia, United States and France. Very little came from Russia in 1915 , and the total showed a decrease. 


\begin{tabular}{|c|c|c|}
\hline & & \\
\hline . & 1914 & 1915 \\
\hline Butter. . & $\begin{array}{c}\text { cwt. } \\
384204\end{array}$ & $\begin{array}{c}\text { cwt. } \\
3.855,395\end{array}$ \\
\hline Margarine.$\ldots \ldots \ldots \ldots \ldots \ldots \ldots$ & $1,529,219$ & $2,052,183$ \\
\hline Cheese. . . . . . . . & $2,433,864$ & $2,726,942$ \\
\hline Milk (condensed).......... & $1,225,316$ & $1,581,799$ \\
\hline & $9,172,603$ & $10,216,319$ \\
\hline
\end{tabular}

Butter-Imports showed a decline in 1915. Three-quarters of the supply came from Europe (Denmark, Russia, France, Sweden and Holland). The balance came from Australia, New Zealand and Argentina. Russia and France sent largely increased quantities; Sweden, Denmark and Holland show large decreases.

The consumption of margarine has greatly increased as a result of short supplies and abnormal prices of butter.

Cheese-Canada supplies half the cheese imported-1,315,177 cwt. in 1915, being almost equal to 1912. New Zealand supplied about half as much as Canada. Imports of condensed milk and margarine showed increases.

Eggs-Imports showed a marked decline from Russia, Denmark and Holland, which are the chief countries contributing.

\section{GRAIN AND FLOUR}

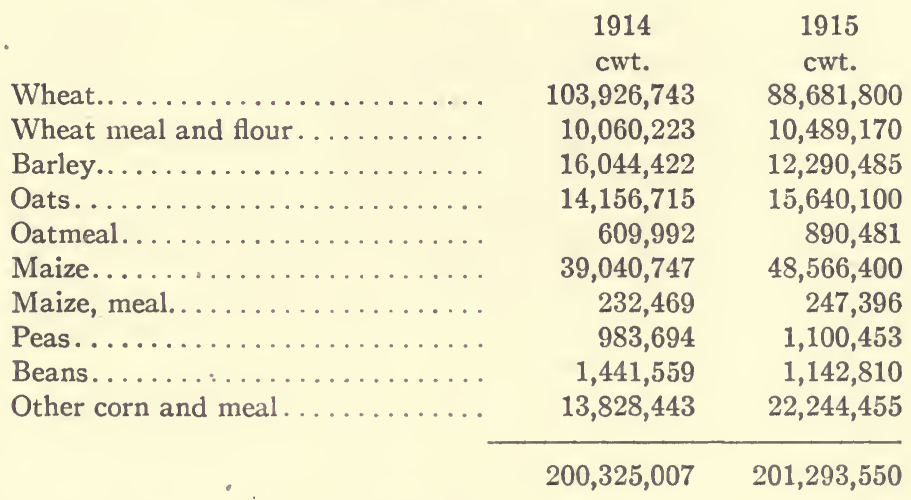

Grain, flour, etc.:-Imports of wheat showed a marked decline. The leading sources of supply were the following, in the order given: United States, Canada, India, Argentina-Russia and Australia did not figure, the latter on account of crop failure. Imports of flour from the United States and Canada, the chief sources of supply, increased slightly.

Normal wheat and flour requirements of the United Kingdom (i.e., home and overseas) are about 150 million cwt., of which home production equals about 22 per cent. Contributions from the Dominions and India show a marked increase, chiefly on account of Canada's increasing production. The ratio of the area of wheat to population is increasing much more rapidly in the British Empire than elsewhere.

Barley was imported from the United States and India in 1915, Russia and Rumania dropping out; total imports declined.

The importation of oats from the United States increased very largely and declined from Canada; Canadian oats going to France direct. None came from Russia, Germany and South-Eastern Europe.

Imports of corn (maize) increased from the United States, Canada and Argentina. Russia and Rumania dropped out. 


\section{MISCELLANEOUS}

\begin{tabular}{|c|c|c|}
\hline & & \\
\hline Wool (lbs.)........... & $712,618,116$ & $926,680,036$ \\
\hline & $1,737,182$ & $1,773,105$ \\
\hline & $1,392,495$ & $1,811,484$ \\
\hline 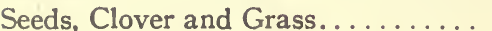 & 175,905 & 260,375 \\
\hline
\end{tabular}

Potatoes................. Importation of 1915 less than onequarter of that of 1914 .

Onions, bush............. ...

Tomatoes, cwt............ ... $1,394,897$

Fresh Fruits...............1915 showed a decrease in all classes except apples, almonds and oranges.

Wool-The bulk of the supply came from Australia, New Zealand, British South Africa, India and Argentina. Receipts show a large increase. The average price showed a one cent per pound increase over 1914 .

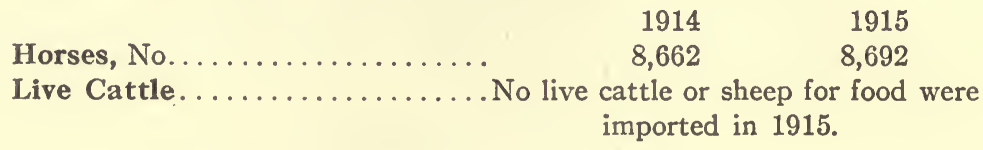

\section{Table showing Increase in Values of Foods Imported into the United} Kingdom in 1915, compared $w$ th Values in 1914.

\section{(British Journal of Agriculture)}

\begin{tabular}{|c|c|c|c|c|}
\hline \multirow{2}{*}{ Beef.$\ldots \ldots \ldots \ldots \ldots \ldots \ldots \ldots \ldots \ldots$} & $\begin{array}{l}\text { Increased val. } \\
\text { per cwt. over } \\
1914\end{array}$ & \multicolumn{3}{|c|}{$\begin{array}{l}\text { Increased val. } \\
\text { per cent. over } \\
1914\end{array}$} \\
\hline & $17 \mathrm{~s}$. & $=$ & 40 per & r cent. ${ }^{*}$ \\
\hline Mutton...................... & $15 \mathrm{~s}$. & $=$ & 34 & $"$ \\
\hline Pork.................. & 4s. $3 \mathrm{~d}$. & $=$ & & \\
\hline Bacon & $6 \mathrm{~s} .6 \mathrm{~d}$. & $=$ & 10.17 & “ \\
\hline 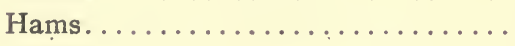 & 1s. 7 d. (d & ecrease) & & \\
\hline Butter................... & $19 \mathrm{~s} .8 \mathrm{~d}$. & $=$ & 16 & “ \\
\hline Cheese. . . & $16 \mathrm{~s}$. & $=$ & 24 & “ \\
\hline Eggs (per ${ }^{* *}$ great hundred)........... & 2s. $3 d$. & $=$ & 23 & “ \\
\hline 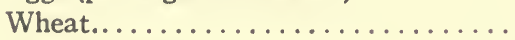 & 4s. 4 d. & $=$ & 50 & “ \\
\hline Wheat Flour ................ & 4s. 10d. & $=$ & 44 & “ \\
\hline Barley..................... & 2 s. $91 / 2$ d. & $=$ & 40 & “ \\
\hline 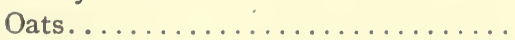 & 4s. $3 \mathrm{~d}$. & $=$ & 65 & “ \\
\hline Maize $\ldots \ldots \ldots \ldots \ldots \ldots \ldots \ldots$ & 1s. $9 \mathrm{~d}$ & $=$ & 29 & “ \\
\hline
\end{tabular}

Nore:-The above are declared values of imported articles; not market prices.

The splendid services rendered by the British Navy in keeping open the high seas insure the continuance of full imports; but the requirements of the army will still demand the first consideration of the Government; and the course of prices in the markets of the United Kingdom must be largely controlled by the proportion of the imports finally released for civilian consumption. 


\title{
BRITAIN'S FOOD IMPORTS IN WAR TIME
}

\author{
Glasgow, Scotland, Nov. 12, 1915
}

An illuminating analysis of world trade with Great Britain during the war is contained in a report issued by the Board of Trade. Since the imports dealt with consist very largely of agricultural produce, the report should be read with interest by Canadian farmers. One finds, for instance, that the United States of America, while adopting an attitude of complaint towards our Navy's control over neutral commerce, is reaping huge fortunes from us directly as a result of the war situation. The figures in the report are those for the first nine months of the present year, and for purposes of comparison with a pre-war period, they are contrasted with the corresponding months of the year 1913. United States exports to this country, on this basis, show an excess of over $£ 83,000,000$. Moreover this figure does not include the revenue from material supplied on Government contract, such as munitions, etc. In the ten months to the end of October of this year we have paid to the States $£ 8,000,000$ more for wheat alone. Another million goes against wheat flour, and barley and oats bring up the total gain for all kinds of grain to fully $£ 13,000,000$. This partly represents increased quantities, but the greater part is due to higher prices and constitutes "unearned increment" for the American producer and exporter. Other food commodities for which we have paid the States more than in a normal year are:-Bacon, $£ 5,300,000$; hams, $£ 2,000,000$; chilled and frozen beef, $£ 3,000,000$; and cheese, $£ 1,800,000$. So that in wheat and other foodstuffs America's gain over the war amounts to the gigantic sum of fully $£ 25,000,000$.

\section{BIG PURCHASES IN UNITED STATES}

The following table shows the purchase of products from the United States alone made by Great Britain during the first nine months of 1915 , as compared with the purchases made during the corresponding period of 1914. The total value of these items is $£ 26,486,333$ for 1915 , as compared with $£ 11,793,651$ for 1914 , an increase of $£ 14,692,682$, or 124 per cent.

\begin{tabular}{|c|c|c|}
\hline Beef, chilled.... & $\begin{array}{r}1915 \\
\text { cwts. } \\
488,339\end{array}$ & $\begin{array}{l}1914 \\
\text { cwts. } \\
2,079\end{array}$ \\
\hline eef, frozen.... & 276,158 & 350 \\
\hline lted... & 43,730 & 23,209 \\
\hline ozen. . & 22,849 & 3,230 \\
\hline$d$ (not bacon or hams)... & 49,504 & 32,280 \\
\hline - & $2,704,363$ & $1,121,969$ \\
\hline & $1,094,499$ & 625,042 \\
\hline & 57,284 & 35,660 \\
\hline$\ldots \ldots \ldots \ldots \ldots \ldots \ldots \ldots \ldots \ldots \ldots \ldots \ldots \ldots \ldots \ldots \ldots$ & 36,548 & 7,347 \\
\hline & 445,934 & 15,131 \\
\hline & 450,700 & 398,598 \\
\hline & 99,209 & 45,374 \\
\hline & $1,740,482$ & $1,294,985$ \\
\hline 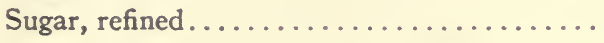 & $1,291,052$ & 370,823 \\
\hline
\end{tabular}

\section{Other Sources of Supplies}

But America is not alone in this prosperity derived from the misfortunes of neighboring Powers. Practically every neutral nation in varying degrees has benefited in trade. The following table presents the position regarding Britain's imports during 
the first nine months of this year. The columns explain themselves, but it should be pointed out that the figure 100 is assumed in this general calculation to represent the normal value of the trade:-

Allied Countries

\begin{tabular}{|c|c|c|c|}
\hline \multicolumn{4}{|c|}{ Allied Countries } \\
\hline & $\begin{array}{l}\text { Three } \\
\text { months }\end{array}$ & $\begin{array}{c}\text { Six } \\
\text { months }\end{array}$ & $\begin{array}{l}\text { Third } \\
\text { quarter }\end{array}$ \\
\hline Russia.. & 28 & 35 & 50 \\
\hline France............. & 60 & 65 & 75 \\
\hline Italy. ................ & 134 & 136 & 148 \\
\hline
\end{tabular}

Northern European

\begin{tabular}{|c|c|c|c|}
\hline Norway $\ldots \ldots \ldots \ldots \ldots \ldots \ldots$ & 157 & 192 & 187 \\
\hline Sweden ................. & 114 & 116 & 174 \\
\hline 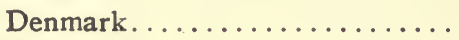 & 108 & 102 & 90 \\
\hline Holland $\ldots \ldots \ldots \ldots \ldots \ldots$ & 110 & 103 & 94 \\
\hline
\end{tabular}

\section{Southern European}

\begin{tabular}{|c|c|c|}
\hline Spain.$\ldots \ldots \ldots \ldots \ldots \ldots \ldots$ & 116 & 132 \\
\hline Portugal............. & 144 & 130 \\
\hline Switzerland.............. & 126 & 130 \\
\hline
\end{tabular}

\section{America and Far East}

\begin{tabular}{|c|c|c|}
\hline United States. . . . . . . . . . . & 136 & 176 \\
\hline Brazil.................. & 60 & 90 \\
\hline Argentine..$\ldots \ldots \ldots \ldots \ldots$ & 173 & 179 \\
\hline 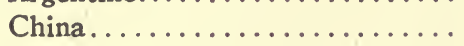 & 183 & 163 \\
\hline Japan & 194 & 221 \\
\hline
\end{tabular}

\section{British Dominions}

\begin{tabular}{|c|c|c|}
\hline 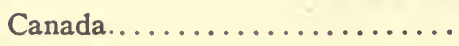 & 131 & 146 \\
\hline Australia.................. & 136 & 134 \\
\hline New Zealand................ & 127 & 126 \\
\hline South Africa $\ldots \ldots \ldots \ldots \ldots \ldots$ & 81 & 100 \\
\hline 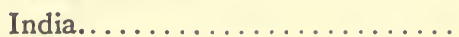 & 124 & 138 \\
\hline
\end{tabular}

It will be seen from these statistics that our allies, with the exception of Italy, have suffered substantially in trade with us. In the case of the United States the gain has been progressive, from a rise of 36 per cent. in the first quarter to 76 per cent. for the half year, and to 118 per cent. in the third quarter. The Argentine, whose huge gain has been consistent, has during the ten months ending October sent us maise valued at $£ 4,000,000$ more than her shipments of 1913 ; wheat, $£ 2,500,000$ more; and frozen beef, $£ 5,000,000$ - an advance in these foodstuffs of $£ 11,500,000$. Sweden and Norway's position on the table is attributed to the dearness of timber. It is surmised that the slump in the last quarter in the trade from Denmark and Holland is due to a falling off in the export of dairy produce. Whether this was due to holding up for higher prices, or the draining of the surplus produce into Germany cannot be determined.

\section{Canada's Share}

It is eminently satisfactory to find that all this overseas excess trade is not going "out of the family." The British Dominions and India have shared largely in it. Hostilities in South Africa spoiled her trade at the first quarter, but she has picked up rapidly. In wool alone Australia has sent an excess of $£ 8,250,000$ for the ten months ending October while her shipments of frozen beef and mutton have risen by $£ 3,000,000$. New Zealand wool exports to us have gone up by $£ 2,800,000$, and her beef and mutton to the same amount while she has also added $£ 1,000,000$ to her cheese account: 


\section{EXPORTS OF CANADIAN AGRICULTURAL PRODUCE}

\section{Principal Articles}

Twelve Months Ended December, 1915

Articles Exported

Animals, living-Total.......

1914
$\$$
Total

$14,068,106$

$\$$

$\begin{array}{ll}\text { To United To United } & \text { Thingdom } \\ \text { Kitates }\end{array}$

To United

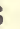

$17,225,406$

$\$$

$\$$

$2,433,985 \quad 13,356,761$

Cattle.................

$8,950,960$

$1,364,193$

Horses................

Sheep.................

282,467

$13,071,370$
$2,653,605$
599,591

105,120

$11,595,577$

$2,328,374$

274,771

Breadstuffs-Total..........

$108,382,551$

$216,865,164$

$178,746,232$

$11,448,025$

Barley...............

$3,796,264$

$2,927,555$

$2,524,344$

117,322

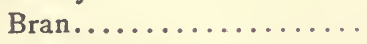

$1,217,324$

$1,427,578$

81,461

$1,224,622$

Cereal foods............

$2,120,241$

$1,928,192$

$1,668,617$

15,265

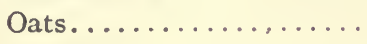

$8,608,778$

$10,394,919$

$4,020,402$

429,255

Oatmeal...............

368,765

293,909

249,521

Wheat................

$69,714,249$

$166,409,710$

$149,976,078$

42,193

Wheat Flour...........

$21,441,812$

$31,461,125$

$19,737,331$

$7,595,058$

843,656

Fruits-Total............

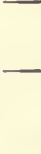

Apples, fresh............

$3,476,498$

$3,336,514$

$2,791,212$

246,040

\begin{tabular}{rrrr}
$2,591,501$ & $2,081,446$ & $1,904,222$ & 19,741 \\
$2,025,300$ & $4,113,521$ & 335,762 & 514,197 \\
$8,206,958$ & $7,179,500$ & 3,752 & $7,162,293$ \\
\hline
\end{tabular}

Hides and skins, other than fur.

Potatoes.................

Provisions-Total. .

\begin{tabular}{|c|c|c|c|}
\hline 687,887 & 506,302 & 7 & 31,582 \\
\hline $36,168,388$ & $61,015,446$ & $56,657,432$ & $2,154,995$ \\
\hline 575,699 & $1,059,764$ & 629,840 & 48,426 \\
\hline $19,205,152$ & $25,112,854$ & $24,874,098$ & 20,770 \\
\hline $9,509,777$ & $23,578,830$ & $23,131,747$ & 360,562 \\
\hline $11,391,245$ & $3,480,129$ & 198,104 & $3,247,408$ \\
\hline
\end{tabular}
Seeds.

Butter.

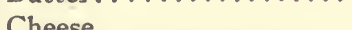

Meats-Bacon and hams.

$11,391,245$

$3,480,129$

198,104

\section{Proportion of Agricultural Exports}

Our export trade is paying the Country's debts, and that the extent to which this is the case may be understood, it may be stated that, for the fiscal year 1911-12, agricultural exports amounted to $53 \%$ of the total export business. In 1912-13, they amounted to $58 \%$; in $1913-14$, to $54 \%$; in $1914-15$, to $51 \%$; and for the eight months to the 30th November for the fiscal year 1915-16, they amounted to $53 \%$. During the latter period, total exports exceeded total imports by the amount of $\$ 121,130,044$. 


\section{CROP PRODUCTION}

"Agriculture is an art that renders those who understand it rich, but leaves those who do not understand it, however hard they may labour in it, to live in poverty."-Xenophon.

\section{SOIL CULTIVATION}

\section{J. H. GRiSDale, Director, Dominion Experimental Farms, Ottawa.}

We cultivate our fields and sow our seed to produce crops. The quality and quantity of our yields depend upon the strength and rapidity of the growth made by the crop. The requirements of strong, rapid plant growth are (1) Moisture, (2) Warmth, (3) Plant Food.

Let us briefly consider these requirements and the extent to which they may be controlled or influenced by the farmer through cultural or other farming operations.

\section{(1) MOISTURE}

The moisture supply depends primarily on precipitation. Precipitation, or rainfall, is, however, not controllable. It is necessary, therefore, to so handle soils as to enable them to conserve or retain the moisture received until required for crop production.

\section{Drainage a Factor in Moisture Conservation}

Several factors influence moisture conservation in soils. Of these good drainage is probably the most important. Well drained soils are free from the danger of baking or puddling, that is, they are friable and loose on the surface, soj preventing evaporation. Well drained soils being free from hydrostatic or free water to a considerable depth are in shape to absorb rain as it falls and preserve it in the form of capillary or hygroscopic water. It is only as capillary or hygroscopic water that moisture can be retained for any length of time in the soil in dry weather, hence good drainage is an absolute necessity where moisture conservation is a matter of importance, just as it is an indispensable condition where seasons are short or rainfall very great in order to carry off the surplus water and allow air to enter the earth to reach plant roots and raise the soil temperature.

\section{Ploughing and Cultivating as Methods of Controlling Soil Moisture}

Shallow ploughing and deep cultivation are, after drainage, probably the most important influences making for moisture conservation. Shallow ploughing by keeping the humus near the surface greatly increases the moisture holding power of that, the most important soil layer. Deep cultivation by stirring the lower stratum of soil helps disintegrate the stiff and probably waterlogged upper subsoil, and so very greatly increases the amount of capillary water readily available near the surface layer for crop requirements.

\section{Surface Cultivation Conserves Moisture}

No matter what the condition of the surface soil and upper subsoil as influenced by ploughing and subsoil stirring, no matter how well drained the lower subsoil, if no precaution be taken to prevent evaporation, a very large amount of moisture is sure to be 
carried off from the surface by every faintest breeze and weakest sun ray. To prevent this, the maintenance of a soil mulch on such surfaces as are exposed to the moving air or direct sunshine is a necessary precaution. A soil mulch may be made by means of a light harrow. Sometimes, too, it may be made by a roller. The roller has usually just the opposite effect; under certain conditions, however, it is of value in this connection. To illustrate, it often happens that two or three weeks after seeding, before the grain is up high enough to protect the soil surface from winds and sunlight, a crust forms and moisture evaporation goes on apace. Going over such a field with a light roller breaks the crust and forms a soil mulch which effectually stops the loss.

\section{Humus Conserves Moisture}

Humus absorbs and retains moisture much more readily than any other constituent of the soil. Hence one of the best methods of improving the moisture storing and moisture conserving powers of a soil is to increase its humus content. This may be done by the frequent turning under of sod and by the use of barnyard manure.

\section{(2) WARMTH}

For plants to grow rapidly, warmth as well as moisture is an absolutely necessary condition.

\section{Drainage Warms Soils}

Drainage was shown to be probably the most important factor in making for moisture conservation. Drainage as an influence affecting soil temperature is of even greater importance. Undrained soils are always cool, usually too cold to favour plant growth, save in the case of certain species accustomed to such peculiar conditions. Practically all cultivated plants require warm soils. Drainage will warm the soil by carrying off surplus moisture and enabling air to enter.

\section{Soil Mulch Affects Soil Temperature}

Once a crust has formed on the surface of the soil, water escapes rapidly through the pores, evaporating as it passes off. The change from liquid to gaseous form means the absorption of large quantities of heat by the escaping water, and in this way much heat is taken out of the soil. Thus in spring, when heat is of such paramount importance it not infrequently happens that a field lying under a bright sun is going down in temperature rather than rising, for the reason that much moisture is escaping from the surface by evaporation. To prevent this and stop the cooling-off process, all that is necessary is a cut with a common harrow, that is, a mulch should be formed.

\section{Humus Warms the Soil}

After drainage and the soil mulch, the colour of the soil is an important factor affecting soil temperature. Dark soils absorb heat readily and rapidly. Humus has the effect of darkening soils, hence the increasing of the humus content of a soil is an important and practical method of raising the temperature of a soil that due to its colour might otherwise be slow in warming up.

\section{(3) PLANT FOOD}

The supply of plant food in a soil is very commonly supposed to be the measure of its crop producing powers. Such, however, is not exactly the case. Even the most barren soils, so far as plant food is concerned, may in a few years be made to produce most excellent crops provided the other conditions of plant growth be right. Any soil to which humus can be added at not too great expense will shortly be found to yield profitable crop returns.

Commercial fertilizers might be of some value in building up a worn-out or barren soil, in as much as they will supply more or less immediately available plant food, and in the case of certain fertilizers being used, such as land plaster, lime or ashes, will 
do something toward rendering available such plant food as may be already in the soil. They will also correct any acidity in the soil, and in the case of ashes and lime will do something to improve the physical condition.

Humus, however, is the material required to get the soil in good crop producing shape. The farmer's aim should be, therefore, not to find out by chemical analysis what clements of plant food appear to be lacking in whole or in part, but rather to improve the physical condition of his soil by adding humus, draining properly and performing the necessary cultural operations in the right way, at the right time.

\section{Cultural Operations and Implements}

The following notes on cultural operations and implements will probably serve to supplement the preceding paragraphs on crop rotation and soil cultivation.

Ploughing-Ploughing is admittedly the foundation operation in all crop production effort. Ploughing has been performed with many different kinds of plough and in many different styles. No definite rule can be laid down as to the best method of ploughing. A safe rule, however, is to plough only when the soil is in shape, that is when not too wet; this rule, of course, applying to heavy soils only.

Ploughing deeply in autumn, turning an upstanding furrow, and ploughing shallow in spring, turning a low-lying or flat furrow, is another general rule and is applicable to a greater variety of soils than the first. Ploughing should, in my opinion, be done whenever possible with the two-furrow gang plough, using four, or at least three horses. In this way, the cost of the operation is materially reduced.

Disc ploughs recently put on the market afford a means of performing this operation at times and under condition where it would probably be impossible for the common mouldboard plough to operate, as for instance, ploughing heavy clay lands when hard and dry. They are also useful in burying manure, grass or weeds and in exposing heavy soils to the action of the frost, since they leave a very rough surface exposed to the air.

Subsoil ploughing is a cultural operation very seldom practised, and one that should be more frequently performed by the farmer, and serves, as indicated in preceding paragraphs, to open up the upper subsoil and so increase the water containing capacity of the root-holding soil strata. The subsoil plough may to a certain extent be replaced by what is known as the subsoil hook, a cheap, light affair, that can be readily attached to the beam of any plough and passing over between the handles, do a good job in the way of stirring to a depth of three or four inches, the upper subsoil.

Harrowing-A great variety of implements have been devised and put on the market wherewith to perform the operation commonly known as harrowing. Of all these implements the disc harrow is probably the most generally useful and the most effective in the work of preparing soil for seed after it has been ploughed. The larger the disc and the more acute the angle at which it is set in operation, the more effectively will it work. To insure good work, however, with a large sharp-set disc, rolling is necessary in order to crush the soil down that it may remain in place when being carved by the disc.

A new disc harrow, known as the Double Cutaway, has recently made its appearance and has proven to be a most excellent implement. It consists of two disc harrows, one in front of the other, cutting, the one with an inthrow and the other with an outthrow; the discs are so placed as to prevent their running in the same track, hence a much more thorough cutting up of the surface soil is insured. Considerably more power is necessary to operate this disc than in the case of a single disc. It is, however, an implement capable of materially reducing the cost of preparing the soil for seed after the land is ploughed.

The spring tooth harrow is an implement that cannot be too strongly condemned, where used, as is commonly the case, on sod land or on rough hard land. This implement tears up the sods, exposes the grass and leaves an exceedingly rough surface, very certain to give poor results in crop production. 
Harrowing is an operation usually very badly performed, and an operation that is almost always ended up sometime before it should be on any given area. Good ploughing is a necessary condition of the best crop results, but thorough harrowing is an indispensable condition of profitable crop returns from any field. Thorough harrowing does not necessarily mean three or four or ten different harrowings, but it means such treatment as leaves the surface of the seed bed smooth and friable, and leaves the bottom of the seed bed firm and solid. Until these two conditions are fulfilled the harrow should not stop.

Where sod land is being prepared for any crop, possibly the best treatment would be about as follows: Roll with a heavy roller, disc harrow lengthwise and crosswise or on the bias; roll again, disc harrow once more, and then smooth harrow with a common spike-toothed harrow. If, however, it is found that the land is not yet in perfect tilth, then it might be necessary to repeat the disc harrowing and the rolling. In any case, seed should not be sown until the soil is in perfect shape for crop production. It is usually safe to harrow again after conditions seem nearly perfect for seeding.

The spike-toothed harrow may often be run over the land when the average farmer would consider it utter folly to use it as all, for instance, in the corn field a few days after sowing or planting the corn, and in the same field a few days after the corn is up. Harrowing the field at such times is almost certain to materially help the crop.

Where large areas of corn are grown, an implement likely to prove of considerable value is what is known as the slant-tooth or tilting harrow. This enables one to control the depth to which the harrow shall sink in the soil, and so permit of harrowing the corn or potatoes at times and under conditions when the common spike-toothed harrow might do some small amount of damage.

Seeding-Seeding is now rarely done by hand. It is, however, in too many districts still done broadcast, that is, what are known as broadcast seeders are used. Such seeders are not nearly so satisfactory as drill seeders. Much of the seed is insufficiently covered, while another part is buried too deeply. Consequently it comes up unevenly, grows unevenly, ripens unevenly, and there is thus considerable loss at harvesting, to say nothing of the seed lost by being buried too deeply or by being insufficiently covered.

The hoe drill and the single disc are the best seeders, and of these, I believe the single disc to be the better. Here, as in the case of the plough and the harrow, as large an implement as possible should be selected, since such implements aid materially in reducing the cost of production.

The Roller.-The roller is commonly looked upon as the implement wherewith to give the finishing touch. It is just at this point, however, that the greatest danger lies. It is as an operation after seeding that rolling is, on the average, of least value. There are, of course, conditions where it is advisable to roll after seeding, but the true value of this implement lies in its usefulness as a means of preparing the land preparatory to seeding, as already mentioned in connection with harrowing. The use of the roller in preparing sod land for grain or corn is much to be commended, and it is here that this implement is of the greatest value to the farmer. In certain soils, as for instance, mucky or peaty soils, it is often advisable to roll once or twice before seeding and two or more times after seeding; this more particularly, if the land is to be seeded down to grass or clover, at the same time as sown to grain.

No land should be rolled after seeding if the surface is at all damp. The surface should be allowed to dry a few days before the roller is put on. Rolling in this way a few days or even two or three weeks after the grain is up, breaks the crust, forms a mulch, and so helps to conserve moisture, as already mentioned in a preceding paragraph.

On light dry soils, rolling is an essential operation after seeding to insure quick germination of both grain and grass seeds. Here again, however, it is often advisable to roll a second time two or three weeks after the grain is up. This helps firm the soil and breaks the crust as before stated. 


\section{CROP ROTATION}

\section{J. H. GRisdale, Director, Dominion Experimental Farms, Ottawa.}

Crops as grown by the Canadian Farmer fall far short in yield per acre of what they might and what they should yield. Under extraordinary weather conditions they sometimes come up to and even surpass what they really should be every year. The year just passed, 1915, was of such a character. Our farmers from one end of the Dominion to the other never before harvested such crops on the average as in 1915 . We could do practically as well every year if we only thought so and bent our effort to the getting of our farms into such condition as would insure such crops.

Extraordinary yields need not be expected every year, but crop failure would be practically unknown, every year might be "a very good year," and 1915 years would come just the same only not quite so strikingly.

The key to the situation is the man. Let the man cultivate better and follow a suitable rotation and crop failure becomes a myth.

Let us consider this matter from the crop rotation side.

\section{Crops Needed by the Farmer}

Farmers in Canada require to grow crops likely to give profitable returns in the form of seeds, that is, grain crops. At the same time they need large quantities of forage, that is, such crops as yield rough feed suitable for live stock must be grown, for instance, clover, timothy, roots and corn for ensilage.

\section{Effects of Certain Crops on Succeeding Crops}

Clover or pasture sods, when turned under, leave the soil in most excellent condition for the production of forage crops, such as roots and corn. Soils which have been occupied by roots or corn have lost by the end of the season a considerable proportion of the humus they contained at seeding time. They are, however, compacted and in most excellent shape for growing grain. The grain crops grown upon fields which have been under some hoed crop the previous year are likely to give large yields of seed with a comparatively small proportion of straw, the ideal condition for most profitable returns.

It is evident, therefore, that each crop affects the condition of the soil in its own peculiar way, and that the condition in which a soil finds itself, after having borne a certain crop, is nearly always the condition best suited for the production of some other crop.

Having observed the peculiarities of crops as to food requirements, conditions of growth and residual effects upon the soil, it is evident that it should be possible to work out a succession of crops where the soil condition after each would be such as best suited the growth of the next. Arranging crops in this way is called "Rotation of Crops."

\section{ROTATION OF CROPS}

Rotation of crops means the following of one crop with another in regular and ever recurring or repeated succession. Rotation comes from the word "rotare," meaning "to turn round." Thence a rotation might possibly include only two crops, as for instance, hay and grain alternately for a long period of time. Generally speaking, however, a longer rotation that is a succession of crops including a greater diversity, is meant when one uses the term rotation. 


\section{Crop Rotations for Eastern Canada}

As rotations possible in Eastern Canada, and as rotations likely to give satisfactory results, I might mention the following:-

"A"-Three year rotation-Grain-hay-hay or pasture.

" $B$ "- Three year rotation-Hoed crop-grain-hay.

"C"-Four year rotation-Hoed crop-grain-hay or pasture-hay or pasture.

" $\mathrm{D}$ "-Fivé year rotation-Hoed crop-grain-hay-grain-hay or pasture.

"E"-Five year rotation-Hoed crop-grain-hay-pasture-grain.

"F"-Six year rotation-Hoed crop-grain-grain-hay-hay or pasture-pasture.

\section{Some Remarks on Rotations}

Rotation "A," of three years' duration, is one suited for the farmer who cannot, on account of the character of his land, or who does not care for some other reason to grow any considerable area of roots, or other hoed crop. This rotation:-

First year-grain, seeded down with 10 lbs. red clover, 2 lbs. alsike and $12 \mathrm{lbs}$. timothy per acre. Second year-timothy or pasture, will provide a large quantity of forage and at the same time do much toward building up or improving the soil on the farm. On a 100-acre farm in Ontario on which this rotation was used for six years the crop producing powers of the soil were practically doubled, and in this particular case very little barnyard manure was used.

Rotation "B," of three years' duration:-

First year-hoed crop, followed by second year grain, seeded down with clover and timothy, say $10 \mathrm{lbs}$. red clover, $2 \mathrm{lbs}$. alsike and $6 \mathrm{lbs}$. timothy per acre. Third year-hay or pasture, is a rotation likely to give very large returns in the way of crop produced and net profit per acre. It is a rotation peculiarly well fitted for certain districts in eastern Canada, where farms usually include considerable areas of rough land fit for pasture, but.not available for crop production. On such farms the division of the arable land into three equal or nearly equal areas and the following thereon of the rotation described, will enable the farmer to carry a much larger number of cattle, and will insure his getting much bigger returns than where a longer rotation is followed and a relatively smaller proportion of the arable land given over to the production of forage crops such as corn, roots and clover hay. On the Experimental Farm, Ottawa, this rotation has proven to be by much the most profitable of all rotations tried.

Rotation "C," a four year rotation, including:-

First year-hoed crop; followed by second year-grain, seeded down with say, $10 \mathrm{lbs}$. red clover, 2 lbs. alsike, 12 lbs. timothy per acre. Third year-hay or pasture. Fourth year-hay or pasture.

This rotation recommends itself for use on farms where most of the land is arable and where provision has to be made for pasturing, to some extent at least, on arable land. It has the advantage of sod being turned down once in four years, of clover occupying the land, to a greater or lesser extent, three years out of four, and of being under pasture to some extent the third or fourth year. This rotation would probably suit a light, sandy soil, even better than rotation " $B$," since rotation " $B$ " in the case of light, sandy soils would probably have a tendency to open up or loosen the soil too much.

Rotation " $\mathrm{D}$," of five years duration, as follows:-

First year-hoed crop. Second year-grain, seeded down with $10 \mathrm{lbs}$. red clover, 2 lbs. alsike and 6 lbs. timothy per acre. Third year-hay, land ploughed in fall. Fourth year - grain, seeded down with $10 \mathrm{lbs}$. red clover, $2 \mathrm{lbs}$. alsike and $6 \mathrm{lbs}$. timothy per acre. Fifth year-hay or pasture, land to be left unploughed till the following spring, manure to be applied during the winter and turned under with a shallow furrow for corn production the sixth year, or the first year of the new cycle of rotation. Such parts of the hoed crop field as it is desired to devote to roots or potatoes should be 
ploughed in late summer the year previous. Immediately after ploughing the land should be rolled, disc harrowed and worked down to insure rotting of the sod. Short manure or rotted manure should be applied during the fall or winter and worked in on the surface preparatory to growing roots or corn next year. This rotation does not allow for the production of timothy hay, but provides a very large supply of clover hay suitable for most live stock, and is certain to give large grain crops, both after corn and after the clover. The crop coming after clover is likely to be somewhat heavier in the straw, but on a stock farm (the kind of farm for which such a rotation is fitted) an extra amount of straw is always valuable. This rotation, since it allows for growing grain on two-fifths of the whole area, may recommend itself to such farmers as desire to grow all the grain feed they require on the farms.

Rotation " $\mathrm{E}$ " is similar to rotation "D." It, however, allows for the production of some timothy hay. It is as follows:-

First year-hoed crop. Second year-grain, seeded down $10 \mathrm{lbs}$. red clover, $2 \mathrm{lbs}$. alsike and 12 lbs. timothy per acre. Third year-clover hay or pasture. Fourth year-timothy hay or pasture, the land under timothy hay or in pasture to be ploughed in August with a shallow furrow, rol!ed, disced and harrowed to insure breaking down or rotting of the sod, and harrowed at intervals during the fall to destroy weeds and get the soil into good working condition. In early Octoher this land should be ploughed again with slightly deeper furrow, or else ridged up with a double mouldboard plough and left for the winter.

Fifth year-grain, seeded down 10 to $12 \mathrm{lbs}$. red clover per acre. This clover is allowed to grow all fall, manure applied during the winter and the whole mass of clover and manure turned down in May for corn or roots. This rotation, while not yielding quite as large a proportion of forage as rotation " $B$ " or " $C$," has the advantage of allowing the farmer to grow more grain, and so providing for almost all his feeds on the home farm. It is a rotation that can be safely recommended to any farmer interested in dairying or beef production in eastern Canada.

Rotation " $F$ " is of six years' duration, and might be of various forms. The form given above:-

First year-hoed crop; second year-grain; third year-grain: fourth year-hay; fifth year-hay or pasture; sixth year-pasture, is probably not the best arrangement of crops, but it is the rotation most commonly followed in many parts of Canada. It has the disadvantage of trying to grow two grain crops in succession. Were it modified to read: First year-hoed crop; second year-grain; third year-hay; fourth year-hay; fifth year-pasture; sixth year-grain, it would be likely co prove more satisfactory, both as a rotation for producing large quantities of forage and as a rotation for keeping the farm in good condition.

\section{Some Reasons for Adoption of a Rotation}

Any one of these rotations carefully followed and the cultural operations connected therewith performed at the right time and in the right way would be sure to increase tremendously the crop production of any given farm, and at the same time increase but slightly, if at all, the cost of production. In addition to the increased returns and lower cost of production per unit of crop, the following advantages might be anticipated from the introduction of a rotation into the farming operations of the average eastern Canada farmer:-

1. The cost of fencing on farms where live stock are kept would be materially reduced, since it would be necessary to fence off only three, four or five fields instead of fifteen or twenty as is very commonly the case. Farmers of course do not always fence off each small field, still, where fields are not fenced, the disadvantage of being unable to pasture any given area when conditions were such as to invite such treatment, and the trouble of driving cattle across unfenced fields to reach other fields, would more than 
make up for the extra cost incurred in the construction of suitable fences. The introduction of a rotation including a few properly fenced fields would do away with all trouble in this respect.

2. All cultural operations of one kind would be in one field, thus lowering the cost of reducing the travelling necessary from one small plot to another. All corn or hoed crops would be together, all grain crops in one group, and all hay crops in another, hence much time would be saved, and so cost of production lowered.

3. Larger machinery.could be used. Where fields are few they are sure to be larger, and larger fields can always be handled more cheaply with large machinery.

4. Every field would receive its fair proportion of barnyard manure, and receive this manure at regular intervals. In this way every part of the farm would be kept in good tilth, and the whole farm kept up to its highest producing possibilities. As operations are usually conducted on farms where no rotation is practised, certain fields adjacent to the farm buildings or supposedly possessing some peculiar soil characteristics are usually favoured to the disadvantage of the rest of the farm. Many farms include small areas upon which practically all the manure is lavished each year, greatly to the detriment of the rest of the farm, and much to the disadvantage of the owner. The influence of a rotation in improving conditions in this respect can hardly be overestimated.

5. Considerably less labour is required to keep fields in good condition where a rotation is followed. While it might be claimed that ploughing a field every third or fourth year would involve a large amount of labour, it can be stated on the other hand that performing these cultural operations more frequently permits of their being performed much more easily year by year. At the same time, if careful record be kept of the amount of labour upon a field where no rotation is followed, it will probably be found that practically just as many hours of horse labour or man labour have been spent as where under a short rotation.

6. Fields under long rotations or no rotations are almost certain to become infested to a greater or less extent with weeds. Fields under a short rotation are practically always clean, provided of course that the cultural operations are properly performed. The value of the rotation in helping eradicate all injurious plant life is a point the importance of which cannot be too much impressed upon our farmers in eastern Canada to-day, where weeds are so exceedingly prevalent.

Many other minor points might be cited in favour of the introduction of a rotation. The above should, however, suffice to indicate its value on the farm. The rotation, as I have attempted to demonstrate, is important, but no rotation can make up for poor cultivation or faulty soil treatment.

\section{WINTER PREPARATIONS FOR CROP PRODUCTION ON THE PRAIRIES}

\section{J. H. GRisdale, Director, Dominion Experimental Farms, Ottawa.}

The demand for all grains will very probably be good in the fall of 1916 . It will therefore be all the more advisable to produce as large crops as possible.

"Increase the area" alone, is a poor watchword. "As much as can be properly handled" is the right idea.

Early on the land, with everything ready beforehand and a fixed determination to put the seed in well and to put in as many acres as you can possibly do well, will work wonders in the way of raising the average acre yield and increasing the average acreage under grain for each farmer. 
Thorough preparation of the land intended for grain is not only advisable but an absolute necessity on the prairies. Here, where the growing season is short at best, no one can afford to neglect any precaution likely to hasten germination, insure steady growth, or in some measure guarantee early ripening.

Motive Power and Implements. - Whether horses, oxen, steam tractor or gasoline tractor be used to do the farm work, care should be taken to have them in good shape for work before actual seeding operations begin. Horses or oxen in poor flesh or long idle cannot be expected to do good work when the rush begins. Feed well for some weeks before seeding can possibly begin and give considerable exercise with a view to getting them into condition for the rush at seed time.

Tractors, whether steam or gas, should be thoroughly overhauled and tried out some weeks ahead of seed time. Repairs come slowly when the land lies ready; better have a few of the more commonly needed parts or repairs on hand before work really begins. Do these things now.

\section{SEED TIME SUGGESTIONS FOR THE PRAIRIES}

\section{J. H. GRisdale, Director, Dominion Experimental Farms, Ottawa.}

\section{SOIL PREPARATION FOR WHEAT, OATS AND BARLEY}

On Summer-fallowed Land.-The treatment to give the land both before and after seeding depends upon the character of the soil and the fall preparation.

All land should be harrowed as soon as it is possible to get thereon in the Spring. The harrowing helps warm it up and conserves moisture.

All land should be in good shape for seed, that is, fairly fine on the surface, quite firm and as smooth as possible before any seed is sown thereon.

After you think the field is just right, give it another stroke of the harrow. Thorough, yes, extraordinary soil preparation pays and pays well.

On Stubble Land-For fall ploughed stubble land the treatment should be the same.

Unploughed stubble land to be sown to wheat might be burnt over the first warm, windy day in the spring, then given one or two cuts with the harrow before seeding and once over after seeding.

If stubble will not burn readily or if it is moderately short and therefore need not be burned over, double disc before seeding and harrow afterwards.

When it is intended to sow stubble land to oats or barley, spring ploughing 4 or 5 inches deep will be found to be the best preparation. If not possible to plough then treat as for wheat.

For Flax-Flax is usually a profitable crop. It may be sown on any kind of soil. Unlike other crops, it will even do well on prairie breaking provided it is sown not later than May.

On Breaking.-Break or plough 3 inches deep, disc well and sow. Roll or pack before discing if breaking is rough or broken, roll or pack after seeding if a good job of breaking was done. Sow 30 to 40 pounds of seed to the acre.

\section{QUANTITIES OF SEED TO SOẂ}

Wheat.-The quantity of wheat to sow to the acre, while an important matter, is one that must be decided at the time of seeding and according to the season and the condition of the land.

Thick or heavy seeding usually matures more quickly than thin or light seeding.

Light, poor land will not carry satisfactorily as heavy a seeding as strong, rich soil. 
A safe rule is to sow from $11 / 4$ to $11 / 2$ bushels of wheat to the acre on a good strong summer-fallow, the lighter seeding if put in early, a considerably heavier seeding if late in season before seeding is done.

On stubble land a considerably lighter seeding should be given. If the land is rather dry, possibly 3 pecks per acre would give the best results.

Oats and Barley.-Oats and barley should be sown as soon as possible after wheat is in. The same general directions as to relative quantities of seed apply as in the case of wheat. Sow $1 \frac{1}{2}$ to $2 \frac{1}{2}$ bushels seed to the acre according to fall preparation and character of the soil.

Flax. - Flax should be sown on summer-fallow or new land at from 30 to 40 pounds to the acre, the lighter seeding on lighter soil and heavy seeding on strong, rich soil. Do not sow too early, May 15th is quite sufficiently early. On stubble lands a lighter seeding should be given, say 25 to $30 \mathrm{lbs}$. to the acre.

In tabular form below are summarized the rates of seeding for the above crops:-

\section{Rates of Seeding to Acre}

On Summer-fallow or New Land

Wheat.........11/4 to $11 / 2$ bus.

Oats.........1 $1 / 2$ to $21 / 2$ bus.

Barley.........11/4 to $21 / 2$ bus.

Flax........... 30 to 40 lbs.
On Stubble

$3 / 4$ to $11 / 4$ bus.

$1 \frac{1}{2}$ to $1 \frac{3}{4}$ bus.

1 to $13 / 4$ bus.

25 to $30 \mathrm{lbs}$.

\section{THE SEED}

1. All grain should be treated for smut before seeding. Steep in bluestone or formalin solution. (For full instructions see below.)

2. See that you are sowing deep enough but not too deep.

(a) On summer-fallowed land sow about two and one-half inches deep.

(b) On stubble land sow about three and one-half inches deep.

(c) If ground is rather dry at seeding time, sow a little deeper.

(d) If ground is fairly damp, a little less pressure is needed.

3. If ground is very loose, pack either before or after seeding.

4. Do the seeding early. Early-sown crops have a considerably better chance of giving good returns than late sown crops.

Germination Test.-If not sure of the germinating qualities of your seed try it out before sowing.

Send a sample to the Dominion Government Seed Laboratories at Calgary or Ottawa or, what will answer the purpose quite as well and possibly better, test it yourself.

To do this' proceed as follows: Count out a hundred kernels the run of the grain, sow in some of your own soil in a shallow box placed in a sunny window and kept at comfortable living-room temperature. Keep soil damp but not wet. Note the growth for two weeks. If only part of the seeds germinate or if the plants grow very slowly it will be necessary to sow proportionally more seed to the acre.

\section{TREATMENT FOR SMUT}

The cost of treating grain for Smut is so very low as compared to the increased yield likely to result therefrom that it should be considered as one of the indispensable practices of every grain grower.

Always treat wheat and oats.

The following treatments will be found most effective:

Bluestone Solution. -5 $\mathrm{lbs}$. commercial bluestone to 50 Imperial gallons water. 
Formalin Solution. - $1 \mathrm{lb}$. of formalin (normal strength) to 40 Imperial gallons of water.

Steeping Method.-In bluestone solution, immerse grain not less than two minutes-not more than three minutes. In formalin solution, not less than four minutes and not more than five minutes.

Sprinkling Method.- Heap grain on clean floor. Sprinkle either solution over it with broom or can; mix well.' 40 gallons will treat $40-50$ bushels of grain. When using bluestone, spread out to dry at once after mixing; form grain into piles when using formalin, and cover for three hours with bags-then spread out and dry.

Moist grain cannot feed the drill as freely as dry grain -adjust your drill.

NotE.-For detailed information on subject, ask for Exhibition Circular 24 or Experimental Farms Bulletion 73, Publications Branch, Ottawa, Ont.

\section{PREPARE FOR NEXT YEAR'S CROP}

'Once the seeding is done for this year begin to get ready for next year's crop.

Too much importance cannot be attached to early and through preparation for the next year.

The proper and necessary preparation is the summer-fallowing of at least one-third of the cropping area where that area or any part thereof has been under crop for more than one year.

Two crops will almost invariably exhaust the moisture in any given area in Saskatchewan or Southern Alberta. In the drier parts of these provinces, as, for example, South-western Saskatchewan and Southern Alberta, one crop on summer-fallow usually reduces the soil moisture to such a low percentage as to suggest the necessity for another summer-fallow. Hence, in these parts, it is frequently advisable to summer-fallow every second year instead of every third year as recommended for parts somewhat more favourably situated as to rainfall.

Summer-fallowing Methods. - The summer-fallow treatment should be begun by giving the field a good ploughing. Plough from 7 to 8 inches deep. Plough in the fore part of June and thus prepare the land to receive and hold the June and July rains. Harrow right after ploughing or better still at the same time, certainly not later than the next day. There is only one right way to handle the land after ploughing. Instructions as to handling might however be given in several apparently distinct sentences, although they all amount to the same thing, thus:

1. Cultivate the summer-fallow frequently throughout the growing season, or

2. Keep the summer-fallow black, or

3. Maintain a mulch or dust coat on the fallow, or

4. Do not allow weeds to grow on the summer-fallow.

\section{FIELD CROPS IN MANITOBA}

\section{PROFESSOR T. J. HARRISON, B.S.A., Professor of Field Husbandry, Manitoba Agricultural College}

Methods of Land Preparation-Due to the heavy crop and adverse weather conditions during threshing time, this operation was greatly delayed, with a consequence that very little land in the Province has been fall ploughed, and prepared for wheat. The high price of wheat last spring also induced many farmers to sow more wheat than they would have done in an ordinary year. The result is that a much less amount of summer-fallow has been prepared, so that the spring of 1916 will find the farmers of this Province with only a small amount of land prepared for wheat. The result will be that a large amount of wheat will have to be sown on spring ploughing. This being true, the best method of preparing the land should be employed. The 
results from a number of experiments conducted both at the College and Experimental Farms throughout the West seem to indicate that the best method of preparing stubble land for wheat is by ploughing about 4 or 5 inches deep, packing and harrowing the same day as ploughed and sowing the seed before the ground has had a chance to dry out. The same method of preparation will also apply to land for oats and barley. If the season should become dry after seeding, the data that has been obtained so far would seem to indicate that it would pay to harrow the growing grain. The first harrowing should be given just as the grain is peeping through the ground and the second harrowing deferred until the grain is from 4 to 6 inches high. The kind of harrow that is used will depend upon the implements the farmer has on hand and the capital he wishes to invest in implements. The lever harrow, with the teeth slanted slightly backwards, gives the best satisfaction, but any light harrow can be used to good advantage, and many farmers are using the ordinary diamond drag harrow.

Variety of Crop to be Sown-Throughout the southern part of Manitoba either Marquis or Red Fife wheat can be used to good advantage. In the northern portion of the Province, especially where there is danger of frost, Marquis will give the best satisfaction, while in the very northern districts Prelude may be sown. In these latter districts it is usually more profitable to use some earlier maturing crop, such as oats or barley. In practically every district in the Province, Victory and Banner oats give best satisfaction, while O.A.C. No. 21 and Manchurian barley are the best of the 6-rowed types. Among the 2-rowed sorts, Canadian Thorpe is considered good.

Seed and Seeding-After the variety has been decided upon, the next important operation is selecting good seed of that variety. If best results are to be obtained, it should be absolutely pure, that is, free from both weed seeds and other kinds of grain. The next point to be considered is its viability. If best results are to be obtained the seed should germinate at least $80 \%$. Some of the seed for the spring of 1916 will not be of a very high quality because of the unusual weather conditions of the fall of 1915 . Some of the oats are frosted, the wheat sprouted and the barley weathered, which will cause a very low germination; therefore, before the seed is sown it should be tested for germination. If the seed is low in vitality, other seed should be procured, or if that cannot be done, a larger quantity of seed should be sown per acre. Before seeding any of these grains, they should be treated for smut, using either a solution of formalin or bluestone. The wheat should be sown as soon as the ground can be worked and not sown later than May 16th. Oats can be sown from the last week in April until about May 20th; barley can be sown from the last week in April until the first week in June. The amount of seed sown per acre will depend upon the vitality of the seed, the preparation of the land and the amount of rainfall. With seed of average germination and soil 'well prepared, in Manitoba, usually $11 / 2$ bushels of wheat, 2 bushels of oats and $13 / 4$ bushels of barley will give good results.

Forage and Root Crops-On every farm some live stock should be kept, and this will necessitate the growing of forage and root crops. While corn last year was badly damaged by frost, this should not discourage the growing of this valuable crop, and every farmer should sow at least five acres. The variety that gives best results generally throughout the Province is Northwestern Dent. The seed of corn should be secured early, as there is likely to be a shortage.

Where summer pasture is to be supplied, spring rye, oats, barley and peas can be used to good advantage. The cereals can be mixed together in about equal parts and gown two bushels of cereal to one of peas. If late fall pasture is required, it can be obtained by sowing winter rye and rape or turnips. Every farmer should plan, however, to seed down a small portion with grass and clover to supply both hay and pasture. Unless the land is useless for other purposes, it should be sown with the intention of breaking it up in about two years, for other crops; if it is to be used for hay, timothy, Western rye and red clover can be used to good advantage; if it is to be used for 
Fasture, Western rye, brome and red clover may be used. If there is danger of the brome becoming too persistent, English blue grass might be substituted.

A few roots should be grown on every farm. Among the turnips, the Perfection Swede is best; Mammoth Long Mangel will also unually give a high yield.

Weed Control-Last fall being very wet, many of the perennial weeds were not killed, and consequently we may expect to find in our summer-fallows more sow thistle, Canada thistle and quack grass than we had last year. Wild oats and other annual weeds should not be so thick. On land that has to be cropped, the best method of controlling the latter class will be to harrow the growing crop. While the prices of grain will have a tendency to induce many farmers to crop as much land as possible, they should be careful to crop only that which is in good condition and summer-fallow the poorest and weediest fields.

Marketing-The market for cereals will undoubtedly be good again next fall because there will be a big demand for wheat and oats. It may not, however, be as strong as this past year because of the large amount of grain being held by farmers. While, no doubt, a large amount has been put on the market, every farmer is holding one or two carloads until spring. This is largely because prices this past two or three years have been much better during May and June than they were during the previous fall.

Labour-One of the biggest drawbacks to the production of large amounts of farm produce this year will be the scarcity of labour. Recruiting is taking away many of the men from the farm who are not very busy during the winter time, but are required for the sowing and harvesting of the crops, so that the farmer should plan to secure his labour early and in this way sow only the amount of crop that he can harvest.

\section{SOME TIMELY HINTS}

\section{PROFESSOR S. A. BEDFORD, Manitoba Department of Agriculture.}

The summer-fallows of Manitoba ought to be more thoroughly cultivated than hitherto. Only on such fallows as are kept perfectly bare of weed growth during the whole season will perennial weeds be eradicated.

As summer-fallows are better prepared, only Marquis wheat should be sown thereon, Red Fyfe lodges too readily on well worked fallows. Mensury barley and Banner oats still give the best results in yield and quality.

Wheat should be seeded as soon as the land works freely, but not later than May 7 th to 10 th. Sow oats as early in May as possible and barley from May 7 th until lune 1st. Sow as deeply as possible in light dry or loose soil and shallow on wet or stiff soil.

Thoroughly harrow the field after seeding, and if annual weeds are plentiful harrow the crop with a weeder or harrow.

As to the eradication of wild oats, it may be noted that skin ploughing in the fall gives excellent results.

Fodder corn is a very satisfactory fodder crop here. It yields well and is one $\partial \mathrm{f}$ the best crops for the eradication of weeds. Soiling crops and grain cut green for hay are also useful for weed eradication.

Manitoba farmers should provide themselves with more granary room and not rush their grain to market all at once. 


\section{THE SASKATCHEWAN CROP GROWERS' PLANS IN WAR TIME}

\section{PROF. JOHN BRACKEN, Professor of Field Husbandry, University of SASKatchewaN.}

To those of us who are not in khaki but who are nevertheless anxious to do their share in bringing victory to the Allies' cause the question of modifying our farm practices to meet the needs of the present crisis is one that deserves our most serious consideration.

The call has come to the Canadian farmer to increase his production, because, in this way, he can be of very material service to the Empire. No one doubts the favourable effect a large crop will have on our staying powers in this war. The question is, can we get the larger crop?

We produced $10,543,796$ acres of grain in 1915 . We fallowed $2,043,841$ acres of land and "broke" 729,553 acres of virgin prairie.

The fallow is practically ready for seeding without extra work. Where it has been done well no additional cultivation other than mulching by surface tillage is necessary or advisable. Where it has not been done well it is too late now to do anything that will make it right; although no doubt, many poorly prepared fields may yet be improved by suitable cultivation in the spring. Our fallow can be depended upon to produce some crop. The climatic conditions will determine whether it will be large or small.

Much of the "breaking" can still be improved, but the time for doing the best wcrk on this land is also past. We can yet see, however, that a suitable seed-bed is prepared and that poorly cultivated land is surface tilled. The breaking lends itself more to improvement than the fallow. It is not so sure to give us a crop as the fallow, but more sure to do so than the stubble land.

Of the 10,500,000 odd acres that were cropped this year, very little has received any preparation for next year's crop. Under ordinary circumstances at least $3,500,000$ acres of this land should be fallowed. This would leave 7,000,000 acres of stubble land to prepare for a crop. The Provincial Department of Agriculture estimates that $1,730,000$ acres of this have been fall ploughed, leaving over 5,250,000 acres yet in stubble.

Under these conditions what is to be done? Shall we sow ill-prepared land and take a chance, as, fortunately, many of us did in 1915, or, shall we sow only the land that can be well prepared? In other words shall we, having made a fortunate stroke, take another turn at the wheel, or shall we play safe? There can be no doubt that the latter is the better plan, not only for the nation but also for the individual.

The Empire's needs must receive first consideration from the farmer as well as from the soldier. But poor farm practice will not result in satisfying the Empire's needs. If we expect that the war will be concluded within from twelve to twenty months, the most patriotic among us may be led to sow all or nearly all of our land, including a portion or all of what should be fallowed. We would serve an immediate need at the expense of the future. We would take chances on our 1916 crop and run an even greater risk with the crop of the following year.

Without a reasonable amount of fallowed land in 1916, what would be our contribution to the Empire's needs in 1917, providing the war continues two years or more? Where would the individual be financially? It is conceivable that the 1917 crop might be a failure. It is not only conceivable, but it is quite probable, that it would be a small one-small in direct proportion to the absence of fallowed land.

Ordinarily the stubble land that is cropped is either fall ploughed, spring ploughed, burned and surface cultivated, or sown on the stubble without any cultivation. Less than one-quarter of the estimated stubble land to be sown was ploughed last fall. It is possible that an equal proportion was disced. This leaves at least $3,500,000$ acres to be prepared in the spring. If the spring opens up early, some spring ploughing can be done for wheat and more for oats. This year, on account of the long stubble, much of the land can fortunately be burned and cultivated, and thus fairly well prepared at 
low cost. But such preparation is not sufficient for grassy land, nor for tight clay soils, nor for some weedy fields. It may be sufficient for immediate returns on other soils that are in good condition.

But some of this land will be sown without ploughing, or burning, or discing. Grassy fields, or those cropped two or more years without ploughing are likely to fail under this treatment. Fields in good condition, and only one year removed from fallow, may return a net profit by this practice if the season is a moist one; but even under favourable conditions such preparation is sure to lower rather than increase our total production, and if the season is unfavourable such fields are likely to result in a loss to the owner as well as to the nation.

Generally speaking our total production can be increased in proportion to the intelligent work we put on the land and to the power at our command for adequately tilling the soil. At average prices for wheat, the net profit to the producer may not be increased by additional cultivation after land has been reasonably well prepared, but as long as high prices prevail it will pay to do more intensive work than we have ever done before.

It would seem that Saskatchewan farmers during this testing time will be able to serve the Empire best,

(1) By concentrating our best thought and greatest effort, not in sowing every acre under cultivation, but in sowing all the land we can prepare well and by fallowing the balance;

(2) By using standard varieties of standard crops, and seed that is free from weeds and disease and that will grow vigorously;

(3) By preventing, as far as possible, the present waste of energy, time and power on the farm, and by increasing the efficiency of the capital and equipment at our disposal;

(4) By putting into practice only tested and proven methods of crop production.

We must not forget that in a semi-arid northern climate crops do not grow large and get ripe merely because it is our wish that they do so. Neither should we build our hopes on having another season such as the one just past.' We must, rather, remember that our efforts during the next year or two years, as in all the years that are to come, will be crowned with success in exact proportion to the intelligent application of the energy and the brains we apply to the undertaking.

\section{PREPARATION OF SEED BED FOR OATS IN SASKATCHEWAN}

\section{J. Tinline, B.S.A., Acting Superintendent, Dominion Experimental Farm, ScotT, SASK.}

Some interesting data has been secured in connection with the preparation and treatment afforded new land for growing oats. A part of a field that had been broken in 1914, was measured off in 5 acre divisions; the work on this field in 1914 was such as is usually given by the best farmers, i.e., it was packed and double disced within three weeks after breaking, and double disced and harrowed with a smoothing harrow in the autumn. In the early spring, all the plots were given a stroke with the smoothing harrow. Ligowo Oats were sown at the rate of $2 \frac{1}{2}$ bus. per acre-on April 30th. The crop was harvested on August 25th and 26th.

The additional treatment and results secured are given in the following table,Plot Treatment Yield per acre. Bus. Lbs.

1. Harrowed, sown, packed, harrowed when grain was $6^{\prime \prime}$ high........................... $94{ }^{-2}$

4. Harrowed, floated, sown................. 932

3. Harrowed, sown, packed after seeding......... $88 \quad 25$

2. Harrowed, sown.................... 832 
The extra treatment given these plots is additional to that usually afforded new land in Saskatchewan, and the results prove that more work can be put on new land with profit.

The packer used was the surface packer. The smoothing harrow the ordinary diamond harrow. The float is a wooden drag, made after a plan of the one used by Seager Wheeler, and is very similar in construction to the ordinary drag used in levelling roads.

\section{RATE OF SEEDING IN ALBERTA}

\section{G. H. HUTtON, B.S.A., Superintendent, Dominion Experimental Farm, Lacombe, Alta.}

The problem of determining the best amount of seed to sow to the acre is a manysided one, involving such considerations as rainfall, ability of the soil to hold moisture, soil preparation and other factors. Experiments were begun at this station in 1908, and continued for four years. At Lethbridge in Southern Alberta, similar experiments have been conducted. These should form a fairly safe guide. From results obtained we have felt warranted in recommending the use of larger quantities of seed than were thought best a few years ago.

Our present field practice is to sow 3 bushels of Marquis wheat per acre on summer fallow, breaking, or following corn, roots or potatoes; of oats, 3 to $31 / 2$ bushels, and of barley, 2 to $2 \frac{1}{2}$ bushels, on fall-ploughed stubble land.

In the drier districts to the south and east of Lacombe it would not be practicable to use such liberal quantities as this, but heavier seeding should be practised in those districts than has frequently been recommended. We recommend not less than $11 / 2$ bushels of wheat on well worked summer-fallow and breaking. While this may prove too much in some years, there are other years when the use of this quantity will insure against frost by inducing early maturity.

Results at Lethbridge indicate that wheat should be sown at the rate of 105 pounds to the acre on non-irrigated land. This is much heavier than was usually recommended a few years ago; but it is based on four years' experiments, and should cover a fairly average group of seasons.

I should not feel justified in advising a general increase beyond the rates above indicated in the amount of seed to be used next spring. Spring ploughing dries out more rapidly than fall ploughing, and if a dry season should follow, such advice would give bad results.

\section{Individual Experiences showing what Good Cultivation will do.}

A farmer near Briercrest reports that from 90 acres summer-fallow on which an outfit worked exclusively during 1914 - that is after seeding up to harvest time-he, this year threshed 4,843 bushels of wheat, almost 54 bushels per acre. On 40 acres stubble he had 1,503 bushels, an average of $261 / 2$ bushels per acre. He had 23 acres of oats on summer-fallow, which yielded 2,065 bushels, and 50 acres on stubble, which gave 1,150 bushels. The stubble for both wheat and oats was disced and harrowed last fall and disced and harrowed this spring, and thoroughly well worked.

In our August issue we referred to crops in Tp. 12, Ranges 5 and 6 , west of $3 \mathrm{rd}$, as the best seen on the trip. We estimated yields at from 40 to 50 bushels per acre, for there were no weeds. The owner of the machine who did the threshing in this district reports as follows: "I have kept account of yields; some farms have yielded 50 bushels per acre, the lowest 40 . Some stubble fields averaged 45 bushels per acre. Oats 80 to 110 bushels per acre. Mr. B's wheat, east of his barn, gave 45 bushels per acre. 
He cut it too green, and it shrank badly. It should have gone away over 50 bushels. This is the field reported on the first week in July as the best stand I had ever seen in Western Canada. Special note was made of these farms as having no weeds.

A farmer, 8 miles north-east of Caron, had a small field of 8 acres extra well cultivated, part of it in potatoes last year, which yielded him 550 bushels of wheat this year, that is $68 \% \frac{1}{4}$ bushels per acre.

Hundreds, yes, thousands of similar reports might be given from Swift Current, Cabri, Vanguard, Pontiex, Maple Creek, Rosetown and Kerrobert districts.

- "The Saskatchewan Farmer."

\section{SIX REASONS AGAINST THE ONE-CROP SYSTEM}

First:-A one-crop system is unsafe economically because it is dependent upon crop conditions and market conditions.

Second:- It does not maintain soil fertility.

Third:-No permanent system of agriculture has been devised that does not include a reasonable livestock industry.

Fourth:-A one-crop system does not permit of economical farm management.

Fifth:-Under the one-crop system the returns come in but once a year.

Sixth:-The one-crop system limits knowledge and narrows citizenship.

Diversification is the biggest and most vital, the most hopeful and helpful word in the story of better farming. It is farm insurance and the beginning of farm profit and permanency. It means raising and feeding more crops on the farm, thus getting two prices and the manure from them-it means something frequently going to market and cash as frequently coming back.

A well-balanced business insures against losses and provides a much better utilization of the labour and equipment.

\section{JUST ONCE MORE}

\section{CUMming, Secretary for Agriculture, Truro, Nova Scotia.}

"I have harvested a bigger crop of potatoes and ronts than any farmer in this community, and as good a crop as I ever put in my barns in any season, and yet the neighbours are all talking about their small yields of these crops this year." So said a farmer living in a community in Nova Scotia, where crop correspondents report only fifty per cent. of a potato yield and seventy-five percent. of the usual yield of roots. "And how do you account for this?" said the person to whom the remark was addressed. "Well," remarked the farmer, "the only reason I can give is that I had a relative staying with me on the farm this year, and when I could not think of anything else for him to do, I told him to go out and run the cultivator through the potatoes and roots." "Probably my fields were thus cultivated two or three times more than those of my neighbours. This is the only reason I can give for my big crops."

Everybody knows in a sort of a way that cultivation pays, but an extended observation of the farms, at least in Eastern Canada, leads the writer to say that, so far as practice is concerned, the whole lesson has not yet been learned. "How often shall I harrow this field before seeding it down?" said a boy of my acquaintance to his father, 
who was well known as a good farmer. "Harrow as often as you think right and then harrow once more," replied the father. The boy who told me this incident added that father always grew big crops of oats.

There is sound scientific knowledge behind each of these incidents and the know. ledge is of a kind that every farmer should bear in mind in the year 1916 as never before. Big crops are needed. Big crops we must have. Fertilizers, which are largely used in the East, are from twenty to thirty per cent. higher than they were before the war broke out, and while one fears that the high prices may lead to farmers using less fertilizer than usual, yet the fact remains that better cultivation than usual with a smaller application of fertilizer will give bigger results.

The average of some two hundred soils of Nova Scotia recently analyzed in the chemical laboratory at the Agricultural College shows that each acre of the depth of six inches contains four thousand pounds of nitrogen, three thousand pounds of phosphoric acid and five thousands pounds of potash. In comparison, a 45 bushel crop of oats plus straw will remove from the soil $52 \mathrm{lbs}$. of nitrogen, $19 \mathrm{lbs}$. of phosphoric acid and $38 \mathrm{lbs}$. potash. This means that even in the first six inches of soil there is enough plant food present to grow upwards of a hundred or more big crops; and then there is the reservoir of the subsoil to draw upon. The trouble, however, is that these vast stores of plant food exist in an insoluble or unavailable condition. Cultivation is the tool with which the farmer can set this plant food free, and it is also the tool that will enable him to get bigger returns from the manure and fertilizer which he adds to the soil.

In general, the fields of Eastern Canada are not big. Moreover, one more harrowing or cultivating calls for horse labour to a greater extent than man labour. Let it be the aim, therefore, of every farmer at least in Eastern Canada in the year 1916 to cultivate just once more, and then, if he has time-once more.

\section{GROWING POTATOES ON SANDY SOILS}

\section{A. L. GibSon, B.S.A., Ontario Agricultural College, Guelph.}

Potatoes are an ideal crop to grow on soils of a sandy nature. Probably no crop can be made to give more profitable returns on sandy soils than potatoes. Even our poorest Ontario sands can usually be made to produce a very profitable crop. Such soils will yield potatoes of the highest quality and practically free of disease. Had all the available sandy soils of Ontario been devoted to potatoes where possible in the season of 1915 , the scarcity of potatoes would have been unknown; moreover a large area of the heavier soils where potatoes were almost a complete failure; could have been devoted to a more successful purpose.

Experiments with Potatoes on Norfolk Sands-During the past year the Department of Chemistry at the Ontario Agricultural College commenced experiments with potatoes on the poorest of Norfolk County sand. These experiments showed that providing a sand is properly treated and fed, remarkable yields can be obtained even in one year. In the case of the soil mentioned the ground was ploughed in the fall and received a dressing of 10 tons fresh cow manure, containing very little straw.

Effect of Lime on Sand-An application of lime to sandy soils invariably pays even though the soil may not appear sour by the litmus paper test. Early in the spring a dressing of two tons of limestone dust was given, followed by a thorough cultivation of the disc cultivator and harrow. Besides permanently improving the 
physical condition of the land and even preventing the sand from blowing, this application of lime alone produced an average increase of nearly two tons per acre with a higher proportion of large saleable potatoes.

Effect of Special Fertilizers-Special fertilizing on such soils is absolutely necessary to obtain maximum yields and profits. In the experiments being discussed, early Irish Cobbler potatoes were planted, and by treating the soil with a mixture of Sulphate of Ammonia and Superphosphate, the yield was further increased over the liming result by four tons per acre. In brief, by liming and special fertilizing, these experiments showed that on a soil that was locally abandoned as unprofitable for cultivation, a crop of 400 bushels per care of early potatoes could be obtained.

Fertilizers recommended-From careful study and observation of these experiments the following general application per acre is recommended for early potatoes on soils similar to the poorest sands of Norfolk County:-

Sulphate of Ammonia 200 lbs.

Superphosphate $400 \mathrm{lbs}$.

( $14 \%$ available phosphoric acid.)

This mixture will contain:-

Nitrogen.................6.3\%

Available Phosphoric Acid....9.3\%

Any available supply of potash such as wood ashes, which can be obtained at a profitable figure, would considerably improve this mixture. Nitrate of Soda may be used in place of Sulphate of Ammonia, but should be applied as a top dressing in at least two applications, after the plants are up at intervals of two or three weeks. Owing to the war the price and supply have almost placed Nitrate of Soda beyond the reach of the farmer. In the case of late potatoes the Sulphate of Ammonia could very well be replaced with $250 \mathrm{lbs}$. of Calcium Cyanamide, a nitrogenous fertilizer now being made in large quantities at Niagara Falls and sold at a very reasonable price. Basic Slag applied in the same quantity in place of Superphosphate gives equally good results on such soils.

Application of Fertilizers-Fertilizers should be very finely crushed and thoroughly mixed with an additional amount of sand to increase the bulk. This insures more even distribution. Where Basic Srg is used it should not be mixed with the Sulphate of Ammonia, but applied separately. The application should be made on a calm day, being broadcasted either by hand or machine about two weeks before planting and followed with a light harrowing.

General Cultivation and Spraying-Seeding and later cultivation should be conducted as commonly practised in good potato culture, special attention being given to avoid the robbing of the crop by weeds. Sprouting of the seed in shallow boxes before planting is recommended, especially where subject to late frosts, so that planting may be delayed without retarding the harvest. It should not be forgotten that even on sandy soils the spraying of potatoes with Bordeaux Mixture is very essential to a good-crop. Bordeaux Mixture may be mixed with Arsenate of Lead or Paris Green when spraying for the potato beetle. This spraying mixture would consist of:Copper Sulphate (Bluestone) 4 lbs., unslacked lime 4 lbs., Arsenate of Lead 3 lbs., or Paris Green $1 \mathrm{lb}$., to 40 gallons of water. The Copper Sulphate is dissolved in a wooden vessel with hot water, poured into a barrel, and cold water added to make 20 gallons; slake the lime, preferably with hot water, and add cold water in which the Arsenate of Lead or Paris Green has been well mixed. Gradually mix the lime and poison solution with the Copper Sulphate in the barrel, stirring well all the time, and finally make up to 40 gallons with more cold water. Spray while the mixture is fresh, taking care that the under side of the leaves get the spray. Give at least two sprayings. 


\section{WAR AGAINST INSECT PESTS THE FOES OF AGRICULTURAL PRODUCTION}

\section{GORDON HEWITT, Dominion Entomologist, Department of Agriculture. OtTawa.}

The Swiss motto, "To cultivate the soil is to serve one's country," is to-day, when the Empire is at war, more applicable than ever to the farmers of Canada. To meet the necessities of Canada and the Empire, it is necessary not only to maintain production at its usual rate, but to make every effort to increase it to a still higher point.

Destruction by insect pests is one of the chief factors in reducing the output of the farm. All crops are affected-field, orchard and forest. The aggregate loss to Canada due to these causes is not generally appreciated. When a serious outbreak of an insect pest occurs on a farm, the farmer realizes the extent of his individual loss, but the aggregate loss caused by the continual destruction effected by insects working insidiously in the fields and diminishing crop production as a whole, is comprehended by few. Careful investigation indicates that the loss averages anywhere from ten to twenty-five per cent. of the crop. On the lower estimate the annual loss to Canada from the depredations of insects is reckoned at over one hundred and twenty-five million dollars. Taking the latest figures of crop production, the loss on a ten per cent. basis works out as follows:-

Field Crops (grain crops, potatoes, sugar beets and

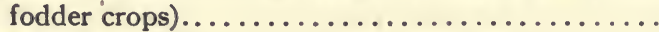

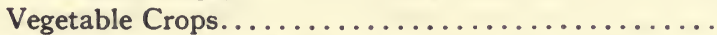

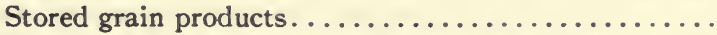

Live Stock (loss in hides, milk and flesh)..........

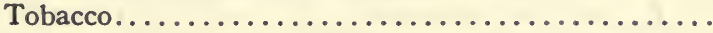

Fruit, orchard and small fruits, including losses and cost of spraying, etc. (Based on 1911 figures)...

$$
\begin{array}{r}
\$ 80,000,000 \\
5,000,000 \\
5,000,000 \\
30,000,000 \\
100,000
\end{array}
$$

$5,000,000$

Total.................... \$125,100,000

Canada suffers proportionately greater losses from insect pests than older countries owing to a number of reasons. The chief reason is that a new and fertile country is being opened up and developed; large tracts of land are being put under cultivation, providing an abundance of food for insects which previously lived in small numbers in restricted cultivated patches or on wild plants. For three thousand miles our territory adjoins that of a country whose development preceded ours, and in the process of this development foreign pests were accidentally introduced with the result that more than half of the worst insect pests are introduced species. Development requires imports of natural products such as trees, plants, seeds, fruit, etc.; such natural products carry pests from their native countries; on establishment in the new country these pests increase more abundantly owing to the absence of their natural enemies, which, unfortunately, are not imported at the same time. All these conditions are mainly peculiar to a new country. A large proportion of the losses could be prevented, even with our present limited knowledge of control measures.

We cannot, particularly at the present time, afford to allow preventable losses to occur. Therefore, it behooves every farmer to take steps, or to redouble his efforts, to curtail losses from this cause, and to increase production by eliminating loss. Insect pests are insidious foes, and the fight against them is an incessant war demanding constant watchfulness. In many cases their presence is unknown until their increase has become so great as to cause serious losses. The destruction and loss goes on year in and year out until finally it reaches a climax in a general outbreak. Recent outbreaks of such insects as the army worm, tent caterpillar, pea aphis, locust, cutworm, illustrate this. These outbreaks might in most cases have been prevented. 


\section{METHODS OF INSECT CONTROL}

\section{GORDON HEWITT, Dominion Entomologist.}

In this connection it is desirable briefly to indicate some of the more general measures that may be adopted with a view of decreasing the annual loss due to insect pests and to prevent widespread outbreaks.

The first essential is clean farming. This involves the destruction of weeds; not only because these enemies of the farm take the food and the place of the crop, but because they also afford permanent breeding places for many insect pests. Fences and hedgerows should be cleaned up. Rubbish and litter, under which numerous noxious insects hibernate, should be collected and burnt. Where grain is grown, the volunteer crop, which nourished certain cereal pests such as the Wheat Midge and Wheat Stem Maggot, should be destroyed. After a crop such as cabbages or roots has been harvested, clean up the field and burn the rubbish which would otherwise serve as food and shelter for insects. A clean field and a clean orchard will mean larger crops.

Special attention should be paid to cultivation. If the ground is properly prepared in the spring with a view to the production of a strong growth, the plants will be in the best state to resist insect attacks. A poor growth cannot withstand insect injury. If the crop has been attacked during the year by insect pests such as certain insects affecting the stems of cereals or root-destroying grubs such as white grubs and wireworms, deep ploughing in the fall should be adopted. In the case of grain the stubble is buried deep enough to prevent the emergence of insects which attack the plants and are passing the winter in the soil. In the case of white grubs and wireworms, which pass the winter at some distance below the surface of the soil, their shelters are broken up and the unprotected tender grubs are in a large measure exposed to adverse climatic conditions. Summer fallowing aids insect control.

The rotation of crops is an excellent means of preventing or controlling certain insect pests. The repeated sowing of the same crop provides a rapid means of increase for insects affecting that crop. In certain cases the best method of controlling an insect is to change the crop. There are certain facts which should always be remembered: if land is infested with white grubs or wireworms, do not plant corn or potatoes in the following year, but sow an immune crop, such as buckwheat or clover. Also, grass land when put into cultivation is apt to be infested with root-eating insects such as wireworms and steps should be taken accordingly.

Too much stress cannot be laid upon the urgent necessity of protecting our native birds, the majority of which constitute our most valuable allies in our war against insect pests. Very few of our birds are really harmful; most of them destroy enormous quantities of insects annually. The policy of the agriculturalist in regard to the birds should be not only non-destructive but also one of active encouragement. The encouragement of birds about the farm involves little expense or labour. Nesting boxes can be made out of rough slabs of lumber or old shingles; these should be distributed about the farm or in the woodlot. Here and there on the farm a few bushes and thickets should be permitted to grow to serve as shelters and nesting sites. The shooting of wild birds should not be permitted on the farm.

In conclusion, constant watchfulness should be practised. The first signs of anything suspicious should be immediately investigated, and if there is any doubt as to the cause of the trouble or its cure the Dominion or Provincial Department of Agriculture should he consulted without delay. Neglect to take action or delay may mean the loss of a whole crop. 


\section{WHAT GOOD ROTATION WILL DO}

1. Rotation keeps the soil in a high state of productivity.

2. Tends to counteract drought.

3. Keeps down weeds.

4. Results in a more even distribution of labour.

5. Decreases cost of production.

6. Provides feed for live stock, with an increase in profit.

\section{ACRE PROFIT COMPETITIONS IN ONTARIO}

\section{F. Bailey, Assistant Deputy Minister of Agriculture for Ontario.}

At a time like this, when food production is admitted to be an important factor in determining che ultimate outcome of the present war, it is interesting to note the results of the "Acre Profit Competitions" recently conducted in Ontario. These competitions were open only to young men who had taken a short course under the District Representative, and as the name implies, were limited in extent to 1 acre of land.

The following statement shows the highest results for the past two years in the nineteen counties where potatoes were selected as the crop for competition:

\begin{tabular}{rrrrr} 
& Yield & Cost Production & Value per Bus. & \multicolumn{1}{c}{ Profit } \\
1914 & 501 & $\$ 32.62$ & $\$ 0.40$ & $\$ 167.18$ \\
1915 & 514 & 42.02 & .75 & 336.72
\end{tabular}

As compared with the average yield per acre for the Province of 116 bushels, this yield of 514 bushels secured by the winner in the competition may seem phenomenal. When, however, the average of the nineteen winners in the competition is taken into consideration, it does not seem unreasonable to believe that the average for the Province might be greatly increased.

The averages of the winners in all counties were as follows:-

$\begin{array}{ccccc} & \text { Yield } & \text { Cost Production } & \text { Value per Bus. } & \text { Profit } \\ 1914 & 337 & \$ 40.43 & \$ 0.40 & \$ 134.80 \\ 1915 & 271 & 40.06 & .75 & 202.77\end{array}$

The year 1915 was an unfavorable one for potatoes. Weather conditions favoured the development of rot which in many instances ruined the crop. Yet, strange to say, a higher yield was secured by the winner in 1915 than in 1914 . While the average yield for 1915 was not so high as the previous year, the average profit is greatly increased on account of the high prices prevailing.

In the counties where oats were selected as the crop for competition, the differences are equally as marked as in the case of potatoes.

The following table shows the results of the winner in the competition for oats for the past two years:-

$\begin{array}{rrccc} & \text { Yield } & \text { Cost Production } & \text { Value per Bus. } & \text { Profit } \\ 1914 & 86 & \$ 15.70 & \$ 0.50 & \$ 25.30 \\ 1915 & 104 & 17.75 & .40 & 23.98\end{array}$

The averages for the winners in all the counties were as follows:-

$\begin{array}{rrrrr}1914 & 73 & \$ 12.52 & \$ 0.50 & \$ 23.95 \\ 1915 & 82 & 15.54 & .40 & 17.38\end{array}$


An analysis of the above tables shows quite clearly that 1915 was a favourable year for oats. While a yield of 104 bushels per acre is very high, it is not by any means the highest on record-a yield of 114 bushels in the Rainy River District having been reported to the writer. The favourable season is further evidenced by the fact that the average of all winners in the counties growing oats amounted to 82 bushels and the average for the Province was 41.9 bushels.

In the mangel growing competition, the winner had a yield of 1,652 bushels, as compared with an average of 498 bushels for the province. The cost of production was $\$ 42.33$, and the net profit was $\$ 155.91$ with mangels valued at 12 c. per bushel. In turnips a yield of 994 bushels was secured in the competition and the average for the Province was only 478 bushcls. Corn for seed also showed a marked increase over the average yield of the Province- 154 bushels as compared with 70 bushels. An even more striking difference was noted in the corn for silage competition, when a yield of $393 / 4$ tons was secured, the average yield for the Province being 11 tons.

When we know that these large yields have been secured by our young farmers, we realize something of the possibilities of agricultural production, and naturally are desirous of learning how such results were obtained. It should be borne in mind in this connection that these results are secured from a limited area, and that the crop no doubt received much more careful attention than could be hoped for when growing crops on a large scale. It is equally true that the land selected for this competition would probably be one of the best fields on the farm. These sacts in themselves, however, do not account in any large degree for the marked difference between the yields secured in the competition and the average for the Province. It will be remembered that the young men taking part in these competitions have come to appreciate the importance of employing up-to-date methods of farming In other words they have selected well drained fields, prepared a good seed bed, secured seed of high germination and desirable variety, given the crop tho:sugh cultivation and where necessary have made intelligent use of spraying materials. These are the factors that have, in the main, been responsible for these large yıclds, and the regret is that their importance is not more widely recognized and more generally adopted.

Note:-In estimating the cost of operation, $\$ 5.00$ per acre is allowed for rent of land; $15 \mathrm{c}$. an hour for manual labour and $10 \mathrm{c}$. an hour for horse labour; a charge of $50 \mathrm{c}$. is made for each two-horse load of barnyard manure. In the same way a charge of one half the purchase price of commercial fertilizers is made against the crop; each contestant must keep a careful record of the cost of operations and in every instance reliable witnesses are secured to weigh or rneasure the crop to be harvested. A valuation based upon the prevailing market price- is put upon the crop but arbitrarily fixed by the Department in order to insure untformity for purposes of comparison. The net profit is arrived at by deducting all , ust of production plus rent of land from the total value of crop. 


\section{GOOD SEED}

"Still will the seeds, tho' chosen with toilsome pains, degenerate if man's industrious hand cull not, each year, the largest and the best."Virgil.

\section{REJECT THE UNFIT}

Only sound, live men are fit for the trenches. The recruits are coming in, enlistment is keen. First of all comes the medical examination. The weaklings, the deficient, the unpromising, are weeded out. They may look fit enough, but the rigid examination discards them for they will not do at the front. Every inefficient man is a burden to the strong and sturdy fellow. Then they are gone over again and any alien enemies are ejected. The alien enemy is even a greater menace than the unfit and untrained. You who are raising food for the fighters at the front are fighting at home. What about your seed? Seed is the parent of the crop. Put it through its testing. Do not waste your energies on weakling seed. Eject the alien enemy seeds-the weeds. Give your soil a fair chance. Do not waste your labour with the poor seed or dirty seed. Fight fair and be fair to yourself.

\section{THE SEED SITUATION}

\section{GEO. H. ClaRK, B.S.A., Commissioner, Seed Branch, Dept. of Agriculture,} OTTAWA.

The seed season of 1915 was a very unusual one in respect to the production of seed, especially in Eastern Canada, as the very wet weather before and during harvest greatly affected the crops. The available supply of foreign seed has also been materially influenced by the war in Europe and by weather conditions in the United States. These circumstances have combined to bring about a condition in respect to the general seed supply which requires careful attention from every farmer.

Wheat-In Ontario, and the other eastern provinces to a lesser extent, the quality of the wheat was materially lowered through wet weather at harvest time. However, where the grain has been well dried and carefully stored it will probably be suitable for seed in most cases, but care should be taken to see that the vitality has not been damaged through heating. Where there is any room for doubt, a vitality test should be made.

Fortunately, there has been a large crop of good quality wheat in Western Canada which may be drawn upon by those districts in the East which require to purchase seed. The difficulty that has hitherto prevailed in securing pure seed wheat from Western Canada should be largely removed this year as a special grade has been established for seed wheat that is free from noxious weed seeds within the meaning of the Seed Control Act. Wheat of either the Red Fife or Marquis variety which has been certified as suitable for seed by a government inspector may be obtained at the government interior 
terminal elevators at Moose Jaw, Saskatoon and Calgary. With this supply of clean wheat available there should be no excuse for dealers or farmers in Eastern Canada purchasing seed wheat contaminated with weed seeds, as has often been done.

Oats-Damage to the oat crop in Eastern Canada was even more extensive than to wheat. In Ontario and parts of the other eastern provinces, good sound seed oats, free from weather damage, are very scarce and difficult to secure. In many cases there is evidence that the vitality of the oats has been seriously affected through weathering or subsequent heating, which makes it more necessary than usual to have vitality tests conducted before sowing the seed.

The crop in Western Canada is very large this year and of good quality and a large supply of good seed oats should be available from this source. As with wheat, special provision is this year made whereby a supply of pure seed may be obtained through the government interior elevators. Oats that are free from noxious weed seeds are being separately stored and will be cleaned for seed and shipped out under a seed inspector's certificate. It is hoped that dealers or farmers in Eastern Canada who require to purchase seed in carlots will take advantage of this special grade and thereby avoid getting oats containing large numbers of noxious weed seeds, as is nearly always the case when ordinary commercial grades are purchased.

Treating Oats and Wheat for Smut-Last season, in Ontario especially, and in the other eastern provinces to a large extent, the damage to the oat crop through smut was unusually great. The loss throughout Ontario has been estimated at from six to ten per cent. of the crop, and in many instances the actual number of heads affected reached from fifteen to twenty per cent. This enormous loss is almost entirely preventable, and every farmer should adopt precautionary measures for next season. The prevalence of smut last year will mean that practically all the oats to be used for seed this year will be badly contaminated with the smut spores, and, if conditions are favourable for their development the disease may be even more serious than last season. In order to prevent an outbreak of this disease the seed should be treated before sowing to destroy the smut spores. This may be effectively done by using a solution made from one pound formalin in thirty-five gallons of water.

The treatment prescribed for oats is equally effective for wheat, and should be followed in all cases in Western Canada where smut is likely to appear. In the eastern part of Canada the damage is often sufficient to warrant treatment of seed wheat.

Barley-Much the same conditions obtain in respect to barley as were outlined for oats, although there is a more limited supply available in Western Canada. At time of writing it is not known whether much seed barley will be available at the government interior elevators in the West, but it is anticipated that there will be at least a limited supply.

Cleaning Seed Grain-The importance of thoroughly cleaning seed grain to remove weed seeds and the small, immature or light kernels cannot be too strongly urged. From the condition of much of the seed actually being sown by farmers throughout Canada, it is evident that better yields and higher quality of grain are sacrificed through lack of attention to cleaning the seed. As a rule, grain intended for seed should be reduced in bulk from one quarter to one half by screening and wind blast. Oats usually require the most severe cleaning. For the farmer who uses his own grain for seed, there is no loss in severe cleaning as what is removed may be used for feed. The extra work involved in cleaning seed several times will be many time repaid in the crop.

Corn-The available supply of seed corn in Ontario, and also in the United States, is considerably below the average in quality. Owing to wet weather, the crop was late 
in maturing and a smaller proportion than usual was selected for seed, and it was not as dry or well matured as in an ordinary season. The quality by next spring will depend largely on storage and weather conditions, but more care than usual will be required both in storing and handling if the ensilage grower is to receive his seed corn in first class condition. There is great danger of damage to the vitality through frost when the seed is not sufficiently dry, and moulds are likely to develop when the weather becomes warm or if the corn is not given sufficient ventilation in storage or during shipment. The situation will demand the most careful attention on the part of all concerned, and farmers are strongly urged to secure their seed early so that there will be time to examine and test the germination before planting. Farmers would be well advised to purchase their seed before the mild weather and to have it well dried by artificial heat in their own buildings in order to lessen the danger of damage by mould. This would also give them plenty of time to have germination tests conducted.

Alfalfa-There was practically no alfalfa seed produced in Ontario in 1915, and the crop in parts of the United States that are considered to produce hardy seed was very limited. Most of the United States seed this year is coming from Texas and Arizona and is not recommended for northern districts. In view of the extreme scarcity of northern-grown seed, farmers are advised to be very careful about purchasing seed this year with the idea of seeding down for a permanent crop. If only a mixture for hay is desired, hardiness is not so essential. If a permanent stand is desired, only seed that can be guaranteed in respect to variety and place of growth should be used. For this purpose southern seed, which is largely on the market this year, will be sure to give disappointing results.

Red Clover-The Ontario crop of red clover seed last year was extremely short and of very poor quality both in respect to purity and vitality. Most of the No. 1 seed on the market this spring was grown in the Western States under irrigation. It is large plump seed of good purity, but there is little information available in respect to the suitability for Canadian conditions. The home-grown seed would probably be preferable if it were equally good in other respects, and it is recommended that native seed be used as much as possible, even though the grade be lower and it may be necessary to sow a little more seed per acre on account of lower vitality.

Alsike Clover-Much the same conditions prevail with alsike as with common red; although there is a greater quantity of Ontario grown seed, it is of rather poor general quality. Much of the seed produced in the central part of the United States is somewhat similar to the Ontario seed. The best appearing and highest grade seed being put on the market this year is from the Western States.

Timothy-The conditions of supply in respect to timothy seed are more normal than with clover. Most of the seed is coming from the United States, and is perhaps rather darker in colour and more hulled than usual. About the average quantity of seed is available in Quebec, and some of this is above average quality. The Prince Edward Island crop is about normal, and there is a limited quantity of seed available in Alberta.

Field Roots and Vegetables-Under normal conditions, most of our field root and vegetable seeds are imported from the countries now at war. Owing to the accumulation of large stocks previous to the outbreak of the war, there will probably not be serious difficulty in supplying the demand for most kinds of seeds this spring, but unless much more seed is grown in North America than usual this year ,the situation may be serious for the spring of 1917 . In 1915 quite a large number of farmers in the different provinces grew root and vegetable seed on a small scale mostly for their own use. In some cases quite large quantities are available for market. The results on the whole were very satisfactory, and farmers are advised to adopt this practice more generally during the coming season in order to insure the supply of seed for 1917. 


\title{
THE PRODUCTION OF HIGH CLASS SEED IN CANADA
}

\author{
L. H. NEWMan, Secretary, Canadian Seed Growers' Ass'n, Ottawa.
}

Canada requires over $40,000,000$ bushels of seed each spring to sow the area at present devoted to the production of ordinary farm crops. The average yields obtained per acre for the different crops is deplorably low, and investigation into the causes of these low yields indicates clearly that the use of inferior seed is one of the chief factors. The great national importance of the use of good seed is easily deducted. Thus, an increase of five bushels per acre in the yield of wheat at $\$ 1.00$ per bushel would mean an increase to the revenue of the country of $\$ 55,000,000$. An increase of ten bushels per acre in the yield of potatoes, which is easily obtainable; would mean an added revenue of almost $\$ 3,000,000$, estimating the price of potatoes at 60 cents per bushel. Oats, one of our most important crops, is influenced readily by the quality of the seed used. An increase of ten bushels per acre in the case of this cereal, selling at 50 cents per bushel, would mean an added income to our country of over $\$ 48,000,000$ annually. In these days when millions are being spent in the terrible toll of war, the figures given are significant.

Many agencies are at work at the present time with a view to instructing and encouraging farmers in securing seed that will give them more bushels to the acre. Possibly one of the most effective organizations concerning itself with this problem is the Canadian Seed Growers' Association. This body is composed of actual farmers who are engaged specifically in producing what is known as "Registered" seed. This is a term given to seed, the breeding, purity and vitality of which is known and vouched for. The members operate under expert direction, being closely in touch not only with the headquarters at Ottawa, but also with local authorities whose duty it is to look after the interests of the individual growers. There are in Canada approximately 1,200 men engaged in this work, and these are now producing many thousands of bushels of seed. This seed is being distributed in a practical way through the ordinary channels of trade, thus enabling farmers not only to procure seed of a superior quality, but also of a variety known to be suitable for the district. The offerings of the different growers are listed in a seed catalogue which is distributed widely throughout Canada, and in this way the grower and purchaser are brought together. 'All registered seed goes out in sealed sacks, to which a special tag bearing the certificate number, is attached. In this and other ways the quality of the seed is practically guaranteed.

Those who wish to obtain full details regarding the work of this Association should write the Secretary, L. H. Newman, Canadian Building, Ottawa, and secure a copy of the booklet entitled "The Canadian Seed Growers' Association and its Work."

\section{CEREALS}

\section{RECOMMENDED VARIETIES AND THEIR CHARACTERISTICS}

\section{Charles E. SAUnders, Ph.D., Dominion Cerealist, Ottawa.}

Before deciding what acreage and what kinds of grain crops to sow, a farmer will of course consider the requirements of his own live stock, and the prices, so far as he can predict them, which are likely to be offered for any grain he may have for sale.

The problem of prices, always difficult, and exceptionally so in war times, scarcely comes within the scope of these notes. The preparation of the land is another matter of very great importance, and one on which the success of grain crops largely depends. A discussion of this topic belongs, however, rather under the head of management than of cereals. 
In so far as the seed alone is concerned, there are three main considerations that are of the utmost practical importance: The first of these is to select suitable varieties, the second is to obtain plump seed of good vitality, and the third is to insure its freedom from weed seeds and foreign grains.

Without attempting to go into details, which will be gladly given to anyone who cares to write for them, the following list of some of the best varieties for Canada, of the different types of grain may be useful.

\section{Spring Wheats}

Marquis-early-very productive-beardless.

Huron-early - very productive-bearded.

Red Fyfe-rather late-very productive-beardless.

Prelude-very early, fairly productive-bearded.

These are all hard, red wheats.

White Russian is a very productive, rather late, beardless variety of somewhat soft character. It is highly prized in the Maritime Provinces, but should not be grown in those provinces that desire to maintain a reputation for producing hard wheat.

\section{Winter Wheat}

For districts liable to wet, cold weather, Dawson's Golden Chaff is perhaps the best sort. It is a beardless variety with excellent field characteristics, but produces rather soft kernels and starchy flour suitable for biscuits and pastry, but unsuitable for light bread.

For localities subject to dry cold, where the young plants are not likely to be well covered with snow during severe weather, Turkey Red is probably the most profitable variety. It is bearded and generally produces rather hard kernels. The flour from this wheat is highly esteemed for bread-making.

\section{Oats}

Banner-rather late-very productive. Ligowo-slightly early-productive.

Daubeney-very early-kernels small.

\section{Barley}

Manchurian, six-row-very productive.

O.A.C. No. 21, six-row-very productive.

- Duckbill, two-row-very productive.

\section{Peas}

Arthur-very productive-rather early-peas of medium size-yellow.

Prussian Blue-very productive-peas blue and of medium size.

Golden Vine-very productive, peas small, yellow.

Among the new varieties of grain now before the Canadian public which have already proved invaluable-but of which the exact rank has not yet been determinedthe following very productive sorts may be mentioned:

Solo peas-a dark variety from Sweden.

Victory Oats-from Sweden, also called Seger and Conqueror.

O.A.C. No. 72 Oats-a selection from Siberian, rather late in ripening but otherwise very promising.

Grain-growers are very strongly advised not to purchase seed at any price (and particularly to avoid purchasing expensive seed) of any variety that has not yet received favourable mention from some of the experimental farms or agricultural colleges. As a rule, new sorts should be tested at first in small areas only, and should be carefully compared with some old standard kind for a year or two, before being grown on a large scale. 
Change of seed is wrong in principle and very dangerous in practice. A good rule is never to change your seed unless you are sure that the new seed is better than the old, and that it is perfectly free from weed seeds. It is generally much wiser to clean and grade up one's own seed than to make any change-unless a new and superior variety is being received.

\section{WHAT VARIETIES SHALL I SOW IN 1916?}

\section{Results of 4,000 Experiments in Ontario, as established by the Experimental Union}

\section{-}

Of all varieties grown in Ontario to-day, the O.A.C. No. 72 is the most outstanding variety. It is the heaviest yielder, has the stiffest straw and the grain has only $27 \%$ of hull. It is also very resistant to smut. Comparing it with the Banner, which is the most widely grown Oat in this Province, we see that over a period of nine years the average yield of the O.A.C. No. 72 was 90.6 , while that of the Banner was only 72.5 bushels per acre.

Another Oat that is coming into prominence is the O.A.C. No. 3. It is a very early Oat and therefore is quite suitable for sowing with Barley where a grain mixture is desired.

\section{Barley}

In the experiments conducted at the College the O.A.C. No. 21 Barley still leads. It is even better than the Mandscheuri variety, introduced by the College 26 years ago. It is now estimated that $96 \%$ of all Barley grown in Ontario belongs either to the O.A.C. No. 21 or Mandscheuri varieties. It is worthy of note that of the 40 entries of Barley at the Winter Fair, O.A.C. No. 21 was the only variety exhibited.

According to the reports of the Bureau of Industries, the yield of Barley per acre for the past 16 years has increased twenty-three per cent. This has undoubtedly been due to the introduction of superior varieties. It is estimated that the value of this increase is approximately $\$ 3,50 \prime, 000$.

\section{Spring Wheat}

The past year has seen an increase in the production of spring wheats, due of course to conditions in Europe which have brought about an increase in the price of wheat. Of the two varieties sent out to experimenters last year, the Wild Goose variety gave the highest yield, 19.9 bushels per acre. However, Marquis yielded 19.2 bushels and has much better milling qualities.

\section{Mixed Grains}

The average results of experiments conducted over a period of five years show that a mixture of one bushel of barley and one bushel of oats give the highest yield. This is sown at the rate of two bushels per acre. For two years, during which the growing season was rather dry, a heavier seeding gave better yields. In each year the poorest yield resulted from the thinnest seeding.

\section{Roots}

In Mangolds, Sutton's Mammoth Long Red gave a slightly higher yield than the Yellow Leviathan. However, taking the result of experiments over a number of years, the Yellow Leviathan has given higher yields and is the most popular mangold in Ontario to-day. 


\section{Potatoes.}

In the Co-operative experiments with potatoes, the Davies' Warrior gave the highest yield. Some farmers have objected to this variety because of its lateness. Of the earlier varieties, Extra Early Eureka still holds its lead. -From O.A.C. Review.

\section{ROT RESISTANT VARIETIES OF POTATOES}

Prof. C. A. Zavitz states that experiments at the Ontario Agricultural College show a very great difference in the susceptibility of the different varieties of potatoes to the rot. For instance, in 1915, a year in which rot was unusually prevalent, two varieties had less than one per cent. each of rot, and two varieties had upwards of fifty per cent. of rot under similar conditions. Taking the average of experiments for five years it has been ascertained that those varieties which were the freest of rot were the Davies' Warrior, the Extra Early Eureka, the Stray Beauty and the Holborn Abundance, and those most subject to rot were the Early Rose and the Beauty of Hebron.

\section{HOW SASKATCHEWAN GRAIN GROWERS MAY DO THEIR "BIT" IN 1916}

\section{G. H. CUTler, Professor of Cereal Husbandry, University of Saskatchewan, SASKatoon, SASK.}

In their effort to assist in the big business of War by providing food for the men at the front, the grain growers of Saskatchewan will do well to give earnest heed to the following details affecting production:

Seed-Good seed is seed that is not only free from every kind of weed seeds, but consists of one variety, of plump well matured grain, of high germinability. As a preventive against the ravages of smut it must be carefully treated with formalin. These statements are supported by the experiments conducted in the Investigation Field at the University of Saskatchewan, quoted below:

1. The value of good seed.

(a) Seeded by weight-11/2 bus. per acre.

Bus. per acre

Average 2 years.

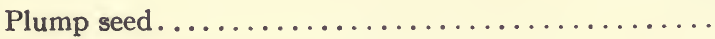
47.665

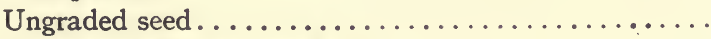
43.875
Light and shrunken seed................, 44.041

(b) Seeded by number on the basis of $11 / 2$ bus. per acre.

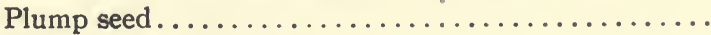

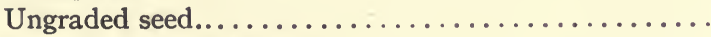

Light and shrunken seed................ 44.208

2. The value of the fanning mill as a means of obtaining the most efficient seed. Bus. per acre

Uncleaned seed..................... 56.666

Grain once cleaned..................... 58.333

Light and shrunken grain............... 55.333

Screenings.......................... 55.000

Weeds introduced through improper cleaning of seed grain not only crowd upon the growing plants and hamper them, but consume most extravagant amounts of moisture and thus reduce production to that extent. 


\section{Control of Smut.}

Treatment

$\%$ of plants diseased

Tagged wheat untreated..................... 46.72

Tagged wheat treated, smut balls floated off.......... 00.

Tagged wheat treated, smut balls not floated off........ 4.72

Clean wheat treated and seeded on soil infested with smut

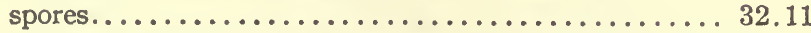

The Formalin treatment is a very essential operation and must not be overlooked. Formalin of known quality is imperative. Don't expect too much from 'leftovers' from treatment to treatment. Throw out all leftovers and give the formalin the benefit of the doubt.

Variety-Let us stand unalterably by Red Fyfe and Marquis. Pioneer may fill a useful place where greater earliness is desired than can be obtained with Marquis. Some of us were deceived into buying Egyptian King in 1915; let us not err in this direction again. Egyptian King will disappoint us in our endeavours just in proportion as it failed in the comparative trials in the Investigation Field, as it shown by the following table:

\begin{tabular}{|c|c|c|c|}
\hline Variety & $\begin{array}{l}\text { Weight per } \\
\text { bus. }\end{array}$ & $\begin{array}{l}\text { No. of days } \\
\text { maturing }\end{array}$ & $\begin{array}{l}\text { Bus. per acre } \\
5 \text { years aver. }\end{array}$ \\
\hline Red Fyfe. & 62 lbs. & 120 & 29.300 \\
\hline Marquis & $63 \mathrm{lbs}$. & 116 & 29.000 \\
\hline Pioneer. & 62 lbs. & 112 & 24.248 \\
\hline Egyptian King........... & $62 \mathrm{lbs}$. & 116 & 23.936 \\
\hline
\end{tabular}

Depth of Seeding-We can sow too deep, and we can also sow too shallow for the best development of root and plant. Seeding in the moisture is a safe guide to follow. Four inches, yes three inches is too deep; on the other hand $11 / 2$ inches is too shallow. Remember that the greatest root-development takes place between $11 / 2$ inches and 2 inches beneath the surface of the soil. Therefore in a properly prepared seedbed $21 / 2$ inches is the depth of seeding that on the average will insure the best development of root and plant and therefore more nearly result in maximum production.

Rate of Seeding - The rate at which we as grain growers shall seed must depend upon several factors. We quote results obtained on fallow in the Investigation Field:

Rate of seeding

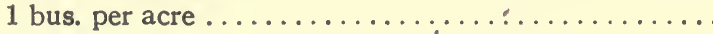

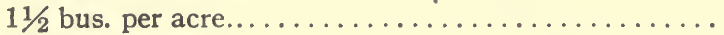

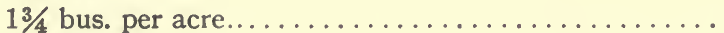

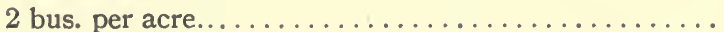

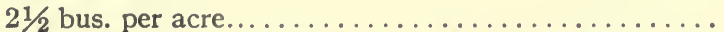

Bus. per acre

2 years average

30.916

29.625

29.354

28.133

These figures indicate that the rate at which we should sow at Saskatoon is 1 bus. per acre. In accepting these data it should be borne in mind that during the past two seasons the rainfall has been lighter than normal; also the additional fact that the seed used was unusually small.

In deciding therefore upon the rate of seeding let us consider the following factors:

1. The size of seed used-large seed heavier rate than small seed.

2. The kind of soil-warm soil less than cold soil.

3. The preparation of the soil-fallow land will require heavier seeding than second or third crop.

4. The time of seeding-late seeding may require more seed.

5. The danger of frost-heavy seeding increases the earliness.

6. The danger of drought-light seeding resists drought and is therefore best in dry areas.

7. The percent and strength of germination. 
Date of Seeding - The following were the results obtained by experiment:Wheat on fallow.

Date Seeded Wt. per bus.

Bus. per acre average 2 years

First seeding ........

63 lbs.

35.208

Second seeding........

63 lbs.

33.250

Third seeding. ........

63 lbs.

34.847

Fourth seeding ......

61 lbs.

32.625

Fifth seeding........

59 lbs.

32.667

To obtain the highest yields of wheat of the best quality these factors should guide our seeding operations:

1. Time spring opens up-late spring, sow wheat as soon as possible.

2. Preparation of land-seed fallow land earlier than second or third crop.

3. Kind of land-seed heavy land first.

4. Geographical location-Northern parts of the province, early seeding desirable for wheat.

5. Thickness of seeding-thick seeding promotes early maturity.

6. Kind and varieties of wheat-Red Fyfe should be seeded first, Marquis later, when these are used upon the same farm.

To "do our bit" as grain growers and produce every possible bushel in 1916, we must employ plump, well-matured seed, free from weeds, treated with formalin, of Marquis or the Red Fyfe variety, seeded at the proper depth, at the proper rate and at the right date.

\section{IMPORTANCE OF THE FANNING MILL}

Let a farm be as clean and well cultivated as it may be and the crop grown a good one, it is still a fact that cleaning the seed will soon pay for a good cleaner. A fanning mill costs, say $\$ 30.00$, a mar needs to make only $\$ 1.00$ an acre on thirty acres to pay for the machine.

The poorly equipped fanning mill is responsible for a lot of inferior and dirty grain being sown. Without a proper complement of screens it is impossible to do good work.

The capacity of a mill frequently gets more attention than it deserves. Efficiency is of much greater importance.

In operating, nothing is of greater importance than the air blast, as it is the scale by which is weighed the heavy and light seed. It should be strong enough to carry over the back all light grains, big or little, and not too strong to blow over much good grain. It is particularly essential that the blast be regular. If the speed is reduced even momentarily lighter grains are sure to fall where they do not belong, if too strong there will be a loss of good grain. Where gasoline or electric power is available, it will prove more satisfactory than the steadiest of man power.

For the most part hand machines are best for ordinary farm purposes. The volume of work can readily be handled by a hand machine and the additional cost of a power outfit is not warranted by the better work they do. But there is a place for the power machine in the hands of the seed centres that are springing up here and there through the country under the supervision of the C.S.G.A.-Prof. JAMEs MURRAY, Macdonald College, Que.

An important factor in crop improvement in addition to good seed is the selection of a good variety. In the growing of any crop one should be sure that he has the variety best adapted to his conditions. After having chosen the best variety, it is further 
necessary to select the best of the crop for seed. In the case of oats or wheat they should be thoroughly fanned and screened through a blower and only thelargest, plumpest seed used.

\section{LOSS FROM GRAIN SMUT}

H. T. Gussow, Dominion Botanist, from observations of two years based on personal counts and calculation, estimates that the annual total loss due to smut in wheat, oats and barley amounts to $\$ 17,000,000$ or 6.2 per cent. of capital invested in these crops. The loss in oats alone is roughly equal to the combined losses of wheat and barley. In the United States it is estimated that the loss due to the smuts of wheat alone amount to over $\$ 14,000,000$, and when all the smuts and rusts are considered the losses amount to hundreds of millions of dollars.

\section{MONEY IN ALSIKE}

R. S. Duncan, District Representative, Port Hope, Ont., writes:-_"A young farmer, by the name of Herman Peters, of Canton, who lives five miles north of Port Hope, has threshed $861 / 2$ bushels of alsike, by weight, from approximately 7 acres. This seed has been sold to a seed merchant in Toronto for $181 / 2$ c.a lb., or $\$ 11.10$ per bushel. This is a total production of $\$ 960.15$, or $\$ 139$ per acre. This is almost a record in alsike seed production." 


\title{
FERTILITY AND FERTILIZERS
}

\author{
The following four articles on manures and fertilizers have been com- \\ piled from the evidence of Dr.F.T. Shutt, given before the Standing \\ Committee on Agriculture.
}

Crop production may be increased either by extending the acreage or by increasing the yield per acre. The resulting output may be the same in either case, but the profit to the farmer will not be the same. The farmer's profit will generally be found in increasing the yield. This, in many cases, is at present below what is profitable. What are the means by which it may be raised?

One of the most important factors governing yield is soil fertility. It is not by any means the only factor. Besides the amount of available plant food contained in the soil, moisture, temperature, vigour of seed, and a number of other conditions have a bearing on the success or failure of a crop. Nevertheless it is one of the prime factors in determining yield.

If available plant food is deficient, the crop will be deficient both in quality and quantity. It is therefore fundamental to successful farming that fertility be maintained where it is abundant and increased where it is deficient.

\section{THE IMPORTANCE OF HUMUS}

Semi-decomposed vegetable matter, or humus, is probably the most valuable of all soil constituents. This is the element that gives to virgin soils their extraordinary richness, and it is the exhaustion of this element by poor farming that destroys fertility.

What are the functions that render humus so important? First, humus is nature's guardian for the important element nitrogen. When the humus is burned out of the soil by irrational methods of farming, the nitrogen goes with it, and the cost of commercial nitrogen is three times that of phosphoric acid and potash, weight for weight.

The productiveness of a soil is governed largely by its physical and mechanical condition. These things depend to a great extent on the amount of humus it contains. The soil must not only contain food available for the growing plant, but it must offer a comfortable medium for the germination of seed and for the growth and extension of the young and tender rootlets. Soil to be comfortable to the plant, must be in the right condition of tilth, must give access to air and retain moisture. Humus assists in all these functions.

The bacteria of the soil feed upon humus. Provided the soil is warm, moist, and well aerated, the more humus it contains, the better will they thrive. The function of soil bacteria is to convert soil elements into forms suitable for the use of plants. No humus, no bacteria; no bacteria no plant food; hence no crop.

\section{THE VALUE OF MANURE}

Farmyard manure is the most effective general fertilizer that we can apply. A ton of fresh barnyard manure of good quality contains, on an average, 10 pounds of nitrogen, 5 pounds of phosphoric acid and 10 pounds of potash. So that, based on its plant-food content alone, a ton of such manure would be worth at least $\$ 2.50$. But 
manure has a much higher crop-producing power than its composition indicates. The reason for this is that manure furnishes humus-forming materials; most commercial fertilizers do not. This constitutes the fundamental difference between manure and fertilizer.

Manure is never of any greater value than it is at the moment of its production. For certain purposes, rotted manure is more desirable than fresh manure, but these need not be discussed. Except for such purposes, it should be at once drawn to the fields and distributed. Manure not so utilized loses from one to two-thirds of its initial value. Even under the best conditions, it is impossible to rot manure without loss, but the loss is least where manure is kept compact and moist and protected from rain. By getting the manure on the field while still fresh, the farmer returns to the soil seventenths of the plant food taken from the soil in crop growth.

Comparatively small applications at short intervals are more effective than larger dressings applied frequently. It is therefore more economical to feed the soil year by year than to endeavour to load it up, say once in five or ten years.

Manure should not be too deeply buried. The food should be where the feeding roots are, and where the moisture is, say within the first six inches of soil. There will be a larger return if the manure is lightly turned under, or merely carried into the prepared surface by discing, than by burying it by deep ploughing. Usually there is at best only a limited amount of manure, and in this way the most will be made of it.

\section{THE VALUE OF CLOVER}

Rational farming means the return to the soil of a large proportion of the plant food taken from the soil by the crops grown upon it. There are only two means of doing this, one through the production and right use of manure, and the other through the growth of clovers. By the introduction of clover or other legumes into the rotation, in districts where these crops grow luxuriantly, a marked increase in soil fertility is invariably the result. It is frequently found that the resultant increase in yield is equal to that obtainable from a five to ten ton application, per acre, of barnyard manure.

The unique property of the legumes is that they are able, with the aid of certain bacteria that live in little swellings on their roots (called nodules) to secrete nitrogen from the air.

When such crops are turned under, they may add from 50 to 150 pounds of nitrogen per acre, thus vastly increasing the soil's productiveness. Even when cut and used for fodder, the soils will still be richer in nitrogen because of the roots left in the soil. Legumes leave the soil richer in nitrogen; all other crops leave it poorer in nitrogen. Alfalfa with its heavy root system appropriates the most nitrogen; red clover comes second.

As to the conditions of soil favourable for the growth of legumes: These crops need a certain amount of available lime, and soils that are acid or "sour" will not produce a thrifty growth. In such cases the application of lime or ground limestone gives very beneficial results.

Some soils are deficient in nitrogen-fixing bacteria. To overcome this, cultures of the required bacteria have been put on the market. Because of liability to loss of vitality, they are very often unsuccessful, and their general use cannot be recommended. A better method is to take a certain quantity of soil from a field where clover, alfalfa or sweet clover is growing luxuriantly. Apply from 100 to 300 pounds per acre, as soon as possible after taking from the field. Make the application on a damp grey day if possible and harrow in immediately.

\section{THE PROFITABLE USE OF FERTILIZERS}

The profit from fertilizers depends on their intelligent use. Their intelligent use depends partly on a knowledge of soil conditions and crop requirements; partly on the combination of the materials and the amount used. These questions have so many 
aspects that their solution can be arrived at only through much study and experiment. To state in a general way what profit, if any, will result from their use is not possible. Fertilizers may be and are used profitably in many instances. On the other hand, their indiscriminate purchase and use is almost sure to result in general loss.

Experimentation, so far as it has gone, has led to some definite conclusions:

First: Commercial fertilizers are not a substitute for manure, and it is not possible to maintain soil fertility by their use alone. To attempt it is not sound practice, either scientifically or economically. They are supplements to manure, not substitutes for it.

Second: In the larger number of instances, where profit has been obtained, it has resulted from the application of a "complete" fertilizer. A compound in which the three elements, nitrogen, phosphoric acid and potash are present is known as a "complete" fertilizer.

Third: The largest profits do not always result from the largest application. Farmers sometimes reason that, if a certain amount of fertilizer is good, more is better. Not at all. That is not the way to look at it. The point to observe is not so much increased yield as increased profit. The increase in yield between the use of 300 pounds and 500 pounds of fertilizer may not be sufficient to justify the increase in cost. Speaking generally, the best returns, dollar for dollar, have been obtained from moderate applications.

Fourth: It is a known fact that the growth of crops is limited by the percentage of plant food that is present in the minimum. If, for instance, there is an excess of available nitrogen and an excess of potash, but only a small amount of phosphoric acid-not sufficient for the needs of the crop-the amount of phosphoric acid will determine results. In this fact will probably be found the chief reason why in the majority of instances a complete fertilizer is desirable. There are occasions, doubtless, where the special requirements of a crop or the deficiencies of the soil call for special applications of one or more of these elements. A knowledge of such facts forms the basis for the economic compounding of a fertilizer.

Many assume that a chemical analysis of soil and crop should determine requirements. The complete analysis of a soil is seldom to be justified for this reason: The immediately available elements in a soil mark its fertility. As, invariably, the immediately available elements are present only in very small amounts, it is not easy to distinguish by analysis between the available and non-available. Nor is it possible to predict by this means the return obtainable from any particular fertilizer. There are, however, one or two chemical tests that enable advice to be given in a general way as to soil deficiencies, with the probability that profit will result from supplying the elements that are lacking. We must appeal to the soil itself by actual tests with fertilizers. Perhaps the best way for the farmer to do this is to leave a strip undressed with fertilizer for comparison; but it should be borne in mind that the full result is not always seen in the first crop that follows the application.

\section{INOCULATION OF LEGUMES}

One of the chief benefits from growing legumes is the nitrogen left in the soil by the decay of the root tubercules or nodules. Every legume in order to have tubercules on its roots must be inoculated with the specific organism that has been isolated from that particular legume, or with soil in which nodulated plants of that legume have been successfully grown. Repeated trials have shown that under ordinary farm conditions bacteria that form nodules on one legume will not produce nodules on legumes of any other species. The bacteria left in the soil by the red clover nodules will not provide inoculation for a successful crop of alfalfa nor vice versa. There is one notable exception to this rule: Cross-inoculation is possible between alfalfa and sweet clover. The strain of bacteria that produce nodules upon sweet clover will also produce nodules upon the alfalfa plant, but this is the only practical example of the kind. 
To ensure the development of nitrogen-gathering nodules, the farmer should use a culture of high inoculating power, isolated from the particular legume he desires to plant, or he should get inoculated soil from a field that has grown this legume with numerous nodules on plant roots.-From The Country Gentleman.

\section{HOW MUCH FERTILIZER?}

\section{CUMming, Secretary for Agriculture, Truro, N.S.}

All the older countries of the world use commercial fertilizer to a greater or less extent. In Eastern Canada, vast quantities are annually used. While it is true that much of this fertilizer is used to poor advantage, and while it is moreover true that many farmers who use commercial fertilizer are apt to become careless in preserving and increasing the quantity of their barnyard manure, yet the judicious use of commercial ferilizer in the East has usually given big returns. This year, however, when it is more urgent than ever that big crops should be grown, the price of commerical fertilizer has soared away up, and at present farmers are hesitating as to what course to pursue.

In a publication entitled "Germany's Food Supply, Can it Last," being a study by German experts, the following sentence occurs: "It is feared that owing to the present difficult circumstances the farmers will be shy of buying manure to any great extent, but this would be to conjure up the danger of a barren harvest next year." The problem is much more serious for hemmed in Germany than for free Canada or any other part of the British Empire, and yet it is a real problem here also.

There is one thing worth remembering and it is that less fertilizer with more cultivation will go further than more fertilizer with less cultivation. Do not cut down your purchases of fertilizer too much, but resolve to make up for any deficiencies by the extra use of the harrow and the cultivator. This is work that makes bigger demands on horse than on man power. If it is done, the farmer will in 1916, once again harvest big crops.

\section{LIME}

\section{R. HARCoUrt, Professor of Chemistry, Ontario Agricultural College, GUELPH.}

Lime is an essential constituent of the food of plants and, at the same time, one of the mineral materials most readily leached from the soil. During the past season's work on the soil survey of this province, thousands of borings were made in the soils of the countries studied. In most cases the surface soils were acid to litmus paper, and there was not enough carbonate of lime present to cause any apparent effervescence until a depth of 20 to 24 inches was reached. In some places there was none even at 40 inches, the maximum depth of our borings.

This downward movement of the lime is due to the fact that, through the action of acids formed by the decay of organic matter in the soil, lime is brought into solution and is then carried downward by the water as it settles into the soil. Consequently, the richer the soil is in decaying organic matter, the faster the natural supply of lime will be depleted, and, as an abundance of organic matter is an essential constituent of a good soil, soils under the best of cultivation are bound to gradually lose their supply of lime.

Many methods have been devised for determining the amount of acid in a soil, but none of these are suitable for field use. In most cases, it is sufficient to ascertain the fact that the soil is acid. For this purpose, a fairly satisfactory test can be made with blue litmus paper, which can be purchased at almost any drug store. It is sold in sheets 
or in little "books" which contain about twenty-five or fifty strips of the paper, about one-half inch wide and two or three inches long. This is the most convenient form in which to have the test paper. If the sheets are purchased, they may be cut into strips the size of those in the books and placed in a clean, dry, wide-mouthed, well-corked bottle, to keep them from acid fumes. When this paper comes in contact with an acid it turns red.

A very simple method and a very satisfactory one, in our experience, of applying the test, is to make a ball of damp soil, break it open and lay the paper on the broken surface, then squeeze the parts together again and allow to stand for from three to five minutes. On opening the ball, if the paper has turned red, we may conclude that the soil is sour, and in need of lime. It is apparent that the hands must be free from acid, and the soil damp enough to press into shape. Unless the soil is very dry, we have usually found, that by getting a sample three or four inches below the surface, there was enough moisture to answer the purpose.

Lime has two main types of action; it supplies basic material which is very necessary for the soil, and it improves the physical condition of both sands and clays. The necessity for a base is very definitely marked, for, in its absence the soil becomes acid and is "sour." Such soil is not well suited to plant growth and will not carry luxuriant crops. Certain weeds, however, grow well, notably sorrel and Scouring Rush or Horse tail. The sourness is not only inimical to plants, but also to micro-organisms, and the differences seen in vegetation are probably no greater than those existing in the nature of the organisms that live in the two classes of soils. Just as certain plants naturally predominate in sour soils, so also do certain micro-organisms, and, apparently, some of these at least, prevent the growth of the most desirable forms. Thus a soil may contain an abundance of organic matter; but, if sour, there will be little or no nitrogen in the form of nitrates, because the nitrifying organisms required for their production cannot develop under the existing conditions.

The alteration in physical condition brought about by liming is probably due to the binding together of the small particles of clay, causing them to act like soils made up of larger particles. Or, in other words, the deflocculated or sticky clay is converted into the flocculated or friable form. The coarse particles of sandy soils are also bound together through the action of the lime and the soil becomes firm and does not dry out so readily.

In addition to correcting acidity and improving physical state, it is probable that lime is absorbed from its solution by certain constituents of the soil, and displaces some of the substances previously absorbed. In this way, lime causes the liberation of a certain amount of potash from the soil so that a dressing of lime may to some extent take the place of an application of potash. When potash is so scarce as it is at the present time, this is an important point.

Taking into consideration all the important functions of lime in the soil and the fact that our soils are steadily losing their lime and that none of our farm crops will grow in an acid soil, it is evident why the application of lime is so important.

Lime may be purchased in the form of quick-lime, hydrated and air-slaked lime, and limestone dust. Hydrated lime is simply the quick-lime slaked, screened and bagged. The air-slaked material is the quick-lime that has slaked without the direct addition of water. It differs from the hydrated lime in that it has taken up some carbon dioxide from the air and part of the lime has passed back into the carbonate condition. Thus quicklime is the oxide of lime $(\mathrm{CaO})$, the hydrated, the hydroxide of lime $\left(\mathrm{Ca}\left(\mathrm{OH}_{2}\right)\right.$ the air-slaked, a mixture of the hydroxide and carbonate of lime $\left(\mathrm{Ca}\left(\mathrm{OH}_{2}\right)\right.$ and $\left(\mathrm{CaCO}_{3}\right)$, and the limestone dust, the carbonate of lime $\left(\mathrm{CaCO}_{3}\right)$.

Gypsum, or land-plaster, sulphate of lime $\left(\mathrm{CaSO}_{4}\right)$, has all the good effects of lime in the soil, excepting that it will not neutralize acid. It is more soluble than the other forms of lime and may be applied at a much less rate per acre.

When considering which of the above forms should be applied, it is well to remember that the fresh lime hastens the decay of organic matter. On soils of free aeration where 
there would naturally be rapid decay of vegetable matter, freshly slaked lime should not be used. In so far as the air-slaked lime has carbonated, it would be safer; but, the best form would be the limestone dust. On the other hand, on a heavy clay, or on a sour "muck" soil, especially if deep, it would be better to apply the freshly slaked lime. The dust will probably give as good results taken over a period of years, but the quicklime will be quicker in its action.

In considering the rate of application it is well to remember that lime is being steadily leached out of the soil and that we do not intend to apply lime every year. Furthermore, $56 \mathrm{lbs}$. of quicklime, $74 \mathrm{lbs}$. of hydrated lime, and $100 \mathrm{lbs}$. of carbonate of lime are equivalent quantities, especially for neutralizing acids. Consequently, 1,000 lbs. quick lime and 1,786 lbs. of limestone dust will have about the same effect in the soil. One ton of quick lime or two tons of limestone dust makes a fair application and probably enough to last three or four years, but where the soil is very acid much larger quantities may be necessary. No ill effects will follow very heavy dressings with the carbonate of lime, but the quicklime will sterilize the soil if applied too heavily, and thus check crop production for a year to two.

For immediate action, the finer the limestone is ground the better, but sufficient lime is commonly applied to last three or four years, and if it is all made very fine, there is great danger that it may leach away too quickly. If the coarser particles are about the size of the particles in corn meal or the finer forms of granulated sugar, and all the fine dust that would naturally be formed in such a reduction be retained, it will be gradually brought in use with less loss of material.

The ground limestone dust is a comparatively new fertilizer product in this Province. The other forms of lime may be procured wherever lime is burned. The limestone dust is simply limestone reduced to a powder. All the firms preparing crushed stone for road purposes, screen the broken stone, separating all material that will pass through $3-16$ or $3-8$ inch screen. These screenings contain a good deal of dust, some of it as fine as desired for agricultural purposes; but the great part of it is very coarse. It is, however, a material well worth considering when it can be hauled directly onto the land, but it is doubtful if it will pay to ship this coarse material by rail. In some places as at the Wentworth Quarries, Canadian Quarries Ltd., Hamilton, Vinemount and Pointe Anne Quarries at Point Anne, the fine dust is separated from the coarser materials of the screenings and a very satisfactory product obtained.

Four firms in Ontario are now preparing the limestone dust for agricultural purposes and are equipped with machinery to reduce the limestone to any degree of fineness desired. They are the Crushed Stone Company, Toronto, The Henderson Farmer's Lime Company, Beachville, and the Standard White Lime Company, Beachville, and the Ontario Stone Corporation, Toronto (Quarries at Uhthoff, Ont.) It may be purchased in bulk or in sacks like cement.

\section{EXPERIMENTS WITH LIME IN NOVA SCOTIA}

During the past two years, experiments with the liming of soils have been carried on at the Nova Scotia Agricultural College by Prof. J. M. Trueman, who supplies the following particulars as to results hitherto obtained:-

In 1914, three plots were sown to oats and three to wheat, in a mixture containing timothy and clover. Before sowing, half of each plot was treated with ground limestone at the rate of four tons per acre, this being twice the quantity usually employed.

The liming made no apparent difference in the yield of grain, but the clover on the limed portions was considerably ahead of that on the unlimed at the time the grain crop was cut. This difference became more and more marked until the close of the season, and continued as growth started in the following spring. 
On four of the plots, the limed portions showed a gain in yield of cured hay ranging from half a ton to a ton and three-quarters per acre. Two plots showed no increase, due evidently to the fact that the soil was in extra good condition and grew clover well even without liming. The second growth showed just as marked a difference in favour of the limed parts as did the first crop. As the benefits of liming continue for a number of years after the application, the results of succeeding crops will be of interest.

Prof. Trueman points out that, according to these experiments, lime gives the best results on soils of medium richness. Where the soil is already in good condition for growing clover, lime does not have any marked result on the yield. Likewise on poor soils the results are unsatisfactory. Such soils are deficient in vegetable matter and plant food, and these things lime does not furnish. These are conditions that the farmer should test for himself by treating at least one acre with sufficient lime to be sure of his results.

\section{THE WAR AND FERTILIZERS}

The recommendations of Dr. Van Slyke, Chemist of the N.Y. Agricultural Experiment station, call for more attention to thorough tillage, a conservation and utilization of all plant food produced about the farm, and use of clovers.

"We shall probably learn," said Dr. Van Slyke, "that we can get along with less potash than we have been led to believe. The propaganda carried on by the German Potash Syndicate induced many to use potash far in excess of their needs. Rock meals, reputed to contain potash, will be offered for sale said the speaker. They are ground from rocks which contain unavailable potash and if you want to get 'stung,' use them." Unleached hardwood ashes may be obtained, and they should contain in the vicinity of 5 per cent. potash. They vary so in composition that they should always be purchased under a guarantee to contain a certain fixed amount of potash. During the coming season some mixed fertilizers, the speaker said, would contain perhaps one per cent. of potash. In this form the potash would be very expensive, and it would not be profitable for farmers to purchase the potash in a mixed fertilizer, as the amount contained therein would be totally inadequate if potash was required, and, furthermore, the price of it would be out of all reason.

The phosphatic manures do not present so difficult a proposition as does potash. Ground phosphatic rock was not a readily available source of phosphoric acid.

The speaker recommended the use of common salt on grass lands and other farm crops. From 150 to 300 lbs. per acre, he said, could often be applied with profit. It was explained that sodium, which is a part of common salt, changes the insoluble potash compounds of the soil into available form.

\section{THE POTASH FAMINE}

According to the British Board of Trade, the German syndicate controlling the potash beds, sold in 1913 potash to the value of $£ 96,000,000$. This amount would have been largely exceeded in 1914 had it not been for the war.

There are few soils that do not contain enough potash in some form, and the amount required to be added should be small. Green crops should be grown and dug into the soil. In this way the latent potash power of the soil will be developed and utilized. There is too great a tendency in modern agriculture to draw from the outside for plant food, rather than to look to the soil to give it. The present potash famine may therefore be of great service to agriculture by compelling the cultivator to bring up his crops on nutriment from the soil, instead of by the feeding bottle of modern manuring. (From West India Committee Circular). 


\section{FLUCTUATIONS IN COST OF FERTILIZER MATERIALS}

\section{Based on actual Selling Prices at New York and Baltimore, from month to month for prompt deliveries.}

\begin{tabular}{|c|c|c|c|c|c|c|c|c|c|}
\hline \multirow{3}{*}{$\begin{array}{l}\text { July, } \\
\text { August, }\end{array}$} & & \multicolumn{2}{|c|}{ Nitrate of Soda } & \multicolumn{2}{|c|}{ Acid Phosphate } & \multirow{2}{*}{\multicolumn{2}{|c|}{$\begin{array}{l}\text { Muriate of } \\
\text { Potash } \\
\text { Normal }\end{array}$}} & \multirow{2}{*}{\multicolumn{2}{|c|}{$\begin{array}{c}\text { Sulphate of } \\
\text { Potash }\end{array}$}} \\
\hline & $1914 \ldots$ & Norma & & Norma & & & & & \\
\hline & $1914 \ldots \ldots \ldots$ & 6.00 & above & 1.00 & bove & 50.00 & above & 30.00 & above \\
\hline Sept., & $1914 \ldots \ldots \ldots$ & Norma & & 1.00 & “ & 60.00 & " & 40.00 & “ \\
\hline Oct., & $1914 \ldots \ldots \ldots$ & 3.00 & below & Norma & & 55.00 & " & 35.00 & " \\
\hline Nov., & $1914 \ldots \ldots \ldots$ & 3.00 & “ & Norma & & 45.00 & “ & 25.00 & “ \\
\hline Dec., & $1914 \ldots \ldots$ & 3.00 & " & Norma & & 35.00 & “ & 15.00 & " \\
\hline Jan., & 1915. & 1.00 & “ & Norme & & 25.00 & “ & 10.00 & “ \\
\hline Feb., & $1915 \ldots$. & 2.00 & " & Norma & & 80.00 & “ & 60.00 & “ \\
\hline March, & $1915 \ldots \ldots$ & 4.00 & " & Unsett & & 115.00 & “ & 95.00 & " \\
\hline April, & $1915 \ldots \ldots$ & 6.00 & “ & Unsett & & 120.00 & “ & 100.00 & “ \\
\hline May, & $1915 \ldots \ldots \ldots$ & 6.00 & " & Unsett & & 135.00 & " & 110.00 & “ \\
\hline June, & $1915 \ldots \ldots \ldots$ & 6.00 & “ & 1.50 & bove & 145.00 & “ & 110.00 & “ \\
\hline July, & $1915 \ldots \ldots$ & 7.00 & “ & 2.00 & " & 160.00 & “ & 130.00 & “ \\
\hline Aug., & $1915 \ldots \ldots \ldots$ & 8.00 & “ & 3.00 & " & 190.00 & “ & 160.00 & “ \\
\hline Sept., & $1915 \ldots \ldots \ldots$ & 9.00 & “ & 4.50 & “. & 210.00 & “ & 175.00 & “ \\
\hline Oct., & 1915. & 15.00 & " & 5.50 & “ & 260.00 & “ & 200.00 & “ \\
\hline Nov., & $1915 \ldots \ldots \ldots$ & 20.00 & “ & 6.50 & “ & 310.00 & “ & 250.00 & “ \\
\hline Dec., & $1915 \ldots \ldots$ & 22.00 & “ & 7.00 & “ & 410.00 & “ & 300.00 & “ \\
\hline Jan., & $1916 \ldots \ldots \ldots$ & 25.00 & “ & 7.50 & “ & 460.00 & “ & 300.00 & " \\
\hline Feb., & $1916 \ldots \ldots \ldots$ & 33.00 & “ & 8.00 & “ & 560.00 & “ & 300.00 & “ \\
\hline
\end{tabular}

-From Ontario Fertilizer Co.

The following price sheet on manurial constituents is supplied by Gunns Limited.

\begin{tabular}{|c|c|c|c|c|c|c|c|}
\hline & & $\begin{array}{c}\text { Blood } \\
\text { Percent. }\end{array}$ & $\begin{array}{c}\text { Muriate of } \\
\text { Potash } \\
\text { per ton }\end{array}$ & $\begin{array}{l}\text { Ammoniam } \\
\text { Sulphate } \\
\text { per cwt. }\end{array}$ & $\begin{array}{l}\text { Tankage } \\
\text { per unit }\end{array}$ & $\begin{array}{l}\text { Acid Phos. } \\
\text { per ton } \\
\mathrm{P}_{2} \mathrm{O}_{5} 16 \%\end{array}$ & $\begin{array}{c}\text { Nitrate of } \\
\text { Soda } \\
\text { per cwt. }\end{array}$ \\
\hline Jan., & 1916 & $\$ 3.30$ & $\$ 490.00$ & $\$ 3.90$ & $\$ 3.20$ and $10 c$. & $\$ 13.60$ & $\$ 2.90$ \\
\hline Dec., & 1915 & 3.30 & 435.00 & 3.55 & 3.20 and $10 \mathrm{c}$. & 12.80 & 2.90 \\
\hline Nov., & 1915 & 3.30 & 245.00 & 3.50 & 3.25 and $10 \mathrm{c}$ & 12.80 & 2.60 \\
\hline Oct., & 1915 & 3.30 & 230.00 & 3.50 & 2.70 and $10 c$ & 8.50 & 2.60 \\
\hline Sept., & 1915 & 2.60 & 230.00 & 3.40 & 2.60 and $10 c$. & 8.50 & 2.45 \\
\hline Aug., & 1915 & 2.65 & 220.00 & 3.40 & 2.60 and $10 c$. & 8.50 & 2.35 \\
\hline July, & 1915 & 2.65 & 210.00 & 3.40 & 2.60 and $10 c$. & 8.50 & 2.35 \\
\hline June, & 1915 & 2.50 & 140.00 & 3.25 & 2.60 and $10 c$. & 8.00 & 2.35 \\
\hline May, & 1915 & 2.55 & 100.00 & 3.20 & 2.65 and $10 c$. & 7.50 & 2.35 \\
\hline April, & 1915 & 2.65 & 100.00 & 3.19 & 2.65 and $10 \mathrm{c}$. & 7.50 & 2.30 \\
\hline Mar., & 1915 & 2.65 & 100.00 & 3.00 & 2.70 and $10 c$ & 7.00 & 2.20 \\
\hline Feb., & 1915 & 2.80 & 90.00 & 2.80 & 2.70 and $10 \mathrm{c}$ & 7.00 & 2.00 \\
\hline Jan., & 1915 & 2.85 & Nominal & 2.65 & 2.70 and $10 c$. & 7.00 & 1.90 \\
\hline Dec., & 1914 & 3.00 & Nominal & 2.60 & 2.85 and $10 c$. & 7.50 & 1.90 \\
\hline Nov., & 1914 & 3.00 & Nominal & 2.65 & 3.00 and $10 c$ & 7.50 & 1.95 \\
\hline Oct., & 1914 & 3.30 & Nominal & 2.70 & 2.95 and $10 \dot{c}$. & 8.00 & 1.90 \\
\hline Sept., & 1914 & 3.30 & Nominal & 2.95 & 3.20 and $10 c$. & 8.00 & 2.05 \\
\hline Aug., & 1914 & 3.15 & Nominal & 2.65 & 3.10 and $10 c$. & 7.50 & $2.071 / 2$ \\
\hline July, & 1914 & 2.90 & 37.07 & 2.60 & 3.00 and $10 c$. & 7.00 & 2.10 \\
\hline
\end{tabular}




\section{CANADIAN FERTILIZER EXPORTS}

(Years ended Mar. 31)

\begin{tabular}{cccc} 
Quantity & \multicolumn{2}{c}{1915} & \\
Bbls. & Value & Quantity & Value \\
434 & $\$$ & Bbls. & $\$$ \\
$\ldots$ & 19,218 & 569 & 26,172 \\
& 29,644 & $\ldots$ & 34,359 \\
$\ldots$ & $1,594,785$ & $\ldots$ & $2,171,352$
\end{tabular}

Ashes, Pot and Pearl........ 434

Ashes, all other..............

Fertilizers "not otherwise

provided".

Of this, 116 bbls. were foreign produce.

Cyanamide, manufactured at Niagara Falls, is exported to United States, as the Canadian market takes only a portion of the product. The exportation of potash and of liquor containing potash from beet sugar factories is prohibited. The question of prohibiting the export of wood ashes is under consideration.

With muriate of potash at $\$ 400$ per ton, wood ashes containing $5 \%$ potash would be worth $\$ 2.00$ per hundred pounds for the potash alone.

\section{CANADIAN FERTILIZER IMPORTS}

(Years ended Mar. 31)

\begin{tabular}{|c|c|c|c|c|}
\hline & \multicolumn{2}{|c|}{1914} & \multicolumn{2}{|c|}{1915} \\
\hline & Quantity & Value & Quantity & Value \\
\hline & cwt. & $\$$ & cwt. & $\$$ \\
\hline Furnace Slag.......... & $\ldots \ldots \ldots$ & 63,764 & & 11,788 \\
\hline Bone Ash, dust, etc.......... & 76,577 & 161,227 & 96,283 & 200,663 \\
\hline Compound Fertilizer..$\ldots \ldots \ldots$ & $\ldots \ldots \ldots \ldots$ & 602,142 & & 714,584 \\
\hline Fish refuse..$\ldots \ldots \ldots \ldots \ldots$ & $\ldots \ldots \ldots$ & 30,755 & $\ldots \ldots$ & 28,836 \\
\hline Guano, etc............... & 64,742 & 90,894 & 63,582 & 93,747 \\
\hline German Potash Salts......... & 397,310 & 2,042 & 760,902 & 13,370 \\
\hline Phosphate Rock............. & $\ldots \ldots \ldots$ & 16,221 & $\ldots \ldots$ & 17,122 \\
\hline Ashes, Pot and Pearl......... & 277,222 & 11,281 & 66,540 & 6,376 \\
\hline Not otherwise classified........ & $\ldots \ldots \ldots$ & 3,513 & $\ldots \ldots$ & 853 \\
\hline
\end{tabular}

\section{FARM DRAINAGE}

\section{Prof. W. H. DAY, Agricultural College, Guelph, Ont.}

Perhaps few will question the statement that, with ordinary soils, the most important factor in crop production is the correct amount of water in the soil during the growing season. In the arid regions of the West where dry farming is practised, summer-fallowing is resorted to once in two or three years in order to conserve sufficient moisture for the production of crops in the remaining years. In humid sections, such as Ontario, Quebec and the Maritime Provinces, there is always a part of each year when considerable areas of land contain excessive moisture. If the excess occurs during the growing season and continues longer than a day and a half to two days, injury to crops will result. There is also the danger of drought, which in humid climates cannot be guarded against by dry farming methods as can be done in arid climates. For both extremes there is a common corrective, viz., to tile drain the land. Obviously, this will remove the excess moisture when such is present, but, just as certainly, it provides a greater supply of moisture for the crops in time of drought. This is effected in two ways: First by rendering the soil more porous and consequently capable of retaining more moisture when the excess has drained away; secondly, by permitting the roots to penetrate deeper than in undrained soil, thus providing them with a deeper feeding ground from which to draw moisture in time of drought. 
The value of underdrainage in a dry season was well illustrated in 1914. Beginning with September, 1913 (when the soil began to store water for the next crop), and ending with August, 1914, the year was one of the driest, if not the driest, on record in Ontario. The rainfall was below normal in autumn, winter, spring and summer; the total deficiency being almost six inches. Yet from eight Drainage Demonstration Plots, sicuated in different parts of the Province, we found that in every case on the drained half of the field the crop was much better than on the undrained half, the average difference in money value being $\$ 14.12$ per acre, and that in one of the driest years on record. The year 1911 was also a dry one, and the difference obtained from reports by twentyfive farmers well distributed was $\$ 16.37$ per acre in favour of drained land.

The type of season in which drainage gives least results is one similar to that of 1915 in Ontario, i.e., a dry spring followed by moderate rains during the growing season and sufficient during the ripening for proper filling. In most parts of the Province during the year 1915, it was not till about harvest time that the rains became excessive. The dry. spring facilitates seeding so that even the undrained land is sown in good condition. The moderate rains during the growing season keep the plants thriving well all the time even on the undrained land. The average returns from fourteen demonstration plots for 1915 show a difference of $\$ 4.48$ per acre in favour of the drained land. But the rain during harvest was so excessive that in many localities some of the grain on low land could not be cut. With the underdrained land there was no trouble of this kind.

The greatest results from drainage are secured in years with excessive rains in the spring and early summer and drought during the latter part of the growing season. In such seasons, germination and early growth are retarded, the root systems are small and lie near the surface, the leaves turn yellowish and sickly in apppearance, and the plants, generally, become stunted. Later when the drought comes, the weakened roots cannot grow deeper as fast as the soil becomes dry; consequently it is only a few days until the plants show signs of wilting, indicating that they are suffering from lack of moisture, and the crop is a meagre one at best. On drained land, seasons of this type give good crops, and reports of farmers show that the average difference in value, taking various kinds of crops and different degrees of benefit, will run over $\$ 20$ per acre in favour of the drained land.

Drains should be laid about two and a half to three feet deep, and about four rods apart where systematic drainage is required. For drainage in a small way, the shovel, pick and drainage plow are used for excavating purposes, but in larger undertakings traction ditchers are now widely used. These cut a ditch full depth, true to grade, ready for the tile in passing once over the ground. For laterals, three or four inch tile are laid, depending on whether the fall is ample or scant, and for mains four to twelve inch for individual farms. For community drains even larger than twelve inch tile are frequently used.

The average cost of draining land throughly, i.e., with a drain every four rods or thereabout, will range from $\$ 25$ to $\$ 35$ per acre depending on local conditions. It will be seen that even when results are least, as in 1915 , ( $\$ 4.48$ per acre), drainage pays from 12 to 18 per cent. on the money invested. In average years the returns range from 35 to 50 per cent.

The amount of drainage required in Canada is immense. In Ontario we estimate that of the cleared land about one-third or nearly $5,000,000$ acres is in urgent need of drainage, while considerably more would be the better of it. Besides this, there are large quantities of slash, swamp and marsh which might be reclaimed by drainageprobably one-quarter of a million acres anyway. And these figures refer to old Ontario alone. Much of the clay belt of new Ontario also will require drainage before it will produce to its full capacity. In Quebec and the Maritime Provinces, where the rainfall is greater than in Ontraio, drainage is even more needed, likewise in parts of British Columbia; while in the eastern portion of the prairie provinces come a number of enquiries showing that some drainage is needed even there. 


\section{TRACTION DITCHING MACHINES}

From information furnished by the Buckeye Traction Ditcher Company of Findlay, Ohio, the following statement has been compiled. The first ditcher was imported into Ontario in 1904. Four more machines came into the same province in the following five years, one into Quebec in 1907 and one into New Brunswick in 1909. Since then no less than 134 have been brought in up to December 31st, 1915, as follows:

\begin{tabular}{|c|c|c|}
\hline $1910: \ldots \ldots \ldots \ldots 11$ & achines & $1913 \ldots \ldots \ldots \ldots 25$ \\
\hline $1911 \ldots \ldots \ldots \ldots 16$ & “ & $1914 \ldots \ldots \ldots \ldots$ \\
\hline $1912 \ldots \ldots \ldots \ldots 24$ & " & $1915 \ldots \ldots \ldots \ldots 27$ \\
\hline
\end{tabular}

The importation by Provinces has been as follows:

\begin{tabular}{|c|c|}
\hline Alberta.. & 1 machine \\
\hline New Brunswick...... & $1 \quad$ " \\
\hline 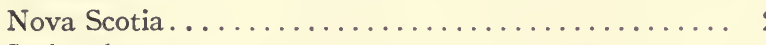 & 2 machines \\
\hline skatchewan........... & $2 \quad$ “ \\
\hline$\ldots \ldots \ldots \ldots \ldots \ldots$ & “ \\
\hline Columbia . & “ \\
\hline$\ldots 12$ & “ \\
\hline
\end{tabular}

Total.

141 machines

The extensive use of traction ditching machines in Ontario is due largely to the instruction and demonstration campaign carried on by the Ontario Agricultural College. This is financed by provincial appropriations and by a portion of the annual grant under The Agricultural Instruction Act. Ontario has an Act for providing cheap money for drainage purposes.

\section{THE COST OF TILE DRAINAGE}

\section{W. W. Hubbard, Superintendent Exferimental Farm, Fredericton, N.B.}

It is impossible to give an accurate forecast of what a drainage system will cost per rod or per acre until a very thorough examination is made of the nature of the soil and subsoil and the depths to which it is required to go to get suitable grades and outlets as well as how close together the drains must be to drain the land. In our generally rolling country, grades and outlets are not difficult, but there is a great deal of subsoil that is. On the Experimental Station land, for instance, outside of perhaps 20 acres, the 370 acres lying between the C.P.R. track and the St. John river has a tenaciousclayey subsoil with many boulders in it that makes machine excavation very slow and hand work very laborious and expensive. In most parts, after the top 18 inches is removed, the pick must be used on every inch below and boulders are encountered that require the use of considerable quantities of dynamite. Explosives add considerably to the cost in two ways. First, their own cost (13c. to 20c. per pound) and by causing much loss of time in that the ditchers must quit work and retire to a safe distance every time a charge is ready to be ignited. While a power ditcher can excavate to a depth of 39 inches for $30 \mathrm{c}$. per rod and sometimes under very best conditions for slightly less, and hand excavation can be made for 50c. per rod, under the conditions at the Experimental Station the cost has been $\$ 1.70$ per rod.

Beside the cost of excavation, in the case of underdrains, the cost of the tile, the stone or the wooden pipe have to be considered. 
At the present time tile are much higher than they might be in New Brunswick. At the Experimental Station three inch tile have cost us from $\$ 15$ to $\$ 28$ per thousand feet and larger sizes in proportion.

To give a general idea as to cost, the following figures may be taken.

With tiles at the given price per thousand, soil that will enable a power machine to dig to a depth of 39 inches at $30 \mathrm{c}$. per rod and a horse device for filling in the ditch, the following will be the cost per rod:

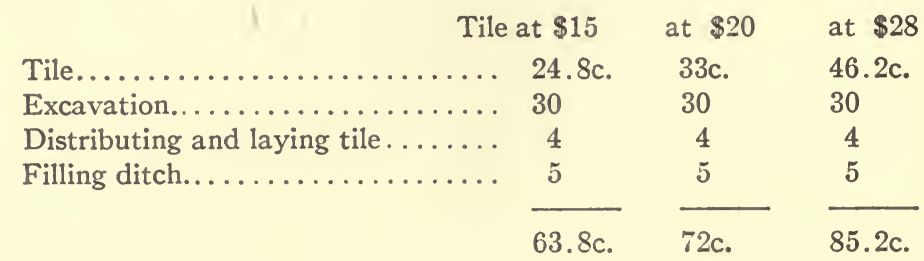

Land under-drained which gave only a half ton of almost worthless hay per acre I have seen yielding, by the aid of cultivation alone, from $2 \frac{1}{2}$ to 3 tons of the highest priced Timothy hay, worth this year from $\$ 13$ to $\$ 18$ per ton. At the Experimental Station we had a field of four and one-third acres so wet that it had never given anything but a light crop of hay. After draining it at the cost of $\$ 75.00$ per acre, with the help of the power ditcher, we had the following season 340 barrels of potatoes from it without the application of $\$ 1.00$ worth of manure. The potatoes yielded at the rate of $781 / 2$ barrels per acre, and sold for $\$ 86.35$ per acre. Deducting cost of raising them, $\$ 38.00$, it left $\$ 48.35$ profit. This would pay the interest on the money invested of $\$ 4.50$ and leave $\$ 43.85$ to go against the cost of drainage, thus in one year reducing the indebtedness against the land to $\$ 31.15$ per acre.

"The man who, expending his energies wholly on private affairs, refuses to take part in public affairs, pluming himself on his wisdom in minding his own business, is blind to the fact that his own business is made possible only by the prosperity of all." -Herbert Spencer. 


\title{
THE LIVE STOCK INDUSTRY
}

\author{
H. S. ARKell, Assistant Live Stock Commissioner, Ottawa.
}

\section{(1) Our Export Trade}

In a list of the articles, in connection with which we may expect to do export business, there may be included - eggs, poultry, bacon, hams, pork cuts, frozen pork, beef for mincing purposes, frozen beef, chilled beef, beef offal, including hearts, livers, tripe, etc., canned corned beef, potted meats, pork and beans and army rations.

It may also be of interest to note, although the matter is not within the purview of our live stock trade, that there exists a very important demand, as having reference to articles that Canada can supply, for canned and dried vegetables, canned fruits, fruit jams, butter and cheese.

\section{Eggs}

British Imports-Of this commodity, as of many others, Great Britain is the largest importing nation in the world. She imports very heavily from Russia, Denmark and other countries, but, as is well understood, her normal supply has now been very seriously interfered with on account of the war. In 1913 her imports from Russia amounted to the value of $£ 4,745,229$ while in 1915 her import from that country had decreased to $£ 1,748,822$. Great Britain's total imports of eggs, which in 1913 amounted to the value of $£ 9,590,602$, in 1915 fell to the low level of $£ 6,122,970$. These figures tell their own story. Because of this deficiency Canada was able to export last year, to the United Kingdom, eggs to the value of $£ 584,234$. $(\$ 2,800,000)$.

Opening of the Market-As the export business developed, particularly during the fall months, the Canadian trade was able to realize that, notwithstanding difficulties and costs of transportation, it might become a lucrative one for this country. There is good reason to believe also that, despite some-losses that occurred on a falling market at the end of the season, British wholesalers have been able to obtain a useful profit upon their Canadian purchases. In sympathy with the export market, Canadian prices have considerably stiffened as against normal values since August last. Moreover, it is already apparent that the extent of the purchases which will be made to meet the demands of this trade may, with some confidence, be depended upon to hold prices to producers at a gratifyingly high level during the current year. An examination of British values, with respect to new laid stock, fresh Irish, as also Russian, Dutch and American supplies reveals the fact that a satisfactory revenue to the producer, wholesaler and the British produce merchant may be obtained by the enterprising prosecution of this business.

It is generally expected that during the period of the war, while free supply of Russian eggs is interfered with, Canada may be able to continue the exportation of large quantities at remunerative prices. The head partner of one influential importing firm, after discussing the matter very freely with me in London, has already visited Canada, with the view of making large purchases for April, May and possibly fall delivery.

Continuance of Trade-Following the war the continuance of our export trade in eggs will be seriously challenged by Russian competition. Viewing the matter carefully, however, from both the British and Canadian standpoint, it does not appear 
improbable that this trade can be maintained, provided that, in the meantime, it is safeguarded against dishonourable dealing, unsatisfactory quality in the produce forwarded and the practice of ineffective or inefficient business methods either here or in England.

Holding the Position.-Whatever steps, therefore, can immediately be taken to ensure uniformity and high quality will be of inestimable advantage to the trade later on. It may not be generally understood that the admission is freely made by Great Britain that, in comparison with local conditions, the egg trade as a produce business is more highly developed and more skilfully organized in Canada and the United States in the methods devised to standardize grades, safeguard quality and educate the consumer to the advantage of buying a first class product. If Canada should be able to transfer this system and this organization to the British market in the sale of our product, such would, without doubt, become of permanent and material assistance to her in her competition with other countries.

\section{Bacon}

British Market-The situation existing with respect to the supply and sale of bacon on the British market, illustrates very clearly the upheavel in trade relationships caused by the war. It, however, suggests the opportunity now presented to Canada, applicable not only in the case of bacon, but of many other products as well, of initiating and developing a trade on practically equal terms as against the competition of other nations. Countries that have been engaged in the business for years, now possess no particular advantage over their younger rivals. A new trade era is being established. Commercial connections and other trade assets which they formerly possessed, have been largely broken down and nullified within the last eighteen months. This is one of the most important and significant features to be borne in mind in any propaganda that may be entered upon looking toward the extension of our business abroad.

The Danish Supply.-Danish bacon has hitherto and even yet continues, nominally, to set the standard for all bacon consumed in the United Kingdom. Denmark has been obliged, however, for various reasons, to very appreciably reduce her killings, and the swine industry in that country has been seriously interfered with. Proximity to the war and her inability to obtain American corn and Russian barley, have operated to reduce the pig stock of the country. Moreover, sales to Germany, which country, it is understocd, is paying forty cents per pound for Danish bacon, have opened up the promise of a new market and may result, temporarily at least, in a gradual discontinuance of shipments to the United Kingdom.

Notwithstanding the greatly increased value of the 1915 product, Denmark exported to England considerably less than in 1914, while for the month of December 1915, the value of her exports to Great Britain amounted to only $£ 703,704$ as against $£ 912,614$ for the similar period in 1914. The wholesale price of Danish bacon is at present one hundred and five shillings per hundred weight. Although this price is twelve shillings in excess of that for any other bacon offered, it is in some sense but a nominal quotation, the supplies being so short as not seriously to effect the market. People who have used Danish bacon for years have been obliged, owing to the short supply, to fill their weekly order from supplies available from other sources.

Increase in Imports-One other fact is noteworthy. Great Britain has enormously increased her imports of bacon since 1913 , the values being $£ 17,428,881$ in 1913 and $£ 25,441,460$ in 1915 . This increased importation is attributable to two causes: first, the very heavy purchases by the British War Office for army use; second, the increased home consumption of meat due directly to the high wages offered and paid in the most important classes of employment in the United Kingdom. It is confidently expected that, even after the war, the meat consumed in Great Britain per capita will considerably exceed the amount previously eaten, inasmuch as the habit of meat eating, once acquired, is not easily broken. 
General Supplies-Not only are the supplies of bacon from the continent decreasing, but the local production as well is being materially reduced, on account of the extra demand for fresh pork, caused by the high prices of beef and mutton. It should be noted that, while Irish bacon is becoming an appreciable factor in the trade, the output is not at all commensurate with the increased demand. Practically the only other sources from which Great Britain can draw her supply are to be found in Canada and the United States. The latter country has more than doubled her exports to the United Kindgom since 1913, and in 1915 forwarded an amount exceeding in value that supplied by Denmark by $£ 3,623,987$. Canada has also increased her exports from $£ 863,139$ in 1913 to $£ 3,324,511$ in 1915 , but at the present moment is exporting about one-quarter only of the amount furnished by the United States. This latter consideration must be recognized, notwithstanding the fact that Canadian bacon is selling at an advance of from ten to twelve shillings per hundred weight above American, and is admitted to be generally of superior quality. The Canadian hog is of a type from which Wiltshire bacon can be successfully produced, while the fat hog of America cannot easily be adapted to the fastidious requirements of this trade. With the stimulus given to all sales and the high prices resulting from War Office orders, there may easily be seen the opportunity that is now presented to Canada to develop a very remunerative bacon trade with Great Britain.

Quality of the Output-This opportunity undoubtedly exists, and if properly safeguarded, can be fully realized. It must be pointed out, however, that while Canada clearly holds the favourable position above outlined, this position can be established only by commiercial enterprise, business development and strict integrity, coupled with volume of supply. I have reason to believe that bacon is at present being exported from this country that is a credit neither to the business experience nor to the honesty of intention of those who are sending it forward.

From another point of view, it should be noted that lack of information with respect to the niceties of the trade, a faulty cure, even ineffective advertising may be just as fatal to the future of our export business as are dishonesty or fraud. In this enterprise Canada will be faced by the keenest competition of wit, business acumen and intense application, that capital and brains can furnish, and we cannot hope to get very far unless we create such an effective system as may enable us to meet such competition on its own ground.

\section{Frozen Beef}

War Demand-A somewhat complicated problem presents itself as regards the sale of this commodity. The price of frozen beef is practically and effectively controlled by the British War Office. This control, it is generally admitted, has prevented a monopoly price being realized by the packers, has provided against any undue rise in value, except from widely operating causes, and has even resulted in a depression of the market in a comparison with prices that might have been expected to obtain, owing to greatly increased demand as against a bare continuance of normal supply. The War Office has been able to attain this pre-eminent position in the meat trade through its control of the transport service, and, while this control remains intact, the price of frozen beef in Great Britain, France and Italy will, undoubtedly, be materially affected by the dictation of the Imperial authorities. It is, perhaps, worth while stating in this connection that contracts with the French and Italian Governments become, by consent, practically inoperative, except when ratified by the British War Office, and that this ratification is refused unless the price is approved, or, in other words, conforms to the figure that the War Office itself is obliged to pay. The fact that Great Britain has undertaken to furnish France with 20,000 tons of frozen meat per month and Italy with 100,000 tons per year, will indicate the extent of the British War Office operations and its practical dominance of the situation. It was intimated that this supply to these two countries would probably be continued during the period of the war. 
Effect of British Control-The general tendency of the facts just noted is to hold the price of frozen beef at a level approximating that which obtained during times of peace. As will be understood, this level parallels, fairly accurately, the price at which beef can be supplied by the Argentine, Australia and New Zealand, where the costs of production, both on the farm and in the packing houses, are considerably lower than in Canada. Notwithstanding, therefore, all the good will that Great Britain may have toward this country, Canada will remain somewhat at a disadvantage in the way of securing contracts and in her ability to sell her beef in Europe during the period over which the Imperial Government is able to exercise its effective control of the market.

Independent Activities-Despite the obvious advantages, however, inherent in this control, it is apparent that certain factors are contributing to weaken somewhat the position of the British War Office in this regard. In the first place, it is being questioned whether Great Britain will be able to continue her practical monopoly of the meat carrying trade, through which she has been able to exercise her regulation of prices. It was pointed out that both France and Italy are interesting themselves in the creation, for their own use, of a fleet of transport ships and have given consideration to the independent purchase of their meat supplies. The perfecting of any arrangements in these directions will considerably weaken the powerful position Great Britain has hitherto held. In the same degree, it will undoubtedly lead to a return to the natural equilibrium, as regards price, which would ordinarily be reached under the untrammelled influence of normal supply and demand. Whatever opinion one may hold respecting developments of this nature, it is felt that attention should be drawn to them because of their bearing upon the position of this country in securing sale for her meat.

Future Demand-Another factor, operating in the same direction, is the increased demand now being created for frozen beef. It has been demonstrated to France by her use of this product for army purposes that it is a thoroughly wholesome article of food. Unless, therefore, the agrarian interests in the country again regain control of the situation, it is expected that France, for a period of years, will open her market to foreign supplies, if not generally, at least from the allied countries. This new European market, together with the increased consumption of meat, which it is believed will continue after the war, should probably serve to create a general rise in price for beef supplied through the export trade. This price, as compared with prices formerly existing, will concinue at least until supply is able to cope with the demand.

Future Supply-Prior to the war, the available sources from which beef could be obtained were able only to furnish the quota required by the United Kingdom. No appreciable surplus was apparent. Heavy purchases from the Argentine, resulting from War Office orders, together with a severe drought in Australia, are resulting in the shrinkage of the current output from these countries. So true is this fact that, notwithstanding War Office control, current prices have risen considerably and to a figure at which both United States and Canada have been able within limitations to compete for business. It was learned, in fact, that, as a result of the conditions just referred to, an additional rise in the price of the imported article might be expected to occur during the current year. Furthermore, the pressure of army requirements has been such as to necessitate several emergency purchases, the general tendency of which has been able to appreciably lift the level of the market. From a general survey of the whole situation, it may be concluded that Canada will be in a better position during the coming months to obtain sale for her product than she has been able to secure during the past year. Having reference to last year's trade it may be stated, on the best of authority, that average prices current on Smithfield Market in 1915 show an increase of $40 \%$ since the outbreak of war.

Market in France-It should now be pointed out that the market for Canadian beef or, at least, for the quality which is being produced, lies in France and in Italy rather 
than in Great Britain. The beef hitherto furnished by Canada has not been such, generally speaking, as to find favour on the Smithfield market nor for war office contract. The British public demands fat meat or at least meat that is prime fed and well finished. The supply furnished by the Argentine, Australia, New Zealand and even by the United States, is able to meet these requirements. Our cattle, as compared with the product of the above mentioned countries, are not prime and lack finish. Canadian grass-fed bullocks cannot stand against this competition, and even our stall-fed stock, at least such of it as is available for export across the Atlantic, takes second place. We shall be obliged to greatly improve our method and manner of feeding before we can expect to secure a firm foothold on the British market.

On the other hand, France and Italy will take and, in some respects, prefer Canadian beef. This is true whether the meat is intended for consumption by the civil population or for army supply. A comparatively lean quality of beef is demanded by the French and Italian people and for this trade our Canadian cattle are likely to find favour.

\section{Live Animals}

Live Stock in France-The situation in France needs to be explained. Owing: to the elimination of the herds in Belgium and Northern France and the reduction of the stock elsewhere in the country, the French market for Canadian cattle may be expected to continue for a considerable period after the war. At the beginning of the conflict, during the period before the supply of frozen beef became available, it is stated that about one-fifth of the national herd was utilized to make good the requirements of the army. It may be noted, further, that, during the past eighteen months, the number of hogs in the country has been very greatly reduced. It was stated to me, on very reliable authority, that the reduction had amounted approximately to two-thirds of the normal stock.

Live Feeding Cattle- The demand for frozen beef, present and prospective, has already been referred to. In France a market exists, also, for live feeding cattle. As regards living animals, Canada is practically the only available source from which France, from the standpoint of bovine health, will consent to draw a supply. These would be placed on the rich pastures of Normandy and Britanny and other departments and, when finished, would be slaughtered for domestic consumption. It is the intention of the Government, as well as the desire of the people, to preserve, as far as possible, the breeding cattle of the country. The French are anxious to maintain and develop their own stock rather than mix it with the blood of foreign breeds. For this reason, cattle for feeding purposes only will be required. It is altogether unlikely, for the same reason, that a market for Canadian breeding cattle will be realized.

Prospective Market for Canada-It will now be apparent that, while certain complications exist as regards the sale of our beef on the European market, and while the prices that prevail do not suggest profits equivalent to those offered in other directions, there can be absolutely no reason to prevent us from finding a comprehensive export outlet in that direction for our product. In fact, many indications suggest that, as the war advances, and possibly for a very considerable period following the final declaration of peace, the price or market tendency will be upward rather than downward. From this it may be inferred that the development of an export beef trade with Europe rests upon a firm economic foundation.

It is quite true that a careful policy will have to be pursued in the means taken to. effect this development. It is absolutely essential also that every contributing market movement should be watched with the greatest care, in order that, while all possible advantages from this trade may be fully assured, losses to our producers may be provided against as resulting from the competition of other countries or the glutting of the market which, at any time, over-supply would create. For the present, Canada ought to be able to sell to advantage all her surplus product. If, later on, our farmers and 
packers may be content with lower prices and willing to secure their profits by operating on a narrower margin with a larger output, I am satisfied that a lucrative trade may be built up to last through a period of years.

\section{Cumberland Bacon, Hams and Pork Cuts}

Cumberland bacon is cured in practically the.same manner as a Wiltshire side. It is, in effect, a side of bacon minus the ham. Cumberland cut bacon is usually made from lighter hogs than are used in making Wiltshire, and is, therefore, perhaps scarcely of as high standard as the latter product. It finds, however, ready sale on the British market.

Cured hams are also selling freely both in the United Kingdom and in France, while cured pork cuts of other descriptions are being imported in quantity into the former country. Fresh pork cuts, however, cannot enter British ports, entry being prohibited under the British sanitary regulations. Were it possible to have these regulations made less restrictive, or should a mutually satisfactory arrangement be worked out between the Canadian Sanitary Service and the Imperial authorities, a very useful market would the opened up for grades of bacon, of which export sale is at present either restricted or practically prohibited. In 1915 , Great Britain imported hams to the value of $£ 5,296,-$ 689 as against $£ 3,068,251$ in 1913 . Of this 1915 importation Canada furnished $£ 434,485$ while the United States supplied $£ 4,859,895$, or more than ten times as much as the Dominion.

Frozen Pork.-Owing to the high price of mutton and beef, the demand for fresh pork has increased very greatly during the past year. Large quantities of fresh pork are consumed, being supplied both locally by the United Kingdom and by importation from the Netherlands. The frozen article, is now, however, finding ready sale. Light pigs are preferred. Carcasses weighing as low as $90 \mathrm{lbs}$. each are popular. While the war lasts and possibly for some time afterward, large quantities of pork may be shipped to Great Britain in a frozen condition and disposed of at advantageous prices. In 1915, the importation of this commodity amounted to $£ 435,908$, of which the United States supplied $£ 288,524$. The total importation in 1913 amounted to only $£ 43,255$.

\section{Canned Goods}

Under this head may be enumerated, canned corned beef, pork and beans, army rations, canned fruits and vegetables, dried vegetables and fruit jams. Enormous quantities of these articles are being purchased by the British War Office and it is understood that the Canadian Department of Militia and Defence is also likely to take considerable orders for use overseas. From what I could learn, for such requirements as are needed, Canada will receive every consideration in the contracts placed, although of course she will be expected to parallel the price quoted in tenders offered by competing countries such as the United States and the Argentine. The importation of preserved and canned beef amounted in 1915 to $£ 10,315,653$ as against $£ 2,692,443$ in 1913 .

\section{Miscellaneous}

Under this category are included frozen beef for mincing purposes, frozen beef cuts, hearts, tongues, livers, tripe, etc. Meat for mincing has a special market and for such supply as is required reasonable returns are obtained. Offal of all descriptions can be sold to excellent advantage at Smithfield. The sale of the latter products, if put up carefully according to market requirements, may be made to yield such a revenue as to assist greatly in securing a remunerative return in the handling of carcass beef. It was freely stated, however, and was in fact very apparent, that from the condition in which material of these descriptions arrived from Canada, much improvement would have to be effected before anything better than mediocre prices could be expected. 


\section{Organization of the Export Trade}

The successful development of our export trade will be dependent primarily upon the following factors: Enterprise in seeking the market, efficient organization, uniform and high quality of the product, volume of supply, together with adequate transportation facilities at reasonable rates. Other factors will, no doubt, contribute materially to the success of the undertaking, but achievement to the extent of our opportunity is definitely dependent upon these considerations. It must be recognized at once that unless Canada goes after this market, in a thorough-going, business-like way, she may expect to fall very far behind in the race.

This is no place to discuss or to outline the measures that may be needed to promote the development of this trade. A few observations, however, respecting features in which improvement should be effected, may serve to bring about a better understanding of the situation. From a general point of view, it appeared to me that there is a lack of connection between our tradespeople here and the tradespeople in Great Britain, and a dearth of information in Canada with respect to all phases of market business in the United Kingdom. Full knowledge of market requirements is absolutely essential to successful trade. Viewing our commercial enterprise in comparison with the organizations already effected by other countries, I have no hesitation in saying that unless a very much closer connection is established by Canada and unless a similarly systematic programme is aggressively proceeded with, our methods, with certain notable exceptions, must continue to be classed as haphazard, futile and incomplete.

\section{Transportation}

During the period of the war, transportation will constitute one of the most difficult problems connected with our export business. Not only is there an insufficient supply of ships, but present rates are excessive, and in some instances almost prohibitive. The commandeering of such a considerable number of vessels for naval use, the changing of the routes of ships, together with the losses that have occurred in the mercantile marine, will make it very difficult to secure normal service to this or to other countries either during or after the war. Adequate transportation facilities, it may be taken at once for granted, furnish one of the most effective weapons in competing for and establishing an export trade. With this understanding of the situation, the need for a coordination of interest between the shippers and the transportation and shipping companies, is easily apparent. To allow such an important matter as this undoubtedly is, to adjust itself under present circumstances as accident or caprice may dictate, is but to invite disappointment and defeat in the realization of our ambition to secure recognition and a national reputation in the development of a comprehensive commercial policy, in association with Great Britain, her allies, and our sister dominions. Neutral nations are taking up this problem, and $i i$ is essential that we, at the very beginning, endeavour to secure for ourselves, the advantages in this direction which the exercise of foresight, careful judgment and aggressive action may so easily obtain. The problem involves a consideration of the volume of our supply, the extent of our market and the permanence of our trade. Producers, produce merchants and shipping companies have each wide interests at stake in the sale of our goods through an export channel. No apology is offered, therefore, for the recommendation that the interests of all be co-ordinated into a policy that shall permanently safeguard the future of our export market.

\section{Nationalization of the Trade}

As has already been intimated, the Dominion is now in a particularly favourable position in all our dealings with the Mother Country to trade upon the term "Canadian."

If, however, Canada and Canadian shippers are content to have the product of the Dominion exported without such supervision or organization as shall secure uniformity and high quality in the material forwarded, we may expect to find the trade hampered 
and restricted in every direction, not only by dishonourable dealing but, as well, by the inability of the British consuming public to depend upon the quality or grade of Canadian goods. Danish bacon, Irish eggs, New Zealand butter and Canadian cheese have been able to set a standard on the British market, because of the organization established in these different countries to direct the manufacture, regulate the grade, improve the quality and control the export of these different commodities. An inspection of the display advertisements in the windows of wholesale and retail produce houses in Great Britain very clearly demonstrates the methods used to catch theattention of the British consuming public. They very definitely suggest, also, the enterprise and efficient organization in these countries, in that they have been able to secure for themselves such a distinct national recognition for their product on the British market. "Finest Irish," "Best Danish," "Prime New Zealand," these are illustrations of the phrases that confront one on the display placards used by English grocers in selling their wares. It was not difficult or surprising to ascertain that such advertising was backed up by an organization in the respective countries which made trade under such a basis possible.

If Canada sets herself to the task, we can secure the same national recognition for Canadian eggs, Canadian bacon, Canadian canned goods and Canadian meats. Canadian produce should always be advertised by having trade brands, trade advertisements and display placards appear under the term "Canadian." This term should precede any firm brand and should be made to secure for itself a clearly defined recognition amongst the British public. So far as I was able to learn, the export produce business to Great Britain has never amounted to anything for any country nor for any product unless the article exported has been made to conform to a practically standard grade, both as regards uniformity and quality. The distinctive national designation under which such products can be sold, when this position is reached, very rapidly becomes a commercial asset which itself definitely tends to extend business and develop trade. How much more of an asset such a distinction might become to this country, through the reputation which has been made for Canada by our participation in the war, may easily be surmised. Granted volume of supply, it remains only to attain this end that we effect an organization that shall nationalize our product both in its production and in its sale. In my judgment, such a course as is here suggested may be made to apply to the development of an egg trade, a bacon trade and a chilled meat trade.

\section{Production}

Hitherto in this article, consideration has been given chiefly to the importance to this country of securing an export market and to the measures to be taken in the improvement or creation of facilities for the building up of our export trade. Action in this direction, however, presupposes a volume of supply which will make this trade worth while. Emphasis upon the one urges the importance of the other. Organization in marketing, therefore, should be paralleled by equally effective organization in production; and only by co-operation between these two great lines of effort will the future of our Canadian Live Stock Industry be assured. The aggressive attitude now being taken by the American people in connection with the development of all their industries is very generally recognized. To them the war has furnished opportunities for national commercial progress which they have not been slow to realize. Despite the difficulties and dangers of ocean transportation and high freight cost, their exports in several directions have increased enormously. A determined feeling is growing up amongst them to more fully and completely organize this business. In appreciation of this position, attention is conspicuously being given to the development and extension of agriculture. Unless as a country we apply ourselves earnestly and intensely to the business in hand, the United States will supplant us on the British market, realizing the advantages and maintaining the position that belongs to us as a national heritage through our relationship with the Mother Country. 
With this message from the land to the south of us, what shall be our attitude toward this question in Canada? It is, in the opinion of many, so suggestive that we cannot afford to ignore it. We are still a young nation. Our problems as compared with the United States are not yet so unwieldy, our business interessts not so varied, our economic difficulties not so acute. Our resources have as large a future, our home industries have more room for expansion, our foreign trade has a greater opportunity, through our relations with the mother country, to effectively win its way in the commercial markets of Europe.

We have reason, then, to set our hands to this task in a more careful manner than that in which we have ever before entered upon any undertaking. We must lift production to a level that shall permanently secure for us a comprehensive surplus, available for export. We must promote an organization that shall obtain for our produce such recognition as is now given to Argentine beef, Danish bacon, New Zealand butter, or Dutch cheese.

To achieve this end, we must have a better understanding, a more complete cooperation, between the producer and the middleman. We must secure a co-ordination of interest between production and transportation. We must endeavour to link up the financial institutions in this movement in such a manner as shall secure their support to every phase of its development. The interests of these great industrial bodies must be clearly allied in attaining the end in view. Each unit has a particular and important part to play in the common programme, and each must recognize that, only as this function dovetails completely and satisfactorily into those of the others, may real and final success be achieved. Only thus may we hope to compete successfully in the great commercial war soon to be engaged in by all the important nations of the world. Only thus may we expect to build up a business in Canada commensurate with our natural resources and worthy of our national ambition.

\section{THE EMPIRE'S SHARE IN THE MEAT TRADE}

In Australia there are about forty freezing works to deal with the exportable surplus from $11,000,000$ head of cattle and $80,500,000$ sheep and lambs.

There are in New Zealand no fewer than forty freezing works, in operation or in zourse of construction, to deal with the exportable surplus from $25,000,000$ sheep and lambs and about $2,000,000$ head of cattle.

Australia and New Zealand are practically the only regular and reliable sources of supply within the Empire, and they together furnished only 284,056 tons of meat in 1915 , out of 664,508 tons imported into the United Kingdom. In addition, there was a small import from Canada, and a still smaller import from South Africa. The Over-seas Dominions should be equipped to furnish much more than one-half of the meat imports of Great Britain.

It is in the interests of the Empire that everything possible should be done to foster the Canadian Live Stock industry. In Canada, the number of cattle is about $6,000,000$, besides $2,000,000$ sheep-a total which, having regard to the population of the Dominion, does not at present leave a very large margin for export. With the probability of preferential trade in food within the Empire there are great possibilities in the expansion of Canadian live stock production. 
IMPORTS BY THE UNITED KINGDOM

\begin{tabular}{cccc}
$\begin{array}{c}1913 \\
\text { Beef, Mutton and Lamb- }\end{array}$ & $\begin{array}{r}1914 \\
\text { Tons }\end{array}$ & $\begin{array}{c}1915 \\
\text { Tons }\end{array}$ \\
$\begin{array}{r}\text { Importations into United King- } \\
\text { dom from foreign countries.. }\end{array}$ & 447,433 & 407,856 & 374,534 \\
$\begin{array}{r}\text { Importations into United King- } \\
\text { dom within the British Empire }\end{array}$ & 273,228 & 286,609 & 289,974 \\
\cline { 2 - 4 } & 720,661 & 694,465 & 664,508 \\
$\begin{array}{c}\text { Beef only- } \\
\begin{array}{c}\text { Importations into United King- } \\
\text { dom from foreign countries... }\end{array}\end{array}$ & 380,135 & 340,525 & 325,453 \\
$\begin{array}{c}\text { Importations into United King- } \\
\text { dom within the Empire..... }\end{array}$ & 79,909 & 101,440 & 104,967 \\
\hline & 460,044 & 441,965 & 430,420
\end{tabular}

\section{THE PRESENT OPPORTUNITY FOR CANADIAN STOCKMEN}

\section{JOHN BRIGHT, Dominion Live Stock Commissioner.}

A study of the live stock situation of the world at the present time cannot fail to convince any practical person that Canadian stockmen will have, in the immediate future, an exceptional opportunity for profitable trade. The question as yet unanswered is whether they will realize the situation in time so to conduct their operations as to take the fullest advantage of it. This is a matter of the utmost importance, not only from the standpoint of the individual farmer but also from a national standpoint.

While the national phase of the question may lie somewhat outside of the consideration of the average farmer, the matter of personal profit may be depended upon to make its own appeal. In considering the latter aspect of the case the stockman who is convinced that an unprecedented opportunity is presenting itself to develop the live stock business of Canada, should not lose sight of the essential factors that will make such development possible. The most important of these factors are:-

(1) The laying of the foundation now by conserving breeding stock;

(2) Improvement in the quality of live stock products by intelligent breeding the use of good sires, the weeding out of all scrubs both male and female, consistent adherence to one breed, early castration of calves and of lambs;

(3) Improvement in the care and feeding of young animals and improvement in the finishing of animals for market;

(4) The providing of a steady volume of trade by remaining continuously in the ranks of the live stock producers despite temporary and sometimes discouraging fluctuations in price as governed by the world's demand for live stock products.

Until the last two or three years, Canadian farmers have annually allowed useful female breeding stock, particularly cows and heifers, to go to market in large numbers. While the rising prices of meats have checked this movement of late years, it must be admitted that, even yet, at certain seasons of the year, there may be seen on any of our large markets females of good type and with many years of usefulness ahead of them. The country cannot afford to lose such animals at the present time and the prevention of their slaughter is one of the first and most important steps to be taken in 
conserving our breeding stock. Similarly, for many years, the high prices ruling for veal resulted in annually increasing receipts for calves on the live stock markets. While male calves of dairy blood formed a considerable percentage of such receipts, unfortunately many excellent calves, both male and female, of good beef type, were slaughtered. The loss to the breeding herds and to the feeders' stalls was serious and we are even yet feeling the effects of this sacrifice of potential beef, despite the fact that during the last two or three years there has been a marked falling off in the offerings of good calves. The prevention of such sacrifices entirely will mark the second and supplementary step necessary to the conservation of our breeding stock.

While it is true that in many parts of Canada our live stock shows the evidence of careful consistent breeding, there is a very considerable area both in newer sections of the West and in the rougher sections of the older provinces in which no improvement in quality has been effected in years. Further, it is unfortunately the case, that in some districts in the West the quality of the cattle is already showing signs of deterioration owing to the practice of foreign settlers of allowing scrub bulls and uncastrated yearlings to run with the herds. The importance of using only good sires is appreciated by a very large percentage of our farmers, but unfortunately, such sires are not always used intelligently. Even in sections in which associations have been formed for the purpose of improving the live stock of the district, the practice of breeding to a sire of one breed for two or three years and then changing to a sire of another breed has been followed, with the natural result that practically no progress has been made. It has been well said that the average Canadian farmer is less conservative on the question of the breed of the live stock raised on his farm than any other question relating to his operations. It is time the fact was more generally realized that real progress can be made only by consistently sticking to one breed, by using the best sires obtainable in that breed and by systematically discarding females that do not prove their usefulness as breeders of animals of good type. Quality, which depends in the first place upon good blood, is one of the most important considerations in live stock breeding and has an important bearing on the price ultimately realized for the product when turned into meat.

It does not require a very intimate knowledge of the methods followed in handling live stock on the farms of Canada to enable one to realize that too many farmers do not appreciate the importance of the first year or of the first few months, as the case may be, in the life of a young animal. It cannot be expected that a calf, no matter how well bred, is going to develop into a well grown breeding animal or into a profitable feeder if it has been allowed to practically raise itself during the first year of its life. In fact, in many of the more backward districts it would appear that money invested in well bred stock would be practically a total loss until the farmers are educated to feed and care for the offspring properly and to give them a chance to develop. There are many sections to which, of course, the foregoing remarks do not apply, but the improvement that would be effected in our total annual live stock receipts by the more general practice of properly feeding young animals would be remarkable. It may be added that even in some of our better districts the cattle sent to market lack finish, and only an exceedingly small precentage of our heavy steers would be suitable for the British market. In addition, the number of cattle sent out of the country in an unfinished condition as stockers and feeders last year was deplorable, particularly in view of the fact that never were larger quantities of feed available. Herein lies one of the most important questions to be solved in connection with the increase of our beef production.

The importance of renewed exertion on the part of Canadian stockmen during 1916 cannot be overestimated, and it is unnecessary to state that the Department of Agriculture, through the Live Stock Branch, stands prepared to support such efforts both by policies at present in operation and by those that may later be inaugurated. 


\title{
THE HORSE INDUSTRY
}

\author{
JOHN BRIGHT, Dominion Live Stock Commissioner.
}

The Canadian horse industry is now entering upon a new era in its history. However, before taking up the existing situation, it would appear advisable to go back a couple of decades and review conditions that obtained during the closing years of the last century, and up to the outbreak of the war.

The periods of so-called good and hard times seem to occur in cycles of years. The cause is the condition of the money market and its consequent effect upon all kinds of business. No industry is so quickly affected by a depression as that of the horse breeder and in probably no country does this statement apply with greater force than in Canada. Being a young country, large sums of money are needed to develop the latent resources of our farms, forests, mines and other industries. To this end it has been necessary to engage extensively in the building of railroad systems and other public works. However, when conditions changed in the money market and the banks refused to loan as previously, a reaction necessarily followed. Manufacturers curtailed operations, while all great works ceased except those really necessary. A study of the horse census of Canada gives a fair idea of these fluctuations in the money market, or cycles of good and hard times.

The Period from 1891 to 1901.-During this decade the horse population of Canada increased, in round numbers, 100,000 as against over 400,000 for the previous ten years. Toward the close of the period light horses became a drug on the market, while the demand for draughters was limited, and the price very low. The result was that in many sections of the country breeders became careless. They ceased patronizing pure bred sires, because of the service fee. In other sections they almost ceased breeding heavy horses for the time being. Others started raising light horses. As it was impossible to get rid of anything but the best, the practice of breeding mares that were old, unsound and of poor conformation became prevalent. This, coupled with the use of scrub sires in many parts of Canada, produced a retrograde movement. Fortunately for the country, however, many of the good districts continued to improve their horses and when conditions changed supplied much of the breeding stock with which to start anew.

The outbreak of the South African War in 1899 had a beneficial effect upon horse breeding. While it lasted many thousands of horses were taken out of the country, and for the country's good. The exportation of the surplus, the brightening of conditions in the money market and the rush of immigration, had a far-reaching effect. People began breeding horses again.

The Period from 1901 to 1913 -Between 1901 and 1911 the horse population increased a little over $1,000,000$, or almost ten times as many as during the previous ten years. During the next three years the increase amounted to over 250,000 , a considerable falling off taking place during the years 1913 and 1914.

The Cause-From 1901 to 1912 the country developed beyond the most sanguine expectations of the people, and the price of horses rose to the highest point in the 
history of the country. The demand for horses made it possible for breeders to get rid of almost anything that might be given that name. Good animals, whether light or heavy, brought good prices. Comparatively speaking, the poorer animals brought higher prices than the better classes, and often very much more than they were worth.

The Light Horse Period-From 1903 to 1908 the light horse came into his own. The good and the bad were in demand at fair prices, while the choice animals were eagerly sought after, and readily picked up at unheard-of figures. The amassing of wealth by many of our citizens, the desire to obtain publicity and to achieve fame in the show-ring and the scarcity of show-ring winners, together with the advent of the automobile, were factors that, in the end, proved the undoing of the light horse. During this period some of the best of our light sires were taken out of the breeding studs and gelded, in order to make show-ring winners of them. Wealthy men, after having achieved 'the successes which they had set their hearts upon, and, having no further interest in the horse industry, quickly disposed of their large stables and dropped out. Others, unable to secure the class of horse they desired turned to the automobile. It might further be explained that automobiles cost much less than it would to establish a first class stable of horses and properly equip it, particularly for city use. The stringent laws and restrictions, imposed by city health departments against the building of stables or the keeping of horses within certain areas, also had a detrimental effect. Thus the demand for, and the number of light horses, by which is meant particularly the carriage horse or high-stepper, also, but in a lesser degree, the saddler and hunter, has slowly but steadily lessened year by year, and it would appear that their day for city use has largely passed. Before they could again take their former place, it would take years of breeding to get a sufficient number, and years to train and fit an entirely new set of grooms and coachmen. Nevertheless, a number of people will continue to use these horses and there will always be a limited market for choice animals, at fair prices. However, as experienced breeders well know, but a small percentage come up to the standard. The everyday farmer should leave this field to the expert.

The Heavy Horse Period-The demand for heavy horses grew with the increase in population and the consequent development of the country. The high water mark was reached in the years 1911 and 1912. Up to this time draught horses, of any kind, found a"ready sale at good paying prices, while the good, big ones were eagerly sought for and quickly picked up at figures heretofore undreamed of. In the opinion of many, the middle class and poorer draughters brought a price much beyond their intrinsic value, but this was largely through the supply not being nearly equal to the demand and also to the fact that often the source of supply was far removed from the centres of demand.

During these years heavy horse breeding took a decidedly onward and upward trend. The free circulation of money made it possible for the people to buy and use a better class of sire than heretofore. Consequently the importers were not only enabled but compelled to bring a rather better class to the country. In certain sections the improvement that took place was truly wonderful. Unfortunately, however, this applies only to certain sections of our country. It was not uncommon to find that, while one district improved the conformation, quality and size of its horses very materially, others adjoining went on using inferior sires and poor mares, just as they had done in previous decades. Nevertheless, there is in Canada to-day a great deal of high class foundation stock, both imported and home bred, which if properly handled will prove of inestimable value to the country.

Conditions in Canada-The outbreak of the war found the country with a very considerable surplus for which there was little demand. Since that date practically the only demand had been for remounts. Up to the end of the Fiscal Year $1915-16$ in the neighbourhood of 50,000 horses had been purchased." Of this 
number the British War Office took close to 14,000 head, the Canadian' Department of Militia, approximately, 26,000, while the contractors for the French Government purchased over $\bar{\nearrow}, 000$ horses. The French contractors who are now buying in the country have still large contracts and are willing to buy every suitable horse that Canada has to offer. One firm writes saying that their contracts call for 10,000 a month while war lasts.

The prices paid for war horses may seem to be low after the exceedingly high prices that prevailed for a number of years. It should be remembered, however, that the class of horse taken is one that, generally speaking, the country can well afford to do without, and, further, that, all things considered, the average price paid is an exceedingly good one for the average class of horse taken.

Allied Countries-At the outbreak of the war practically all suitable horses were commandeered by the British and French for army service. It is true that they saved their best stallions, but, generally speaking, they were forced to send forward large numbers of their good breeding mares. It will be necessary, thercfore, at the close of the war for those countries to import horses until they can re-establish breeding operations.

The horse industry of Belgium has been practically wiped out. A few of their good breeding animals were driven into France, but the Germans seized all the good horses and sold them by auction in Germany. This means that when peace is restored, the horse industry in that country will have to be completely re-organized.

Future Demand-The good crop of the past year has enabled the Canadian farmers to go out and buy a part of the horse-power so badly needed, and, accordingly a good number of horses have gone into needy districts, with more to follow. Carload lots are being shipped quite commonly. Already the number of horses from east to west far exceeds the total number shipped during 1915. The increase in immigration, which is expected to follow the war and must of necessity go to the land, will create a still further market.

What to Breed-The only safe advice that can be given to the farmer is to start now to breed good draught horses, sound, of good conformation, and as large as possible. These will undoubtedly be wanted in numbers both at home and abroad.

The only light horse that bids fair to be wanted is the good, big roadster; a square trotter of good conformation and sound, weighing from 1050 pounds upwards. However, the demand for this class of horse will not in any way compare with the demand for draughters. Nevertheless, there should be a steady market for good animals such as has been described.

Commercial Breeding-During the past the attention of the farmer has been directed almost exclusively to the sire. True, nothing but pure-breds of good conformation and quality should be used. The time has arrived, however, when, in the best interests of the industry and in order to achieve the greatest success in breeding, particular attention should be given to the breeding mare. The best should be carefully preserved for breeding purposes. The good results from the use of high class stallions will be greatly minimized if the mares are poor specimens. Mares that are worn out, unsound, faulty in conformation or affected with any hereditary unsoundness should not be used for breeding purposes. Further, better feeding, care and management should be practised in raising the colt. A high percentage fail to develop normally through lack of proper care and sufficient nourishment. Horses are made or marred by the usage they receive when coming to maturity. Careful mating coupled with good feeding and management will result in the production of a high percentage of marketable horses. 
In passing, it might be noted that, despite all the educational work that has been done and despite the various enactments that have been passed in aid of horse breeding, there still is to be found in the country a rather high percentage of horses that fail to pass the remount inspectors. "As you mate, so shall you breed," or, in other words, if you mate sires and dams that are of poor conformation and unsound, you may be sure that a high percentage of the progeny will possess these undesirable characteristics.

Pure-Breds-The breeders of pure-breds are to-day at the parting of the ways. Heretofore, the magic word "IMPORTED" has carried much weight. There is much good imported stock in the country. The question arises, Is it necessary to go on importing year by year and paying high prices for imported stock when the breeders, by giving attention to mating and to the feeding, care and management, which is the other half of successful breeding, can produce a horse as good as if not better than a high percentage of the animals heretofore imported? The horsemen of Canada have an opportunity now such as never hitherto came their way. There are many good purebred mares in the country as well as good sires. Now is the time for the good horsemen, who have the interests of the industry and of the country at heart, to devote their attention as never before to the production of more and better horses. Let them not only mate carefully but feed and develop the progeny, from birth to maturity, as do the breeders of the European countries. Let our importers prove title to their claim of being practical horsemen by breeding and developing high class animals.

A Pure-Bred Market-During the past year the Dominion Live Stock Branch has had official inquiry from Australia regarding our horse industry. It was pointed out that, after the war, Australia would be in the market for good Clydesdales with which to improve the horse stock of the country. Particular attention was drawn to the fact that only good stallions were wanted. The distance from Canada being much less than rom Britain, it is felt that horses could be much more conveniently obtained here.

\section{LEGISLATION AFFECTING HORSE BREEDING}

During recent years much valuable educational work was done by the Breeders' Associations and the various farmers' organizations. Ultimately this work brought results. To-day in every province, except Quebec, stallion owners are compelled by Act of Legislature to enroll their stallions with the local Agricultural Department before standing them for service, and to publish in all advertisements a copy of the Enrolment Certificate. It is now possible for all interested to learn from the stallion poster whether a particular stallion is a pure-bred, grade or scrub.

The Provinces of Saskatchewan, Manitoba, Ontario and Nova Scotia have gone a step further. In Saskatchewan any district may prevent the use of unsound horses, grades and scrubs by a majority vote. In the Province of Manitoba only pure bred stallions are allowed to stand for service. In the Province of Ontario all unsound grades and scrubs must be retired; and in 1918 only pure bred stallions will be allowed to stand for breeding purposes. In Nova Scotia, as well as the three provinces above mentioned, all horses standing for service must be veterinary inspected, and all advertisements must give a copy of the license granted, which states, not only to what breed the horse belongs, but also whether he is sound or unsound.

By persistent effort and the gradual process of educating the people to the necessity of using better sires, and the profits to be derived therefrom, these useful and beneficial laws have been secured. It will be necessary for the other provinces to immediately enact similar legislation. Otherwise, they will not only find themselves out-distanced, but they will also become market centres for the poorer animals. It would appear that a uniform Stallion Enrolment and Inspection Act for all provinces of the Dominion would be a still further step in aid of horse breeding. 


\title{
THE NECESSITY FOR INCREASING OUR HERDS AND FLOCKS
}

\author{
JAMES AUdley, Statistician, Meat and Canned Food Division, \\ Health of animals Branch, Ottawa.
}

That production of live-stock in Canada is not keeping up with the great demands made on our meat supply for English and foreign requirements is quite evident from the following:

Swine - The number of swine slaughtered at inspected establishments in Canada during the fiscal year ending March 31,1915, was 2,598,338, an increase of more than 40 per cent. over the previous year, the total for 1914 being 1,799,060. (Table I.)

The high killings of 1915 were altogether due to increased production in our Western provinces. Up to the end of December, 1915, the number of hogs killed is in excess of the same period of the previous year by 20,000 . Still, with this increase following a record slaughter, we have had to import from the United States during the past eight months 103,164 "singed" and "scalded" hogs as well as several millions of pounds of pork in the form of backs, bellies, hams, shoulders, etc. (See table III.)

During the past twelve months, the prices of hogs were much higher in Canada than in the United States. This should have been an inducement to Canadian farmers to produce larger numbers of swine, more especially in Ontario and the Eastern provinces where the production does not seem to make much headway.

The Western provinces excelled themselves during 1914 in their output of hogs, Winnipeg handling through her stockyards over 460,000 .

Owing to feed shortage and lower prices in the fall of 1914, large numbers of female stock were marketed, with the result, unfortunately, of a decrease in the numbers marketed through Winnipeg from Manitoba and Saskatchewan in the year 1915, the decrease of the two provinces being 37,000 head.

Alberta, on the contrary, almost doubled her output in 1915 , sending 123,000 to Winnipeg; the total number marketed there being 485,000 head. (Table II.)

Out of this total, 299,000 were shipped to eastern packing plants for slaughter, and 21,000 went to the U.S.A., the balance being used in the local establishments inWinnipeg.

Cattle-Our cattle slaughterings tell the same tale as that of swine-the necessity of importing to meet demands.

During the year ended December $31,1915,530,525$ cattle were killed in inspected houses against 531,994 in 1914; while April to December 1915 killings show an increase of about 8,000 head over the same period of the previous year. (Table I.)

It is interesting to note that of 138,000 cattle marketed in Winnipeg from January to December $1915,63,783$ went to United States points, of these $701 / 2 \%$ were stockers and feeders and $291 / 2 \%$ butcher cattle.

The Winnipeg receipts were 28,000 over those of 1914 , the three Western provinces showing increases.

Our exports of beef during 1915 were greatly in excess of 1914, large shipments being made to France and Italy as well as to England, and it is likely that these European countries will need a further supply for some years after the war is over owing to the depletion of their live-stock.

That after peace is made there will be a demand for pure-bred cattle in Europe to fill up the losses from confiscation and slaughter for food purposes, goes without saying, also that Canada can supply a goodly portion of same provided our farmers raise the increase of their herds. Immigration also will be largely increased at the same time, and we must have the increase of live-stock to meet these demands without buying outside.

Sheep-The sheep stock of Canada does not seem to be making any headway whatever, the last figures published by the Census Department showing that we had only $2,038,000$ head in June of 1915 , while the census of 1910 gave $2,200,000$. 
During the year ended March 31, 1915, there were slaughtered in inspected establishments 447,173 head, while for 1914 the slaughter was 499,284 . This decrease is still being carried on, for our killings from April 1st to December 31st, 1915, are still about 52,000 head short of 1914 ; while our imports of mutton were nearly two million pounds in the eight months ended November 30th, 1915.

Canada should have a much larger stock of sheep, for while the home consumption may not be any more than equal to our present production, yet there is always a market in the mother country for first class mutton and lamb.

New Zealand with its 104,000 square miles and one million population supports a flock of, in round numbers, 24,000,000 head of which it exports in dressed carcass form, to England over 6,000,000 per year.

The Argentine Republic and Australia are also large producers and exporters of mutton and lamb to England. South Africa is also a coming competitor in this line. Why cannot Canada become a competitor for this lucrative trade?

It will not be many years after the termination of this war that Russia will surprise us with the extent of her resources in agricultural products, wheat, beef, mutton, butter and cheese being among the principal items she will put on the English and European markets.

Conclusions-To sum up, Canada should at once set about increasing her live-stock and be in a position to get into English and European markets at the first opening for pure-bred stock and meat products and not wait to see what the other fellow has for sale.

While England will supply a proportion of the pure-bred stock, Canada and the United States will have to supply the greater proportion, for no other countries outside have any stock to spare.

TABLE I.

\section{Live Stock slaughtered at Inspected Establishments.}

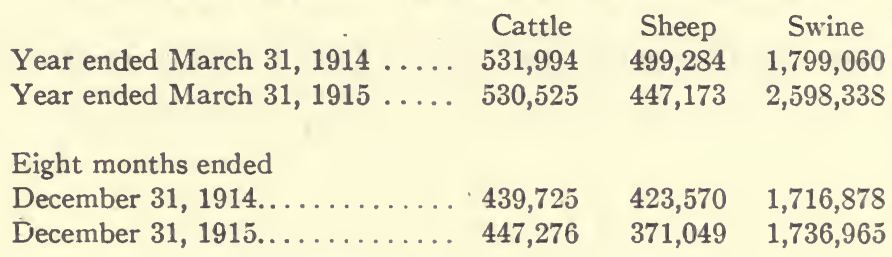

TABLE II.

\section{Live Stock Receipts}

TORONTO

\begin{tabular}{|c|c|c|c|c|}
\hline & Cattle & Hogs & Sheep & Calves \\
\hline Year 1913. & 367,977 & 346,367 & 204,777 & $53, \$ 54$ \\
\hline Year 1914... & 279,154 & 462,144 & 201,619 & 45,436 \\
\hline Year 1915... & 301,948 & 484,162 & 212,986 & 41,350 \\
\hline \multicolumn{5}{|c|}{ MoNTREAL } \\
\hline Year 1913 & 198,337 & 193,445 & 146,947 & 117,850 \\
\hline Year 1914. . & 178,782 & 204,125 & 142,456 & 98,182 \\
\hline Year 1915. . & 163,140 & 210,365 & 158,895 & 97,395 \\
\hline
\end{tabular}

\section{WINNIPEG}

$\begin{array}{ccccc}\text { Year } 1913 \ldots \ldots \ldots \ldots & 111,163 & 179,830 & 54,912 & \text { Included } \\ \text { Year } 1914 \ldots \ldots \ldots \ldots & 127,049 & 461,889 & 15,017 & \text { in } \\ \text { Year } 1915 \ldots \ldots \ldots \ldots & 138,534 & 484,997 & 13,801 & \text { Cattle }\end{array}$


TABLE III.

Imports and Exports of Meats

Live stock years ended March 31st, 1914, 1915.

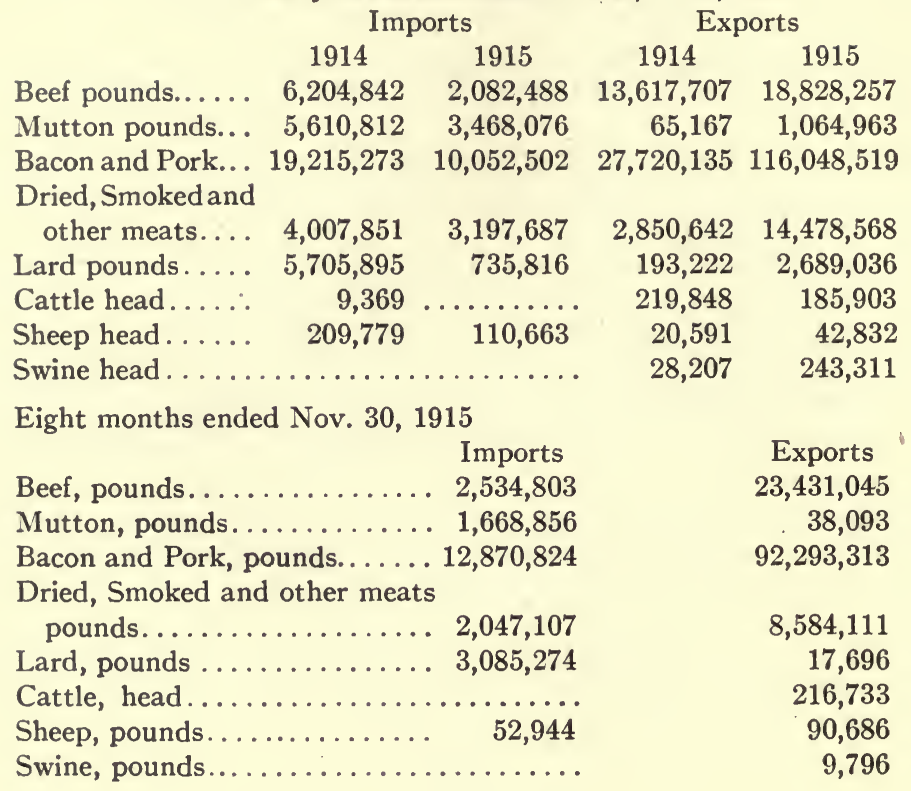

\title{
SPECIAL ASSISTANCE TO THE LIVE STOCK INDUSTRY
}

\author{
JOHN BRIGHT, Dominion Live Stock Commissioner.
}

\section{Distribution of Animals for Breeding Purposes.}

The Dominion Department of Agriculture through the Live Stock Branch in 1913 inaugurated a policy of loaning pure-bred sires to associations specially organized in accordance with regulations set forth by the Branch. The purchase price of all animals distributed is borne by the Branch and the freight is paid to the shipping point most convenient to the association. These sires are loaned for only one year at a time and an association is required to meet the cost of maintaining an animal as long as it remains in its hands. The right is reserved by the Branch to inspect the animals at any time and to withdraw assistance in the event of its being found that an association is not living up to its agreement. An association may renew its application for the loan of the same animal at the expiration of the term and, if all the requirements of the Branch have been complied with, such applications are promptly approved. When necessary, sires are exchanged but only for animals of the same breed. The latter is one of the most important features of the policy inasmuch as the mixing of breeds in a district and the resulting lack of progress in live stock improvement is thereby discouraged.

Assistance under this policy is confined to newly settled districts or to districts in the older provinces in which pure-bred sires would not otherwise be available and in which the farmers are financially unable to purchase same for themselves.

Only Canadian bred sires are purchased, and as far as possible, the animals placed in any Province are bought in that Province. In this way Canadian breeders are 
receiving encouragement and their márket is increased, not only directly but indirectly, through the emphasis given throughout the country to the value of pure-bred sires. At the same time, as already stated, no animals are placed in districts where privately owned pure-bred sires of the same class are already standing for service and interference with private enterprise is thus avoided.

Up to December 31st, 1915, 146 stallions, 1014 bulls, 1069 rams and 416 boars had been placed in the hands of associations.

The results attained by the introduction of sires of superior type into districts which formerly had to depend on scrub sires have been very gratifying. Reports received from inspectors and secretaries of associations during the past three seasons indicate that a marked improvement in the stock of the districts affected is becoming apparent and that the efforts of the Department are appreciated.

\section{Purchasing Breeding Stock in Car-load Lots}

In order to assist in effecting a more equal distribution of our live stock population the Minister of Agriculture, through the Live Stock Branch, has decided to grant assistance to farmers wishing to secure good breeding stock. Under this policy the Branch pays reasonable travelling expenses of the representative or individuals or associations from any section of Canada desiring to purchase one or more carloads of breeding stock in any part of the country.

The expenses allowed cover railroad transportation and living expenses from the home of the purchaser to the point at which it is expected that the purchase will be made, also hotel expenses and livery expenses for the time which should be sufficient to purchase the consignment.

No assistance in the payment of freight is rendered nor is any responsibility assumed by the Branch in connection with the purchase price of the consignment. It should also be definitely understood that no assistance under this policy is rendered if stock is purchased for speculative purposes. Should it be desired, a suitable person will be nominated by the Live Stock Commissioner to accompany the purchasing agent and assist him, as far as possible, in buying and shipping the consignment.

It is expected that during the present season this plan will have an important influence in conserving the breeding stock of the country and in increasing our live stock production.

\section{Federal Grants to Fair Associations}

At the time of the outbreak of the war, it became apparent that with the resultant upsetting of normal economic conditions the holding of the annual Winter Fairs and the larger Exhibitions throughout the country would become a somewhat precarious enterprise. To allow such important institutions to suspend operations even temporarily would have meant the loss of one of the most important stimulating influences affecting the live stock industry. To offset the possibility of such a contingency the Minister at once authorized, through the Live Stock Branch, the offer of a federal grant annually to such fairs as have their prize lists open to the whole Dominion and to those that had paid out the previous year prize money amounting to at least five thousand dollars in the utility classes of horses, cattle, sheep, swine.and poultry.

To fairs qualifying under the above two requirements, a grant equal to fifty per cent. of the total amount paid in prizes in the above mentioned classes is made, the maximum grant in any case not to exceed five thousand dollars. The amount of the grant allowed is determined by the audited statement of the sum actually paid in prizes. In applying for the grant, fair associations are required to submit their prize lists to the Live Stock Commissioner for approval.

During the fiscal year of $1915-16$, the total amount paid out by the Live Stock Branch in grants to fairs under this policy will be approximately $\$ 125,000$. 


\section{Assistance to Horse Breeding}

To overcome the handicap to horse breeding that exists in many sections because of the lack of pure-bred sires, the government grants aid to clubs formed for the purpose of hiring such animals. Last year a number of districts took advantage of the offer, and from the appreciations already received, it is expected that a still larger number will do so this year.

For particulars regarding the above, write the Dominion Live Stock Commissioner, Ottawa.

\section{THE SWINE INDUSTRY AND THE OPPORTUNITY PRESENTED BY THE BRITISH MARKET}

\section{PROF. G. E. DAy, Ontario Agricultural College, Guelph.}

Economic Production-It would not be safe to advise all farmers to feed more hogs. Every farmer must be his own judge in this matter, and some farmers should probably not attempt to raise hogs, owing to the fact that either the man himself is not adapted to the business, or his conditions are unsuitable. Nevertheless, it is true that hogs might be kept profitably upon many farms where they do not find a place to-day. The hog is especially valuable for consuming the by-products of the farm, and the number of hogs carried to advantage on a farm is governed very largely by the quantity and the character of the by-products to be consumed. When carried in appropriate numbers, the hog is an exceptionally economical producer of meat, preventing waste, and giving cash returns for substances that are frequently wasted, or which have little market value. Trying to take advantage of fluctuating market prices by alternately over-stocking and under-stocking with hogs, is seldom a financial success. The man who consistently follows up the business upon conservative lines, is the man who is well suited with the hog as a source of profit.

Market Outlook-At the present time we are facing an abnormal condition of affairs. Great Britain has, in the past, received large shipments of bacon from Denmark, but the war has very seriously crippled this trade, and Britain has had to look elsewhere for her supplies. As a result, we find that our exports of pork products have increased very largely indeed during the past two years, and so long as the war continues it would look as though prices for hogs are bound to keep at a high level. From the standpoint both of patriotism and profit, it would seem the part of wisdom to extend, to some extent at least, our production of hogs. While this advice is believed to be perfectly sound, it must be distinctly understood that no farmer is urged to do any plunging in regard to the matter. A farm that is distinctly over-stocked with any kind of animals, can seldom be run at a profit, but there are very few farms in Ontario that are overstocked with hogs at the present time, and there are many farms where more hogs could be fed to advantage.

The Type in Demand-Experiments with breeds of swine demonstrate the fact that breed and type have little or nothing to do with a hog's ability to make economical use of food. A healthy, thrifty, growthy hog will make cheap gains no matter what breed he belongs to, and no matter whether he is of a lard or bacon type. Though breed and type have little or nothing to do with economy of production, the question of type enters very largely into the very important question of marketing our hogs. A glance at the prices commanded by hogs on Canadian and American markets should convince us that there must be some radical distinction to bring about the difference in price that presents itself. We have already stated that Britain's supplies from Denmark have been greatly curtailed, and every person should know that the class of pork products furnished by Denmark are the products of what we call the bacon hog, namelyWiltshire sides. This being the case, Britain is naturally looking for a new source from 
which to obtain the required number of Wiltshire sides. She cannot obtain this supply from the United States because the methods of feeding hogs, best suited to American conditions, are not suitable for producing hogs that will furnish Wiltshire sides, or in other words-bacon hogs.

The United States has no export trade in Wiltshire sides; that is an important point to remember. That being the case, Britain must look to some other country for her supplies, and the most natural direction in which to look is towards Canada. It is this demand that has sent up our exports in bacon, and which is holding prices at the present high level. Surely the man who is able to read can easily form an opinion as to the character of the hogs that should prevail in Canada at the present time, in order to take advantage of the British market.

Increase the Supply of Bacon Hogs-The lard type of hog answers very well for certain branches of our home market, but if the products of this hog are exported to Great Britain, they will receive no preference over the product sent from the United States, but the shortage in Britain being a shortage of Wiltshire sides, and the United States being unable to supply this demand, surely this is Canada's opportunity to demonstrate her ability to supply the British market with the class of bacon in demand in that country.

In viewing the whole situation, it seems impossible to avoid the conclusion that if we are to increase our exports to Great Britain, we must increase our supply of bacon hogs. The mere fact that a hog is bred in Canada does not make it worth any more in Great Britain. Our exports must sell on their own merits in competition with those from other countries.

\title{
LIVE STOCK IN MANITOBA
}

\author{
F. S. JACOBS, B.S.A.,
}

\section{Professor of Animal Husbandry, Manitoba Agricultural College.}

Manitoba farmers could well afford, now that prices, if not high, are at least firm, to dispose of as many of their surplus horses as possible. Horse feed sells readily for money, and to use it on idle horses is very obvious waste. A policy that would eliminate waste horse power and conserve valuable feed would be in the interests of agriculture as a whole.

With respect to cattle, I think farmers would be well advised to continue (as now seems to be the general policy) in steadily increasing production, always, of course, with due regard to elimination of unprofitable types and the development of cattle possessing in the greatest degree the functions of meat and milk production.

At the present time wool is a valuable commodity and sheep are in great demand. There seems to be a tendency on the part of a considerable number of men to increase the sheep supply, so that little needs to be said to urge further production of sheep. In view of this tendency, it would, I think, be a good policy on the part of those raising sheep to utilize every animal possible to further increase the supply.

With respect to swine, it is difficult to make suggestions. As long as the war lasts we may expect to see grain at a substantial price, and, by the same token, hog feed a high price as compared with the market prices for swine. It would seem, however, quite possible to raise hogs at present prices, despite the high price of hog feed, but I doubt if it would be wise to urge those who are not thoroughly adept to go more extensively into the business. That is one phase of our farming to-day which requires maximum skill in order that the feed used may be turned to the best possible advantage.

The following statement of the receipts at and shipments from the Union Stock Yards, St. Boniface (adjoining Winnipeg), shows a steadily increasing amount of business and warrants the opinion that a good demand for live stock is likely to continue. 


$\begin{array}{ccccc} & \text { Cattle } & \text { Sheep } & \text { Hogs } & \text { Horses } \\ 1914 \ldots \ldots \ldots \ldots \ldots & 110,452 & 15,017 & 461,889 & 5,928 \\ 1915 \ldots \ldots \ldots \ldots \ldots & 138,534 & 13,801 & 484,997 & 6,214\end{array}$

The origin and disposition of these animals is shown as follows:-

Origin of Stock Received at the Yards

$\begin{array}{lrrrrrr} & \text { Man. } & \text { Sask. } & \text { Alta. } & \text { B.C. } & \text { East } & \text { Total } \\ \text { Cattle....1914 } & 46,730 & 54,010 & 9,389 & 206 & 117 & 110,452 \\ \text { Cattle....1915 } & 69,972 & 60,378 & 16,926 & 425 & 833 & 138,534 \\ \text { Sheep.....1914 } & 5,756 & 5,226 & 3,821 & 214 & \ldots & 15,017 \\ \text { Sheep....1915 } & 8,169 & 4,694 & 586 & \ldots & 352 & 13,801 \\ \text { Hogs......1914 } & 131,637 & 264,824 & 62,891 & 2,427 & 110 & 461,889 \\ \text { Hogs.....1915 } & 124,390 & 237,403 & 123,195 & \ldots & 9 & 484,997 \\ \text { Horses...1914 } & 1,069 & 2,681 & 902 & 283 & 993 & 5,928 \\ \text { Horse....1915 } & 2,770 & 648 & 1,510 & 75 & 1,211 & 6,214\end{array}$

\section{Disposition of Stock from the Yards}

$\begin{array}{lrrrrr}\text { Cattle....1914 } & 35,962 & 33,418 & 7,488 & 33,709 & 110,577 \\ \text { Cattle....1915 } & 47,466 & 17,425 & 9,796 & 63,783 & 138,470 \\ \text { Sheep.....1914 } & 13,290 & 542 & 1,039 & 146 & 15,017 \\ \text { Sheep.....1915 } & 12,710 & 93 & 688 & 300 & 13,791 \\ \text { Hogs.....1914 } & 213,049 & 210,482 & 1,788 & 36,114 & 461,433 \\ \text { Hogs......1915 } & 161,687 & 299,184 & 883 & 21,685 & 485,439 \\ \text { Horses....1914 } & 839 & 3,722 & 1,347 & 21 & 5,928 \\ \text { Horses....1915 } & 383 & 4,033 & 1,588 & 211 & 6,214\end{array}$

It will be seen that during the year 1915 almost one half of the cattle passing through these yards went south into the United States. Of these a very large number were exported during the latter half of the year, when Manitoba farmers had on hand great quantities both of roughage and of grain feed, and as $70 \%$ of these exported cattle were classed as stockers or feeders, it would seem as though a good opportunity to make profit by feeding cattle had been missed. It is quite possible that a repetition of the same process may recur during 1916, and, in view of this fact, it is pertinent to point to the opportunity open to every farmer of Manitoba in the way of securing some of these cattle for winter feeding.

\section{QUALITY IN LIVE STOCK}

Wm. A. Munro, Rosthern, Sask., Supt. Experimental Station.

Much has been said relative to "Greater Production" and more remains to be said and still more must continue to be said until the war is over. But the greatest mistake that is being made everywhere is the emphasis laid on quantity with a corresponding disrespect for quality.

Let us illustrate from our own personal experience during the past year as purchasers of live stock. Last spring we had occasion to buy eight horses for work on the Experimental Station. We could obtain horses that might do the work for one hundred and fifty to two hundred dollars, but the kind we wanted were such as carried both weight and quality. We could not get these for less than $\$ 250$ to $\$ 325$, because large transfer companies and others were after the same type and the supply was limited. The right kind was scarce. The under-sized, poor-constitutioned, ill-formed animals were plenty. The higher priced animals were more valuable for two reasons: they were bred from superior stock and they had been well nourished during their growing period.

Again we set out to buy feeding steers. From one man we could obtain two-and-ahalf year old steers at $41 / 2$ c. per pound, which would net the owner about $\$ 40$ per animal. From another man steers of the same age could be had at no less than $5 \frac{1}{2} \mathrm{c}$., which 
would net the owner $\$ 64$ per steer. The first bunch of steers were not bought because they were of a wrong type. They were not wanted by the butcher nor the packer nor the feeder. They were up-standing, of poor constitution and the kind that never do well. Along with this they had been ill nourished during their growth. The second lot of steers was purchased because we knew that they "had the habit" of thrift and would respond to feed and would be in demand. We knew also that the first lot would not respond to feed and were not the kind to attract buyers.

Again, we purchased some poultry for high class caterers. From one farmer we secured his spring chickens at $25 \mathrm{c}$. each and from another the same aged birds at $12 \mathrm{c}$. per lb. which netted $64 \mathrm{c}$. per chicken. It was only as a favour that the first lot was taken off our hands. They were small, and thin and altogether undesirable. The others were sold at a little less than one dollar per bird and we were requested to obtain more of the same kind.

Inferior stock is the first to respond when the market takes a downward trend from normal. In a slump it will not sell at all. High class stock is the first to respond when the market takes a rise from normal, and is always saleable even in time of a slump.

There is more need than ever for "Greater Production" but the greatest need is "Good Stuff." There is more need than ever for quality in everything we produce and particularly in live stock of every kind from horses to poultry. We are the gainers and our confreres in Europe are the gainers if we breed well and feed well, and exert all the power that is in us in these two directions-increased quantity, better quality.

\section{REDUCING COST OF PRODUCTION; GRAIN CROPS-PORK}

\section{G. H. Hutron, B.S.A., Superintendent Experimental Station, Lacombe, Alta.}

One sure way to increase production is to demonstrate how production may be made more profitable. If increased profit can be shown, increased production will follow.

It is equally certain that if we reduce cost, increased profit will at once result. This statement applies to all lines of farm production. Since costs may readily be reduced, we have here a source of present and immediate increased profit.

To illustrate the variation possible in the cost of producing a bushel of grain, I might use the figures from the different rotations now being compared at this Station. In one of these rotations wheat is disced in on wheat stubble- a practice followed on some farms and adopted by us for comparison as to cost per bushel. In 1915 it cost 77.8 cents to produce a bushel of wheat under this system, while under another rotation the cost per bushel was reduced to 21.1 cents. Hence we submit that the adoption of the best methods of farm practice would result in a much larger volume of food-stuffs available for export, and in tremendously increased profits for the farmers of Canada. Any reduction in cost of production is a profit that may at once be realized. It is not merely a hope of what the future may bring, but is a means at hand under our own control for increasing profits now.

While large increases in pork production cannot now be arranged for in 1916, yet figures illustrating how cost of pork may be reduced should enable many growers to make additional profits with the usual volume of business, and should lead to increased production in 1917, when food products in abundance will still be required by the Empire.

Data as to the cost of producing pork on different pastures and in a dry feed lot has been secured at the Lacombe Experimental Station during the past season. Seven groups of hogs were used, the pastures being composed of wheat, oats and barley sown in equal parts by weight; oats, barley and wheat singly; alfalfa, and rape. The pigs in the dry feed lot had a small run, but at no time during the season were they given any green feed. The pigs were put on pasture at about 10 weeks old when weaned, 
and were carried on shorts and skim milk for the first 30 days, after which they were fed a three per cent. ration of ground wheat until the conclusion of the experiment. In figuring these costs, the following prices were used; shorts, $\$ 1.65$ per 100 pounds, ground wheat, $\$ 1.00$ per 100 pounds; skim milk 20 cents per 100 pounds. The total amount of grain consumed is shown in the table. If these prices vary from those prevailing in any district, the necessary adjustments can be made in estimating cost in that district. Taking all the pastures together, the average cost of gains for the period shown is $\$ 3.54$ per 100 pounds, while the cost of producing pork without pasture is $\$ 5.30$, a saving of $\$ 1.76$ per 100 pounds. These figures do not include labour nor do they place a value on pasture. The hogs were placed on pasture at the rate of 15 to the acre and since this number was insufficient, particularly at the beginning of the test to keep the pasture down, it is believed that an acre will average from 10 to 15 head according to the class of pasture used for the entire season. If further experiments prove the hog carrying power of different pastures to be within these limits, then the per acre return of land that will carry from 10 to 15 hogs until they reach a weight of 200 pounds will compare favourably with the return from any other farm crop. Surely such a saving in the grain cost of pork production should be an inducement for farmers to use pasture more freely in the production of pork in 1916, and to increase in future the number of hogs kept.

\section{THE SWINE INDUSTRY IN QUEBEC}

\section{H. Nagant, Editor, Journal of Agriculture.}

Out of the large revenue that Canada derives from the swine raising industry only a small portion goes to the Province of Quebec. This is in spite of the fact that Montreal is one of the most important markets for hog products in America. Its packing houses are capable of handling 20,000 hogs per week. Quebec furnishes but a small proportion of the required amount, most of the supplies coming from Western points. In dairying, Quebec takes a leading place. With the by-products of cheese factories and creameries available for, the production of exactly the quality of hog the export trade requires, and with a market of large capacity at its door for hogs on the hoof of the right type and quality, it would appear that the industry is capable of great local development. With the aid of the Federal funds provided by the Agricultural Instruction Act, active measures are being taken at the present time by the province's department of agriculture to develop the industry.

The main factors to consider in any attempt to develop hog raising in the province may be briefly stated as follows:

1. Improvement of type-The prevailing type of hogs has already improved a great deal, but there still is a lot of improvement to be done.

2. The number of pigs is on the increase in the province, but there are reasons to think that a much larger quantity of these animals could be profitably reared and sent to the trade. The splendid development of the dairy industry in Quebec, with the quantity of by-products that are derived from it, make a magnificent basis for a prosperous swine industry.

3. The great defect, at the present time, is the fact that too many light, thin and poorly finished hogs are put on the market. A bacon hog should weigh from 175 to 225 pounds.

4. Too many sows are sent to the market after their first litter. These sows will never produce a first class meat. Farmers would get far more profit out of them if they kept breeding them after the first or even the second litter.

5. In order to get the best and most profitable markets, hogs must be sold on the hoof, that is alive, instead of selling after slaughtering to meet the limited local demand for fresh pork as is the prevailing custom. 


\section{THE PRODUCTION OF VEAL}

\section{H. Nagant, Editor, Journal of Agriculture.}

The feeding of calves for veal has perhaps been more neglected in Quebec than any other branch of agriculture. Drastic laws had to be adopted prohibiting, under the penalty of a fine, the sale of meat unfit for consumption, and providing for the seizure of any animal not old enough to be sent to the market. Every year, a large number of calves are sent to the reduction tank, to the great detriment of the farmers and to the loss of the trade.

How often do we hear people say: "It does not pay to fatten a calf; better get rid at once of the calf not wanted for breeding purposes. The milk that it would use brings an immediate profit at the end of the month when sold to the factory." They overlook the fact that at calving time, in the spring, the price of milk is at its lowest, while veal of good quality sells at a high price. Experience has shown that the production of veal at that time brings at least one third more than the sale of milk to factories. Calves not fit for breeding should, as a general rule, be fed for veal.

The feeding of calves includes two periods-the preparatory and the finishing period.

In the first period no feed can take the place of the mother's milk. It alone is sufficient to finish the animal and produces meat of the best quality. The exclusive use of the mother's milk for a minimum of fifteen days (a month is better), appears to be essential for the calf that is to be fed for veal, as well as for the calf that is kept for breeding purposes. Afterwards, the best mixture to take the place of whole milk is: One part flax seed, two parts ground oats, and two parts corn. This may be stirred into milk, or, better still, given in a dry condition after the calf has drunk its milk. Regular feeding is important.

The fattening of calves may be hastened by inducing them to eat as much food as possible. To do so, the following mixture should be given in the shape of small balls, after the milk is consumed: Equal parts of ground corn, barley, oats, flax seed and shorts, soaked in milk, making the balls about the size of an egg. The quantity will depend on age and appetite. Under this treatment, the calves make rapid gains and weigh on an average one hundred and fifty pounds at the age of two months.

\section{MUTUAL CONFIDENCE AS A FACTOR IN INCREASED PRODUCTION OF LIVE STOCK}

\section{A. P. Westervelt, Live Stock Branch, Department of Agriculture.}

In marketing live stock the producer does not come into direct contact with the consumer for the reason that the only outlet for the product is through meat handling plants. The only way in which the manufacturer is able to get his raw material is from the producer. It follows, therefore, that a very close relationship exists between the producer and the manufacturer.

The transaction may be looked at either as a straight sale in which the producer has no further concern, or he may regard it as to his interest that the consumer should be supplied with an article of good quality and in the greatest quantity that the market can take care of. Considering the dependence of the producer upon the manufacturer, and the manufacturer upon the producer, the latter would appear to be the reasonable view to take. Sympathy and co-operation are required between the two. Business should be so conducted that outside of the reasonable profits of the manufacturer, the proceeds should go to the producer. The success of both depends upon the success of each. There must be recognition of the principle that what is best for the live stock business as a whole, is best for all individuals concerned.

Mutual confidence is the key note to the situation. Misunderstandings should be swept away. The manufacturer and the producer should feel that each one has certain 
interests in the general business which entitle him to all reasonable details of that business. All business should be transacted in such a way as to encourage this confidence and every effort made to understand the various problems of each end of the business and to endeavour to solve these problems.

To get the maximum trade it is essential that the manufacturer should be given what he needs in the way of raw material, both as to quantity and quality and with regularity. On the other hand, it is just as essential that the manufacturer, acting as agent, should satisfy the producer that his product has been handled in a business-like way, that the business has been run having in view the welfare of the whole trade, and that the producer is receiving a reasonable share of the profits for the product he supplies. It should be generally recognized, though it may perhaps differ from the usually accepted theory, that the interests of the manufacturing industry are best served by the payment of high prices for live stock, thus encouraging increased production. It would appear that the greater the volume of business done by the manufacturer the smaller the margin required to operate his plant and profitably conduct his business. The two factors affecting this volume, without regard to ordinary competition of trade, are the price charged the consumer by the manufacturer and the price paid by the manufacturer to the producer. The lower the price paid by the consumer the greater the consumption. The higher the price paid the producer the greater the production.

It therefore follows that as the profit of the manufacturer depends upon the volume of business, it is in his interest to reserve the smallest possible margin on the turnover of his business, so that the highest price possible may be paid to the producer and the lowest price possible may be paid by the consumer. With lessened production and less raw material for the manufacturer the cost of manufacturing will be increased and the margin retained by the manufacturer will be greater, as the lessened supply cannot be manufactured into dressed meats with the same economy as when the plants are running at capacity. An increased price to the consumer will naturally follow. At the time of the greatest consumption and of greatest supply of raw material, the price of live stock should come nearest to corresponding relatively with the retail price of meat; the manufacturers will be receiving the greatest aggregate profit but will be operating on the smallest margin.

The interests of the manufacturers will warrant preserving the balance of prices between that received by the producer and that paid by the consumer, where it will encourage the greatest production. So far as the producer is concerned, that price must be sufficiently high to insure a profit on his breeding and feeding operations. This is certainly common ground for establishing confidential relations. Confidence in each other will generate a confidence in the live stock business, and will encourage the live stock man to feed live stock to the full capacity of his farm and will enable the manufacturer to take care of the maximum amount of trade in dressed meats.

\section{BIG FALLING OFF IN BEEF CATTLE}

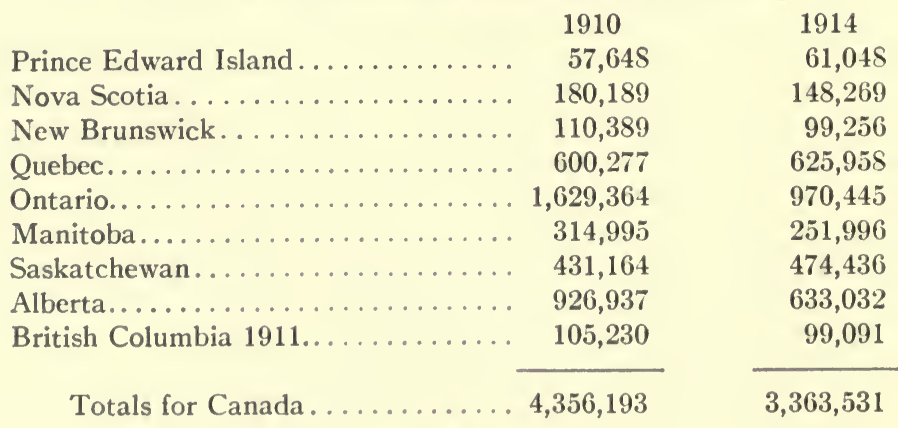




\section{LIVE STOCK ON ONTARIO FARMS}

Numbers of live stock on farms in Ontario on July 1, 1915, compared with the two previous years, were as follows:-

\begin{tabular}{lrrr} 
& \multicolumn{1}{c}{1913} & 1914 & \multicolumn{1}{c}{1915.} \\
Horses......... & 902,628 & 904,975 & 903,527 \\
Milch Cows...... $1,141,071$ & $1,085,843$ & $1,077,808$ \\
Other Cattle.... $1,460,015$ & 970,445 & 935,606 \\
Sheep......... & 705,848 & 640,416 & 611,789 \\
Swine......... $1,652,440$ & $1,553,624$ & $1,469,573$
\end{tabular}

\section{WESTERN HOLDINGS OF STOCK}

In the past year supplies of live stock have withstood the draining effect of the demands from the United States very well. Swine have decreased markedly in every Province, but in all other departments an increase is shown over the figures of 1914 . According to the Dominion Government figures, the following table shows the holdings of live stock in the three middle western Provinces since 1911:-

\begin{tabular}{|c|c|c|c|c|c|}
\hline Manitoba- & 1911 & 1912 & 1913 & 1914 & 1915 \\
\hline Horses............. & 280,374 & 293,776 & 304,088 & 316,707 & 317,847 \\
\hline Milch Cows.......... & 155,337 & 148,471 & 152,792 & 156,306 & 157,494 \\
\hline Other Cattle......... & 279,776 & 267,130 & 256,926 & 251,996 & 246,603 \\
\hline Sheep............. & 37,322 & 40,800 & 42,840 & 45,303 & 50,880 \\
\hline Swine............. & 188,416 & 183,370 & 184,745 & 186,276 & 163,308 \\
\hline \multicolumn{6}{|l|}{ Saskatchewan- } \\
\hline Horses............. & 507,400 & 551,645 & 580,386 & 609,521 & 630,062 \\
\hline Milch Cows.......... & 181,146 & 184,896 & 194,843 & 204,624 & 211,684 \\
\hline Other Cattle.......... & 452,466 & 461,244 & 468,255 & 474,436 & 543,609 \\
\hline Sheep.............. & 114,216 & 114,810 & 115,568 & 126,027 & 133,311 \\
\hline Swine.............. & 286,295 & 344,298 & 386,784 & 454,703 & 411,324 \\
\hline \multicolumn{6}{|l|}{ Alberta- } \\
\hline Horses.......... & 407,153 & 451,573 & 484,809 & 519,424 & 544,772 \\
\hline Milch Cows.......... & 147,687 & 157,922 & 168,376 & 179,068 & 183,974 \\
\hline Other Cattle.......... & 592,163 & 587,307 & 610,917 & 633,032 & 660,000 \\
\hline Sheep.............. & 133,592 & 135,075 & 178,015 & 211,001 & 238,579 \\
\hline Swine..$\ldots \ldots \ldots \ldots$ & 237,510 & 278,747 & 350,692 & 397,123 & 229,696 \\
\hline
\end{tabular}

\section{MORE LIVE STOCK IN SASKATCHEWAN}

There is an increase in Saskatchewan's live stock returns. According to the province's statistics, in the south-west and west-central crop districts there is an increase of 7 per cent. in milch cows, and a total increase for the province of 6 per cent. over last year. Hogs show a decrease, but hogs so easily rise or fall in numbers that they reflect the state of the market more quickly than any other branch of the live stock industry. Horses have held their own in numbers, although the market has not been encouraging. A good omen is the increase in the number of sheep. Sheep will play an important part in checking weeds, and the province needs their aid. The totals, of live stock for the years 1914 and 1915 are as below:-

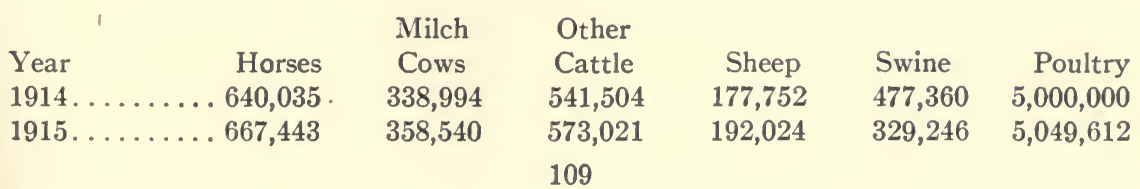




\section{MIXED FARMING IN THE WEST}

Those who have persistently preached mixed farming to the western farmer undoubtedly will see a wide adoption of that gospel throughout the West this year. The present world-wide need for beef and dairy stuffs will stimulate a rapid increase of the production of those commodities. Up till now the West has replied to the adviser of mixed farming that as the grower of grain required money and the means of caring for animals he could not delay in engaging in the live stock industry. The returns from the crop of the past season will enable many a western grain-grower to purchase his first few head of beef or dairy cattle.

\section{SASKATCHEWAN BEEF IN CHICAGO}

The following particulars are given regarding a shipment of Hereford steers from Saskatchewan (Matador Ranch) to Chicago packing houses in October, 1915:-

Number of head shipped............... 2,037

Total Weight....................... 2,450,830 lbs.

Average Weight.................... 1,203 "

Average price.................... \$7.77

Dressing percentage................... 61

Remarks: "Beef very firm."

\section{ALBERTA BEEF FOR THE STATES}

Gleichen, Alta., Dec. 1915-D. P. McDaniels of Calgary recently purchased 600 head of beef cattle from the W. P. Trend ranch at this place, price $\$ 6.25$ per 100 , total purchase money about $\$ 55,000$. They were taken to Calgary by the "hoof route" and there embarked on special train for Seattle, for which market they were bought.

A shipment of 185 head of Range cattle was made by A. E. Cross, 'of Nanton, Alberta, in November, 1915. The cattle were shipped to Chicago and were handicapped by a 30 hour delay at Portal. They weighed in all $250,900 \mathrm{lbs}$. The freight charges were $\$ 2,183.70$, other charges $\$ 322.80$, leaving net receipts $\$ 17,409.98$. Average weight 1,356 lbs., average net value $\$ 94.10$ or 6.94 cents per pound live weight delivered at Chicago.

\section{BREEDING AND BEEF PROFITS}

The following table shows weight of a cross-bred Hereford-Shorthorn steer in the junior yearling class, compared with the weight of a common steer, at the Ontario Provincial Winter Fair, 1915.

\begin{tabular}{|c|c|c|c|c|}
\hline$=$ & \multicolumn{2}{|c|}{$\begin{array}{l}\text { Prime } \\
\text { Steer }\end{array}$} & \multicolumn{2}{|c|}{$\begin{array}{c}\text { Common } \\
\text { Steer }\end{array}$} \\
\hline Live Weight. .............. & \multicolumn{2}{|c|}{1,320 pounds. } & \multicolumn{2}{|c|}{1,130 pounds. } \\
\hline Dressed Weight............... & 856 & & 620 & \\
\hline Dressing Percentage............ & \multicolumn{2}{|c|}{$64.9 \%$} & \multicolumn{2}{|c|}{$54.8 \%$} \\
\hline Weight of Side.............. & \multicolumn{2}{|c|}{430 pounds. } & \multicolumn{2}{|c|}{315 pounds. } \\
\hline Hind Quarter, round........... & 105 & “ & 85 & “ \\
\hline Long Loin............... & 84 & “ & 50 & “ \\
\hline Kidney Suet........... & 12 & “ & 5 & “ \\
\hline 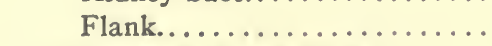 & 24 & “ & 12 & “ \\
\hline Front Quarter Prime Ribs......... & 48 & “ & 31 & “ \\
\hline Chuck................. & 88 & “ & 77 & “ \\
\hline 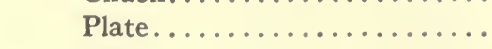 & 55 & “ & 35 & “ \\
\hline Shin................ & 10 & “ & 10 & “ \\
\hline
\end{tabular}


"Wee McGregor" of Brandon, Man., grand champion at the Ontario Provincial Winter Fair Guelph, 1915, weighed alive 1,500 pounds, dressed 1,040 lbs. (69.3 per cent.)

"The tremendous losses that have been suffered by agriculture in Europe since August, 1914, baffle imagination," states Mr. Victor Fortier, of the Ottawa Experimental Farm. "In France alone, in the part invaded by Germany, it is estimated that 610,000 horses, 1,500,000 head of cattle, 1,600,000 sheep, 700,000 pigs and 3,000,000 fowls have been destroyed. In Belgium, the damages to agriculture amount to over $\$ 280,000,000$, including about $\$ 130,000,000$ for cattle and other domestic animals slaughtered." 


\title{
THE DAIRYING INDUSTRY
}

\author{
J. A. RUDDICK, Dominion Dairy Commissioner.
}

1. The total number of milch cows in Canada in 1911, as given in the Fifth Census, was $2,594,179$. The following table shows how they were distributed by provinces as compared with 1901.

2.

TABLE I.

\section{Milch Cows in Canada}

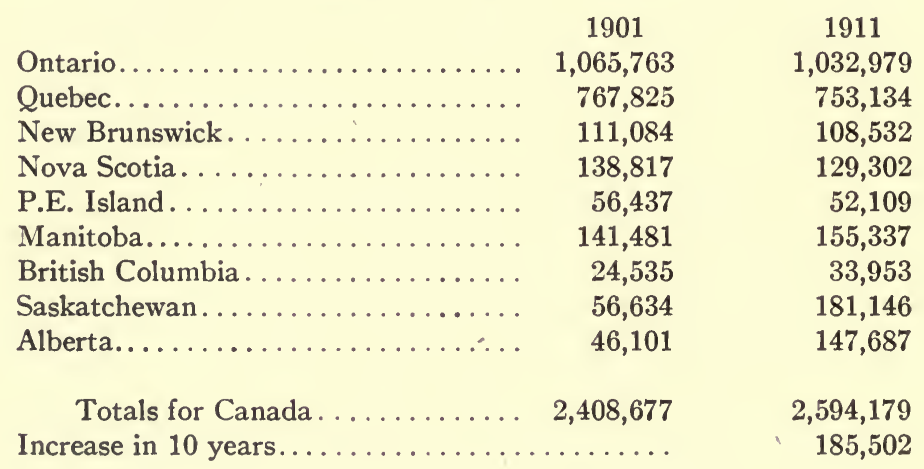

3.

TABLE II.

\section{Total Value of Dairy Products by Provinces in 1910 as compared with 1900}

1900

Ontario........\$34,776,330

Quebec.........20,207,826

New Brunswick... 2,260,537

Nova Scotia...... 2, 2,85,997

P.E. Island. . . . . 1,111,614

Manitoba....... 2,792,606

British Columbia. . . 1,159,993

Saskatchewan..... 729,574

Alberta........ $\quad 546,476$

Totals for Canada... \$66,470,953
1910

$$
\begin{array}{r}
\$ 43,332,047 \\
31,663,220 \\
3,998,742 \\
4,618,108 \\
1,607,672 \\
6,077,982 \\
2,620,495 \\
7,566,007 \\
7,855,751 \\
\hline \$ 109,340,024
\end{array}
$$

Increase

$\$ 8,555,717$

$11,455,394$

$1,738,205$

$1,732,111$

496,058

$3,285,376$

$1,460,502$

$6,836,433$

$7,309,275$

$\$ 42,868,981$

4. Increase in number of cows 7 per cent.

5. Increase in value of total products (butter, cheese, condensed milk, and milk and cream consumed) 60 per cent.

6. In 1900 the value of the total product per cow was $\$ 27$. In 1910 it was $\$ 42$, due partly to higher prices. The figures for 1914, if known, would be still higher. 
Comparative Statistics of the Dairying Industry expressed in Terms of Milk, showing Production, Exports, Imports, and Total and Per Capita Consumption in the Census Years 1901 and 1911

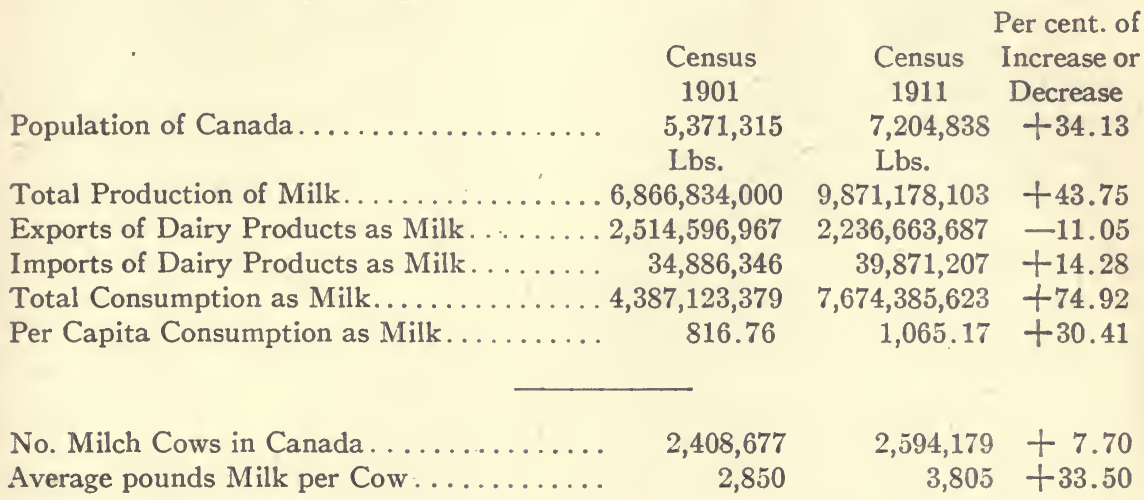

Note-As milk production was not included in the 1901 Census the quantity shown in the 1901 column was arrived at as follows: The total value of all dairy products in 1900 was $\$ 66,470,953$, which included the manufactured value of cheese and butter made in factories, and the average gross value of the milk supplied to factories was 96.8 cents per hundred lbs. Taking this figure as a basis, the above total value represents a total milk production of $6,866,834,000$ lbs.

8.

TABLE IV.

\section{Value of Different Products in 1910}

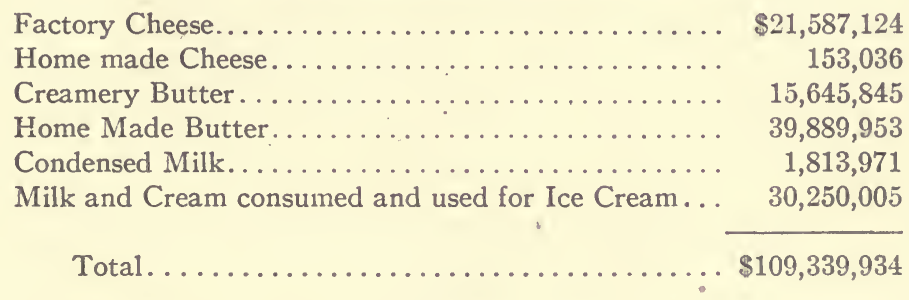

9. The average annual yield per cow increased in 10 years from 2,850 pounds to 3,805 pounds. It would have required $3,463,571$ cows at the average production of 1900 to have produced the quantity of milk shown in the Census for 1910-an increase of $1,054,894$ instead of the actual increase of 185,502 . 'This increase in yield represents at least $\$ 25,000,000$ a year for the number of cows milked in 1910 , and it is safe to say that the sum would be larger if it were known for 1914 .

\section{The Export Trade}

10. The export of cheese reached the maximum of $233,980,716$ pounds in 1904 . This high water mark was followed by a steady annual decline until in 1914 the total exports were only $137,601,661$ pounds. The figures for the year 1915 show a large and gratifying increase. The total quantity exported in that year amounted to $160,659,808$ pounds, or an increase of over $16 \%$ for the year. 
11. The export of butter reached the maximum of $34,128,944$ pounds in 1903 and then declined until 1912, the total quantity exported for that year being only 828,323 pounds. Since that year there has been a gradual increase and during the calendar year 1915 the quantity exported was $3,592,791$ pounds.

\begin{tabular}{crc} 
& $\begin{array}{c}\text { Quantity } \\
\text { lbs. }\end{array}$ & \multicolumn{1}{c}{$\begin{array}{c}\text { Value } \\
\$\end{array}$} \\
Butter-calendar year $1915 \ldots \ldots \ldots \ldots \ldots \ldots$ & $3,592,791$ & $1,059,764$ \\
Butter-9 months to Dec. $1915 \ldots \ldots \ldots \ldots$ & $3,151,075$ & 940,003 \\
Cheese - calendar year $1915 \ldots \ldots \ldots \ldots \ldots$ & $160,659,808$ & $25,112,854$ \\
" -9 months to Dec. $1915 \ldots \ldots \ldots \ldots$ & $157,166,196$ & $24,536,994$
\end{tabular}

12.

TABLE V.

\section{Detailed Exports of Dairy Products for year ended March 31, 1915}

\begin{tabular}{|c|c|c|}
\hline & & Value \\
\hline To all Countries & Quantity & $\$$ \\
\hline Cheese.................Lb. & $137,601,661$ & $19,213,501$ \\
\hline Butter................." & $2,724,913$ & 639,625 \\
\hline Cream................Gal. & $1,895,575$ & $1,836,006$ \\
\hline Condensed milk. ..........Lb. & $18,355,975$ & $1,181,300$ \\
\hline Casein ................... & 230,045 & 13,923 \\
\hline Fresh Milk. ..............Gal. & 477,692 & 68,205 \\
\hline
\end{tabular}

13. The export of cream to the United States has attracted some attention since the reduction of duty from 20 cents to 5 cents per gallon under the Payne-Aldrich tariff of August 5, 1909. It was expected that the reduction of the U.S. duty on butter to $21 / 2$ cents per pound and of cheese to 20 per cent. with cream on the free list on October 3,1913 , would have the effect of greatly increasing the shipments of these articles to that market but these expectations have not been realized.

14.

TABLE VI.

\section{Exports of Cheese and Butter}

\section{Butter}

\begin{tabular}{|c|c|c|}
\hline $\begin{array}{c}\text { Year } \\
\text { Year ended June 30: }\end{array}$ & $\begin{array}{l}\text { Quantity } \\
\text { Lbs. }\end{array}$ & $\begin{array}{l}\text { Value } \\
\$\end{array}$ \\
\hline $1880 \ldots \ldots \ldots \ldots \ldots \ldots \ldots \ldots \ldots$ & $18,535,362$ & $3,058,069$ \\
\hline $1890 \ldots \ldots \ldots \ldots \ldots \ldots \ldots \ldots \ldots$ & $1,951,585$ & 340,131 \\
\hline $1900 \ldots \ldots \ldots \ldots \ldots \ldots \ldots \ldots \ldots$ & $25,259,737$ & $5,122,156$ \\
\hline 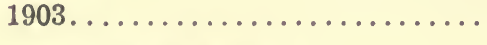 & $34,128,944$ & $6,954,618$ \\
\hline \multicolumn{3}{|l|}{ Year ended March 31: } \\
\hline $1910 \ldots \ldots \ldots \ldots \ldots \ldots \ldots \ldots \ldots \ldots$ & $4,615,380$ & $1,010,274$ \\
\hline $1911 \ldots \ldots \ldots \ldots \ldots \ldots \ldots \ldots \ldots$ & $3,142,682$ & 744,288 \\
\hline $1912 \ldots \ldots \ldots \ldots \ldots \ldots \ldots \ldots \ldots \ldots$ & $8,844,402$ & $2,077,916$ \\
\hline $1913 . \ldots \ldots \ldots \ldots \ldots \ldots \ldots \ldots \ldots$ & 828,323 & 223,578 \\
\hline $1914 . \ldots \ldots \ldots \ldots \ldots \ldots \ldots \ldots \ldots$ & $1,228,753$ & 309,046 \\
\hline $1915 \ldots \ldots \ldots \ldots \ldots \ldots \ldots \ldots \ldots \ldots$ & $2,724,913$ & 639,625 \\
\hline
\end{tabular}


Cheese

\begin{tabular}{|c|c|c|}
\hline Year & Quantity & Value \\
\hline Year ended June 30 : & Lb. & $\$$ \\
\hline $1880 \ldots \ldots \ldots \ldots \ldots \ldots \ldots \ldots \ldots$ & $40,368,678$ & $3,893,366$ \\
\hline $1890 \ldots \ldots \ldots \ldots \ldots \ldots \ldots \ldots \ldots$ & $94,260,187$ & $9,372,212$ \\
\hline $1900 \ldots \ldots \ldots \ldots \ldots \ldots \ldots \ldots$ & $185,984,430$ & $19,856,324$ \\
\hline $\begin{array}{l}1904 \ldots \ldots \ldots \ldots \ldots \ldots \ldots \ldots \\
\quad \text { Year ended Mar. } 31:\end{array}$ & $233,980,716$ & $24,184,566$ \\
\hline $1910 \ldots \ldots \ldots \ldots \ldots$ & $180,859,886$ & $21,607,692$ \\
\hline $1911 \ldots \ldots \ldots \ldots$ & $181,895,724$ & $20,739,507$ \\
\hline 1912. & $163,450,684$ & $20,888,818$ \\
\hline 1913. & $155,216,392$ & $20,697,144$ \\
\hline $1914 \ldots \ldots \ldots \ldots \ldots$ & $144,478,340$ & $18,868,785$ \\
\hline $1915 \ldots \ldots \ldots \ldots \ldots \ldots \ldots \ldots \ldots$ & $137,601,661$ & $19,213,501$ \\
\hline
\end{tabular}

\section{Markets for Canadian Dairy Produce}

15. During the past ten years Canada has exported dairy products to some 30 different countries, but the quantities are very small outside of the United States, the West Indies and Newfoundland. The United Kingdom is still and will continue to be our chief market.

16. In 1913 the imports of butter into the United Kingdom were $463,570,464$ pounds. The imports of cheese of all kinds during the same period were $257,328,848$ pounds, of which Canada supplied 56 per cent.

17. The decrease in shipments of cheese from Canada since 1904 has been met by a corresponding increase in the exports from New Zealand, the only other country which supplies the United Kingdom with cheese of the same class as Canadian.

18. New Zealand cheese has not driven Canadian cheese out of the market. New Zealand is simply supplying the quantity which Canada has been unable to supply.

19. Canadian cheese easily holds the premier place in the importations of the United Kingdom, both in point of quantity and quality. Importers complain only that they cannot get more of it.

20. It would be quite possible to repeat the increase of 1915 in the shipments of cheese to the United Kingdom, as Canadian cheese would receive the preference over the New Zealand.

21. While the export trade has always attracted most attention it must not be forgotten that the home trade is by far the most important, and that it is five times as large. The total value of milk and its products consumed in Canada is over $\$ 100,000,000$ annually.

\section{Probabilities for Enlarged Markets}

22. During the year ended March 31, 1915, Canada imported 6,959,409 pounds of butter, chiefly from New Zealand. There is no reason why all this butter should not be produced in Canada, as it will be in the near future.

23. As stated in 20, the United Kingdom is prepared to receive a larger quantity of butter and cheese from Canada than is now being sent.

24. The home market has increased enormously during the past 10 years (see Table III.)

Three factors have contributed to this increase, namely-1. Increase of population. 2. Improvement in quality of products. 3. Increased purchasing power.

Another factor should be added by judicious advertisement of the higher food value of milk and its products as compared with other foods now much more extensively used. 


\section{Possibilities of Increased Production}

25. The production of milk in Canada, while amounting to a large quantity in the aggregate, is comparatively small per acre or for the area devoted to dairy or mixed farming.

26. It is claimed that more cheese is produced within a radius of 40 miles of Whitchurch, Shropshire, England, than is exported from the whole of Canada.

27. Holland, the area of which is only equal to that part of Ontario lying southwest of a line drawn from Southampton on Lake Huron to the city of Hamilton, produces over $180,000,000$ pounds of cheese and $140,000,000$ pounds of butter annually.

28. There is more cheese produced in England and Scotland than in the whole of Canada, and the bulk of it comes from a half dozen counties.

29. In parts of Switzerland as many as 263 dairy cattle are maintained per square mile.

30. The average yield of milk per cow is still very low in Canada and might easily be increased 25 or even 50 per cent. The records of the Cow Testing Associations and Dairy Record Centres show that many farmers have, by judicious selection, following systematic testing, increased the yield from their herds as much as 25 and 30 per cent. in three years.

31. The farmers of Canada as a class have not yet learned how important it is to keep cows in good condition. If their feed is scarce the cows get short rations. In older dairying countries the farmers take the view that they cannot afford to allow the cows to get into poor condition.

32. The growth of our towns and cities, with an increasing demand for winter milk and cream, together with the shortage of butter, gives a new importance to winter dairying. Following the inauguration of the winter dairying movement about 20 years ago there came a period of low prices which discouraged many who were inclined to produce winter milk. Moreover, at that time the farmers were not generally so well equipped as they are now - there were not so many silos for one thing. The winter market is now a high one and is likely to be so in future.

33. A very important factor in keeping up winter prices is the demand for milk and cream which comes from the New England centres of population. If one looks at the map it will be seen that this great manufacturing district has only a limited territory within the United States from which to draw supplies, and much of that territory is very unproductive. If they look to the southward they compete with New York City. As a result these cities are looking to southern Quebec for a portion of their supplies.

34. A more regular production throughout the year makes it easier to retain good customers, simplifies some of the labour problems, both on the farm and in the factory, by affording yearly employment.

35. Percentage of cattle compared with population in different countries (No. of cattle to every 100 of population).
New Zealand. . . 197 per cent.
Denmark......................... 83 per cent.
United States. . . . . . . . . . . . . . . . . . . . 69 per cent.
Sweden.......................... 48 per cent.

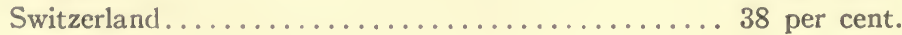

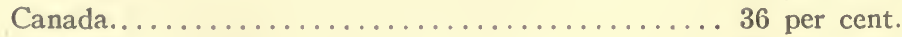

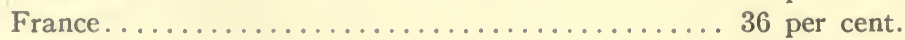

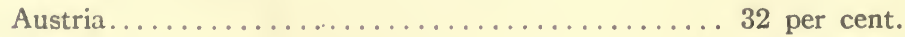

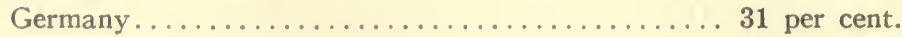
United Kingdom................... 27 per cent.

For a country without a large industrial population Canada takes a very low place in the foregoing list. 


\section{CHEESE PRICES}

Montreal, July 1914 to Feb. 1916

\section{Finest Western}

July . $1914123 / 4$ to $131 / 8$ cents per pound.

August... $131 / 8$ " $141 / 4$

September. $143 / 4$ " $153 / 4$

October. 15 " $15 \frac{5}{8}$

November 15

December 15 “ $15 \frac{5}{8}$

January.................. 1915

February...

$15 \frac{1}{4}$ " 17

March $161 / 4$ " $171 / 2$

April 17 " $17 \frac{1}{2}$ $163 / 4$ “ $171 / 2$ $171 / 2$ “ $191 / 4$

May

June. $15 \frac{3}{4}$ “ $183 / 4$

July . $13 \frac{3}{4}$ " $171 / 4$

August. $121 / 2$ " 14

September. $13 \frac{3}{4}$ “ $151 / 8$

October. $143 / 4$ “ $16 \frac{1}{2}$

November. 16 " $173 / 4$

December $173 / 4$ “ $181 / 4$

January $181 / 4$ " $181 / 2$

February. $181 / 2$ “ $183 / 4$

\section{MARKET PRICES OF FINEST WESTERN CREAMERY BUTTER}

\section{Montreal, July 3rd, 1914, to January 27th, 1916}

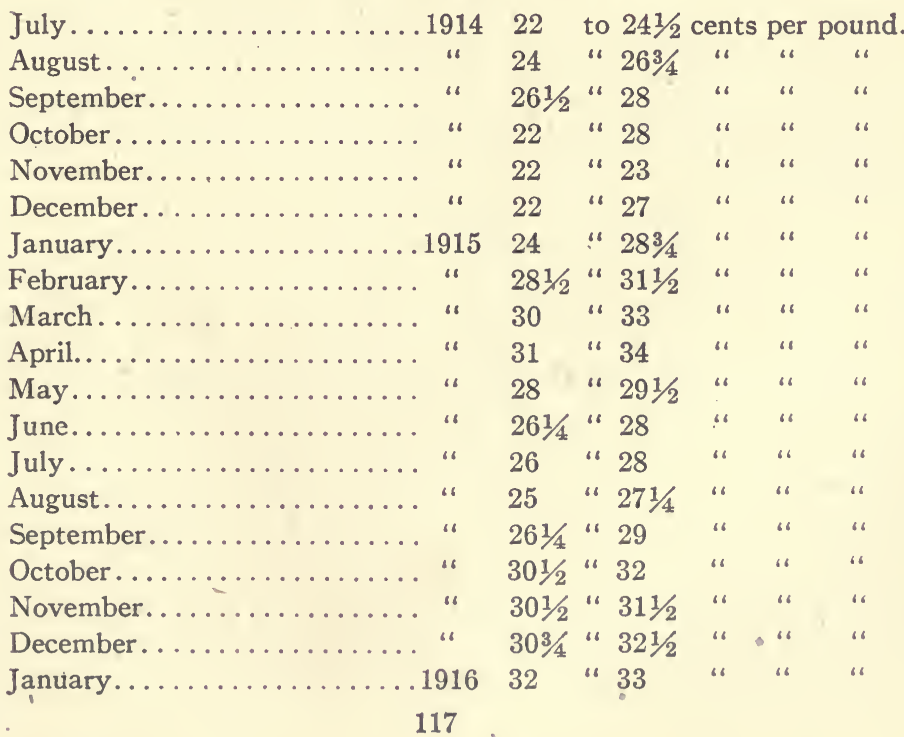




\section{A MESSAGE TO ONTARIO DAIRYMEN}

\section{H. H. DEAN, Professor of Dairy Husbandry, O.A.C., Guelph.}

The year 1915 will be known in dairy history as one of the best ever experienced by Ontario dairymen. The causes contributing to this year of success were plenty of rain in nearly all parts of the Province, which made grass and all other kinds of feed grow abundantly; good prices, due to the great demand for milk and its products caused chiefly by the call for cheese as a part of the army rations; and also to the extra efforts put forth by dairymen to increase their production. But the dairy business cannot exist on past performances. The present and the future are of more importance than the past. What of the future? What about 1916? These are the questions anxiously asked at the opening of another dairy season.

\section{Grow more Feed than ever During 1916}

Some one has said, "We can judge of the future only by the past." If this be true, we may be reasonably sure that so far as demand for dairy products is concerned, the present year will be fully as good as last year. We may also expect that the dairymen and cows will do their part, but the part the weather will play cannot be foreseen. Farmers are peculiarly subject to adverse weather conditions. The dairy farmer, can, to a certain extent, outwit the "weather-man" by growing a variety of crops, so that if one fails another is likely to be successful. A season unfavourable for grass is usually a favourable one for corn, hence the dairyman should grow plenty of both grass and corn, so that a crop of feed may be assured for his cows.

Keeping hungry cows on a farm is one of the biggest losing games in the whole dairy business. A hungry cow is a discontented cow; a discontented cow is a poor milker because her nervous energy is dissipated while longing for, or hunting for, feed to satisfy her appetite, instead of being utilized for the secretion of milk.

\section{Weigh and Test each Cow's Milk}

The weighing and testing of milk from individual cows in the herd should receive more attention than ever during the present year, in order that owners of dairy cows may intelligently breed and weed out their stock. It would not be a wise policy for all dairymen to discard at once all cows that fall below a standard of $6,000 \mathrm{lbs}$. of milk or $250 \mathrm{lbs}$. of butter in a year. Cheese factories and creameries, milk-condensing and city milk plants would close their doors in many cases, if this plan were adopted immediately. But the method of weeding out all cows that do not reach a certain standard should be systematically followed until the dairy cow owner is able to place in his stable the following notice:

\footnotetext{
"Every cow that enters here

Must give 10,000 lbs. a year."
}

The Record of Performance and the Record of Merit are two organizations that assist the owners of pure-bred dairy cattle to breed, own, and sell registered stock of merit. The Cow-Testing Association is for the purpose of assisting the man who owns grade or pure-bred stock to know his cows individually, as determined by the scales and Babcock test. But the owner of cows need not wait for any of these to help him. He should act on his own initiative and purchase a milk scale and tester, or arrange to have samples from each cow tested two or three times during the lactation period. Record milk sheets are furnished free by both the Ontario and Dominion Departments of Agriculture. The time required to weigh the milk from each cow and record the same is very short. No one can afford not to do this. It is good business to know how much milk each cow is giving daily and what her milk tests, but there is an added advantage, not commonly reçkoned by cow owners, namely, that the records indicate the 
approach of disease or ill-health. If the milker finds that a cow has dropped suddenly in her milk-yield, he should at once look for the cause, as indigestion or some other of many troubles to which cows are subject is indicated.

\section{Cleanliness and Cooling}

Cleanliness and proper cooling of milk and cream are topics worn thread-bare at dairy conventions and in the dairy press, but those who are in the dairy business know the need there is for continually calling attention to these matters. Milk and its products are human foods. The consuming public is becoming more critical each year with reference to food. Many of the ills of mankind, particularly those afflicting children, are caused by impure milk. The unclean cow and the unclean man or woman handling milk should not be tolerated. It might not be out of place to require such persons to utter the cry, as required in olden times of certain persons: "Unclean." "Unclean."

The time is not, I hope, far distant when the man who produces a clean, wholesome, standard product will receive a much higher price for it than will the man who produces goods of inferior quality. Too long has continued the plan of paying practically the same price for all qualities and conditions of milk and cream. The dairyman who has clean cows in a clean stable, who milks in a cleanly manner and cools the milk, immediately after milking or separating, to a safe temperature for transportation or manufacturing, should receive a greater reward than the man who disregards these principles. How to bring into actual practice this admittedly desirable state of affairs is puzzling the brains of leading dairymen at the present time, but a solution must be found somehow, somewhere.

Milk and its products, particularly cheese, are among the cheapest foods for human consumption that the family buyer can purchase. The British Government showed wisdom in selecting cheese for the men at the front, thereby giving the world at large a lesson on the value of cheese as a food which will not soon be forgotten; hence we may expect a continued increased demand for Ontario cheese not only during 1916, but for many years to come.

\section{NOTES ON DAIRYING IN EASTERN ONTARIO}

\section{G. G. PUBlOW, Chief Dairy Inspector.}

Never before was so much cheese made in Eastern Ontario as during the season just closed. Never before was it produced at so little cost. Never before were prices so high. Never have farmers, particularly dairy farmers, made so much money out of their herds. All this was due to a most unusual combination of circumstancesphenomenal production and high prices. At the beginning of the season a special appeal was made for the "biggest ever" in production. The dairymen responded to the call, and Providence helped them out with one of the best seasons for pasture we have ever had.

Cheese prices averaged $151 / 2$ cents for the year as compared with $131 / 2$ cents for the year previous. The 1915 price constitutes a record. Circumstances justify continued high prices for this season at least. I look for a permanent benefit to our cheese industry as a result of the war.

In Eastern Ontario in 1915 there was an increase in output of 15 to 20 per cent. over the year previous. Given a reasonably fair season for pasture in 1916, there ought to be an increase in output over 1915 .

This year with abundance of feed and high prices for products there is practically no selling of grade dairy cattle and the number of milkers has increased. Not only are the herds increasing in size, but they are improving in quality. Aside from the 
unusually favourable season there was an increase in the average milk production last year of between 400 and $500 \mathrm{lbs}$.-due to better breeding and better feeding.

In the syndicate dairy districts of Eastern Ontario, 400 additional silos were erected last year.

The dairy industry meant an income of nearly $\$ 15,000,000$ to Eastern Ontario last year aside from the whole milk and home-made butter trade. Dairying is a big thing for Ontario- it is one of Canada's big things.

\section{DAIRYING IN ONTARIO IN 1915}

FRANK HERNS, SECRETARY, LONDON, ONT.

Prices for Dairy Products-The average price for cheese during the past season was the highest ever received in Canada. A considerable amount of American cheese was, we understand, exported to England during the past winter and early part of the spring season. Had this cheese not been available prices would probably have reached an even higher level. It is a source of gratification to know that the Canadian cheese and butter industry is in a position to supply a large quantity of such excellent food products for the soldiers of the Empire.

The butter market assumed a high level early in the season and has been active most of the year resulting in good prices to cream producers.

The statistical position of both cheese and butter is strong and prospects for 1916 are encouraging.

We trust that the increased price of rennet may not tend to induce some makers to "skimp" the proper quantity; it would be a very shortsighted policy to risk the quality of the cheese through a misguided sense of economy. Insufficient rennet means slow and imperfect coagulation, loss in yield and possibly coarse textured cheese.

After the war is over there may possibly be a temporary drop in the prices for dairy products, especially during the readjustment period, but the hope is expressed that, should prices decline for the time being, this may not to any extent influence milk producers to decrease their herds but rather continue to make dairying a permanent feature of their farming operations. Past experience has proven that there is no other line of agriculture that will, over a period of years, pay better than dairy farming.

There has never been a time when the prospects seemed better for a steady demand for live stock. We do not know how long this world war is going to last, but when hostilities cease, there is every evidence that a great demand for dairy products, live stock and meat products will follow. Depleted European herds must be replenished and our country is one of the natural sources from which to draw for this purpose.

\section{MANITOBA DAIRY PRODUCTS}

\section{F. S. JACOBS, B.S.A., Professor of Animal Husbandry, Manitoba Agricultural College.}

Notwithstanding the great increase in grain production in Manitoba during 1915, the dairy industry did not suffer therefrom, but rather expanded considerably. The prices for creamery butter, dairy butter and cheese all showed an improvement, and in every case the quantities made were increased. The result was that the value of our dairy products was increased by over $12 \frac{1}{2}$ per cent. as compared with the year before. During 1915 Manitoba exported between 50 and 55 carloads of creamery butter, part of it going eastward and part of it to British Columbia. The fact that Manitoba is capable of winning and holding a place as an exporter of butter is now becoming well recognized.

During the past year, too, our rather small cheesemaking industry made encouraging growth, and the big demand for eastern cheese caused by the war affords us a good opening for our products.

Professor J. W. Mitchell, Dairy Commissioner for Manitoba, says:-

"During 1915 the dairymen of the Province made their contribution towards increased production. We made over $1,000,000$ pounds more creamery butter and 
over 25,000 pounds more cheese than in 1914 . We could, and with a little care would, have made even a better showing. An analysis of our output by months shows that $83 \%$ of our total make of creamery butter was made during the six summer months (the first of May to the end of October) and $17 \%$ during the other six months of the year. Careful attention should be given to the growing of suitable fall and winter foods and to the proper housing of the cows during the 'all months. This, in itself, would enhance production very considerably. A very strong effort should and will be made to increase the quantity and improve the quality of our dairy products during 1916."

\section{CANADIAN DAIRY RECORDS}

\section{Production Increased by Testing}

\section{Chas. F. Whitley, Dairy Branch, Department of Agriculture, Ottawa.}

\section{Average Yields in Canada}

While the increase in the number of cows in Canada between 1900 and 1910 was only seven per cent. the total production of milk during the same period increased forty-three per cent. The census figures for 1910 give the average yield per cow as 3,805 pounds of milk. In 1914 the average yield per cow of 14,559 cows on the register of the cow-testing associations was 5,121 pounds of milk, 3.6 test, 189.4 pounds of fat. Probably the explanation of the forty-three per cent. increase in milk yield is to be found in the fact that the cow-testing movement as carried on by the dairy division of the Dominion Department of Agriculture is exerting a powerful influence not only on its immediate membership but on the thought and practice of many dairy farmers in Canada.

The value of cow-testing lies in the fact that definite, exact knowledge is obtained of each individual cow; her actual production, her profitable response to more feed, her likelihood of improvement. One point is strongly insisted upon and constantly reiterated-a knowledge of the individual, not the average or total yield. This is essential if cows are to be handled intelligently. What a disappointment it must be to any novice in cow-testing to find that though his herd of 12 cows may average 4,160 pounds of milk, an analysis of the work of each individual for the year discloses the fact that five mature cows, kept under precisely similar conditions as the rest of the herd, failed to pay for their $\$ 35.00$ worth of feed, each one of the five incurring an average loss of over five dollars. If five, or if only three, in a herd of twenty average cows are found to be unprofitable, the loss of time, feed and energy spent in handling is very great.

Cow-testing aims at making every hour, every pound of feed, every unit of power, every acre fit for cows not only profitable, but increasingly so.

\section{The World's Records for Breeds.}

It may be interesting to note what individual pure-bred cows have done. The latest available yields are:

Breed

Name of Cow

$\begin{array}{lccc}\text { Age } & \begin{array}{c}\text { Lbs. } \\ \text { of } \\ \text { Milk }\end{array} & \begin{array}{c}\text { Per } \\ \text { Cent. } \\ \text { Fat }\end{array} & \begin{array}{c}\text { Lbs. } \\ \text { of } \\ \text { Fat }\end{array} \\ \text { Mature } & 27,761 & 4.3 & 1,205.09 \\ \text { Mature } & 30,452 & 3.1 & 951.30 \\ \text { Mature } & 17,557 & 5.6 & 999.2 \\ \text { Mature } & 24,008 & 4.5 & 1,098.1 \\ & & & \\ \text { Mature } & 23,022 & 3.9 & 917.60 \\ \text { Mature } & 10,767 & 4.2 & 453 .\end{array}$

Holstein........ Duchess Skylark Ormsby

Holstein........ Tilly Alcarta

Jersey.......... Sophy 19th of Hood Farm

Guernsey.........Murne Cowan

Ayrshire.........Auchenbrain Brown Kate 4 th

French-Canadian. . Fille

Mature 10,767

4.2

453.

All the above records are held in the United States, except that of the FrenchCanadian. 
There are several grade cows in Canada giving from 9,000 to 18,000 pounds of milk, and from 300 to 500 pounds of fat in the year. These have been discovered through cow-testing.

\section{Records of a Few Canadian Herds}

The record of a pure-bred herd in Western Ontario for 1915 was, 22 cows averaged 8,357 pounds of milk, 4.2 test, 354 pounds of fat; 344 days in milk. Included in the 22 cows are no fewer than 9 two-year-olds. One two-year-old gave over 10,700 pounds of milk and 478 pounds of fat, while a seven-year-old gave only 6,053 pounds of milk and 266 pounds of fat.

The following is a sample record of a herd in Western Ontario. The average yield of 16 cows (only one, a two-year-old pure-bred) was 9,519 pounds of milk and 305 pounds of fat. One six-year-old bought at a sale gave 5,965 lb. milk, $197 \mathrm{lb}$. fat; the best yield was from a seven-year-old, $12,773 \mathrm{lb}$. milk, $401 \mathrm{lb}$. fat. This owner, in two years, has increased his average yield by over two thousand pounds of milk and sixty pounds of fat per cow.

In a herd of 8 grade cows near St. Hyacinthe, Que., the average, including a twoyear-old and 2 three-year-olds, was $4,354 \mathrm{lb}$. milk and $154.8 \mathrm{lb}$. fat, showing an average net profit, above the $\$ 33.50$ feed cost, of $\$ 15.85$ per cow.

At St. Joseph, New Brunswick, the average yield of 19 grade cows, including 3 two-year-olds and 4 three-year-olds, was $5,976 \mathrm{lb}$. milk and $221 \mathrm{lb}$. fat. With a feed cost of $\$ 48.00$ the average net profit was $\$ 18.36$ per cow. One cow made $\$ 40.80$ clear profit.

The following analysis of a herd at Avonmore, Ont., where the owner weighs the milk daily, indicates upon what a good working basis cows may be put; but even here are several contrasts in yields and net profit.

\begin{tabular}{|c|c|c|c|c|c|}
\hline \multirow[t]{2}{*}{ Age } & \multicolumn{2}{|c|}{ Total Yield } & Value & Cost & Net \\
\hline & $\begin{array}{l}\text { Lbs. } \\
\text { Milk }\end{array}$ & $\begin{array}{l}\text { Lbs. } \\
\text { Fat }\end{array}$ & $\begin{array}{l}\text { of Milk, } \\
\text { at } \$ 1.36 \text { per } \\
100 \mathrm{lbs} \text {. }\end{array}$ & $\begin{array}{l}\text { of } \\
\text { Feed }\end{array}$ & Profit \\
\hline $9 \ldots \ldots$ & 6,828 & 261.6 & $\$ 92.86$ & $\$ 58.06$ & $\$ 34.80$ \\
\hline $8 \ldots \ldots$ & 7,428 & 271.0 & 101.02 & 57.67 & 43.35 \\
\hline $4 \ldots \ldots$ & 6,551 & 190.5 & 89.09 & 57.50 & 31.59 \\
\hline $4 \ldots \ldots$ & 7,041 & 252.9 & 95.76 & 57.55 & 38.21 \\
\hline $9 \ldots \ldots$ & 7,690 & 281.8 & 104.58 & 58.83 & 45.75 \\
\hline $9 \ldots \ldots$ & 5,767 & 213.3 & 78.31 & 43.75 & 34.56 \\
\hline $8 \ldots \ldots$ & 5,389 & 176.4 & 73.29 & 45.00 & 28.29 \\
\hline $4 \ldots \ldots$ & 4,637 & 175.4 & 63.06 & 52.63 & 10.43 \\
\hline verage. & 6,450 & 231.9 & 87.71 & 53.94 & 33.78 \\
\hline
\end{tabular}

\section{Increased Production}

Wherever cow-testing is taken up intelligently, more careful feeding, breeding with a purpose, and thorough crop cultivation to insure abundant suitable feed are results that may confidently be expected to follow. These results follow just because the scale and sample indicate that it pays. Poor cows need not be kept simply to fill up the stable, deception as to the real merit of any one cow cannot be practised on the man who studies milk and feed records.

The efficient modern dairyman will know how much his protein costs per pound, whether he gets 200 or 1,400 pounds of milk per acre, whether the feed cost of milk is 62 or 82 cents per 100 lbs., whether each cow makes two, or twenty, or sixty dollars clear 
profit in a year above the cost of her feed. Thus the possibilities of increased production, more economical production, are difficult to limit. Certain it is, the best herd, the best individual cow, the best factory return, the best district average is yet ahead of us.

In one creamery in Nova Scotia the average yield in 1909 was only sixty-three pounds of fat per cow from 445 cows. In 1915 there were 2,739 cows supporting the creamery with an average of ninety-two pounds of fat.

The following table relating to Ontario cows is full of significance.

Some Sample Increases in Three Years' Cow-Testing, Both in Number of Cows and Yields of Milk.

\begin{tabular}{crrrrrrr} 
& \multicolumn{2}{c}{$\begin{array}{c}\text { Last Year } \\
\text { No. of } \\
\text { Cows }\end{array}$} & $\begin{array}{r}\text { Average } \\
\text { Lb. Milk }\end{array}$ & $\begin{array}{r}\text { No. of } \\
\text { Cows }\end{array}$ & $\begin{array}{c}\text { Average } \\
\text { Lb. Milk }\end{array}$ & $\begin{array}{r}\text { Increase } \\
\text { Pbs. Milk }\end{array}$ & \multicolumn{2}{c}{$\begin{array}{c}\text { Percentage } \\
\text { Increase } \\
\text { Lbs. No. of } \\
\text { Herd }\end{array}$} & $\begin{array}{c}\text { Lbs. } \\
\text { A }\end{array}$ & 9 & 7,225 & 5 & 6,287 & 938 & $14 \%$ & $80 \%$ \\
B & 14 & 7,574 & 8 & 5,894 & 1,680 & 28 & 75 \\
C & 8 & 6,404 & 5 & 4,704 & 1,700 & 36 & 60 \\
D & 11 & 7,255 & 8 & 5,266 & 1,989 & 38 & 37 \\
E & 7 & 4,844 & 2 & 2,811 & 2,033 & 72 & 350 \\
F & 8 & 10,935 & 5 & 7,689 & 3,246 & 42 & 60 \\
G & 16 & 7,259 & 12 & 4,572 & 2,687 & 58 & 33 \\
\hline Average... & 73 & 7,392 & 45 & 5,405 & 1,987 & 36 & 62
\end{tabular}

So much better was the general average of the cows kept, that the total milk yield was more than doubled.

\section{ASSISTANCE IN COW TESTING}

The assistance from the Dairy Division of the Department of Agriculture at Ottawa, in regard to cow testing, is just as liberal as in former years. Where a cow testing association is organized and a thoroughly competent person will do the testing of milk samples from individual cows once a month, supplies of preservative tablets and sulphuric acid will be sent free of charge, together with the necessary blank forms; beyond this, a payment of five cents per sample tested will be made. Factory owners, cheese and butter makers will do well to note these facts and act promptly.

\section{WHAT ONE FARMER HAS DONE IN BUILDING UP A DAIRY HERD}

William Pollock, of Harold, Ont., reports that in eight years, 1908 to 1915, he increased the output from the same number of cows from $\$ 800$ to $\$ 1,726$. This was accomplished by breeding better, keeping records, culling out, raising his calves and feeding a little better.

He states:- "Every dairyman should use a pure-bred sire-the best he can afford. Three years ago I milked 12 heifers, two years old at freshening. Eight of them were sired by pure-bred sires and four by a mongrel, but from as good cows as we had in Plum Grove Factory. The eight all proved good but one. The other four were only boarders and I ruled them out the first year. The mature cow that will not give me 9,000 lbs. of milk in ten months must go. My average per cow in 1915 was $9,293 \mathrm{lbs}$. I consider it time well spent to weigh every milking and keep records." 


\section{A GREAT CHEESE YEAR}

The cheese exports from Montreal during a period of five years, the average price per box, and the approximate value were as follows:

\begin{tabular}{|c|c|c|c|}
\hline & $\begin{array}{c}\text { Quantity, } \\
\text { boxes }\end{array}$ & $\begin{array}{l}\text { Price per } \\
\text { box }\end{array}$ & Value \\
\hline $1915 \ldots \ldots \ldots \ldots \ldots \ldots \ldots$ & $1,851,731$ & $\$ 13.44$ & $\$ 24,887,264$ \\
\hline $1914 \ldots \ldots \ldots \ldots \ldots \ldots$ & $1,482,538$ & 11.07 & $18,493,179$ \\
\hline $1913 \ldots \ldots \ldots \ldots \ldots \ldots$ & $1,571,165$ & 10.25 & $16,104,441$ \\
\hline $1912 \ldots \ldots \ldots \ldots \ldots \ldots$ & $1,723,021$ & 10.04 & $17,299,130$ \\
\hline $1911 \ldots \ldots \ldots \ldots \ldots \ldots$ & $1,810,666$ & 9.84 & $17,816,953$ \\
\hline
\end{tabular}

The production of cheese and butter has been somewhat handicapped in Holland by the breaking of the North Sea waters through the dykes. Immense areas have been flooded with salt waters, human lives have been lost, cattle drowned and great damage done to farm homes. In some places only the church towers are to be seen above the flood. It will take years to reconstruct the dykes, pump out the water and restore the land to its former condition.

Owing to German demand, Danish shippers have raised their quotations to the extraordinary price of 208s. per cwt., and it is thought that this action will unfavourably affect the future popularity of Danish butter in Great Britain.

Commenting upon the butter situation, the London Standard states in its issue of October 14:-

"The high price of butter, created apparently through the advance of butter prices at Copenhagen, where the Germans are bidding high figures to secure it for their own consumption, has caused some of the best families in all parts of the United Kingdom to purchase margarine rather than pay such high prices for butter. All the leading wholesale merchants have been seriously pressed since the last advance in butter prices for supplies of margarine, and the supply is inadequate to meet the demand. The cheapest Danish butter has now an average price of 1 s. $9 \mathrm{~d}$. per pound, whereas the best class of wholesome margarine can be obtained at $1 \mathrm{~s}$. 


\title{
THE POULTRY INDUSTRY
}

\section{THE EGG AND POULTRY SITUATION IN CANADA}

\author{
W. A. BROWN, Live Stock Branch, Ottawa.
}

The Egg and Poultry situation in Canada might be summed up in the form of a simple equation. On the one side the fact that Great Britain requires all the surplus eggs and poultry Canada can produce; on the other, the fact that, although Canada has all the facilities for the production of a quantity far in excess of her own requirements, the present magnitude of the industry is but a mere fraction of what it might be if advantage were taken of our present opportunities.

According to the last census, there were almost as many poultry in the state of Iowa, as in the whole of the Dominion of Canada. There is no reason why this record cannot be equalled and even excelled by each or all of the three great Western Provinces, Manitoba, Alberta, and Saskatchewan, to say nothing of the greatly increased production possible in Eastern Canada.

In the Maritime Provinces, Prince Edward Island is the only province that is anywhere near doing its duty in the production of eggs and poultry. Still, with the relatively high prices prevailing, there is no reason why it could not do more. Nova Scotia and New Brunswick both import eggs in quantities, the cities of St. John and Halifax alone securing $50 \%$ and $60 \%$ respectively of their supplies from Prince Edward Island. It is said that the main reason for this limited production is the lack of home grown grain. If so, the remedy is simple.

The Province of Quebec imports eggs from both east and west. The poultry: industry is well developed in the eastern townships, but the whole agricultural region east, west, and south from the city of Quebec fails to supply sufficient eggs for the requirements of that market.

The Province of Ontario is the banner province in the Dominion insofar as the production of eggs and poultry is concerned. According to the last census, over $13,000,000$ of the $29,000,000$ head of poultry in Canada were found in Ontario, and of the $123,000,000$ dozen eggs produced, Ontario produced 58,888,614 dozen.

Ordinarily, a large part of Ontario's surplus goes to supply Montreal and the chief consuming centres of the Province of Quebec. During the past year, however, with increasing production elsewhere, a large part of this surplus has been shipped to Great Britain.

The poultry industry in the Western Provinces is still in its infancy. According to the last census the total poultry population of Manitoba, Saskatchewan and Alberta was only $8,012,634$, as against $13,414,318$ head in the province of Ontario. This number, however, represented an increase over the number in 1900 of nearly $400 \%$, and in the year 1915 , for the first time in the history of the Dominion, fresh-gathered eggs in car lots were shipped from the Western to the Eastern Provinces of the Dominion.

The Western Provinces offer great possibilities for the further development of the poultry industry. It has been amply demonstrated that not only is high summer egg production possible, but if properly housed, tended, and cared for, even the more tender varieties of poultry give profitable returns in the winter season. The Western Provinces, too, have arr asset in the remarkable effect that the long summer days and the wealth of vegetable and insect life have upon the early maturity of the stock. 
British Columbia, although far-famed as being the home of the largest poultry ranches in Canada, still remains an importing province, and much development is required before supply will be equal to demand.

Canada should have a surplus of eggs for export, and except for a period of six years between 1908 and 1913 inclusive, has consistently followed this course. During the time that supply was less than demand, prices ruled high. High prices resulted in increased production, and during the past two years Canada has again been in a position to export.

Great Britain is Canada's logical market for eggs, but under normal conditions Canadian dealers-not having made a special study of the requirements of the British market and suddenly being obliged to find a market for a surplus of several million dozen -would have met with most strenuous competition. The emergency of the hour has, however, given Canada access to the British market in a way and to an extent which, under normal conditions, would have been difficult to obtain.

Fifteen years ago, when Canada was shipping to the British market, Canadian eggs compared favourably in the matter of quality with eggs from other countries. In the interval, however, on account of the strenuous competition they had to meet, marked improvement was made in the quality of the Danish, Irish, Dutch, and other nearby fresh receipts, while in Canada, with such prosperous conditions at hand, it is only recently that any decided improvement has occurred.

To this improvement the educational campaign carried on by the Live Stock Branch of the Dominion Department of Agriculture during the past few years has largely contributed. Some important results have been achieved; the trade in bad eggs has been checked, quality payment has been inaugurated in many parts, and co-operative marketing on the part of the producers encouraged. Tentative standards for eggs have been suggested, and these have been adopted by the trade. These standards provide for three classes for eggs, namely, "Fresh-Gathered," "Storage," and "Cracked and Dirties." In the Fresh-Gathered class, there are four grades:- "Specials," "Extras," "No. 1's," and "No. 2's;" in the Storage class there are three grades, "Extras," "No. 1's," and "No. 2's;" and in the third class, "Cracked and Dirties," there are two grades, "No. 1's" and "No. 2's." For deterioration in transit an allowance of $10 \%$ is made; that is, eggs should grade at point of delivery $90 \%$ of the grade named at the point of shipment.

The various grades are defined as follows:-

Specials-Eggs of uniform size weighing over $24 \mathrm{ozs}$. to the dozen, or over $45 \mathrm{lbs}$. net to the 30 doz. case; absolutely clean, strong and sound in shell; air cell small, not over 3-16 of an inch in depth; white of egg to be firm and clear, and yolk dimly visible; free from blood clots.

Extras-Eggs of good size, weighing at least $24 \mathrm{ozs}$. to the dozen, or $45 \mathrm{lbs}$. net to the $30 \mathrm{doz}$. case; clean; sound in shell; air cell less than $3 / 8$ inch in depth; white of egg to be firm and yolk slightly visible.

No. 1's-Eggs weighing at least 23 ozs. to the dozen, or 45 lbs. net to the 30 doz. case; clean; sound in shell; air cell less than $1 / 2$ inch in depth; white of egg to be reasonably firm; yolk may be quite visible but mobile, not stuck to the shell or seriously out of place; air cell not necessarily stationary.

No. 2's-Eggs clean; sound in shell; may contain weak watery eggs, and eggs with heavy yolks, and all other eggs sound in shell and fit for food.

These regulations have been well received by the produce trade, particularly so in the Western Provinces. Several of the large produce associations have strongly commended the Department for its activities along this line, and have recommended that not only should the standards above mentioned be legalized, but that inspectors should be appointed to supervise the egg trade of the Dominion, particularly the grading of that portion of the product intended for export, in order to insure the term "Canadian Eggs" becoming synonimous with quality in the export markets. 
That the work among producers is also appreciated is evidenced by the observations of an egg circle secretary in one of the older settled portions of the Eastern Provinces:-

"The forming of the Circle has, in my opinion, made the people more careful in the quality of the article offered for sale. Cash sales meet with greater approval than trade or barter. The circle is bound to grow. Our products are meeting with the warmest commendation from the Central Association."

The expansion of the Canadian egg trade.along progressive lines is a matter of the greatest economic importance to the whole country. It is not in the interest of Canadian producers to compete on the British or any other of the world's markets with Russia, Austria-Hungary, Rumania, Egypt, or other countries supplying eggs of only very ordinary quality. If the poultry industry in Canada is to be a profitable undertaking, it is evident that steps must be taken to place Canadian eggs on the British market in such quantities and of such a high quality as will command the highest possible price.

The war is affording Canada an exceptional opportunity, at a most opportune time, to become permanently established on the British market. Every effort should be put forth to take the greatest possible advantage of this opportunity. Each producer, each produce man, each exporter in Canada has a duty to perform, and it is not only necessary to produce more and better eggs this year than before, but also to take such steps as may be necessary to insure that the quality of the eggs exported is such as will provide a fitting advertisement for Canadian eggs when times of strenuous competition again prevail.

\title{
THE PROFIT-MAKING HEN
}

The World's Best Layer-What is the world's egg-laying record? So far as we have authentic records of yield the honour must go to Lady Englantine, a White Leghorn hen owned by the Delaware Agricultural College. She laid 314 eggs in 365 days.

In the British Columbia egg-laying contest, the average number of eggs laid in the year by 240 birds was 165 . In the winning pen the average per bird was 223 . When we consider that the yield per hen on Canadian farms was only 46 (1911 census) a wide field for practical poultry improvement opens up. It is obvious that like the average cow the average hen is a poor and unprofitable producer. The principles that are being applied in milk production must also be applied to egg production. The hen that does not come up to the standard of profitable performance must be rigidly discarded. Write to the Dominion or Provincial Poultryman for information as to "bred-to-lay" poultry. Your time, chicken food, and eggs are all worth money.

In 1911 the poultry and eggs sold off Canadian farms were worth between $\$ 31,000,000$ and $\$ 32,000,000$. It is estimated that the egg production alone in Canada for 1915 was worth $\$ 30,000,000$. This is two and a half times the value of the whole fruit crop of Canada, six times the value of all the sheep, and half the value of all the cattle produced. -W. A. Brown.

\section{IMPROVING ONTARIO'S EGG PRODUCTION}

\author{
PROF. GRAHAM, O.A.C., GuElPH.
}

We chose Barred Rocks for our experimental work simply because our correspondents in the last six years have demanded more Barred Rock stock than all other breeds and varieties put together. The people had them before we started to improve this breed, and they wanted more. It was easier to improve them with the aid of the 
Ontario poultrymen than to start with a new variety. Even before the bred-to-lay bird was produced, Barred Rocks were fairly satisfactory. However, ultimately it is the strain, not the breed, that counts.

Last year we distributed 16,000 eggs, principally through the schools. There will be so many roosters raised that the effect will be felt all over the Province. It is the male that controls the egg-laying characteristics. Mate a rooster from an egg-laying strain to a hen that scarcely lays a dozen a year, and the pullets of the first generation produced will be good layers. Therefore, if we can distribute roosters through the country every spring the improvement in Ontario's egg production will be very marked.

How do we propose to do this? The average District Representative takes 100 dozen eggs to distribute through the schools in his county. These eggs are hatched by the children, who raise the chicks, show the best at the rural fairs, sell the surplus roosters and generally get the whole community interested.

We are establishing breeding stations, where it is possible, in every school section. To accomplish this we get a farmer who is interested in chickens, clean out his old stock, and supply him with eggs. We never let him use his own males, but supply him from the college. We give him three and a half cents apiece for all the eggs he can produce during the first month of the breeding season. The farmer gets a good price for his hatching eggs, besides having the advantage of high-laying hens. The best cockerels are usually bought by us, sorted out, and the choicest ones used.

In this manner we shall be able to produce an enormous number of hatchable eggs each year to supply the whole Province with birds bred for utility, pullets to lay eggs, and cockerels to make a dinner.

\section{QUEBEC'S OPPORTUNITY IN POULTRY RAISING}

\section{A. Jull, Poultry Department, Macdonald College, Que.}

Eggs and dressed poultry are in constant and increasing demand by the consuming public of Quebec. This is partly due to improvement in the quality of the products marketed, which is largely responsible for an increased popularity of eggs. They are received with greater favour and are enjoyed with more relish than heretofore, and of course there is no substitute for such a unique commodity as eggs. An annual increase in the population of the Province and an increase in consumption per capita are responsible for the increased demand. Increased production has not nearly kept pace with the increased demand, with the result that Quebec is importing eggs and poultry in large quantities. The farmers of Iowa, Missouri, Kansas and Ontario are supplying the people of Montreal, Quebec, Sherbrooke and other cities with many of their eggs. The farmers of Quebec thus lose a good share of the profits in their own market.

The farm flock has to supply the market requirements of the people in towns and cities, as well as the farmer's own needs. The cost of living in farm homes would be reduced if more eggs and poultry were used on the table, since these products are produced more cheaply than other farm products. The number of poultry kept on the average farm is surprisingly small, indeed, some farms are not producing enough eggs and poultry for their own use.

To furnish the demand for eggs and poultry due to the increase of city dwellers, the Province imported quantities of eggs as shown hereunder:-

$1913-812,201$ doz. at $19 \mathrm{c}$. per doz., value $\$ 156,740$.

$1914-1,103,118 \mathrm{doz}$. at $25 \mathrm{c}$. per doz., value $\$ 280,429$.

The value of exports of eggs and poultry from Quebec in 1914 amounted to $\$ 396$ for eggs, $\$ 6,113$ for live poultry, and $\$ 17,112$ for dressed poultry, a total of $\$ 23,621$. 
The farmers of Quebec are favoured with one of the best markets on the continent. The average annual wholesale price for eggs in Montreal is slightly higher than in Toronto or Winnipeg, whilst in these three cities the wholesale prices average higher than New York and Chicago markets. For the better quality of poultry produce Montreal offers, in many cases, better prices than any other market on the continent.

Notwithstanding an increased annual importation, there has been a substantial increase in production. In 1901 there were 3,066,304 fowls on the farms of Quebec, and in 1911 there were $4,833,013$. In 1911 , the value of poultry on the farms amounted to $\$ 2,422,568$; the egg products were valued at $\$ 3,812,838$; live poultry at $\$ 662,343$ a total of $\$ 6,897,749$.

The number and value of poultry in Quebec is low compared with Canada as a whole. In 1911 the average number of fowls per farm in Canada was 44.5, while the average number of fowls per farm in Quebec was only 32.3. The number and quality of the stock can be increased considerably and would mean an increased production. In 1911 , the average value, per family, of poultry for all Canada was $\$ 9.84$, while in Quebec it was only $\$ 6.53$.

The most reliable information places the average annual production per hen in Quebec at 50 eggs. This is abnormally low and can be raised to 100 eggs per hen with proper care and management. This increase would almost double the value of the industry, and would more than double the profits of the producers. It takes about 80 eggs to pay for a hen's keep for one year, so that many hens in Quebec are being kept at a loss. Another very significant fact is that over 50 per cent. of the eggs are produced in the months of March, April, May and June, and these are the least profitable months in which to produce eggs. More eggs should be produced between November and March, when prices are highest and profits are greatest.

Notwithstanding existing undesirable conditions relative to poultry production in Quebec, the Province is afforded a great opportunity to become one of the foremost poultry producing provinces of the Dominion. Conditions brought about by the great war have altered the market situation in Canada to such an extent that Quebec is placed in a very advantageous position. The enormous supplies of eggs from Russia and other countries which went to supply a good share of the requirements of the British market have been greatly reduced since August 1914, and Great Britain has looked to the United States and Canada to replace the deficiency. A number of shipments of eggs have been made from Canada, most of these shipments being supplied by Ontario and the Western Provinces. The significant fact in regard to Canadian exportations of eggs is that practically none were obtained in Quebec, although most of the shipments have gone through Quebec shipping points.

\section{SELECTING POULTRY FOR EFFICIENCY}

\section{A. Jull, Poultry Dept., Macdonald College, Quebec.}

A feature of great importance in connection with the poultry industry has been developed as a result of the war. It is that poultry keepers throughout the country must practise greater economy. It is common knowledge that prices of poultry feeds have risen considerably although prices of poultry and eggs have not risen in the same proportion, consequently, it must be admitted that poultry keepers today are not making the profits they were before the war broke out. This condition of affairs will probably last as long as the war lasts and for sometime after. Every economy should be practised. This applies to the feeding of poultry, and along this line I should like to mention two things to which farmers and poultrymen should give greater attention in order to eliminate, as far as possible, all unnecessary expense. 
The first is the selection of the yearling stock. No one should keep birds on hand that are over one year old, except where, under special circumstances, two year-old birds are considered of a special breeding value. The selection of the yearling stock should be very rigid, and everyone should aim to keep over only the birds that will lay well during the winter. Select out the drones and discard them. The late moulters are often the best layers. Keep only birds that are in good health and have plenty of constitutional vigour.

The second point is the selection of the pullets. Usually pullets are more profitable than yearling hens as winter layers, and consequently the farmers should keep the minimum number of yearlings and the maximum number of pullets. At the same time a very careful selection should be practised in culling out late hatched and poorly developed pullets. Early hatched birds are the more profitable, particularly among the general purpose breeds. Select the early hatched birds and mark them with leg bands or by some other means so that when they are placed in the laying pens you will be able to discard all unprofitable birds.

Conditions at present indicate that prices of eggs in future will be good and all poultrymen should endeavour to secure as large an egg production as possible in order to make good profits. The greatest hope of increasing the fresh egg supply during the early months of the winter, lies in the proper handling of the pullets during the growing season. Select your stock for the highest possible efficiency and thus increase your profits.

\section{PROSPECTS FOR POULTRY IN MANITOBA}

\section{F. S. JaCOBS, B.S.A., Professor of Animal Husbandry.}

The market for both live and dressed poultry was a great deal more satisfactory during 1915 than in 1914, and the present outlook is for good poultry prices during the year 1916. The report of the Manitoba Department of Agriculture shows the following figures as to Manitoba's poultry production for market:

Poultry Disposed of by Farmers

\begin{tabular}{|c|c|c|}
\hline & 1915 & 1914 \\
\hline Turkeys. & 154,969 & 184,236 \\
\hline Geese... & - 83,961 & 81,720 \\
\hline Chickens & 881,335 & 815,852 \\
\hline
\end{tabular}

During the late fall and early winter of 1915, Manitoba Agricultural College undertook to receive chickens from the farmers of the province, fatten them according to the best method and market them on a co-operative basis. There is good reason to hope that in the matter of marketing poultry the College and the Department of Agriculture can give considerable assistance.

Professor Herner, head of the Poultry Division at the Manitoba Agricultural College, says: "There was a shortage of eggs and diessed poultry in 1915. I would advise uniform production, distribution of marketing over a longer period of time and improvement of the product through education, organization and co-operation. Many farmers expect high prices for a comparatively inferior product, both in eggs and dressed poultry. Much of the produce is not of the highest order, and the best prices cannot be paid for such products."

With the encouragement now being given to marketing eggs by the egg circle system, it seems certain that the returns from poultry keeping will be considerably improved. 


\section{POULTRY IN WESTERN CANADA}

The British market is bound to require enormous quantities of eggs this year, and Canadian eggs should be the ones to meet this demand.

Thus far the West has produced little more than sufficient to supply its own needs.

Before the West can look forward to competing in the larger markets, we must improve the quality of the poultry products. Improvement can be effected, first, by keeping a better class of poultry on the farms, thereby improving the egg and meat producing qualities. Second, by proper care and management of the farm flocks and by better methods of handling and marketing the outpout. This is what we are seeking to accomplish by educational methods.-M. C. Herner, Poultry Department, Manitoba Agricultural College.

\section{B.C. LAYING CONTEST}

J. R. Terry, Director of Poultry Work for the British Columbia Department of Agriculture, gives the following summary of results obtained in the fourth International Egg-laying contest for the year ending October 22, 1915:

\begin{tabular}{|c|c|}
\hline Duration of contest (months) $\ldots \ldots \ldots \ldots \ldots \ldots \ldots$ & 12 \\
\hline 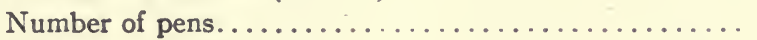 & 40 \\
\hline 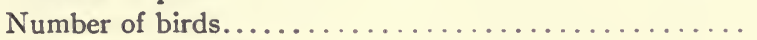 & 240 \\
\hline umber of eggs laid.. & 39,757 \\
\hline 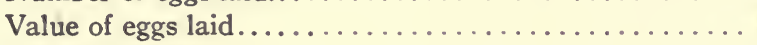 & $\$ 1,076.75$ \\
\hline 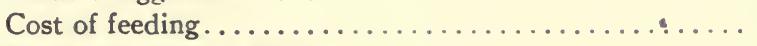 & 527.38 \\
\hline ost of feeding . . . . . . . . . . . . . . & 549.37 \\
\hline ce of eggs per dozen................. & 32.5 \\
\hline eggs................ & 15.9 \\
\hline pen................ & 993.9 \\
\hline bird............... & 165.6 \\
\hline 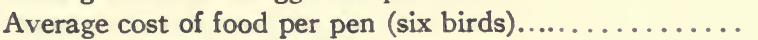 & 13.18 \\
\hline & 2.19 \\
\hline & 13.73 \\
\hline$\ldots \ldots \ldots \ldots \ldots$ & 2.28 \\
\hline one).............. & 1,341 \\
\hline d winning pen (class one) . . . . . . . . . . & 223.5 \\
\hline inning pen (class two).............. & 1,342 \\
\hline erage per bird winning pen (class two)... & 223.6 \\
\hline
\end{tabular}

\section{Shortage of Eggs}

Commenting upon the egg shortage, the London, England, Standard of the 17th of November says:-

"There is a great shortage of eggs, and whatever may be the popular opinion, there has been no increase in home production since the war, despite the fact that our imports of eggs are for the first ten months of this year less by 75,000 tons than those received in the same period of the year before the war. Many people may be keeping poultry who did not do so before the war, but, on the other hand the high price of food stuffs has led to poultry keepers in a large way of business reducing their stocks.

"The hospital demand is another important factor in the situation. I should place the eggs required for the hospitals in the London districts alone at about 250,000 a week, and this demand, which is, of course, not peculiar to London, naturally leads to the diversion of supplies from the ordinary public." 


\section{EGGS ARE DEAR}

To the British housewife to whom eggs and bacon are something of a fetish the price of both articles is becoming an alarming problem-that of the egg more than the bacon. Before the war they preserved an even ratio; and the new laid egg at 4 cents matched the rasher at the same price. But now they have become divorced, for with bacon at 36 cents a pound (and the rasher 6 cents), the new laid egg has soared even beyond that, and some suburban tradesmen in well-to-do neighbourhoods have tried to extract 7 to 8 cents for an alleged new laid egg.

The middle-class British housewife will not pay more than 80 cents a dozen for eggs, and if dealers still try to force the price up they will find that they have lost their market, and, to paraphrase the old saying, their only customers will be the goose that buys the golden eggs.

\section{NOTES}

The rooster is the direct cause of a loss to Missouri farmers and poultry raisers of fully $\$ 3,000,000$ every summer, says an agricultural journal-a loss that could be prevented by the simple expedient of getting rid of the adult male birds as soon as the hatching season is over. It is the fertile egg that spoils in hot weather. An infertile egg will keep for weeks, even when subjected to a high temperature. A general observance of "rooster day" throughout the State is expected to make Missouri eggs sought after in the fancy egg markets of the world, and add millions to the income of poultry raisers. Other states have heard the battle-cry and are arranging similar "rooster" days. 


\title{
SPECIAL CROPS
}

\author{
SUGAR AND THE SUGAR BEET-HONEY- \\ MAPLE PRODUCTS-FLAX-FRUIT AND VEGETABLES.
}

\section{Canadian Sugar Statistics.}

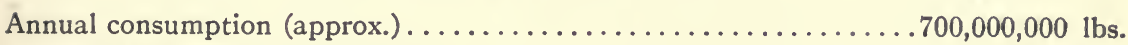

Consumption per capita (approx.)...................... 100 lbs.

Quantity of sugar imported-average of years $1912-13-14 \ldots \ldots \ldots \ldots 643,318,862 \mathrm{lbs}$.

Value of sugar imported-average of years $1912-13-14 \ldots \ldots \ldots \ldots \ldots 16,051,436$

NotE.-Canadian imports of cane sugar come chiefly from the West Indies, including San Domingo, Cuba and the British West Indies; also from British Guiana, Fiji and Peru. San Domingo, the coloured republic; figures largely, while importations from Fiji and Peru are quite important.

Number of beet sugar factories operating in Canada (Berlin and

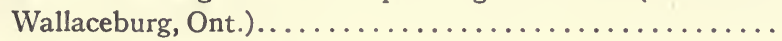

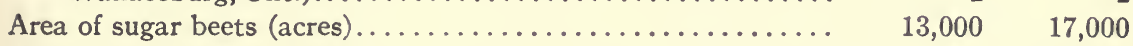

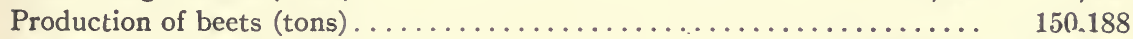

Production of refined sugar (lbs.) . . . . . .

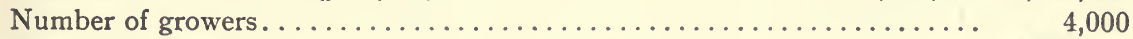

Amount paid growers. . . . . . . . . . . . . . . . . . . . . $\$ 873,150$

Average production per acre (tons) $\ldots \ldots \ldots \ldots \ldots \ldots \ldots \ldots \ldots \ldots \ldots$

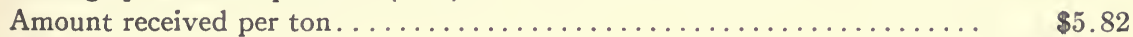

Average received per acre............................. \$52.00

\section{United States Beet Sugar in 1915}

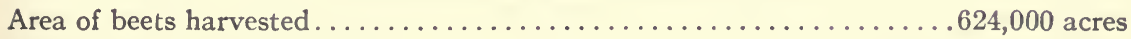

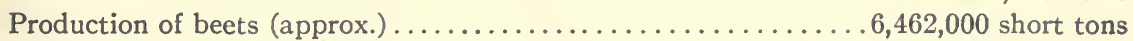
Production of refined sugar .................... 862,800 short tons NOTE-The crop of 1915 was the largest ever harvested.

\section{FROM SUGAR BEET TO WHITE GRANULATED SUGAR}

\section{DR. MiChaEl POTVliet, Sugar Expert from Holland.}

The history of the sugar beet goes back as far as 1747 , when Marggraff tested for the first time the wild growing beets from Southern Germany and Northern Italy. The percentage of sugar found in the pressed beet juice amounted to from 2 to 4 per cent. It took Marggraff many years to improve the quality of the beets by proper selection and at the end of the 18th Century the sugar content was as high as $10 \%$.

Continuing the work of his teacher, Achard in 1801 started to operate the first sugar factory in Kunern, Schlesien, Germany. Every one acquainted with the technical side of beet sugar manufacturing can understand the tremendous difficulties Achard had to fight. The way to sugar manufacturing was open, however, and it took a genius, like Napoleon Bonaparte, Emperor of France, to continue and improve the success of his German neighbour. 
In 1803 England declared war on France and blockaded the coast of the French Empire so thoroughly that France could not import any more sugar from her colonies. Napoleon saw the necessity of home production, and, therefore, induced the French Government to pay large premiums to the farmers and manufacturers, in order to improve and help this new industry. Since then the sugar content in the beets as well as the method of purifying the beet juices in the beet factories improved very rapidly. Sugar beets with from $15 \%$ to $20 \%$ sugar, are very common now, and even as high as $25 \%$ to $28 \%$ sugar in Californian beets is a yearly recurring fact.

The yield of a beet crop differs according to climatical conditions, and the work done in the field. The average for California is 12 tons; Colorado, 11 tons, and for Michigan and Canada 10 tons per acre. As a rule, the more work that is done in the beet field, and with the proper quality of beet seed, the higher the yield. Even in Canada, yields of 18 tons to the acre are not uncommon.

The beet seed proposition is a very important one, especially now during the war. Before the war the price was about $\$ 10.00$ per $100 \mathrm{lbs}$.; if you are able to buy it at present for $\$ 25.00$ and higher, you are lucky. Home-grown beet seed is still very scarce. In Utah, U.S.A., experiments are being made to raise beet seed on a large scale, and apparently with some success. The Dominion Sugar Company is experimenting in this line in the vicinity of Berlin, Ont., and last year was able to raise quite a number of bags of good quality beet seed.

Growing beet seed is rather expensive to start with. Planted with imported beet seed for the first year, the grown beets are very carefully tested, and the beets with the highest sugar selected and separated. After being siloed, these selected beets, stecklings, are planted out in the second year. The seed raised from these mother beets in the second year, is planted out again, the harvested beets are selected and, after siloing again, planted, etc. The seed crop in the fourth year will net about 1,200 lbs. per acre. During the following selection special care is taken not only as to the amount of sugar but also as to the weight of the root. A factory slicing the beets from 8,000 acres would require 100 acres planted for beet seed. This would mean that if the Dominion Sugar Company was going to raise the amount of beet seed necessary for its three factories, (225 tons) 375 acres planted with stecklings would be required. Considering the yearly rotation of crops, from 2,000 to 2,400 acres would be necessary. If the war continues for another year or so, something will have to be done or the sugar industry will be seriously affected.

As to beet sugar vs. cane sugar: there is no difference between a good quality beet sugar and a good quality cane sugar. There is no difference of taste, odor or from any other physical, chemical or technical standpoint, between the two kinds of sugar. The discussion of this question in 1907 led the Agricultural Experimental Station of the University of California to a very interesting experiment. About 2,000 cans containing different kinds of fruit were preserved, half of them with refined cane sugar and half of them with beet sugar. After being stored in a rather unfavourable location for two years the cans were opened. Seven of the cans from the cane sugar lot and six of the cans from the beet sugar lot were spoiled, in all probability due to imperfect sealing. The quality of the fruit in the remaining cans was perfect; not the slightest difference could be noticed in the fruit or in the preserving syrup. This proves, in my opinion, that any argument against the use of beet sugar cannot be taken as serious.

\section{SUGAR, A CANADIAN PRODUCT}

\section{H. HOUSOn, Wallaceburg, Ont., Secretary, Dominion Sugar Co.}

The use of the sugar beet for the production of sugar has during the past 100 years, but more especially during the past 50 years, developed in Europe to such an extent that it is now one of the most important economic factors, employing a large percentage of the population of the European countries. 
Each of the following European countries produces all the sugar that its people consume, and previous to the war, all but four of these countries were exporters of sugar, viz.:-Germany, Russia, Italy, Denmark, Austria, Holland, Norway, Rumania, France, Spain, Sweden, Bulgaria, Serbia. There are over 1,500 sugar refineries located in the above countries, which, before the war, exported over 2,500,000 tons of sugar.

In Canada and the United States the industry has been making very favourable strides, and it is expected that in the coming year sufficient acreage will be sown to beets in the United States to insure a beet root crop sufficient to produce $1,000,000$ tons of refined sugar. The above figures we are sure could easily have been reached in the season just ended had tariff matters been settled earlier in the United States. However, a decision favourable to the beet sugar industry has been made public since, and confidence is again restored. We therefore predict a very heavy increase of the beet sugar production in the United States for many years to come.

For the year 1914 Canada cultivated 13,000 acres of sugar beets, and produced $29,000,000 \mathrm{lbs}$. of refined sugar; for the year just ended we cultivated 17,000 acres of sugar beets and produced $37,000,000 \mathrm{lbs}$. of refined sugar, an increase of over 30 per cent. A much larger increase is anticipated for the coming year. With the large beet sugar refinery that is in the course of erection at Chatham, Ont., which alone will have sufficient capacity to take care of 15,000 acres of beets, it is expected that at least 30,000 acres will be cultivated in Canada. This should indicate a production of at least $70,000,000 \mathrm{lbs}$. of the very finest quality of refined sugar that can be manufactured anywhere.

The progress of the sugar beet industry, which in 100 years' time has outgrown the production of the cane sugar, is largely due to the following causes:-

1st. Intelligent legislation for the home beet sugar industry.

2nd. Scientific culture of the sugar beet, which has doubled the sugar content.

3rd. The failure of science to perceptibly increase the sugar content of cane, or in other words, the sugar cane has a long time since reached the limit of its perfection.

4th. The sugar beet, being a plant that grows in a moderate climate, that is in the most highly civilized portions of the world, has concentrated the efforts of the most scientific investigation and achievement which results in the agricultural improvement of the beet root, as well as in technical invention and scientific discovery, reducing the cost of its manufacture.

Wherever the sugar beet has been grown in Canada, soils have become richer in fertility. There are several reasons for this; the two main causes are, that to successfully produce sugar beets, the soil must not only be put in fine tilth, but must be cultivated during a portion of the growing period, and this further work has nearly as much effect on the succeeding crop as it has on the beet crop. The second reason is that, as a rule, the roots of crops reach only as deep as the land is ploughed, the soil underneath being hard and infertile. With the introduction of the beet, it is necessary to gradually prepare and plough the soil a little deeper, so that the aerated part of the soil gradually gets from the conventional six or seven inches, to from ten to twelve inches, thus gaining a soil that is well aerated and full of humus to a greater depth than heretofore, and creating chance for the development of bacterial life, which seems, according to our latest researches, to be the indisputable medium for healthy and thrifty plant growth. The changes thus created in the soil are also the main reasons why the sugar beet as a rotative crop has so greatly increased the production of other soil crops per acre.

The best teacher in the world is Experience, and since we have now grown sugar beets in Canada for the past fourteen years on a commercial basis, most growers are familiar with the routine work which the cultivation of the crop demands. Each spring the Dominion Sugar Company circularizes all growers, giving them full instructions as to the proper cultivation of the crop, and most of the old growers are just as familiar with methods as we are, and work jointly with us to obtain the highest results the sugar beet can give, both in a direct financial way and also as a soil improver. 
The most important feature of the beet sugar industry in Canada to-day is the fact that we are absolutely independent of foreign countries, as it has been demonstrated that the seed can be grown in Canada to equal advantage.

The production of seed is of necessity an essential part of the industry, and the growing of it demands extraordinary care. A large amount of work and scientific study of the root is necessary. The Dominion Sugar Company has a seed farm located in Western Ontario, and has been experimenting with the growing of sugar beet seed for the past five years, with very fair success. The results obtained from the home grown seed have been quite as satisfactory as those obtained from the imported seed. The cost, which is practically all attributable to labour, has been greater owing to the fact that we have a much higher wage scale here than in Germany.

Canadian consumers are now alive to the "Made in Canada" spirit, and as the refined sugar from beets is made every bit in Canada, direct from the soil, there is no good reason why it should not have the preference in all Canadian homes. We are glad to be able to state that it is securing the preference.

Refined sugars, whether they are manufactured from the beet or the cane, are identical. Sugar is sugar no matter from whence it is derived, provided it is manuiantured properly. No chemist in the world can detect the difference-therefore, our own home-made Canadian sugar is equal to any that the world produces.

Note By EDITOR-The Dominion Sugar Co. has two factories or refineries; one at Waliaceburg, Kent County, and the other at Berlin, Waterloo Co. A third is being erected at Chatham. It is worthy of note that this company, which was the only company handling Canadian-grown sugar in 1915, paid the Ontario farmers last year $\$ 75,000$ as bonus over and above contract agreements.

\section{SUGAR PRODUCTION AND CONSUMPTION}

The following table, prepared by William J. Showalter, assistant editor of the National Geographic Magazine, shows' the production, exportation, importation, and total and per capita consumption of sugar in the leading countries of the world.

\begin{tabular}{|c|c|c|c|c|c|}
\hline Country & $\begin{array}{l}\text { Production } \\
\text { (Pounds) }\end{array}$ & $\begin{array}{l}\text { Exports } \\
\text { (Pounds) }\end{array}$ & $\begin{array}{l}\text { Imports } \\
\text { (Pounds) }\end{array}$ & $\begin{array}{l}\text { Total } \\
\text { Consumption } \\
\text { (Pounds) }\end{array}$ & $\begin{array}{l}\text { Per Capita } \\
\text { Con- } \\
\text { sumption } \\
\text { (Pounds) }\end{array}$ \\
\hline Canada........ & $26,880,000$ & & $651,000,000$ & $677,880,000$ & 94.1 \\
\hline United Kingdom & $\ldots \ldots \ldots \ldots$ & & $3,693,000,000$ & $3,693,000,000$ & 80.8 \\
\hline France......... & $1,904,000,000$ & $373,000,000$ & $672,000,003$ & $2,203,000,000$ & 55.8 \\
\hline Germany...... & $5,945,000,000$ & $953,000,000$ & & $4,992,000,000$ & 76.9 \\
\hline Denmark...... & $298,000,000$ & & $31,000,000$ & $329,000,000$ & 118.7 \\
\hline Norway....... . & $\ldots \ldots \ldots \ldots$ & & $99,000,000$ & $99,000,000$ & 43.0 \\
\hline Sweden........ & $291,300,000$ & & & $291,300,000$ & 53.3 \\
\hline Russia.... . . . . & $2,687,000,000$ & $830,000,000$ & & $1,857,000,000$ & 10.9 \\
\hline Austria-Hungary & $4,185,0 \mathrm{C} 0,000$ & $1,540,000,000$ & $\ldots \ldots \ldots \ldots$ & $2,645,000,000$ & 52.9 \\
\hline Italy.......... & $470,500,000$ & $\ldots \ldots \ldots$ & $16,000,000$ & $486,500,000$ & 13.8 \\
\hline Turkey........ & $\ldots \ldots \ldots \ldots$ & & $445,000,000$ & $445,000,000$ & 20.9 \\
\hline Japan (including & & & & & \\
\hline Formosa)... & $313,500,000$ & & $303,000,000$ & $616,500,000$ & 2.03 \\
\hline Spain.......... & $291,200,000$ & & $\ldots \ldots \ldots \ldots$ & $291,200,000$ & 14.9 \\
\hline Argentina...... & $324,500,000$ & $\ldots \ldots \ldots \ldots$ & $67,000,000$ & $391,500,000$ & 43.5 \\
\hline Brazil......... & $456,500,000$ & $10,000,000$ & & $446,500,000$ & 18.6 \\
\hline United States... & $3,764,202,826$ & $66,569,033$ & $4,536,843,342$ & $8,234,477,235$ & 85.04 \\
\hline Australia...... & $445,600,000$ & ........ & $220,000,000$ & $665,600,000$ & 151.1 \\
\hline
\end{tabular}




\section{HONEY PRODUCTION}

\section{F. W. L. SLADEN, Apiarist, Dominion Experimental Farms}

The statistics of honey production on farms during the year 1910, given in the Fifth Census of Canada, amount to 713,250 pounds for the whole of Canada. Following is the production in pounds by provinces:

Ontario, 516,658; Quebec, 169,507; Manitoba, 8,958; British Columbia, 6,460; New Brunswick, 6,004; Nova Scotia, 3,857; Alberta, 931; Saskatchewan, 520; Prince Edward Island, 355.

These figures, however, are much below the actual production of honey in Canada, and this in turn is only a small fraction of what could be produced. Honey in paying quantities may be obtained over the greater part of this vast country, and thousands of tons are going to waste annually for want of bees to gather them.

With the reduction in the young manhood of the country during the war, our occupations should be productive and profitable in the highest degree. Bee-keeping is such an occupation if the bees are well managed, and are kept in a place where, within one or two miles of the apiary, the principal honey producing plants are plentiful. Chief among these, in the farming sections, are white Dutch clover and alsike clover, and, in the timber lands, willow herb or fireweed (Epilobium angustifolium), which often springs up in abundance after forest fires. The honey from alsike and white clover, and also that from fireweed, is of the best quality, being light in colour and mild in flavour. Such honey is worth from 10 to $111 / 2$ cents per pound wholesale in Ontario. As the outlay and working expenses in bee-keeping are small, it pays well to obtain eighty pounds or so of honey per colony in an average season. This amount can be obtained from clover and other sources in most farming sections in Eastern Canada with proper management of the bees, and places may be selected where 100 pounds or more can be got. The expert apiarist needs to examine his bees only once a week during the active season, and can thus easily keep as many as 200 colonies without help. Bee-keeping, however, is an occupation that has to be learned.

Many bee-keepers are not giving their bees proper attention, and the adoption of progressive and systematic methods by all would enormously increase the output of honey and add considerably to the wealth of the country. A somewhat careful estimate of the number of bee-keepers in Ontario has been made by Mr. Morley Pettit, Provincial Apiarist, and he considers that there are about 10,000 in this province alone. Those bee-keepers who are succeeding would find it highly profitable to increase their stock by breeding or purchasing bees, especially queens, and, if the neighbourhood of the home apiary is already well stocked, to establish an out-apiary in a place not less than two or three miles from the home apiary where the above-mentioned plants are plentiful.

Weather, especially during the period of honey flow, very largely affects the yield of honey, as it also does most farm crops. In a season that is very wet or cold, or very dry, the honey crop may be a failure, but such years are rare, especially in the interior of Canada. In a good year heavy yields may be got in favourable localities by experienced men. Taking one year with another, in a favourable locality as large an annual income may be obtained from bee-keeping as from any branch of farming. For keeping an apiary, it is not necessary to occupy more than an acre or so of land, and half an acre often proves sufficient.

It is usually more profitable to produce extracted-honey than comb-honey, because about double the amount of honey is thus obtained and less skill is required, and the demand for comb-honey, which is a luxury, is limited. Under present conditions the advantages of extracted-honey production over comb-honey production are becoming greater. A popular retail package for extracted-honey is the tin pail in sizes holding $21 / 2$ pounds, 5 pounds and 10 pounds of honey. Economical considerations should tend to develop the demand for this package at the expense of the various styles of glass jars which, though they show the honey well, hold less and cost more for the 
receptacle in proportion to the value of the honey it contains. It cannot be too widely known that honey can be kept without deterioration for months, or from year to year if necessary, if stored in a dry place. The producer is, therefore, not compelled to part with his crop immediately, as in the case of perishable produce.

Prices for honey in Canada are as high as, or higher than, in nearly all countries that take Canadian produce; consequently, practically no Canadian honey is exported. It may here be remarked, however, that the members of the Ontario Bee-keepers' Association have generously presented to our soldiers in France a considerable quantity of Canadian honey which has been highly appreciated. Honey has also been supplied by the Germans to their troops in the field, and, being a valuable fuel-food which is much relished, it makes a very satisfactory ration.

To keep up and improve the home demand for honey in competition with imported and inferior sweets, such as cheap molasses and corn syrup, it is essential that the supply should be large and increasing so that Canadian honey may be extensively displayed for sale, causing its superior merits to be more widely known. At present the greater part of the season's supply is sold soon after the crop is harvested, but it might well be produced in larger quaniities, so that it could. be displayed in the stores in quantity and sold steadily until spring. The industry cannot be said to be well developed until not only this has been done, but an export trade has been established. Extensive producers of honey sometimes deprecate attempts to increase the number of bee-keepers in Canada for fear of over-production, but the lack of foundation for this fear is shown by the fact that they usually sell their honey quickly at a satisfactory price. Over-stocking a neighbourhood with bees has occurred in a few instances, but apiaries are unevenly distributed, and for one over-stocked neighbourhood there are thousands of first-rate locations that are without bees.

The price of honey in 1915 has averaged a little lower than in 1914. This drop in price has been brought about more by sympathy with the lowered American market and the reduced buying power of the people than by an abundant supply, the crop having been about an average one in the chief producing centres. However, the prices are very firm, the good grain harvest in the west having helped to steady them. The slight fall from the high price of 1914 is not discouraging, and will have its influence in making Canadian honey more of a staple.

Bee-keeping is a very healthful occupation, involving outdoor exercise in fine and warm weather only-most of it in no sense laborious. Soldiers returning home in broken health or paftially disabled will find it a restorative and profitable vocation, but those who have no knowledge of the business should not embark on it extensively until experience has been gained. After the war many who formerly spent their lives in offices or stores, having learned the benefits of fresh air, will respond to the cry of "back to the land" and, doubtless, some will take up bee-keeping.

\section{THE MAPLE SUGAR INDUSTRY}

\section{JOS. H. LEFEBVRE, Waterloo, Que., Secy., Maple Sugar and Syrup Association}

The maple sugar and syrup industry of Canada has shown a marked falling off in production during the last twenty years. This was due to several causes, but chiefly to the variability in the quality of the product, the difficulty in obtaining a pure unadulterated article, and the lack of organization for marketing the output. The low prices realized led, in some cases, to the cutting down of groves and the abandonment of the industry.

The Province of Quebec makes a specialty of this industry. The output of that province in 1910, according to the Census, was 9,427,694 pounds of sugar and 984,282 gallons of syrup, valued at $\$ 1,680,000$; while the Ontario output was valued at $\$ 831,480$. 
The first steps looking towards improvement in conditions in Quebec were taken in 1913, with the organization of the Maple Sugar and Syrup Co-operative Association of Waterloo, Quebec. This was followed by a Dominion Act to prevent the adulteration of maple sugar and syrup or the marketing of any substitute therefor under the term "maple."

It was estimated that not more than fifteen per cent. of the producers were good sugar makers. To instruct growers in improved methods of manufacture, four sugarmaking schools were opened on farms in different parts of Quebec. At these schools anyone desiring to learn the art of making fine maple goods may obtain free instruction. These schools, while under the direction of the provincial agricultural department, are financed through federal grants provided under the Agricultural Instruction Act, and information as to their work will be found in the report on this Act issued by the Department of Agriculture, Ottawa.

The Association referred to has made arrangements for the marketing of its products and those of other similar organizations in the Province, by the Quebec Cheese-Makers' Co-operative Association of Montreal. These efforts are expected to result in improved quality, greater profit to the farmers and an increased output, so far as Quebec is concerned. Doubtless similar action in Ontario and the Maritime Provinces would lead to similar results. For such action the time would appear to be opportune. Not only is the home market capable of great development, but the removal of the United States duty should lead to a greatly increased export demand.

\section{PROSPECTS OF THE MAPLE INDUSTRY}

The outlook for the maple syrup and sugar market was never brighter than this year. Last season's harvest was so small that the stock has been completely cleared out. High prices have prevailed and are practically certain to continue this year, however great the production. The United States duty on syrup and sugar is to come off on May 1st, thus opening to our makers the greatest market in the world for their products. The demand from England and France during the past year was considerable.

- "The Journal of Agriculture."

\section{SUGAR FOR SOLDIERS}

"The chief pride of the Italian Bersaglieri is their marching powers. During the war between Russia and Japan the distances covered by the infantry of the latter Power were regarded as almost incredible, and it was asserted in several quarters that no European troops could vie with them in powers of endurance. The Italian Light Infantry accepted the implied challenge, and speedily showed that not only could they cover the same amount of ground with comparative ease, but that they could go one better and yet finish fresh. They give rather a curious explanation of their powersthat when the men are marching they are supplied with a large amount of ordinary loaf sugar, which sustains them better than anything else could do, and at the same time does not need a halt to be called for them to consume it. During the manceuvres of the French army some four or five years ago the commanding officer of one of the foot regiments decided to carry out a similar experience with his men, and received the necessary permission from his superiors. He had them paraded early one morning, served them with a substantial ration of sugar, not a little to their surprise, and sent them off on their way. The result was extraordinary. Examination showed that they had covered a greater distance, with fewer mishaps, than had previously been accomplished in the same time by any French troops on the march. Therefore sugar now forms a very important part of the dietary of the French army. 


\section{THE FLAX SHORTAGE}

\section{James A. McCracken, Sećretary, The Canadian Flax Growers' Assn.,}

St. Mary's, Ont.

A call for flax straw in baled form has come from Belfast and Dundee flax-spinning companies. They have actually tried to buy great quantities of green flax straw in Ontario with the intention of transporting it across the Atlantic and extracting the fibre. For every ten tons of such straw they would get only about one ton of usable fibre. The cost of transportation alone would amount to several times the normal price of the fibre.

We do not export wheat in the sheaf, why should we export flax straw in bulk?

The flax stringency, which arises chiefly from the fact that Russia's flax production is reduced by $40 \%$ and Belgium flax cannot be had, is aggravated by the high rates of transport. The second factor is little less potent than the first in creating a demand for more flax.

As a result of the shortage Irish flaxes have risen in price to between $\$ 700$ and $\$ 850$ a ton, and Canadian fibre to about $\$ 450$ a ton-these figures being double those obtaining in pre-war times. Though all grades of flax are eagerly picked up, the most crying need is for the finer grades, largely because the ability to substitute jute and hemp for flax decreases as the spinning material advances in quality and purpose.

Need of more Exports-Though the Empire in this hour can do without flax better than without bread, we face the fact that there are several nations (e.g. Argentina and the United States) outside the zone of warfare which are ready and able to increase the production of wheat, while there is none, except Canada and Japan (both in a limited degree), ready to increase the supply of flax fibre for spinning. Neither Canada nor Japan, it may be stated, ordinarily exports enough flax fibre to be placed in international trade statistics.

Canada can do a good deal more in this direction than she is doing. "The urgency grows stronger when we appreciate that every acre of flax devoted to fibre purposes means from $\$ 75$ to $\$ 100$ in exports. Whatever flax we export gces mainly to the New England mills and to Ireland, thereby assisting in restoring our trade balance and relieving, directly or indirectly, the needs of the hour.

Cultural Practices in Canada-Wherever the usual Canadian practice of farming is followed, it is customary for the flax grower to work in co-operation with a flax mill. About 25 of these mills (several reopened) are now bargaining for land rentals in S.W. Ontario. It is usual for the millman to rent fields from the farmers in the district at from $\$ 10$ to $\$ 14$ an acre. The farmer tills the land, and in some cases hauls in the crop. The farmer undertakes the tasks of sowing, weeding and harvesting. Though the custom hitherto has been to restrict rentals to distances within team-haul of the mill, there is a growing tendency for mill men to buy flax or rent land at points upwards of fifty miles, and transport the flax in baled form by rail to the central mill. For such straw delivered at a siding, from $\$ 13$ to $\$ 15$ a ton, seed on, is paid.

Various considerations, purely agricultural, sometimes make flax the best crop a farmer can sow. Some of these factors are:

1. The presence of wire worm. (Flax immune to the pest.)

2. Excessively rich soil. (Too rank for grain.)

3. Unevenness of soil surface. (New breaking stump-strewn.)

4. Shortage of labour. (Indians or other outsiders harvest the crop.)

5. The need of a longer rotation.

6. Need of early cash returns.

How to Cultivate-In Southern Canada flax does well on fertile loams and clays when deep-ploughed,'underdrained and well pulverized. The seed is sown broadcast by hand or with a flax drill, usually at the rate of $84 \mathrm{lbs}$. of (90\% germinating) seed to 
the acre. Blue Blossom Dutch Child or White Blossom Dutch Child gives the best results. White Blossom yields several bushels more seed, grows several inches longer and matures about two weeks later than Blue Blossom. Pulling takes place when for about 6 inches up from the root the stem leaves have withered away. The importance of timely harvesting is so great and this year's outlook for harvesting help so uncertain that Canadian flax growers are keyed to the need of a pulling machine. Some sort of contest, in which half a dozen makes of machines are likely to compete, will probably be arranged for this harvest time. The most satisfactory machine yet produced pulls and binds about 4 acres of flax a day, thus doing the work of a dozen men. Other alternatives in times of labour shortage are the common mower and selfbinder.

The Fibre of Seed Flax-To turn to account in the fibre market the vast quantities of seed flax straw produced in the Western provinces, the methods of cultivation need to be changed. Heavier sowing than the customary half-bushel per acre would improve the quality of the straw, and probably yield more seed as well. A sowing at the rate of from $40 \mathrm{lbs}$. to $50 \mathrm{lbs}$. per acre, especially on new lands, is suggested if growers aim to dispose of the fibre. Earlier harvesting, closer shoring, and more careful threshing of such flax would be required to make the fibre at all suitable for coarse yarns. Elaborate attempts to use the ordinary straw for making satisfactory binder twine have so far failed, in a commercial sense. The fault seems to have been in poor straw. Linen rugs, however, are being successfully made from the better grades of flax straw obtained from seed flax in the North-western States, and great quantities of such straw go to tow mills and insulation-board factories in those States.

The chief obstacle to using our Western flax straw in the present emergency lies in its distance from available textile markets. Without radical departures in cultivation and handling, cheaper transportation, and large plants for preparing the flax, it does not seem feasible for us to place Western flax straw or its fibre on the European market.

Over 30,000,000 bushels of flax seed are consumed in North American oil mills annually in the manufacture of linseed oil, oil cake, etc. The demand is increasing. During 1915, 13,000,000 bushels of seed were imported from Argentina, and the price in Winnipeg went to two dollars a bushel.

Statistics
Fibre acreage in Ontario- $1913-2,500$ acres
$1914-1,400$ acres
$1915-4,000$ acres
$1916-5,500$ acres (estimated)
Fibre production in Russia- $1913-600,000$ tons
$1914-324,000$ tons
$1915-487,000$ tons

Average annual export of fibre from Russia (1911-1913)-288,133 tons

Fibre available for export from Russia (1915) - 140,000 tons

\section{PRODUCTION OF FLAX IN ONTARIO}

According to information furnished by Mr. James A. McCracken, Secretary, Canadian Flax Growers, the area under flax grown for fibre in southern Ontario during 1915 was about 4,000 acres. From this area the production of flax fibre was about 800 tons, which at the average price of approximately 20 cents per lb., or $\$ 400$ per ton, was of the total value of $\$ 320,000$. In addition, 80 tons of tow at $\$ 35$ per ton realised $\$ 2,800$. The same crop also produced seed at the average rate of nearly 12 bushels per acre, or a total yield of 48,000 bushels, the value of which at the 
average rate of $\$ 1.60$ per bushel, was $\$ 76,800$. About 30 per cent. of the total production of fibre is shipped to Ireland, the rest being exported to New England States.

Under the straight rental system, the farmer always performs the cultivation, and in some cases hauls in the crop when harvested. The mill operator arranges for the seeding, weeding and harvesting. The mills manufacture the retted straw into flax fibre ready for the hackles of the spinner. Retting in Canada has heretofore been done almost exclusively by the dew retting or meadow system.

"I look to see a large increase in the acreage of flax as well as sugar beets and beans. Flax is no harder on the land than an ordinary grain crop, but it must be used in rotation, the same as any other crop."

-Prof. C. A. Zavitz.

\section{Flax Investigations in Great Britain}

The British Flax and Hemp Growers' Society, Ltd., has just published its first report. This society was formed to administer a grant from the development fund for the purpose of conducting experiments in the cultivation and separation of flax and hemp in order to ascertain the commercial possibilities of these industries in Great Britain.

A hopeful view is taken of the prospects of the enterprise, more particularly in view of the great prominence which the products of flax and hemp have received as a result of the war.

Bulletin No. 669 of the United States Department of Agriculture, entitled "Fibre Flax," by F.C. Miles, was reprinted in No. 12, Vol. 5, of the Bulletin of Foreign Agricultural Intelligence, issued by the Department of Agriculture, Ottawa.

\section{FLAXSEED OR LINSEED}

Linseed, the seed of the flax plant, yields a drying oil which is used in the manufacture of paints, varnishes and linoleum.

The following table shows the source of the imports of linseed to the United Kingdom in 1913 and 1914:

\begin{tabular}{|c|c|c|}
\hline From & $\begin{array}{c}1913 \\
\text { Quarters }\end{array}$ & $\begin{array}{c}1914 \\
\text { Quarters }\end{array}$ \\
\hline India.................... & 682,948 & $1,108,430$ \\
\hline 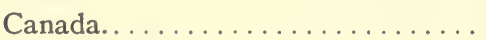 & $1,277,673$ & 113,372 \\
\hline Other British............... & 413 & 367 \\
\hline Total British.............. & $1,961,034$ & $1,222,169$ \\
\hline 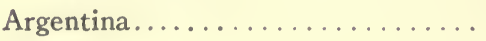 & $1,126,866$ & $1,027,617$ \\
\hline Russia................... & 99,247 & 114,278 \\
\hline United States. . . . . . . . . . . . . & 42,936 & 12,339 \\
\hline 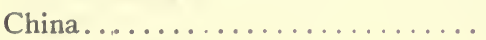 & 7,709 & 5,404 \\
\hline Netherlands.................. & 13,587 & 14,285 \\
\hline 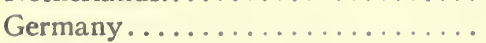 & 9,652 & 616 \\
\hline Belgium.................... & 5,325 & 11,750 \\
\hline Morocco.................. & 1,538 & 17,424 \\
\hline Other Foreign $\ldots \ldots \ldots \ldots \ldots \ldots$ & 6,168 & 25,896 \\
\hline m & 4,062 & $2,451,778$ \\
\hline
\end{tabular}




\section{IMPORTS AND EXPORTS OF FLAXSEED}

\begin{tabular}{ccccccc} 
Countries & \multicolumn{3}{c}{ Imports } & \multicolumn{3}{c}{ Exports } \\
& Months & 1914 & 1913 & Months & 1914 & 1913 \\
& 1915 & & & 1915 & & \\
& Bushels & Bushels & Bushels & Bushels & Bushels & Bushels
\end{tabular}

Great Britain and

Ireland...... 13,521,000 18,213,000 24,321,000

United States.... 11,688,000 9,247,000 $6,580,000$

Canada........ 77,000

$0 \quad 5,000$

$\begin{array}{rrr}0 & 0 & 0 \\ 5,000 & 24,000 & 283,000 \\ 1,322,000 & 7,953,000 & 22,949,000\end{array}$

The quantity of oil obtained from a bushel of flax seed varies from 14 to $19 \mathrm{lbs}$., according to the quality and cleanness of the seed.

For the year ending March 31, 1914, Canada imported 293,512 lbs. of Linseed Oil, valued at $\$ 25,705$.

\section{Germany NeEds Fats}

Germany could not exist without fats; no country can, least of all a country at war. Glycerine is derived from fats, and explosives largely from glycerine.

British gentlemanliness has been permitting tremendous quantities of fat to enter Germany by the smugglers way from neutral countries, and even from our own Empire!

"That must not happen again!" says Mr. E. S. Grew writing in the London Graphic. "Several other kinds of supplies which have been carried in British ships, and have leaked through neutral countries to Germany, will also not happen again. For the whole range of vegetable fats grow outside Germany, and for the most part must cross the North Sea to get to her. Apart from tallow and a small quantity of linseed, Germany produces no other fat. Imagine, then, with what greed she ponders on the oils and fats which come from the colonies she has lost and by the ocean highways from which her ships are shut off. Cocoanut, or copra, cocoanut oil, palm oil, palm-kernel oil (a rising Germany industry that was), other oleaginous seeds and kernels, linseed oil, soya bean (for cattle food and oil), olive oil, sesame seed and moura seed-here are riches which, properly prized, would yield Germany all the fats she wants. From linseed oil can be obtained glycerine, and from glycerine can be got nitroglycerine, food for the guns as well as for the men behind them. Lard, too, will give glycerine, though we cannot imagine that Germany's fat-hunger would yield this precious stuff even for that purpose. She wants fat to eat; and that is the real reason why the linseed oil, the oil seed, the oleaginous nuts and kernels, the cocoa-nut oil and the cotton-seed oil-all of which left this country in double, or even treble, the normal quantity during the first year of war-must be decisively shut off from Germany and put out of her reach."

Copra, dried cocoanut kernel, is rich in glycerine and fats, and makes a food for mortals, and in its waste-products a ration for pigs. Germany has still 20,000,000 pigs left out of her usual $50,000,000$.

-From "Montreal Herald."

\section{FRUIT PRODUCTION DURING THE WAR}

\section{F. H. Grindley, Fruits Branch, Dept. of Agriculture, Ottawa.}

After eighteen months of war in which men and money have been almost incalculably sacrificed, in which homes have been destroyed and the wheels of commerce and 
industry put to the most supreme tests, we cannot yet see the end nor predict its duration. We only know that Great Britain and her Allies are steadfast in their determination to continue the sacrifice, to fight to a successful end regardless of the cost. Under such conditions what message can we give to the fruit producers that will be helpful to them? Only one, and that one seems both timely and necessary. Do not be disheartened. Do not abandon the methods you have adopted during a progressive decade in the belief that so long as the war continues there is little likelihood that any demand will exist for your product.

Has there in the past season been any indication of a falling off in the demand. for strictly high class fruit? We think not. But there has been a falling off in the quality of fruit which Canadian growers have put upon the home and British markets.

We in the Fruit Branch are not directly concerned with production, but in our endeavour to develop the commerical end of the fruit industry, we must have the support and co-operation of the growers; and so we feel it necessary to assure them that we believe the demand for 'strictly high class fruit will continue and not be affected by the Empire's struggle.

What has caused the falling off in the quality of Canadian fruit? Simply the fact that many growers have abandoned the thorough care of their orchards pending the arrival of what they believe will be more prosperous times. Efficient cultivation and careful spraying have not been as consistently carried on during the past year as formerly. The result is that in the season now closing at least $75 \%$ of the apple crop was too seriously affected with scab to grade No. 1, and No. 3 fruit has been a drug upon the market.

It must be apparent that if our work in this Branch is to meet with the success we hope for, if methods of distribution and marketing are to be perfected, then the quality of the fruit must also approach perfection-and quality rests with the growers.

Quite apart from that, however, it seems obvious that any grower who hopes to economize temporarily by allowing his spraying machines and orchard implements to be idle, will be the ultimate loser, for when times become more prosperous and he considers it safe to again adopt the methods he has neglected, he will have to combat the accumulated strength of insects and fungus diseases, and it will probably be years before his orchard will be again free of these pests.

Reports from our Canadian markets during the past few months, and from the markets of Great Britain, show that prices for No. 1 fruit of all varieties have been excellent. There has, however, been so much fruit of poor quality placed before the public that, in some cases, it had to be withdrawn on account of the poor prices offered.

There is no reason why the Canadian growers should not produce fruit equal in quality to that grown in any part of the world. That has already been proven at the Panama Pacific International Exhibition now closing at San Francisco. From all sources comes the undeniable report that the Canadian fruit exhibit not only equalled but surpassed that from any other section.

And so we send this message to the growers, not as a complaint but because it is timely advice. We realize that it does not apply to all growers. There are many who have continued their thorough methods and realize now that they have done right. But we feel that if Canadian fruit growers will join hands in an effort to keep up the reputation which their product has heretofore gained for itself, they will have years of prosperity, with the added compensation of knowing that they are doing their share towards a common end-the sustenance of an Empire fighting for its existence.

\section{FRUIT LOSSES FROM INSECTS IN ONTARIO}

As a rule the great mass of people who have small orchards seldom get anything worth speaking of for their fruit. This is as much because they do not know how to sell it, even if it were clean, as because of insect injuries. Three years ago I passed 
through the county of Oxford, when there were at least ten thousand barrels of good fruit lying on the ground. This was because the people did not know how to reach the markets with it, and there were no buyers sufficiently interested to think it worth while to purchase it.

The great mass of our best fruit is put on the market by men who are spraying their orchards, cultivating and giving them the necessary care. In these orchards, in many cases, not more than 5 per cent. of the apples are injured by insects. I know of many an orchard in Ontario where the insect injury is not even 5 per cent.

The probability is that in unsprayed orchards, taking the Province as a whole, 50 per cent. of the fruit would be rendered culls by insects. There are, of course, a number of orchards that are sprayed and in which the insects are not at all satisfactorily controlled, because the owners do not know how to spray thoroughly and do not take the necessary pains to learn how. Such orchards might be classed among the unsprayed.

Fruit is made unsaleable both by insects and by disease; in fact, Apple Scab is probably a much greater foe to the apple grower than any of our insects, that is, taking the Province as a whole.-L. Caesar, in the "Canadian Horticulturist."

\section{BEANS}

\section{J. O. LAIRD, BLENHEIM}

The fact that beans have been a good price for a number of years, and also that they are of very great food value, should encourage every person who can to grow as large a crop as possible this coming season.

Beans have been most extensively grown in a loamy soil, but of late years it has been found that they will do well even on a fairly heavy clay soil, providing the land is well drained. The heavier land that is intended for beans should be fall ploughed, but land that is of a more loamy nature is as well not ploughed until spring. Sod land with a coating of ten or twelve loads of farmyard manure has been most frequently used for beans. The use of manure just before the bean crop may, however, continue or produce a disease, and, if so, some other system should be practised.

Bean ground that has been fall ploughed should be kept in a fine state of tilth during April and May, in order to kill as many weeds as possible and to retain the soil moisture. If ploughed in the spring, the land should be rolled soon after ploughing, then disked and harrowed, and kept in good condition until planting. The seed should be even in size and free from disease. The amount used is from three pecks to one bushel per acre. The planting may take place between May 28 and June 15. The ground is usually rolled before planting, and the seed planted with the ordinary grain drill, letting only three tubes run on an eleven-tube drill, making the rows 28 inches apart.

The Pea Bean is the standard variety and commands the most uniform price. There are a number of fancy varieties grown, such as the Yellow Eye, Turtle Soup, and Marrow Fat.

Cultivation of the bean crop is, of course, very important. It is a good practice to harrow the beans before they are up. Beans germinate quickly and, under favourable conditions, will be up in four or five days. The weeder is often used before they are large enough to cultivate. Whether the weeder is used or not, the shields on the two horse cultivator should be raised just slightly off the ground, so that the earth will cover any small weeds near the plants. The beans shculd be cultivated atout every ten days, or after each rain. When the blcssorrs come out it is best to cease cultivation, as the cultivator will knock off a great many blossoms. If the cultivation has been thorough, not much hand hoeing will be required.

Beans are usually ripe the first or second week of September. A bean-pulling attachment can be placed on the two-horse cultivator which will cut two rows at once. 
The knives are placed V-shaped, and so put two rows into one. After pulling they are bunched up by hand in some cases, but more frequently a side delivery rake is used. This will rake three or four rows into one. The beans are left to dry for a few days and then turned over, and after another day's drying they are usually ready to take into the barn. A great deal depends on the weather. If the weather is wet, the only way to save the crop is to turn them often, as care must be taken not to draw them in when damp. Each sling load should be mowed when it is put into the mow. It is a good plan to place a big pole across the mow, so that the sling load will drop on it and be broken up, thus making it much easier to mow away.

As soon as the beans are harvested, it requires but a small amount of work to make the land ready for fall wheat.

As a rule, the yield varies greatly, some yields being as high as 35 bushels an acre and others as low as 12 bushels. The threshing is not done with an ordinary threshing machine, but with a machine specially constructed, having two cylinders, a slowmoving one and one that runs quickly. The bean straw is very good feed for cattle or sheep, and should be kept in the barn if possible.

Western market prices will not be influenced this year by foreign beans, and for that reason we should produce a bumper crop. The world will need them.

\section{Prices of Beans at Blenheim, Ont.}

Each Month Since July, 1915

\begin{tabular}{|c|c|c|c|}
\hline & 1914 & 1915 & 1916 \\
\hline January................... & $\ldots$ & $\$ 2.50$ & $\$ 3.50$ \\
\hline February $\ldots \ldots \ldots \ldots \ldots \ldots \ldots \ldots$ & $\ldots$ & 3.00 & 3.50 \\
\hline 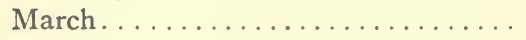 & & 3.10 & $\ldots$ \\
\hline 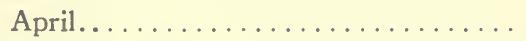 & & 3.00 & $\ldots$ \\
\hline 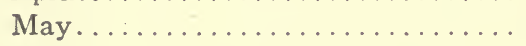 & & 2.75 & .. \\
\hline 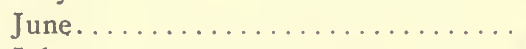 & & 3.00 & $\ldots$ \\
\hline 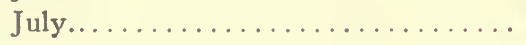 & $\$ 1.70$ & 3.00 & $\cdots$ \\
\hline August $\ldots \ldots \ldots \ldots \ldots \ldots \ldots$ & 2.25 & 3.00 & ... \\
\hline September.................. & 2.75 & 3.00 & $\ldots$ \\
\hline 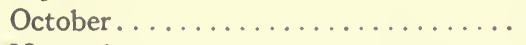 & 2.25 & 3.00 & . . \\
\hline 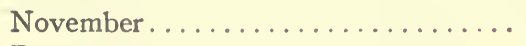 & 2.25 & 3.00 & .. \\
\hline December.................... & 2.25 & 3.75 & \\
\hline
\end{tabular}

British Imports of Beans

The import of beans (not fresh) other than haricot beans, to the United Kingdom in 1913 and 1914 were:

From

India

New Zealand

Other British.

Total British

China.

Germany.

Russia.

Other Foreign

Total.
1913

Cwt.

43,121

15,880

5,690

64,691

$1,291,980$

49,450

67,635

66,649

$1,540,405$
1914

Cwt.

32,650

4,650

12,137

49,437

$1,254,684$

19,750

8,890

108,798

$1,441,559$ 


\section{Beans as a Cash Crop}

The New Hampshire Department of Agronomy has sent out a leaflet calling attention to the possibility of adding field beans to the limited number of cash crops of that state. The reasons given are:

Beans work into the rotation as a cultivated crop.

They are legumes, and therefore do not exhaust the soil of its nitrogen.

They will always sell for cash.

They can be harvested, stored, and threshed out to be sold in winter when there is little profitable work to do on the farm.

While beans will sometimes make a crop on pretty poor land, they will do better on good land. Where an old field is foul with twitch grass, the sod should be subdued and got rid of its weeds before planting it to beans.

On soils that are rather infertile, an application of barnyard manure will help make the crop. If commercial fertilizers are used, most or all of the nitrogen may be left out:

In a general way, beans will do well on soils that are not quite rich enough for a good crop of corn. They thrive well on sandy loams, loams, and clay loams. The straw is a better roughage than most hays. It is better than corn stover, but not quite as good as clover hay. Those who throw away bean straw or burn it are overlooking a good source of gains for live stock.

\section{SHORTAGE OF PEAS}

Wholesale houses report a scarcity of blue peas in the United Kingdom. The price of peas is advancing, and there does not appear to be any relief in sight. Some idea of the increase can be ascertained by comparing the quantities and values of imports during the first nine months of 1914 and 1915, respectively. Imports during the former period were 837,831 cwts., valued at $£ 443,933$, and during the latter period 719,920 cwts., valued at $£ 536,933$, an advance of $\$ 1.04$ per cwt.

British imports are chiefly from the following sources:

Peas (not fresh) other than split peas $\quad 1913-14 \quad 1914-15$

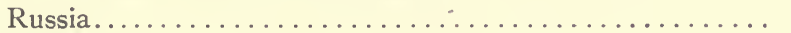

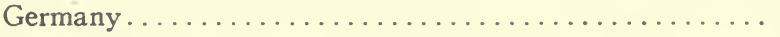

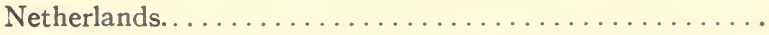

Japan (including Formosa and Japanese leased territories

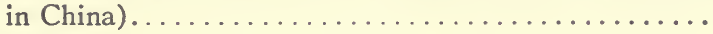

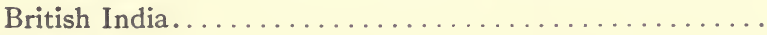

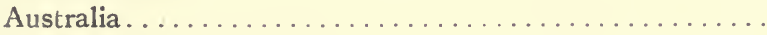

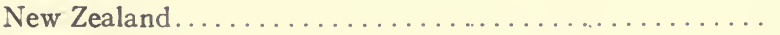

$£ 56,589 £ 62,904$

$149,721 \quad 63,818$

$145,804 \quad 55,711$

$114,347 \quad 100,390$

$342,144 \quad 76,432$

$2,898 \quad 18,087$

Canada's contribution was valued at $£ 5,932$ in 1914 and at $£ 7,599$ in 1915 .

\section{ONIONS}

By S. C. JOhnston, Vegetable Specialist, Ontario Dept. of Agriculture

The onion ranks high in commercial importance among the vegetables grown in Oniario. Next to the potato it is the commonest vegetable in the home. Average prices afford excellent returns for the production of the crop, and, in spite of the fact that Ontario annually produces many thousands of bushels, the imports are very heavy. For this reason an increased production in this crop is warranted. 
Soil-The onion is successfully grown in many soils, and a soil that is not originally conducive to its growth may readily be made productive by the application of manure. Sandy and sundy loam soils are excellent. Black mucks, properly handled, are probably the most favourable soils for onion growing in Ontario. The soil should be rich in vegetable matter, fairly level, well drained and as free as possible from stones. A soil of this nature will produce onions posisessing large bulbs of excellent quality.

Manuring and Fertilizing-Land to produce good crops of onions should be manured heavily, excepting in the case of black mucks. It is a good practice to apply well rotted manure, but this cannot always be secured handily. A sand or sandy loam soil should receive annual applications of from 35 to 50 tons of manure per acre. Black muck soils can be handled satisfactorily with the aid of commercial fertilizers. One consisting of $2 \%$ nitrogen, $8 \%$ phosphoric acid, $10 \%$ potash at rate of from $500 \mathrm{lbs}$. to 1 ton per acre, supplemented with applications of nitrate of soda used as a top dressing, gives good results. Nitrate should be applied during the growing season at the rate of 150-200 lbs. per acre, spreading it between the rows. Applications should be made several weeks apart.

In some cases, onions are grown on the same soil for many years in succession. Where this is practised, liming the soil once in three years is advisable. From 1,000 lbs. to a ton of lime should be applied to the acre either in spring or fall. This applies particularly to muck soils.

Planting-In Ontario, onions are usually grown from seed. This seed should be of unquestionable quality and germinating value. Seed should be planted in rows 12 to 15 inches apart. Sufficient seed should be used to produce 8 to 10 plants per foot. Extensive growers use from $4 \frac{1}{2}$ to $6 \mathrm{lbs}$. per acre, depending on quality of seed and soil. Seeds should be covered by half an inch of soil in fairly heavy soils and by one inch in light soils. It is imperative that the seed drill be accurately set to sow the seeds as directed.

Cultivation-If onions are properly drilled in, thinning is unnecessary. Weeds should be kept down by constant cultivation by means of a wheel hoe. Hand weeding will be necessary at least once a season and oftener if the onion land is very weedy. This is an expensive operation, and the freer the soil is from weeds, the cheaper the cost of produciion. Commence cultivation as soon as the top can be seen.

Harvesting-Maturity of the crop is indicated by a drying and falling over of the tops. The roots die off at the same time as the tops, and the onion should be pulled when the roots are almost entirely dead. If left in the soil after this period, the onion sends out fresh roots and also starts young growth of the stem inside the bulb, which causes considerable loss during storage. Onions are usually pulled by hand, four rows being laid in one windrow butt to butt. They should be allowed to dry for from three to six days in this position. After this, it is advisable to take them in slat boxes to a shed. Topping can commence at once, and this should be done by cutting off the top one inch from the bulb, using a sharp knife or a regular onion topping machine, which will handle many bushels per day. The latter machine is recommended where a large acreage is grown.

The onions should then be placed in open slat boxes or on shelves in a building which allows free access of air on all sides. After two or three weeks of curing they are ready for market.

Marketing-Ontario onions are marketed from Vancouver to Halifax. They are shipped in bags weighing $75 \mathrm{lbs}$. and holding one bushel and a half. Small quantities are handled on local markets. Grading is necessary to command the top market price. Only by careful topping, grading and shipping will the onion grower build up a business that will net him satisfactory returns. Too often low prices are realized not because of over-production, but owing to immense quantities of inferior quality and grading being dumped on the market. 
The following gives approximate yields and prices received at Leamington for last 5 years:

\begin{tabular}{|c|c|}
\hline Yield per acre & $\begin{array}{l}\text { Aver. price } \\
\text { per } 75 \mathrm{lb} \text {. } \\
\text { sack. }\end{array}$ \\
\hline $1914-300$ sacks, 450 bushels.... . & $75 \mathrm{c}$. \\
\hline $1913-350$ sacks, 520 bushels. . . . . . . . . . . . . & $\$ 1.25$ \\
\hline 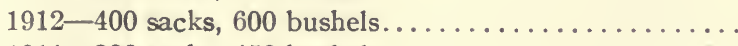 & $25 c .-60$ c. $*$ \\
\hline 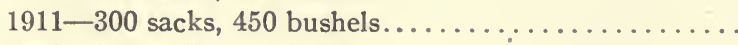 & 90 c. $-\$ 1.50$ \\
\hline 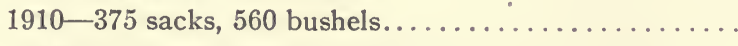 & $90 \mathrm{c}$ \\
\hline
\end{tabular}

Storing-Onions should not be stored for winter keeping in. bags or in bulk. They should be kept on shelves or in open slat boxes so that there will be plenty of space for air circulation. If placed on shelves, the layers should not be more than 10 to 12 inches deep. The cellar of the home can be used satisfactorily if it is kept cool. When the crop is large, they should be stored in cool, dry, well ventilated buildings and the temperature should remain as close to freezing as possible. Freezing and thawing will cause the onion to rot.

Cost of Production-One grower in the Leamington district produces a first class crop at less than $\$ 60$ per acre, while for others the cost averages about $\$ 100$ per acre. Much depends on the management of the crop and the machinery and buildings used for harvesting and storing.

Varieties-From Seed: Southport Yellow Globe-rapidly becoming a favourite; good yielder and shipper. Danvers Yellow Globe-a standard variety, but inclined to break in shape; good yielder and shipper. Red Wethersfield-a standard flat red onion, grown particularly for French markets; excellent yielder and shipper. Red Globe-coming more into favour; good shipper.

Sets-Yellow Strasburg-solid sets; good keepers.

\section{Small Pickling Onions}

Over $\$ 6,000,000$ worth of onions are imported annually by the United Kingdom, among which are large quantities of small onions used by picklers. Consignments have arrived from Canada in past years, and sales could be considerably augmented if the smaller onions were selected for this market. The sizes in common demand range from one to two inches in diameter, and they are preferred, unpeeled, in bags containing 100 pounds.

\section{TOBACCO CROP IN 1915}

In 1910 the total production of tobacco in Canada, as returned by the census of 1911, was $17,632,342$ lbs. from 18,928 acres. Since this date no definite statistics of the area and yield of tobacco in Canada have been published. The following figures of the acreage and yield of tobacco in Quebec and Ontario in 1913, 1914 and 1915 are rough estimates put forth under all reserve.

Provinces

Quebec.

n.............

Ontario............ 6,000

Total. ......... 11,000

\section{3 \\ 1914}

acres

5,000 acres

4,750

5,000

9,750
1915

acres

4,500

4,500

9,000
1913

lb.

$4,500,000$

$8,000,000 \quad 6,000,000$

$12,500,00011,000,000$
1915

lb.

$4,053,000$

$4,950,000$

$9,000,000$ 


\section{DRIED VEGETABLES}

One line to which special attention was given last year was the encouragement of increased production of vegetables, mainly for home use. This resulted in the production of very large quantities on vacant lots in towns and cities, which, of course, materially assisted in domestic consumption.

Apart from this, extra efforts were made in some of the provinces for increased field production of vegetables. In Ontario, through unfavourable weather, a shortage occurred, particularly in potatoes. In Alberta, but especially in British Columbia, enormous quantities of vegetables were available in the fall of 1915 . Just when the growers were somewhat perplexed as to the disposal of the same, contracts for dried vegetables were placed by the British and French War Departments with the Graham Company, Limited, of Belleville, Ont. These orders amounted to over ten million pounds, in fact the contracts were and are limited only to the possibilities of production. The result is that this company has handled the big surplus of British Columbia, and has even drawn large supplies from the adjoining Western States and also from New York State.

The following table shows the reduction of the vegetables, which are dried separately and then mixed.

\begin{tabular}{|c|c|c|}
\hline & Fresh & Dried \\
\hline 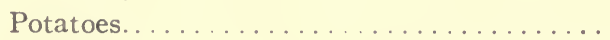 & 200 lbs. & $32 \mathrm{lbs}$ \\
\hline Turnips ...... & $200 “$ & $22 \quad$ “ \\
\hline Carrots........... & $200 “$ & $24 \quad$ “ \\
\hline Cabbage $\ldots . . . \ldots$. & $150 “$ & $101 / 2 “$ \\
\hline 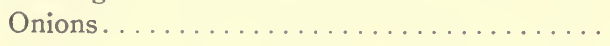 & $100 “$ & 6 “ \\
\hline 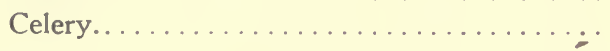 & 50 “ & $31 / 2 *$ \\
\hline Peameal & 900 lbs. & $\begin{array}{r}98 \text { lbs } \\
2\end{array}$ \\
\hline
\end{tabular}

100 lbs.

The above indicates that $900 \mathrm{lbs}$. of vegetables are dried to 98 , to which is added a small quantity of peameal. This dried mixture is shipped to Belleville, Ontario, where it is put up in packages of $15 \mathrm{lbs}$. The daily production in January was 90,000 lbs., which was sufficient for the making of 180,000 gallons of vegetable soup. The material thus obtained is marketable at from 20 to 25 cents a pound. Two ounces with a pint of stock will make a quart of soup.

The practice at the Front is to soak the dried material for one hour in cold water; then it is boiled, some stock being added, flavoured to taste, and served hot. Meat scraps and cheap cuts may be added if available and desirable, thus producing a complete army ration. In this shape it forms the breakfast for the French troops who much, relish it. Its possibilities in the hands of a good cook need not be enlarged upon.

Vegetables in this form will keep indefinitely. Although reduced to one-tenth their original weight, their flavours and food values are retained, while the reduction in bulk renders storage and transportation easy and inexpensive. The increase in Apartment House life should help to create a home demand, and the possibilities of building up a domestic trade for this product and thus promoting a new industry would appear to be worthy of serious attention. 


\section{O. P. V. SILAGE FOR THE MARITIME PROVINCES}

\section{OATS, PEAS AND VETCHES}

In the Maritime Provinces and other parts of Canada where corn will not as a rule mature sufficiently for silage, the question of a reliable source of winter feed is one of vital importance, particularly to farmers engaged in dairying. A reliable fodder crop is wanted that will be of equal value to corn for feeding purposes, and at the same time make good silage.

Prof. John M. Trueman, of the Agricultural College, Truro, N.S., appears to have satisfactorily solved the problem, so far at least as that province is concerned. A mixture of oats, peas and vetches will meet the requirements. All these plants, he declares, are vigorous and hardy, and certain to produce a good crop every year. With proper cultural methods their yields are very large.

In 1914 , on 5.7 acres he produced 65 tons of green feed, which is at the rate of 11.4 tons per acre. Three acres of this yielded at the rate of 15 tons per acre; the remainder of the land was wet and reduced the average. On good land in proper condition it is an easy matter, he states, to raise 12 tons or more per acre.

The crop is cut just as the oats are ready to enter the dough stage, and put through the regular silage cutter. In the silo it cures well and comes out in excellent condition for feeding, so that young stock eat it readily and there is no waste.

O.P.V. silage is a complete food, and, pound for pound, has a higher food value than corn. The great advantage in its favour, as Prof. Trueman points out, is the certainty of its producing a good yield in the great majority of seasons. Being suited to the climate, it will grow when other crops would be an almost certain failure. Furthermore, it can be grown with less labour than either roots or corn.

Farmers have asked whether this mixture cannot be cured into hay. The difficulty is that a heavy crop will lodge before it is ripe enough to cut and cure. The necessary week or two of continuous sunshine cannot be depended upon. By putting it into the silo, the farmer is practically independent of the weather.

The method followed in 1914 was: Clover hay sod was ploughed the fall previous, and the land well harrowed in the spring after a light dressing of barnyard manure had been applied. The seed was sown with a grain drill at the rate of $23 / 4$ bushels per acre in the proportion of $11 / 2$ bushels of oats, $3 / 4$ bushel of peas and $1 / 2$ bushel of vetch.

\section{ROOT HOUSE CONSTRUCTION IN ALBERTA}

\section{S. G. Carlyle, Surt. Demonstration Farms, Edmonton, Alta.}

There are two kinds of root house used in Alberta, one built above ground and the other below. The one below ground may be more correctly called a root cellar and is made by excavating to a depth of about seven feet, a width of twelve feet and to any length required.

The best material for the walls of a root cellar is cedar posts standing close together, and set in the ground to a depth of at least six inches. The tops of the posts should be even and a $2 \times 6$ plate should be laid on them and spiked to each post. The top of the wall should be even with the ground level and the space behind the posts should be filled with earth, which should be carefully tamped down to keep the walls from spreading. 
The roof is likewise made of posts. It is a double pitch roof. A piece of timber $6 \times 6$ should be run along the centre eighteen inches higher than the plates. It should be supported on posts eight or ten feet apart. This timber supports the end of the posts at the peak of the cellar. Openings two feet square should be made in the roof for the filling of the cellar. The roof should first be covered with a layer of straw extending on the ground beyond the walls. This should be covered with earth and a second layer of both straw and earth should be put above this. The top layer should be smooth and firm so as to shed the rain. If the cellar is built up to the side of a barn or stable, steps can be made inside to form an entrance to the stable. This insures both warmth and convenience.

Another plan is to build a wooden structure above ground with one end attached to the stable. The walls should be about 7 feet high, and the building may be any width and length desired. Use $2 \times 4$ or preferably $2 \times 6$ studding boarded up on the outside with shiplap, covered with heavy building paper and drop-siding. The inside should be two thicknesses of shiplap with heavy building paper between. The ceiling should also be ceiled with shiplap. A couple of openings in the wall, $2 \times 3$ feet, 3 feet from the ground, may be used for filling, the openings being fitted with double doors to keep out frost. A couple of ventilators made from $1 \times 2$ inch slats extending from the ground to an opening in the peak of the building should be constructed to let out the heat during the sweating process when the roots are first stored.

The advantage of this house over the other is that the floor is almost level with the floor of the stable, thus saving considerable labour when feeding. The disadvantage is that in extreme cold weather, the frost is liable to come through the wall and freeze the roots. This building is also more expensive than the root cellar and is therefore not so well suited to people of small means. 


\title{
WHEAT AND THE WAR
}

\section{THE COURSE OF EVENTS-OCEAN FREIGHTS AND PRICES- THE STATISTICAL POSITION-FUTURE PROSPECTS}

\author{
T. K. DOHERTY, LL.B., Commissioner International Institute of \\ Agriculture, Ottawa.
}

The Course of Events

\begin{abstract}
After the declaration of war, Europe offered the unique spectacle in the world's history of tens of millions of men turned from the processes of production to be consumers and devastators of crops. Men, horses, and motive power were devoted to destruction. Russia, one of the great sources of supply, was cut off from the rest of Europe by the central allies. The Entente Allies and neutrals, anxiously concerned with the uncertainties of the future, promptly proceeded to accumulate supplies, and notwithstanding the enemies' submarine campaign, effectively drew upon the cereal stores of the western world.
\end{abstract}

Immediately after the declaration, the Entente Allies and the neutrals protected themselves by the prohibition of the export of cereals and the abolition of customs duties on imports. The removal of 37 cents a bushel in France and 40 cents in Italy was a particularly effective stimulus to imports. Owing to the world's abundant crops in 1913, together with the low prices and low freights prevalent at that time, the year end stocks in the importing countries were large and exporting countries were also reputed to have carried over larger supplies than usual. But 1914 produced a world's total which the International Institute of Agriculture estimated to be $8 \%$ smaller than that of the preceding year and, unfortunately, Canada and Australia furnished a substantial proportion of that percentage. However, owing to the abundant harvests in Russia, United States, Argentina, and India, the supplies would have been nearly equal to the average requirements had there been no war.

In October last, 1915, Sir James Wilson, K.C.S.I., Delegate for the United Kingdom and the British Dominions on the Permanent Committee of the International Institute, in the course of an interesting analysis of the situation quoted figures to establish that fact. It appears from them that the exporting countries taken together, including Russia, could have spared $692,000,000$ bushels of wheat to meet a total estimated demand of $697,000,000$ bushels. He compares the actual trade for the grain year 1914-1915 with the five year average of 1909-1914. Dealing for imports with those of the United Kingdom, Italy, France, Switzerland, Holland, Sweden, and Spain, and for exports with those of the United States, Canada, Argentina, India, Algeria, Russia, Rumania, and Australia, Sir James' analysis may be summarized and tabulated approximately as follows: 
Imports (7 countries)

$\begin{array}{cccc} & \begin{array}{c}\text { Wheat } \\ \text { Bushels }\end{array} & \begin{array}{c}\text { Flour } \\ \text { Bushels }\end{array} & \begin{array}{c}\text { Wheat and Flour } \\ \text { Bushels }\end{array} \\ 1914-15 \ldots \ldots \ldots \ldots & 367,000,000 & 36,000,000 & 403,000,000 \\ 1909-1414 \ldots \ldots \ldots \ldots & 337,000,000 & 49,000,000 & 386,000,000\end{array}$

Exports (8 countries)

$\begin{array}{rrrr}1914-15 \ldots \ldots \ldots \ldots & 436,000,000 & 104,000,000 & 540,000,000 \\ 1999-1914 \ldots \ldots \ldots & 531,000,000 & 102,000,000 & 633,000,000\end{array}$

Sir James estimated that the normal exports of these eight countries for 1914-15 had there been no war would have been $676,000,000$ bushels. He observes that the United Kingdom in 1914-15 imported $8, \varepsilon 00,000$ bushels less than the advance average estimates had indicated, and he quotes Broomhall as stating that at the end of the grain year the stock in first hands amounted to $18,000,000$ bushels as compared with $14,600,000$ bushels the previous year. He concludes that the consumption, owing to high prices and other causes, was less than average, and that the year ended with fairly increased stocks. He observes, moreover, that the actual imports into France were $70,000,000$ bushels compared with $40,700,000$ bushels estimated as the normal requirement. Sir lames states: "It seems probable that owing to increased imports and reduced consumption she (France), notwithstanding the loss of wheat caused by the war, will end the year with stocks in hand considerably larger than she had at August 1st of last year."

Following this statement of facts, views, which from the point of view of the importer were optimistic, appear to have been pretty generally held in Europe, and especially in the United Kingdom, in the midsummer and early autumn of 1915. The United Kingdom had harvested a record crop of 74,000,000 bushels of wheat. Importers were confident that with a prospective big world's supply from the 1915 crop the British farmers would sell freely and imports would soon flow in from the abundant North American harvests. European buyers, and especially those of the United Kingdom, as we shall show more in detail later, were not at first induced by the low prices of midsummer to make substantial purchases. It was, however, realized later that the stocks carried over had been overestimated and were rapidly dwindling to an insignificant amount. Exports from India which had been disappointingly small were practically stopped in October in view of the dry weather having persisted for some time in a number of the large wheat producing provinces. Owing to the protracted heavy rains in the United States winter wheat regions, the harvest was late, and the quality was poor as we shall later show. When the European demand did appear it was most persistent and only limited by the lack of ships and the consequent extraordinarily high freight rates which up to the close of the year did not cease climbing until approximately 50 cents a bushel was charged from Atlantic ports to Liverpool and $\$ 1.00$ from Argentina.

Just a word more about the progress of events during 1915 from the point of view of production and trade. Early in the war, by the wiping out of the German mercha $n$ marine and the sinking of many British and neutral ships, the number of ships engaged in ocean traffic was so reduced that those remaining were unable to cope with requirements, and with the increased freights, higher insurance, and greater cost of exchange, there resulted an ever-widening margin between the price received by the producer of wheat and the price paid by the European consumer.

In January, 1915, Australia's wheat crop had been reported as only 25,000,000 bushels against $103,000,000$ the previous year. Some time afterwards the Argentina total, at first unofficially reported to be nearly $200,000,000$ was subsequently lowered to $168,000,000$ bushels compared with $113,000,000$ the year before. This was followed by the Indian total at first reported as nearly $400,000,000$ bushels, but subsequently reduced to $383,000,000$ bushels. 
Then came the earlier reports of the all important United States winter wheat, which for area in crop exceeded the previous year by about 4,000,000 acres. Concerning it grave fears had been expressed at the opening of the winter but the official report for April placed the condition at 88.8 , which was better than had been expected. The May report with the small abandoned acreage foreshadowed a crop about equal to the record one of the preceding year. The increased acreage and excellent condition of spring wheat in Canada as well as in the United States at the same time suggested enormous total yields for both countries.

The May option in Chicago, which had been $\$ 1.68$ in February, ended the month of May at $\$ 1.39$, and the much talked of corner had not materialized. The entry of Italy into the war, the German submarine campaign culminating in the sinking of the Lusitania, the higher condition of spring wheat in the United States (94.9), the increased acreage and excellent condition of the Canadian crops, together with optimistic reports concerning the growth of European cereals, were all features that operated for lower prices. Red winter wheat in Chicago touched $\$ 1.11, \$ 1.08$, and 98 cents in June, July and August respectively. The range was from 98 cents to $\$ 1.191 / 2$ in both August and September.

Stocks carried over into the new cereal year in Europe, August 1st, were with one or two exceptions considered low. The quantity on passage over the ocean had rarely been as small, not at least for 10 years back had there been such a small floating supply. European buyers, as we have said, were slow in taking advantage of the opportunity for making cheap advance purchases of supplies, a circumstance which contributed not a little to the high prices soon to prevail. Mr. Geo. Broomhall on August 31st gives imports to Great Britain in the fourth week of that month as $1,936,000$ bushels as compared with $5,832,000$ in the preceding year, and imports for the four weeks of that month were only $10,416,000$ bushels compared with $20,064,000$ bushels for the corresponding month of the previous year. The total shipments into the United Kingdom and to the Continent for the same period compared as 23,304,000 against $32,992,000$.

Both Mr. Broomhall and H. N. Bathgate \& Co. so analyzed the situation about that time as to show the expediency of vigorous measures to replenish British stocks. On the 22 nd and 24 th of June, Bathgate \& Co. had referred to the danger involved through neglect to purchase after the heavy decline that had recently taken place. The Bathgate statement of September 8th is worthy of being reproduced here as the warnings sounded in it were prophetic of coming events.

"The present and prospective large wheat crops for the current season are very welcome; but unfortunately the fact that the promise is so good is having an adverse effect in curtailing buying for forward delivery. It is of course well known that weekly shipments have been small for two months, no doubt in anticipation of the relief to be expected from Canada and U.S.A. This is all right so far as it goes, as naturally both merchant and retailer would desire to avoid entering a new season with a heavy stock of dear wheat and flour. There is, however, another side of the matter, and that is that, if everyone refrain too long from 'buying, we shall be in the unpleasant position of being faced with a spot shortage in a world of great plenty."

The Bathgates continue in their weekly issues of their report to insist that British buyers order early for forward movement, and on November 24th stated: "At this moment the stocks of wheat and flour in this country are only about half the customary average at this season of the year; and, indeed, if we consider the smallness of invisible stocks in the hands of retailers, the total quantity may be actually a great deal less than half." In the same issue the Bathgates observe:

"In this country farmers are beignning to send their wheat to market more readily, and will probably be free sellers just when native wheat is least wanted. They ought to remember that they still have to dispcse of fully three-quarters of a very abundant 
crop, and that they have to sell it in a season when possible supplies of foreign wheat are the largest ever known. To hold on too long, with all sorts of political developments on the card, appears to us to be a policy not likely to be justified by events."

In July, August, and September, came from Canada and the United States reports which exceeded each the preceding one in establishing record figures, but other influences than the large production of wheat soon assumed paramount importance. There had been extremely heavy rains in Kansas and the surrounding country, the downfall being the greatest on record with the exception of 1904 and 1908.

At harvest, in Kansas and the surrounding Western States, it turned out that a very large proportion of the wheat crop was unfit for milling purposes and consequently unmerchantable. Estimates of the quantity of wheat unmillable have varied between 60 million and 150 million bushels. Mr. George Broomhall, having first accepted the larger reduction, seems to have finally accepted, for practical purposes, that 100 million bushels were unmerchantable.

Towards the close of the year, while generally optimistic reports on the North American crops were appearing, the prospects for the approaching harvests in the Southern Hemisphere were equally promising. At this time the world's statistical position seemed to indicate a very considerable surplus above all requirements, and crop reporting authorities of international repute, such as Mr. George Broomhall in the "Corn Trade News" of January 4th, ascribed "the high F.O.B. prices in the United States and Canada at that time to artificial causes, or in other words, to speculation." However, on September 21, 1915, the Bathgates while acknowledging "world's harvests of huge dimensions" make this significant observation: "On the whole we would say that the tendency this year is to exaggerate the total quantity likely to be available, whereas a year ago there was a disposition to underrate the supply." Further on however, acknowledging that there would be more than sufficient wheat to go round and leave a liberal surplus to carry forward into the next season, he says: "The trouble we think will be experienced in moving the wheat from one part of the world to the other owing to the shortage of shipping. It stands to reason that the more exporting countries desire to sell, the keener will be the competition to obtain steamers, and as a natural consequence freights will 'be likely to increase." As a matter of fact, at the end of September the advance in freight rates had been as much as $50 \%$ in a little over a month, and $2 \frac{1}{2}$ times as much as the rates ruling the year previous when they were considerably above normal.

Having thus outlined the general trend of events during 1915 , let us give particular attention to the two features of prime importance just mentioned, viz., ocean rates and prices.

\section{Ocean Freight Rates}

In view of the important role of freights in fixing the price of wheat it will be of interest to present a few salient facts. Bearing on the cost of ocean freights on wheat before and since the war, Sir James Wilson, in a recent analysis of the cereal situation, elaborated some data compiled by the staff of the International Institute of Agriculture from Broomhall's "Corn Trade News." We use that analysis freely in the following review.

A rough comparison between prices and rates of freight may be made, always remembering that the figures are not strictly comparable. Taking the average price of wheat imported into the United Kingdom for ten years at $\$ 1.07$ per bushel, broadly speaking, the difference between that price and the average price of wheat in the overseas exporting countries is mainly accounted for by the cost of ocean freight, which in normal times, as will be seen from the five year average 1909-13 given below, varies from an average of 4.8 cents per bushel from New York to 18.5 cents from the North Pacific ports. 
The course of ocean freight rates for that average of five years and other more recent dates, is presented in the following table:-

\begin{tabular}{|c|c|c|c|c|}
\hline Date & $\begin{array}{l}\text { New York } \\
\text { to } \\
\text { Liverpool }\end{array}$ & $\begin{array}{l}\text { Karachi } \\
\text { to } \\
\text { Liverpool }\end{array}$ & $\begin{array}{c}\text { Buenos Aires } \\
\text { to } \\
\text { Liverpool }\end{array}$ & $\begin{array}{l}\text { Australia to } \\
\text { United } \\
\text { Kingdom } \\
\text { (Sailer) }\end{array}$ \\
\hline & $\begin{array}{c}\text { Cents per } \\
\text { Bushel }\end{array}$ & $\begin{array}{c}\text { Cents per } \\
\text { Bushel }\end{array}$ & $\begin{array}{c}\text { Cents per } \\
\text { Bushel }\end{array}$ & $\begin{array}{c}\text { Cents per } \\
\text { Bushel }\end{array}$ \\
\hline $\begin{array}{l}\text { Average of } 5 \text { years } \\
\text { ending } 1913 \ldots .\end{array}$ & 4.8 & 10.9 & 8.6 & 17.0 \\
\hline July $1914 \ldots \ldots$ & 5.3 & 7.9 & 6.9 & 12.2 \\
\hline Jan. $1915 \ldots . . .$. & 20.5 & 21.3 & 40.8 & $\ldots$ \\
\hline August $1915 \ldots$ & 20.3 & 29.9 & 40.8 & $\ldots$ \\
\hline Sept. 10, 1915... & 26.6 & 27.6 & 39.0 & $\ldots$ \\
\hline Oct. $15,1915 . \ldots$ & 40.6 & 27.6 & 42.3 & 40.8 \\
\hline Nov. $12,1915 \ldots$ & 40.6 & 39.0 & 55.5 & 45.6 \\
\hline Dec. $10,1915 \ldots$ & 38.8 & 45.6 & 73.3 & 47.7 \\
\hline Jan. $6,1916 \ldots .$. & 40.6 & 68.4 & 91.2 & 48.9 \\
\hline Feb. $1,1916 \ldots$ & 50.0 & 88 (b) & 94 (a) & 49 (c) \\
\hline
\end{tabular}

(a) For Government account to United Kingdom 88 to 90 cents per bushel.

(b) From Bombay, India, from 91 to 94.6 cents per bushel.

(c) For steam 72 cents per bushel.

Roughly speaking, the extreme high rates quoted up to the 15th of February had been 50 cents from New York and $\$ 1.00$ from Argentina to Liverpool. Between these rates and the average prevailing during the five years before the war, we had therefore the striking difference of over 45 cents a bushel on the New York-Liverpool route and over 91 cents on the Buenos Aires-Liverpool route.

Moreover, the insurance on wheat, which on average $\$ 1.00$ wheat before the war amounted to $1 / 2$ cent per bushel, amounted recently on $\$ 1.35$ wheat to about 2 cents per bushel.

Sir James Wilson remarks that "taken by itself the increase in ocean freights together with the insurance would, other things being equal, account for an increase of this amount in the difference between the price of wheat imported into the United Kingdom and the prices of the various exporting countries."

The difference between the Liverpool and the Winnipeg prices for No. 2 Northern Manitoba wheat were in July $1914, \$ 1.08$ and 88 cents respectively, whereas on the 10 th of December they had risen to $\$ 1.81$ and to $\$ 1.00$. The increases in price were 73 cents and 12 cents respectively. Why should the advance of the Liverpool price be so much greater than that of Winnipeg? Sir James believes it is to bc ascribed to the extent of 35 cents a bushel in the increase in the cost of freight and insurance; and to the extent of about $31 / 2$ cents to the $3 \%$ fall in the exchange value of a pound as compared with a dollar. The rest of the increase in the difference between the prices may be, he says, due to the greater cost of inland transport and to the increased profits and expenditures.

The shipper from Canadian ports and from New York on the 6th of January, 1916 , had an advantage in rates over the shipper from Buenos Aires of 50 cents a bushel. $\mathrm{He}$ had an advantage over the shipper from Karachi, India, of nearly 28 cents, and over the shipper from Australia by steamer of 31 cents, whereas before the war his advantage in that respect averaged only about 6 cents per bushel over the shipper from Buenos Aires or Karachi, and 12 cents a bushel over the shipper from Australia.*

*Our readers are requested to bear in mind this fact of utmost importance to Canadians, affording them an exceptional opportunity and advantage in the marketing of their wheat. 
In the middle of July, just before the war, the price of No. 2 Hard Winter wheat at Liverpool was about $\$ 1.07$ a bushel. Its cash price at New York was then about 92 cents a bushel- a difference of 15 cents a bushel. At that date the cost of freight from New York to Liverpool was $51 / 4$ cents a bushel, and of insurance about $1 / 2$ cent a bushel, making the cost of freight and insurance about 6 cents a bushel, and leaving 9 cents a bushel to cover other charges and profit. On 6th January, 1916, the price of Choice Hard Winter in Liverpool was $\$ 1.90$ per bushel and the cash price of No. 2 Red Winter in New York was $\$ 1.42$ per bushel, a difference of nearly 48 cents per bushel. The cost of freight on that date from New York to Liverpool was 40 cents a bushel and the cost of insurance about 2 cents a bushel-a total of 42 cents, leaving 6 cents a bushel to cover other charges and profit. The increase of 33 cents in the difference between Liverpool and New York prices is thus accounted for by the rise in the cost of freight and insurance of 36 cents a bushel.

On the average of the ten years before the war the price of wheat imported into the United Kingdom was $\$ 1.08$ a bushel and the price of wheat exported from the Argentine was 94 cents a bushel, a difference of 14 cents a bushel. The average rate of freight from the River Plate down river to the United Kingdom was for the five years before the war $81 / 4$ cents per bushel. According to Broomhall on 6 th January, when Baril wheat was selling at Liverpool at $\$ 1.95$ a bushel, the price of wheat at Buenos Aires was $\$ 1.08$ a bushel, a difference of 87 cents a bushel. The cost of freight from Buenos Aires to Liverpool had risen on that date to 91 cents a bushel, an increase of 83 cents above what it was before the war. This increase in the cost of freight is more than enough in itself to account for the increase in the difference between the prices at Liverpool and Buenos Aires.

What is responsible for this extraordinary increase in ocean freight rates? The "Australian Age" of November 9, 1915, is probably correct when it summarizes the situation as follows:-

"Some $25 \%$ of the world's tonnage is either locked up in enemy ports or at the bottom of the sea. Another $20 \%$ has been requisitioned by the Admiralty for transport and war purposes. The British Admiralty, so we are informed, has 800 steamers, not including trawlers, and is requisitioning more every day. The enemy submarine campaign, although it has suffered a severe check, still is to be reckoned with"..... ......"Even when freight is chartered, no one can say definitely, as in normal times, that so much freight will be available; it may be sunk or it may be requisitioned."

A proper conception of the extent of the rise in ocean freight as compared with the rise in prices was given by Broomhall in the "Corn Trade News" of January 18, 1916, in the following statement:-

"The difference between the C.I.F. price now and in January, 1914, of Canadian, Australian and Argentine wheat is $30 \mathrm{~s}$. 6d. per quarter (92 cents a bushel), a rise of roundly $90 \%$; whilst freights have advanced from 3 s. $6 \mathrm{~d}$. to 20 s. $6 \mathrm{~d}$. per quarter $(101 / 2$ to 62 cents per bushel), a rise of nearly $500 \%$."

\section{Past and Present Prices of Wheat}

In previous wars the prices of wheat have been relatively higher and have fluctuated widely. In the case of many wars the high level of prices has often continued for some time after the declaration of peace. The course of prices during the present conflict, as we shall see later, seems so far to confirm this general tendency.

A remarkable chart prepared by $\mathrm{Mr}$. Geo. Broomhall, and published recently, (sold by Broomhall's "Corn Trade News" of Liverpool at the modest price of $2 \mathrm{~s} .6 \mathrm{~d}$. a copy) enables us to give as follows a table in which are presented official average prices of home grown wheat in the United Kingdom for 115 years. We have given only the typical years in the first half of the 19 th century up to 1842 ; but from this date we have 
given the price for each year. It is to be remarked that there is a difference in prices between British wheat and imported wheat. The imported was higher and varied in the 10 years, $1905-14$ from 5 to 10 cents a bushel, and averaged 7 cents for the whole period.

Average price per Bushel of British Wheat for the Calendar year, 1800 to 1915.

\begin{tabular}{|c|c|c|c|c|c|c|c|}
\hline Year & & Year & & Year & & Year & \\
\hline 1800. & $\$ 3.47$ & $1850 \ldots$ & $\$ 1.22$ & $1872 \ldots$ & $\$ 1.73$ & $1894 \ldots$ & $\$ 0.68$ \\
\hline 1801. & 3.62 & $1851 \ldots$ & 1.17 & 1873. & 1.78 & 1895. & 0.70 \\
\hline 1802. & 2.13 & 1852. & 1.23 & $1874 \ldots$ & 1.70 & 1896. & 0.79 \\
\hline 1803. & 1.80 & 1853. & 1.61 & $1875 \ldots$ & 1.37 & 1897. & 0.91 \\
\hline 1804. & 1.89 & $1854 \ldots$ & 2.19 & 1876. & 1.40 & 1898. & 1.03 \\
\hline 1805 . & 2.74 & 1855. & 2.27 & 1877. & 1.73 & 1899. & 0.78 \\
\hline 1810. & 3.22 & 1856. & 2.10 & 1878. & 1.40 & 1900 . & 0.81 \\
\hline 1812. & 3.86 & 1857. & 1.71 & $1879 \ldots$ & 1.34 & 1901. & 0.81 \\
\hline 1815. & 2.01 & 1858. & 1.34 & 1880. & 1.36 & 1902. & 0.85 \\
\hline 1817. & 2.92 & $1859 \ldots \ldots$ & 1.33 & $1881 \ldots \ldots$ & 1.37 & $1903 \ldots \ldots$ & 0.81 \\
\hline 1822 . & 1.37 & $1860 \ldots \ldots$ & 1.62 & 1882. & 1.37 & 1904. & 0.87 \\
\hline 1825 . & 2.07 & $1861 \ldots \ldots$ & 1.67 & $1883 \ldots$ & 1.25 & 1905. & 0.90 \\
\hline 1835. & 1.19 & $1862 \ldots$ & 1.67 & 1884. & 1.07 & 1905. & 0.85 \\
\hline 1839. & 2.16 & 1863. & 1.33 & 1885. & 1.00 & 1907. & 0.94 \\
\hline 1842 . & 1.75 & 1864. & 1.22 & 1886. & 0.94 & $1909 \ldots .$. & 0.99 \\
\hline 1843. & 1.52 & 1865. & 1.27 & $1887 \ldots$ & 0.96 & $1909 \ldots \ldots$ & 1.13 \\
\hline 1844. & 1.55 & 1866. & 1.52 & 1888. & 0.97 & 1910. & 0.96 \\
\hline 1845 . & 1.55 & 1867. & 1.95 & 1889. & 0.91 & 1911. & 0.96 \\
\hline 1846. & 1.67 & 1868. & 1.94 & 1890 . & 0.9 & 1912. & 1.05 \\
\hline 1847. & 2.13 & $1869 \ldots \ldots$ & 1.46 & $1891 \ldots \ldots$ & 1.13 & $1913 \ldots \ldots$ & 0.96 \\
\hline 1848. & 1.55 & $1870 \ldots \ldots$ & 1.43 & $1892 \ldots \ldots$ & 0.91 & $1914 \ldots \ldots$ & 1.05 \\
\hline 1849. & 1.34 & $1871 \ldots \ldots$ & 1.70 & $1893 \ldots \ldots$ & 0.79 & $1915 \ldots \ldots$ & 1.61 \\
\hline
\end{tabular}

As an instance of high prices and violent fluctuations during war times and for some time after the declaration of peace, readers are requested to examine the above table for the period of the Napoleonic Wars and the two years following them, viz. 1800-1817, also the period 1812 to 1815 of our war with the United States. Note the fluctuations from the opening of the century: $\$ 3.62$ a bushel to $\$ 1.80, \$ 3.86, \$ 2.01, \$ 2.92$; the latter being the price for 1817 .

Prices then fell rapidly to $\$ 1.37$ in 1822 , rose in 1825 , and fell again lower in 1835 , when there was a large British crop, but soon climbed again in 1839 to $\$ 2.16$, declined from that until 1843 and 1844 , when large British crops brought wheat to $\$ 1.52$ and $\$ 1.55$ respectively and the same prices the following year. In 1846 there was a bad harvest and potato diseases; in 1847 was the Irish famine, followed in 1848 by another bad harvest. In 1849 the Repeal of the Corn Laws became effective and there was a decline gradually until in $1851, \$ 1.17$ was reached, and in $1852, \$ 1.23$.

Now came the Crimean War in which Great Britain, France, Italy, Russia, and Turkey were engaged, initiated in 1853, ended by the signing of the Articles of Peace in the winter of 1856 . The prices for these years were $\$ 1.61, \$ 2.19, \$ 2.27$, and $\$ 2.10$ respectively, and in 1857 , the price was as high as $\$ 1.71$.

The Italian War in 1859 caused a rally which ran into the beginning of the American Civil War, 1861 to 1865 . Then, however, the prices only advanced during 1861 and 1862. In 1863 and 1864 there were two big British harvests, followed in the next two years by wet harvests and then by a drought in 1868, bringing wheat for two years to $\$ 1.95$. In 1866 there was the war between Prussia and Austria. In 1869 the 
1s. per quarter duty on wheat was removed and with a big crop in 1870 the price remained as in the preceding year, around $\$ 1.43$, but on the continuance of the FrancoPrussian War from 1870 to 1871 prices began mounting, and remained high through 1872,1873 and 1874. In addition to war influences, the crops had been short in these years with the exception of 1874 , when both in England and in France crops were good, but this was also the year of the Bengal famine.

The last of very high priced wheat was seen in 1876 and 1877 , coincident with the Turko-Serbian War and the other Balkan Wars, which were finally settled in 1878 . In 1877 there also occurred the severe Indian famine. Still there was a poor British harvest in 1879 and a wet harvest in 1881 , so fairly high prices persisted until and including 1882 , being $\$ 1.37$ in the last two years.

We now witness a persistent slump between the latter year and 1895 , a period which marks the advent of advanced methods of agriculture, including fertilizers, machinery, and especially the opening to cultivation in several countries of enormous areas of virgin lands, factors tending to the cheapening of production and the creation of abundant supplies. Europe was flooded with the wheat of the Western States. These big shipments began in 1877 and were more or less predominant until 1907. The wheat corner in 1898 apparently had little effect outside of the United States.

In 1882 India, and especially Russia, expanded their production and exports. Argentina began its first shipments in 1886 and from 1900 on became a serious competitor in the world's markets.

During this latter period Australia to a smaller extent and Canada to a greater extent became additional contributors to the world's supplies, so that Canada in 1915 rose to the third rank of the world's producers, the United States having in that year wrested the first position from Russia.

Some apprehension has been expressed at various times on the part of producers that with the continued expansion in the cultivation of wheat on virgin soils, together with improved methods of production, there would be in the world a permanent plethora of wheat with continued low prices. Still, with the accession since 1877 of all these new sources of supply, it must be borne in mind that since 1895 there has been established from year to year a slightly higher level of prices persisting until 1909, and it is doubtful if we shall ever see again, except in short-lived, temporary fluctuations, even the low average prices of 1910,1911 and 1913.

\section{The Examination of the Situation arising from Supply and Demand}

In dealing with the question of supply and demand our attention will be confined to those countries only which are not, through the operations of war, cut off from free communication with the commercial world. Consequently, Germany, Austria-Hungary, Belgium, Serbia, Bulgaria, Turkey, and even Rumania and Russia are excluded. We shall refer later to the limited part Russia is enabled to take in this trade.

For the purpose of enabling our readers to obtain a bird's-eye view of the situation in the demand countries of Europe, there are presented in the following table in parallel columns for the three years 1913,1914 , and 1915 , three paramount trade factors, viz.: (1) production; (2) imports; (3) a combination of the first two to form the total supply available for consumption. The imports for 1913 and 1914 are the actual imports, while for 1915 the amounts contained in the corresponding column are estimated requirements.

The figures in the following table refer to the grain year beginning August 1st, and comprise not only wheat but wheat flour converted into an equivalent of wheat. 


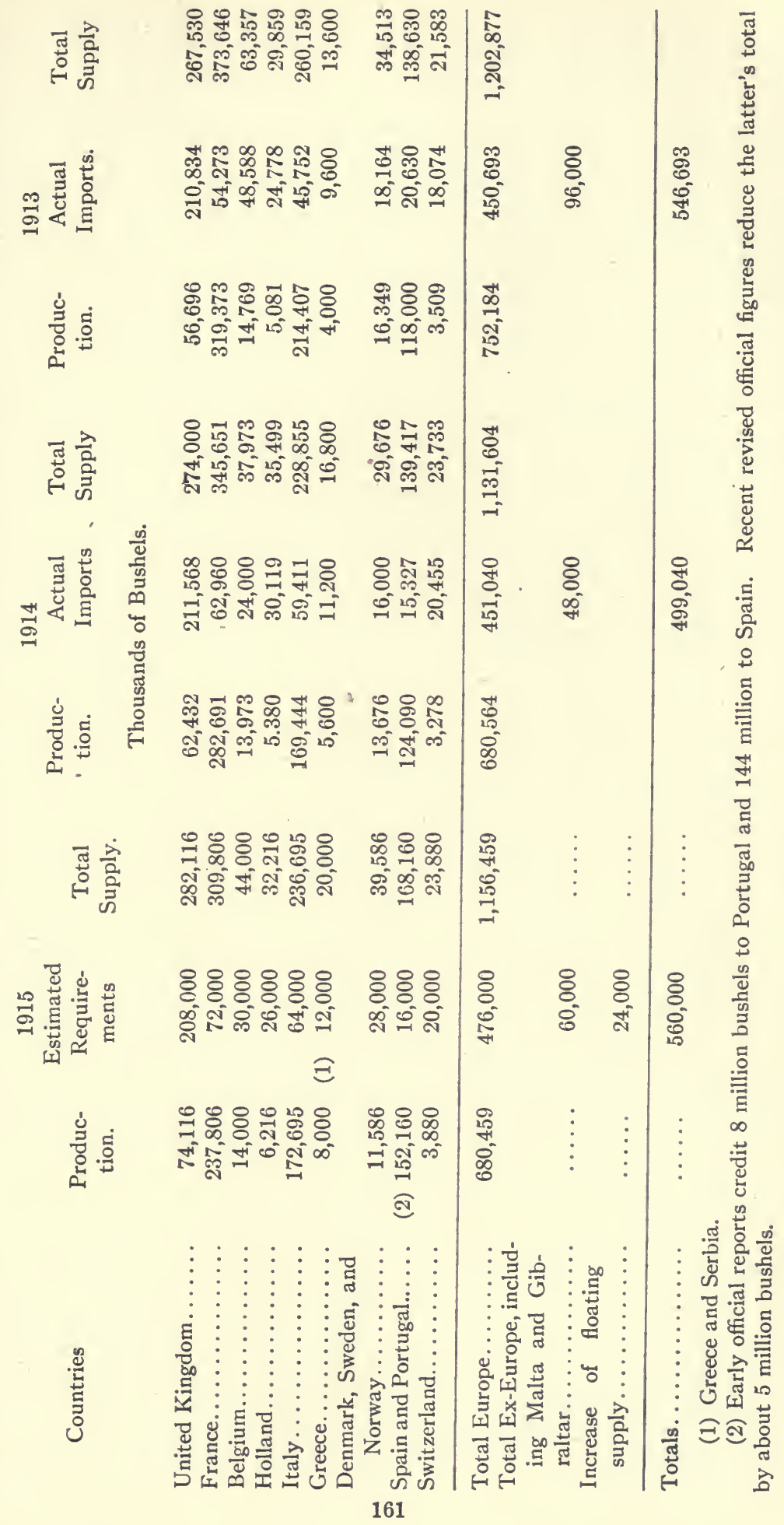


All the data in the above table have been taken from the Bulletin of Agricultural and Commercial Stacistics, excepting those of the estimated requirements for 1915, which are from Broomhall's "Corn Trade News" of January 25, 1916.*

There has often been a tendency on the other side to begin the season by underestimating the requirements. It will be remembered that Mr. Broomhall on the 31 st of August, 1915, estimated these requirements for 1915-16 at only $416,000,000$ bushels, Bathgate \& Co. on November 3rd estimating them at 506,000,000 bushels. We would venture the opinion that even Mr. Broomhall's latest estimate of $560,000,000$ bushels-in which is included the provision for increasing the floating supply to a normal size at the close of the grain year-will turn out to be much too small, especially the $476,000,000$ bushels allotted to Europe.

In a forecast of this nature in the absence of ascertained facts there are certain features which it is well to take into account. It appears from the above table, for instance, that the European production of 1915 is practically the same as that of 1914 , but that it is $71,725,000$ bushels smaller than the production of 1913 . In 1913 the total domestic production of these countries, plus the imports, gave a total supply of $1,202,877,000$ bushels. In 1915 the total production of these countries, plus the $476,000,000$ which Mr. Broomhall allows for imports, furnishes a total supply of $1,156,459,000$ bushels, an amount 46,418,000 smaller than the total for 1913. In order therefore to provide supplies of equal amount for 1915 , it would be necessary to add $46,418,000$ to the $476,000,000$ required imports estimated by $\mathrm{Mr}$. Broomhall, making in all for these European countries total requirements of 522,418,000 bushels. This would bring the world's total exclusive of provision for the short floating supply to $582,418,000$, and with that floating supply a world's total of $606,418,000$ bushels.

The amount of $60,000,000$ bushels for countries outside of Europe compares with the normal of $96,000,000$ in 1913 . Allowing Broomhall's estimate to stand, although it may appear somewhat small, it will be well to consider that an amount of $606,000,000$ of imports is not excessive. In times of peace for the five years previous to the war the world's imports averaged $624,000,000$ annually. The grain year $1914-15$ was an abnormal one because of the crop failures in certain of the exporting countries. There was a good deal of disorganization of the ocean traffic from the first successes of the German submarine campaign, at the same time that prices, especially in North America, ranged at a high figure. Then that year, it is admitted, started with abundant supplies carried over from 1913 when there was everywhere a plethora of wheat. In the latter half of the grain year 1915-16 the disturbance in transport owing to high freights has through the recent intervention of the allied European Governments been somewhat relieved, with the result that a comparatively free movement of cereals at more reasonable rates is confidently expected. Prices in the exporting countries are not unduly inflated, inflation being confined altogether to ocean freight rates; the needs of the importing countries are more urgent than ever, and stocks of wheat must be accumulated from the world's abundant crops against the many uncertainties of the future. The necessity for holding larger reserves is quite as imperative in the exporting countries, whose supplies were so cleaned out on the 1st of August, 1915, that the customary ocean floating supplies were reduced by one-half.

It will be of interest to dwell for a moment on the very considerable needs of France in the current year. The table shows her total supply of wheat to have been reduced from $373,000,000$ bushels in 1913 to $345,000,000$ in 1914 , and that with the $72,000,000$ of imports allowed by Mr. Broomhall she would have during the current year only $309,000,000$ bushels for consumpion. The remark made in the "Corn Trade News" of January 4th is significant: "Recently the Government have been importing flour from England and taking large quantities of wheat flour from America, which imports,

* Mr. Broomhall in the same issue published a revised up-to-date statement of the imports for 1914-15 at $524,464,000$ bishels, which figures should, for practical purposes, be substituted for the 499,040,000 mentioned above. 
with the many complaints of lack of supplies, especially in the southern region, tend to confirm the claim that the crop of 1915 was a very poor one and much below the official estimate." The acreage in wheat varied as follows for the years 1913, 1914 and 1915 respectively, $16,170,000$ acres, $15,155,000$ and 14,065,000 acres, the latter for 1915 being 2,105,000 acres under the acreage for 1913 . The official report of winter wheat seeded up to January 1, 1916, gave an acreage of $12,500,000$. It is hoped, however, that this may eventually be substantially increased.

On August 31st last Mr. Broomhall quoted the "Times," in which it was stated among other items of news concerning the French wheat crop that the "total French requirements of wheat have been officially ascertained at $43,000,000$ quarters" $(344,0 \mathrm{c} 0,000$ bushels). If we are to accept Mr. Broomhall's more recent statement that the French crop has been "a yery poor one and much below the official estimate" $(237,000,000$ bushels), the French requirements would appear to be larger than the Broomhall estimate which we have used, viz. 72,000,000 bushels. Reducing the official estimate by only $13,006,000$ bushels to $224,600,000,120,000,000$ bushels would be needed to replenish the supplies. However, a great saving in wheat will doubtless result from the French decree directing that the people should use a loaf in which enters only $75 \%$ of wheaten flour. The decree defines what may be used in the other $25 \%$; certain unusual but valuable foods of the sago, tapioca, and arrowroot types are suggested as ingredients, and such a loaf would be $5 \%$ cheaper than the whole wheaten loaf. But even 20,000,000 bushels would be a large saving under such an arrangement, and $100,000,000$ bushels would apparently have to be imported to make up the deficiency.

Unfortunately, the out-turn of the other crops in 1915 was such that it is difficult to conceive how they can serve as substitutes for wheat. The following is the showing for the past three years:-

\begin{tabular}{|c|c|c|c|}
\hline Rye. . & $\begin{array}{c}1915 \\
\text { Bushels. } \\
39,086,000\end{array}$ & $\begin{array}{c}1914 \\
\text { Bushels. } \\
44,814,000\end{array}$ & $\begin{array}{c}1913 \\
\text { Bushels. } \\
50,056,000\end{array}$ \\
\hline Oats.... & $242,912,000$ & $299,610,007$ & $336,049,000$ \\
\hline Barley.... . . . . & $36,113,000$ & $46,136,000$ & $47,939,000$ \\
\hline Potatoes.... . & $332,791,000$ & $440,657,000$ & $477,115,000$ \\
\hline ugar Beets. & $\begin{array}{c}\text { Short tons. } \\
1,662,500\end{array}$ & $\begin{array}{c}\text { Short tons. } \\
4,134,880\end{array}$ & $\begin{array}{c}\text { Short tons. } \\
6,647,000\end{array}$ \\
\hline
\end{tabular}

It may here be mentioned incidentally that the number of cattle in France were reported on July 1,1915 , as $12,286,849$ head compared with $13,120,649$ on December 31,1914 , a decrease of 833,800 head in six months.

The situation, in so far as our gallant and loyal ally is concerned, may enable the reader to form some conception of the terrible havoc that war is playing with agriculture in practically all the belligerent countries and of the unlimited demand on the abundant stores of the exporting countries which is likely to persist.

Broomhall, February 22nd, gives French imports for five months August 1stDecember 31 st as 40 million bushels. Imports at the same rate for the remaining seven months would reach a total of 96 millions.

It is now necessary to-examine the sources of supply that are called upon to furnish the 600 odd million bushels of wheat that the importing world will require, and also to replenish the reserves of the exporting countries in such manner that they will not be unduly depleted, as they were on August 1st of last year.

The chief exporting countries with their actual exports of wheat and wheat flour converted into wheat during the grain years 1913-14 and 1914-15, together with their estimated exports during 1915-16 are given as follows:- 


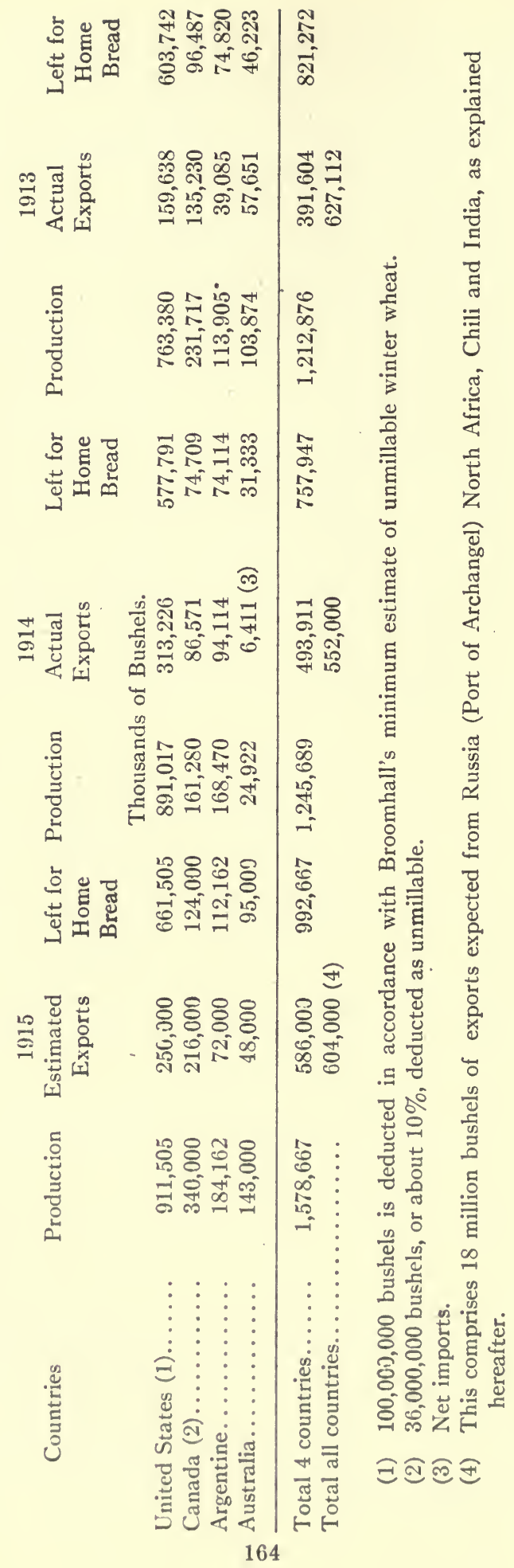


A word about some exporting countries that are not included in the above table, and which it is estimated may export an additional 18 million bushels, making the above total of estimated exports 604 million. Russia, which exported in 1913-14, $173,000,000$ bushels, only exported $1,120,000$ in 1914-15. Via the port of Archangel since the 1st of August, 1915, to the 12th of February she had exported 3,472,000 bushels and by the 1st of August, 1916, Broomhall expects her to send out by that route in all about 8,000,000 bushels. Broomhall estimates that for the current year North Africa, Persia, and Chili may be able to spare about $8,000,000$ bushels; but only $2,000,000$ bushels are expected from India where in two of the great wheat producing provinces, drought has been so persistent it is feared the coming Indian harvest in March will not yield more than sufficient for home consumption. Still she had contributed to the world's exports 26,000,000 bushels out of her 1914 crop and 23,000,000 bushels out of her crop of 1915.

It therefore devolves almost exclusively upon the four great producing countries mentioned in the above table to supply the world's requirements during the current grain year. These countries, after satisfying the demands upon them for export, had remaining for home consumption in 1913 a total of $821,000,000$ bushels; in 1914 the total remaining was only $757,000,000$. It will be seen from the estimated distribution of the 1915 crop that it is expected $992,000,000$ bushels will remain for home bread requirements. That these quantities will be needed to replenish depleted reserves cannot be doubted. If the remaining supplies for 1914 and 1915 were evenly divided between these two years there would be for each year $875,000,000$ bushels without making any deduction from the Argentina and Australian crops on account of unmillable wheat. And this amount is not excessive, especially in times like the present when the occurrence of crop failures would be disastrous in the absence of abundant home reserves.

Bathgate \& Co. recently made an observation which is worthy of attention and that is, that in times of scarcity, crop reports, official and otherwise, are inclined to pessimism, while in times of abundance there is a tendency to exaggerate in the opposite direction. Too little attention is generally paid to crop damage of the nature of that of last year to the winter wheat crop of the United States. Damage of various kinds to a more or less extent affects the milling value of a considerable proportion of every crop and that proportion is not to be ignored in a crop of such size as Canada harvested in 1915. The final analysis of the disposal of such a crop always discloses considerable quantities that cannot stand the milling test. We have, therefore, as indicated above, reduced the Canadian total by about $10 \%$ to meet that condition, and the damage of unknown extent that is recognized to have, for instance, seriously affected some of the Ontario wheat and a larger quantity of Western wheat. Much of this is still in the shock, having gone into the winter wet, and in its frozen state must await favourable spring weather before it can be threshed. A further and perhaps larger quantity having been threshed and piled in the fields with an insufficient straw covəring, will be exposed to serious damage in the spring.

In order to apply a further test to the data used in the above table, we present the following analysis of the disposition of the United States and Canadian crops using for that purpose chiefly the data furnished by Mr. Broomhall and our own Census and Statistics Office. 


\section{Disposition of the U.S. Crop}

Seed Requirements for 1916 crop (same as 1915 official) ................ .

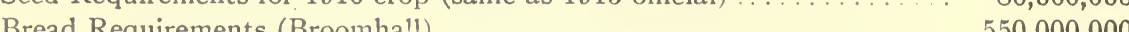

Bread Requirements (Broomhall) . . . . . . . . . . . . . . . . . . 550,000,000

Damaged Wheat unsuitable for flour $(10 \%) \ldots \ldots \ldots \ldots \ldots \ldots \ldots$. . . . . . . 100,000,000

Carry over in excess of last year (Broomhall)............... 25,000,000

Total ........................

Exportable surplus. . . . . . . . . . 250,0 . . . 200,000

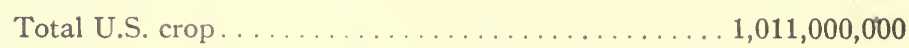

(1) Broomhall allows $150,000,000$ bushels.

\section{Disposition of Canadian Crop}

Seed Requirements for 1916 (Census Office) . . . . . . . . . . . . . . . . 25,000,000

Bread Requirements (Census Office) . . . . . . . . . . . . . . . . 50,000,000

Damaged Wheat unsiutable for flour $(10 \%)$, (Census Office) . . . . . . 37,000,000

Carry over in excess of last year..................... 12, $\quad 12,000,000$

Total. ........................... 124,000,000

Probable actual exports (Broomhall) . . . . . . . . . . . . . . . . . 216,000,000

Probably held over for subsequent export . . . . . . . . . . . . . . $36,000,000$

Total Canadian Crop.................. 376,000,000

(2) Double this quantity might be nearer the real requirements for reserve stocks.

In view, therefore, of Europe's great needs, it seems providential that Nature should have provided such an abundance of supplies. These, however, from our analysis of the situation, do not appear to materially exceed the requirements of importing countries for food and the replenishing of reserve stocks nor do they exceed the requirements of the exporting countries themselves to replenish their own stores against the uncertainties of the future, some of which are already developing into serious threats of future shortage. 


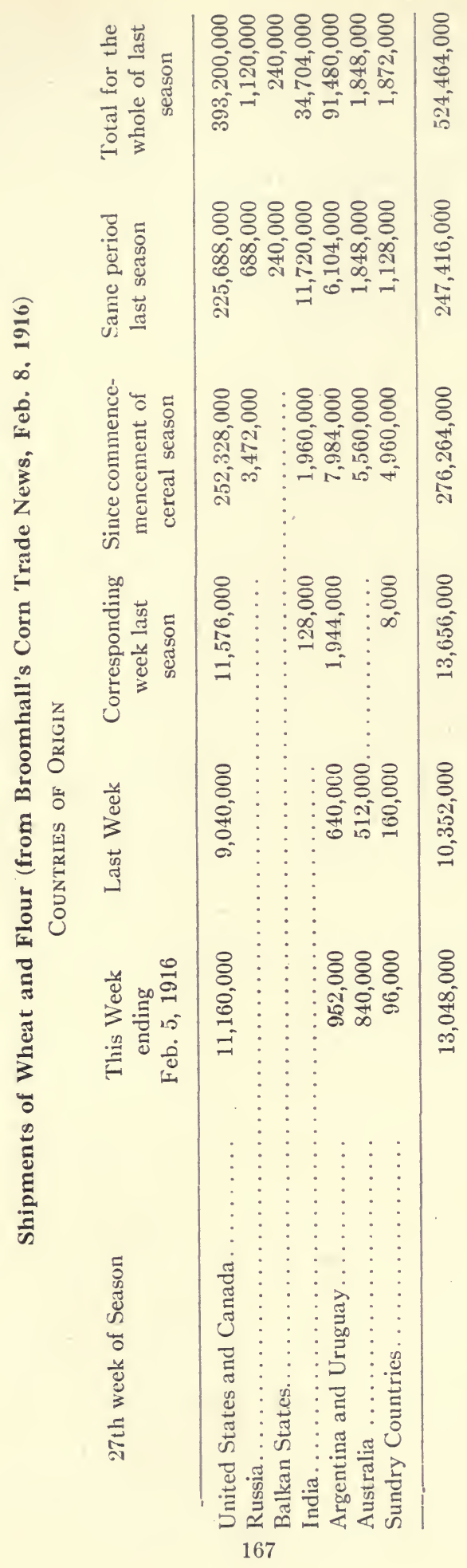


Russell's Commercial Review of February 8, 1916, has a paragraph reading in part as follows:- "As a result of a movement of wheat from North America from July 1 to December 31st, the official exports from the United States were 120,693,000 bushels against 177,088,000 bushels, last year, and Canada 129,539,000 bushels against $55,612,000$ bushels last year. During the five weeks just past the exports from North America have been $55,666,000$ bushels against $46,658,000$ bushels a year ago, with a large portion of these shipments still of Canadian wheat."

In the above table Broomhall shows what a large proportion of the total shipments are credited to Canada and the United States together. The official figures of exports of Canadian wheat and flour as wheat since the 1st of August, 1915, secured from the Canadian Customs Department follow:-

\section{Exports-Canada}

Bushels

Aug. 1915

$3,149,532$

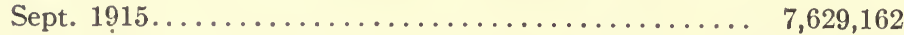

Oct. $1915 \ldots \ldots \ldots \ldots \ldots \ldots \ldots \ldots \ldots \ldots \ldots \ldots \ldots \ldots \ldots \ldots \ldots \ldots \ldots \ldots \ldots \ldots \ldots \ldots \ldots \ldots \ldots \ldots \ldots \ldots, 144,450$

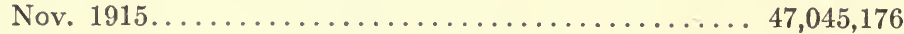

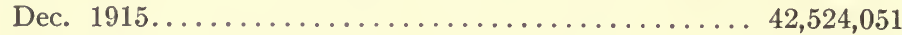

Jan. $1916 \ldots \ldots \ldots \ldots \ldots \ldots \ldots \ldots \ldots \ldots \ldots \ldots \ldots \ldots \ldots \ldots \ldots \ldots \ldots, 245,627$

Total. ...................... $\overline{143,737,998}$

Apart from Canada's exceptionally large crop, is there any explanation to offer why her exports should compare so favourably with those of the United States? It is understood that through the energetic representations of the Federal Government an understanding had early in the shipping season been reached with the British Government by which the latter should furnish the maximum number of ships for the distribution of Canadian grain. Apart from that, however, the Canada Grain Act of 1912 establishes definite grades of quality and provides for the control of these grades through strict inspection under the Grain Commission. The object of the Act was to perfect the system of Government supervision and control of the grain trade and to do away with difficulties and grievances which had arisen under the former law. In a supplement to George Broomhall's "Corn Trade News" of January 4, 1916, there is contained a long statement from the "London Corn Trade Association" communicated by the American Ambassador in London to the United States Secretary of Agriculture. In this statement-made on behalf of the London Corn Trade Association and "many European buyers of United States Grain shipped from Atlantic and Gulf ports," there is "expressed grave dissatisfaction with the conditions of trading in respect of the quality of grain exported on Certificate."

The rules governing the inspection of No. 2 Hard Winter Wheat in the State of Illinois are quoted and the statement denying that any of the specified qualities existed follows:

"Large quantities of No. 2 Hard Winter Wheat, 1915 crop, Chicago Inspection, have been sold and shipped in the last few months. A very large proportion of this wheat was neither dry, nor sound, nor sweet, nor did it weigh 59 pounds per bushel, nor even was it in any degree hard on its arrival in this country. Evidence in support of these statements is provided in Appendix A. accompanying this communication."

The representations rather favour buying on sealed sample as practised in the Russian trade but commend the Canadian law and practice in the following words:

"Prior to 1912, serious complaints were made against Canadian grading, but the Dominion Grain Act of 1912 and the administrative arrangements ancillary thereto, have effected very great improvements so that all European buyers have now confidence in Canadian certificates, and though a great number prefer trading on sample or on standard, they acquiesce in the system of grading and its concomitant 'certificate final,' as established by Canadian law and carried out by Canadian practice."

It may be inferred from the long communication that Canada's success in marketing her huge crop is to be ascribed in a considerable measure to the beneficial operation of the Grain Act, as the last paragraphs which we quote as follows show how strongly the London Association feel on the question of federal inspection: 
"It is indisputable that in normal times when the harvests in the producing countries are favourable, the state of affairs which has led to the present complaints will militate strongly against American certificated wheat obtaining its proper intrinsic value in competition with those of other countries. It is hard to believe that even those sellers who are dominated by considerations of merely personal advantage can be satisfied with this state of affairs, and it must be in the highest degree unsatisfactory to honourable traders in the States who have to suffer for the misdeeds of the unscrupulous ones.

"Federal Inspection seems to be the only way to produce a uniformity in quality. Any other way may well be described as a "stupendous undertaking." The want of uniformity in a system of grading must result in a lowering of the value of the whole crop, for buyers naturally base their price on the poorest quality they may receive. Separate grading by different ports tends to the lowering of the grades in the endeavour to secure trade.

"In our opinion neither sellers nor buyers should serve upon grading Committees nor have control of inspections.

"The chief point we desire to emphasize is that grain should be graded on its intrinsic merits according to standards which should not vary from season to season. Uniformity of treatment should be accorded to domestic and foreign buyers. For these and other reasons Federal grading appears to be necessary if operations in American grain are to be conducted to the greatest mutual advantage of traders on both sides of the Atlantic, and if the producer is to receive the highest current prices for his grain.'

\section{Record Crops, their Infrequency and their Recurrence-Significance of this Fact.}

The United States have, in the last three years, 1913, 1914, and 1915, established each year a new high record production of wheat, viz.: $763,000,000,891,000,000$, and $1,011,000,000$ bushels respectively. We have examined the annual production of the United States since she began to become a big exporter in 1882 and find no repetition of such an extraordinary performance. There are not even two new high records following each other. An examination of the following table will show how infrequent these new high records have been and how sometimes long periods of average low production have followed them.

\begin{tabular}{|c|c|c|c|}
\hline Year & & $\begin{array}{l}\text { Millions } \\
\text { of Bushels }\end{array}$ & \\
\hline $1882 \ldots$ & $\ldots \ldots \ldots$ & 504 & Record. \\
\hline $1883 \ldots \ldots \ldots \ldots \ldots \ldots$ & $\ldots \ldots \ldots$ & 421 & \\
\hline $1884 \ldots \ldots \ldots \ldots \ldots \ldots$ & $\ldots \ldots \ldots \ldots \ldots \ldots$ & 512 & Record. \\
\hline $1885 \ldots \ldots \ldots \ldots \ldots \ldots$ & $\ldots \ldots \ldots \ldots \ldots \ldots$ & 357 & \\
\hline 1885 -90 Average 6 years. . . & $\ldots \ldots \ldots \ldots \ldots \ldots$ & 425 & \\
\hline $1891 \ldots \ldots \ldots \ldots \ldots \ldots \ldots$ & $\ldots \ldots \ldots \ldots \ldots \ldots$ & 611 & Record. \\
\hline $1892 \ldots \ldots \ldots \ldots \ldots \ldots$ & $\ldots \ldots \ldots \ldots \ldots \ldots$ & 515 & \\
\hline 1892-97 Average 6 years. . . & $\ldots \ldots \ldots \ldots \ldots \ldots$, & 466 & \\
\hline $1898 \ldots \ldots \ldots \ldots \ldots \ldots$ & $\ldots \ldots \ldots \ldots \ldots \ldots$ & 675 & Record. \\
\hline $1899 \ldots \ldots \ldots \ldots \ldots \ldots$ & $\ldots \ldots \ldots \ldots \ldots \ldots$ & 547 & \\
\hline $1900 \ldots \ldots \ldots \ldots$ & $\ldots \ldots \ldots \ldots$ & 522 & \\
\hline $1901 \ldots \ldots \ldots \ldots \ldots \ldots$ & $\ldots \ldots \ldots \ldots \ldots$ & 748 & Record. \\
\hline $1902 \ldots \ldots \ldots \ldots \ldots \ldots$ & $\ldots \ldots \ldots \ldots \ldots \ldots$ & 670 & \\
\hline $1904 \ldots \ldots \ldots \ldots \ldots \ldots$ & $\ldots \ldots \ldots \ldots \ldots \ldots$ & 552 & \\
\hline * $1902-12$ Average 11 years. . & $\ldots \ldots \ldots \ldots \ldots \ldots$ & 659 & \\
\hline $\begin{array}{c}\text { Million } \\
\text { Acres }\end{array}$ & $\begin{array}{l}\text { Yield } \\
\text { Per Acre. }\end{array}$ & & \\
\hline $1913 \ldots \ldots \ldots \ldots 50$ & 15.2 & 763 & $\operatorname{Rec}$ \\
\hline $1914 \ldots \ldots \ldots \ldots$ & 16.6 & 891 & \\
\hline $1915 \ldots \ldots \ldots \ldots \quad 59$ & 16.9 & 1,011 & Record. \\
\hline
\end{tabular}

${ }^{*}$ Average acreage $46,000,0 c($, acres. 
Note the total acreage and yicld per acre during the last three new high record years; also the sharp rise from the 11 -year average of $46,000,000$ acres to 50,53 , and 59 million acres respectively. The yields per acre in the last two years, viz. 16.6 and 16.9 have not been equalled, not only in the whole period since 1882 but at any time. And the yield for 1913, 15.2, was in the 11-year period repeated only in 1906, 1909, and 1912, when the yields were $15.05,15.4$, and 15.9 respectively.

Moreover, the whole period of 33 years, with the exception of the last three, does not show a grouping of three successive years of big crops. Observe in the table the years of low production which have almost invariably followed high record years.

Other producing countries have had very similar experience although not so striking. Argentina had three good years in succession, 1906, 1907, and 1908, producing 155,192 , and 156 million bushels; but 1909 only produced 131 million. 1911 and 1912 gave 166 and 187 million bushels, but 1913 only 113 million bushels. Although during the last two years the Argentine crops were fair ones, the record crop of 192 millions reaped in 1907 has not since been repeated. Russia produced 154 million quintals in 1905; the production fell very much below that afterwards until 1909 when there was a record of 193 million quintals and a new record was not established again until 1913 when there were 228 million quintals.

In Europe, the United Kingdon, Germany, and Austria-Hungary have had a pretty steady production, with the United Kingdom and Germany increasing their production. France and Italy, however, hardly hold their own.

Canada's two good years 1912 and 1913 were followed by the short crop of 1914 and the tremendous harvest of 1915 . The determining factor in this big crop was not so much the increase of some $2,700,000$ acres in crop but the difference in yield per acre between 15.67 in 1914 and 28.90 in 1915 practically doubled the crop. Such a magnificent result can be reached again only by the miracle of perfect co-operation of Nature with the extraordinary efforts of our patriotic farmers. If Nature should not be propitious, then what a responsibility in this terrible conflict upon those who do not exert themselves to the utmost! Already there has been a bad start in that only $53 \%$ of the ploughing is reputed to have been done last fall in comparison with $71 \%$ in the fall of 1914. The official figures in November last were that at the end of October from 27 to $36 \%$ were ploughed compared with from 56 to $92 \%$ the previous year. There were 193,000 acres less sown to wheat last autumn than were sown in the previous autumn, besides there was $20 \%$ less summer fallowing than in 1914 .

What if the United States in the coming year should return to their 11-year average of $659,000,000$ bushels and have only sufficient for their own absolute needs? Conditions were so unfavourable last fall that the acreage they were able to put in winter wheat was $4,756,000$ acres short of that sown in the fall of 1914 . The crop has already had a bad start with insufficient snow covering on a large area and has been visited by dangerous frosts. Damage is also reported from serious inundations so that the abandoned acreage in the coming spring is almost certain to be larger than last season which was exceptionally favourable from that point of view. With a serious drought affecting the crop which India is about to harvest in March, placing her probably outside of the group of exporting countries, how disastrous would be a crop failure in both Canada and the United States!

\section{Crop Prospects for the World's Wheat Crops in 1916-Conclusions}

A few notes from the official reports and the leading Agricultural and Trade Journals will furnish some information concerning the conditions under which winter crops have been sown, how they are wintering, etc. 
England and Wales-According to the January report of the Board of Agriculture, up to the end of December three-fourths of the land intended for wheat had been seeded, and the sowings showed 6 to 7 per cent. decrease compared with those of the previous year. The condition of early sown wheat was generally good, but that of late sowings was not satisfactory. During January the condition of late sown wheat improved. On February 24th Mr. George Broomhall reported that weather in the United Kingdom was fairly seasonable and that some sowing was being done. (March 14.-Weather unfavourable, being wet and late; seeding is being adversely affected.)

Scotland-The wheat area is reported as considerably less than that of last year Except in a few localities the crop on February 1st was in promising condition.

United States-The acreage sown to winter wheat in the United States last autumn is estimated at $37,256,000$ acres, against $42,012,000$ acres sown in the previous autumn, a reduction of $4,756,000$. Besides this large reduction in the area sown all reports go to show that there will be a greater area abandoned this spring on account of winter killing than there was in the spring of 1915. During January and February very unfavourable reports of the condition of the crop were published. Reports irom the "Modern Miller" republished in Broomhall's "Corn Trade News" stated that early in January the winter wheat belt in the United States had lost its snow cover. Towards the end of the month a general absence of snow was still complained of. On February 8th according to Broomhall, there were several reports mentioning cold weather in the winter belt and stating that frost had set in after rain had cleared the snow from the fields. In Kansas, Missouri, and Nebraska the frost was preceded by snow. On February 25th, Russell's "Market News" quoting from the "Modern Miller" stated that snow covering had been removed from the winter wheat crop, and unfavourable reports were coming in from a wide area. The crop was thin and the winter kill above the average. Unfavourable reports were coming in from southern Kansas, southern Illinois and southern Indiana.

France-October was in general a good month and sowing and preparatory work were reported as proceeding with all possible speed. The weather in November was rainy, cold, and dry by turns, with storms, frost, and snow. Cereals showing above ground had generally a fine appearance. Towards the end of December George Broomhall's correspondent reported that the official estimate of the crop, making the total production 237,000,000 bushels, was "greatly overestimated." On January 25th the Government had published their estimate that $12,500,000$ acres had been sown to winter wheat up to January 1st compared with 14,500,000 bushels the preceding year. Still, he hoped more winter wheat would be sown in January and February and, weather favouring, some 500,000 to $1,200,000$ acres might be sown to spring wheat. February 1st, there was reported continued mild weather which caused some anxiety, as it promoted the growth of rank weeds and the development of insect pests. February 8.-Many complaints of excessively wet fields. It was hoped that later on when the cereal crops had made better growth that they would get ahead of the weeds and smother them. Labour has been very short for the seeding of new crops. It was stated that during February and March it was expected arrivals of foreign wheat and flour at French ports would be at the rate of 5,600,000 bushels per month and that from April 1st onward the arrivals would be at the rate of $7,200,000$ bushels per month.

The estimated requirements in 1914-15 were $41,000,000$ bushels, but the actual imports turned out to be some $70,000,000$. It is believed that for the year 1915-16 also the forecast will be exceeded by the reality. Broomhall's cable of February 24th stated that the outlook for wheat was fairly satisfactory. It was hoped that the Government would furnish sufficient labour for large spring sowing. Imports for the five months, August to December 31, 1915, were about 40,000,000 bushels. March 14.-Broomhall cabled: Supplies insufficient; importation continues on large scale.

Italy-In November it was reported that in northern Italy cereals were growing under satisfactory conditions, but that elsewhere there had been too much rain in 
places. January 4.-The outlook for the new crops was generally favourable. Jan. 4.It was reported that the Government had commandeered all the wheat and maize; that, moreover, an arrangement had been made for the better supply of steamers to bring necessary supplies of wheat, coal, and provisions. The report of February 1st, although generally favourable, complained that the southern districts lacked rain.

February 24.-Official report stated the crop outlook was satisfactory with the weather seasonable. March 14.-Crop outlook fair; reserves light.

Egypt and North Africa-Reports from the beginning indicated wheat had been sown under favourable conditions, subsequently the germination had been good and young plants healthy. February 24.-Rains had fallen and crops benefited.

Russia-The conditions of winter sowing were reported extremely favourable. Out of 64 provinces the sowings in 12 were satisfactory and in 52 above average in various degrees. December 19.-Broomhall's correspondent stated that up to that time the fields in many regions had not possessed a good blanket of snow, but that the winter sowings had gone under snow in a healthy condition. Various reports mention a decrease in the area under winter grain, but the position of the new crop was reported as quite satisfactory. According to Broomhall's Corn Trade News for Feb. 15th a report just received from Petrograd confirms that in some parts there has been a sharp decrease in the land put under winter cereals. The causes of the decrease are given as scarcity of labour and scarcity of horses, whilst in some parts war conditions are directly responsible for the smaller sowings. It is thought that the area under spring crops in the south and south-east of Russia will also show a large decrease. In January there were complaints that the millers found it difficult to obtain supplies owing chiefly to railway waggons and scarcity of bags. Jan. 11. - There was severe frost reported in the centre and north; in the south rain and snow alternated. February 8.-Conditions generally favourable although in the south in parts where there was no snow covering there were fears of damage from late frosts. Supplies appeared to be about fair. February 24. - Snow covering reported thin and parts of territory very cold. Officials believe that crops are all right. Private reports are unfavourable. Officials confirm $20 \%$ decrease in acreage.

Germany and Austria-Hungary-Crop conditions were from the beginning reported to be generally favourable. At the end of December frequent food riots were reported in Germany. February 10.-Hungary was issuing bread tickets giving the right to one-half pound daily for each person. Potatoes arriving in Berlin showed much damage from frost. Jan. 4.- It was reported that 50,000 railway waggons of Rumanian wheat were bought by Germany at $161,000,000$ francs; $39,000,000$ francs of export duty had to be paid, $131 / 2$ millions of it in gold. Much dissatisfaction was expressed by the Germans at these conditions. Jan. 18.-Crop conditions in Germany were reported as generally favourable, but heavy rains did some damage. The official Census Report was that there were sufficient supplies of breadstuffs until the new crops, but later the supplies turned out not to be as big as expected, therefore the bread ration had to be reduced, and instructions given that no more low-class rye meal must be used for the pigs.

February 1. - There were complaints at the slow marketing of the crops, and the Government provided for a gradual increase in the maximum prices of products to induce free sales. The marketing of potatoes was especially slow; although the poorer qualities for cattle were more freely offered, the better qualities were held back in the hope that a higher maximum price would be fixed. In February the weather was reported moderately colder with some slight frosts. There were some complaints of floods which, however, were not excessive. The statement that there was no scarcity of cattle foods is very much doubted. February 24. - Weather was reported moderately mild with occasional rain. No complaints heard from crops. Reports from Hungary, same date, indicated weather and crop news were favourable. 
Spain-The recent official estimate of the 1915 crop reduced the previous one by some $5,000,000$ bushels, making it $139,200,000$ bushels, which compares with $116,000,000$ bushels in 1914. Mr. Broomhall states that "official and unofficial authorities grant a large crop for 1915, but so far the supplies have not been in accordance with the estimates and imports have been made freely." ...... "The imports already made and the different qualities authorized to be imported free do not confirm the big crop estimates. If the large crop was actually gathered, it would appear that the growers must be holding back a considerable part of their wheat." At the end of December the weather was reported favourable for the new crops. February 1.-The new sowings were reported as follows:-

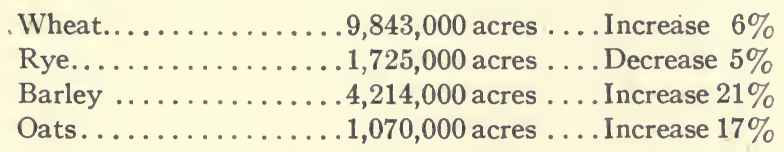

The sowings were made under good conditions with germination regular. March 14. - Outlook fair; reserves light.

Scandinavia-Extraordinarily low temperatures have prevailed in these countries, but it is not yet known whether the very severe frosts have had any harmful effect on the winter crops. February 8.-Norway abolished the duty on wheat and Sweden had already taken similar action to be effective until July.

South Africa-February 8.-The winter harvest at Cape Town was reported as favourable, but the official advices indicated that the out turn in the other parts of the Union was much less favourable, and the general harvest reported $10 \%$ below last year's. March 14.-Drought damage denied.

Australia-An arrangement was made in November for marketing the whole Australian wheat crop. The Federal and State Governments adopted a scheme for financing and handling the harvest, a Government Committee of experts to act as sellers and pool the proceeds, all the expenses of handling, transport, and sale of the harvest to be paid out of the pooled funds. The balance is to be distributed to the farmers, who will receive an advance up to 3 s. per bushel. February 8.- It was announced the crop movement was developing slowly. Offers were not large but very steady. March 14.-Favourable rains for new crop. Offerings are limited, and chartering slow.

Argentina-The crop harvested in January 1915, 168,470,000 bushels, furnished for actual export $94,356,000$ bushels according to Broomhall. The officials expected that the crop harvested in January of the present year, $184,000,000$ bushels, $16 \%$ larger than that of the previous year, would normally supply for export about $110,000,000$ bushels. In the official Bulletin of August-September, 1915, the disposition of a former crop of like amount $183,000,000$ bushels was referred to as normal and should furnish for export $110,000,000$ bushels, for seed $20,000,000$, for consumption $40,000,000$, in all $170,000,000$ bushels, leaving $13,000,000$ bushels to be discarded as unmillable wheat. The Argentine "Times" of December last estimated however that owing to the scarcity of tonnage not more than $70 \%$ of the available supplies from the $1915-16$ crops would be shipped. According to Broomhall's cable of February 24th wheat offers were moderate and quality satisfactory.

India-Since October the greatest anxiety has been felt concerning the crops owing to the existence of droughty conditions especially in the great wheat producing provinces of the Punjaub and in the United Provinces. A cable from Calcutta at the end of February states, however, that beneficial rains have fallen in the Punjaub, the United and Central Provinces and in Bihar. Our correspondent at Muzaffarnagar, United Provinces, cables that there they have had light, beneficial rains.

One-half of the area of the Punjaub and in the United Provinces fortunately is irrigated, that is, 5,800,000 acres are irrigated, and this encourages the hope that 
although this year's crop may not be a good one yet it will be sufficient to prevent any fear of famine. In the other provinces irrigated area would probably not average five per cent.

February 1.-Total area in wheat was reported revised to $28,244,000$ acres as against $29,752,000$ the previous year, a decrease of $5 \%$. Exports from India were stopped in October on the first appearance of dry weather. March 14.-Crop promises well, of fair quality.

\section{Conclusions $\backslash$}

The statements and data mentioned in the preceding pages may now be briefly summarized. When it became known by the midsummer of 1915 that the world's wheat crops would reach a record figure prices fell on this Continent even considerably below the dollar mark. Overseas importers with low reserve stocks at home, while floating supplies were reduced by one-half, neglected for a time to take advantage of the opportunities for the purchase of comparatively cheap wheat. When it was realized that a large proportion of the United States winter wheat crop was unmillable and supplies of merchantable wheat were slow in coming to market a sudden demand sprang up for wheat and for ships to carry it. The fact that huge spring crops of prime quality had been harvested did not interrupt that persistent demand nor did the fact that the subsequent harvests of the Southern Hemisphere were equally promising. Note, however, was taken of the seriousness of the drought prevailing in India where earlier in the season a bumper crop had been predicted. A further discouraging factor from the importer's point of view was the United States winter wheat report indicating a reduction of $4,700,000$ acres seeded to that cereal and a disappointing pre-winter condition.

However, the ocean freight situation had become of greater importance to the European importer than the enhanced prices. At the end of September freights had already advanced as much as $50 \%$ in a month and were already twice as high as the rates ruling the year previous when they were considered above normal.

Practically one-half of the merchant marine had disappeared from the ordinary channels of trade, and there was the keenest competition to secure the tonnage of the remaining half, so that by January the previously unheard of rates of 50 cents per bushel from New York to Liverpool and $\$ 1.00$ from Buenos Aires were reached. Mr. Broomhall aptly observed on January 18 th that while the price of wheat had risen $90 \%$ there had been a rise of nearly $500 \%$ in freights. Then came Government intervention. The Government of Australia intervened to remedy the situation in so far as the transportation of the Commonwealth wheat crop was concerned, and the British Home Government subsequently took action that tended at first to steady and afterwards to reduce the exorbitant charges.

Concerning prices, we have observed in this war the same tendency as in other great wars for the price of wheat to rise and fluctuate widely with the predominance of a comparatively high level even in spite of record production in the exporting countries. We have examined how for thirty years the enormous stores of wheat from virgin lands flooded Europe with cheap wheat; how increased population, and demand from increased consumption was finally capable of absorbing the whole production; how there followed what might be termed a stabilizing of production, so that fluctuations through a series of years resulted in a fair average, there being shown an increase of only $2 \%$ per annum in the total production of the world's wheat crops during the ten years ending August 1914.

Even with the exploitation of new sources of supply there has been from year to year since 1895 a higher level of prices, which persisted until 1909, and there is some better basis than a mere pious hope that the low average prices of 1910,1911 and 1912 will not be repeated.

Our tables have shown that since the outbreak of the war fairly high prices have been maintained with the exception of about three months in the late summer and fall of 1915. It has been suggested that some big milling interests and elevator companies were last season, as they had been often before, quite active in inducing the 
needy and timid producers to dump their wheat on to the market at any price until such time after the completion of the harvesting and threshing as the buyer's depleted supplies had been replenished. There were, however, many excellent reasons which have been mentioned why prices should rise again and maintain a fairly reasonable average. And in times of such stress in the Motherland and among our Allies, it is indeed fortunate that Mother Earth should have, during the past season, yielded up her treasures in such extraordinary abundance that, with prices only good to average the farmer should have been able to receive a very satisfactory reward for his toil. In the autumn of 1915, Europe's needs apparently had developed beyond the expectations of our Allies, some of whom at first naturally took the most optimistic view, inspired by the fair outturn of home grown crops and the reputed unlimited supplies soon to be available from abundant foreign harvests. The demands of France early became particularly urgent, and her first needs having been satisfied by imports from the United Kingdom, the latter's stores, with very little wheat arriving from overseas, soon dwindled to a record low point. Then arose the exorbitant freight rates nearly doubling the price to the European consumer, with nearly one-half of the total price, especially in the case of wheat from Argentina, going to the ship owner. This abnormal rise in freights, although having a tendency to deprive the producer of a due proportion of his legitimate profits, established a margin of difference of charges in favour of the North Atlantic route as compared with the rates from the Southern Hemisphere. Fortunately, the Canadian exporter was protected further because of the beneficial operation of the "Grain Act" and its wise administration, by means of which grain of uniform good quality is assured to the importer. Then there was an unlimited supply of Hard Wheat of prime quality for which there has been an almost unlimited demand. We have seen that Mr. Broomhall expected Canada's exports to exceed those of the United States, and it will not be surprising if there should be a demand limited only by the facilities for shipment, and the huge shipments of October, November and December may be repeated on the opening of navigation, with India practically out of the field as a competitive exporter. It is to be noted that the exports in our tables are estimated to the end of the world's grain year, namely August 1st, so that shipment of Canada's old crop may continue practically for two months longer without coming into competition with the new crop.

There seems a good basis for the opinion that the United States will not repeat in the coming season the great crops reaped during the last two years. The history of the past shows the improbability of it, and the ascertained facts concerning the winter crop, which has already been sown, emphasizes the improbability of it. It will be noted that, in so far as facts are definitely known, conditions in Europe, especially at sowing time, were not propitious. In the enormous preparations that have been going on for probably the fiercest struggle of the great conflict during the next few months there has been, and there must continue to be, a lack of labour and motive power as well for the sowing as for the subsequent tilling and harvest. It has become practically impossible to resort to the customary intensive methods with the use of fertilizers on regular rotations. We see in France the unfortunate results from forced abandonment of the old methods in the rank growth of weeds that probably can be but imperfectly controlled. Mr. Richardson, of Australia, has estimated from consideration of these and various other causes a reduction in Europe's wheat production for 1915 of at least $15 \%$. It is doubtful if this is not an underestimate as applied to the coming season, because the production of crops other than wheat, and especially roots, will suffer even more than that cereal from the war conditions. We have seen an instance of this in the very striking drop in the French production of potatoes and sugar beets, probably because of the absence of labour and fertilizers needed in their cultivation.

The conclusion therefore appears obvious. There is a reasonable expectation that remunerative prices will be well maintained, and there is every inducement to the Canadian farmers to extend to the utmost in the coming spring the cultivation of 
wheat. Nature is not always prodigal of her treasures, and although the yield per acre for the 1915 crop was at the record figure of nearly 29 bushels per acre, the average yield for the preceding five years 1910-14 was only 18.55. Assuming an acreage equal to that of the past year and with a good fair yield of 20 bushels per acre, there would be harvested a crop of $260,000,000$ bushels or over $100,000,000$ bushels less than that of last year with which to face a demand which, from all present appearances, will exceed anything that we have seen in this war.

The price of meat products is also well sustained, and the cultivation of the coarser grains and fodders required will ensure good profits to the live stock farmer. Economic interests unite, therefore, with patriotic duty in stimulating the agriculturists of Canada to extraordinary productive efforts during the forthcoming season.

World's Production of Wheat

\section{Countries}

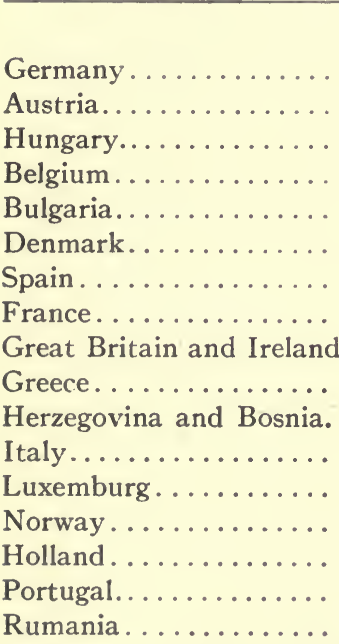

Russia in Europe (54 Governments)......

Serbia..............

Sweden.............

Switzerland...........

Canada...............

United States. .........

Mexico..............

Argentina............

India.

Japan...............

Russia in Asia (10

Governments).......

Algeria.............

Egypt..............

Tunis.............

Australia............

Totals excluding Germany,

Austria, Belgium and

Serbia..............
1915

Bushels

$\ldots \ldots \ldots \ldots$
$\ldots \ldots \ldots \ldots$
$151,407,000$
$46,612,000$
$4,917,000$
$139,160,000$
$237,806,000(\mathrm{a})$
$74,116,000$
$8,000,000$ (b)
$1,600,000$ (b)
$172,695,000$
516,000
269,000
$6,216,000$
$8,000,000$ (b)
$108,761,000$

$764,975,000$

..........

$6,400,000$ (b)

$3,880,000$

$376,303,000$

$1,011,565,000$

$8,000,000$ (b)

$184,162,000$

$383,376,000$

$23,669,000$

$$
\begin{array}{r}
143,849,000 \\
34,655,000 \\
39,148,000 \\
11,023,000 \\
143,000,000
\end{array}
$$

\section{$4,094,021,000$}

1914

1913

Bushels

$152,000,000$ (b)

$60,842,000$

$105,144,000$

$13,973,000$

$29,414,000$

$5,788,000$

$116,090,000$

$282,691,000$ (a)

$62,432,000$

$5,600,000$ (b)

$1,600,000$ (b)

$169,444,000$

613,000

269,000

$5,380,000$

$8,000,000$ (b)

$46,296,000$

$573,300,000$

$8,000,000$ (b)

$7,619,000$

$3,278,000$

$161,280,000$

$891,017,000$

$8,000,000$ (b)

$168,470,000$

$311,688,000$

$21,645,000$

$179,348,000$

$20,000,000$ (b)

$32,832,000$

$2,205,000$

$24,922,000$
Bushels

$171,077,000$

$59,626,000$

$167,351,000$

$14,769,000$

$60,627,000$

$6,695,000$

$112,402,000$

$319,373,000$

$56,696,000$

$4,030,060$ (b)

$2,560,000$ (b)

$214,407,000$

644,000

324,000

$5,081,000$

$5,600,000$ (b)

$84,192,000$

$813,784,000$

$11,024,000$

$9,330,000$

$3,509,000$

$231,717,000$

$763,380,000$

$10,400,000$ (b)

$113,905,000$

$362,693,000$

$25,20 \overline{7}, 000$

$121,143,000$

$36,848,0 \mathrm{C} \cdot 0$

$38,427,000$

$5,515,000$

$103,874,000$

(a) Not including territory occupied by enemy.

(b) From Broomhall's Corn Trade News. 


\begin{tabular}{|c|c|c|c|}
\hline & 1915 & 1914 & 1913 \\
\hline Countries & Bushels & Bushels & Bushels \\
\hline Germany........... & $\ldots \ldots \ldots$ & $567,575,000$ & $629,871,000$ \\
\hline 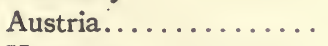 & $\ldots \ldots \ldots \ldots$ & $154,796,000$ & $173,606,000$ \\
\hline Hungary............ & $75,404,000$ & $81,447,000$ & $93,937,000$ \\
\hline Belgium............ & $\ldots \ldots \ldots \ldots$ & $46,816,000$ & $45,136,000$ \\
\hline Bulgaria............. & $8,983,000$ & $8,116,000$ & $12,968,000$ \\
\hline Denmark............ & $48,956,000$ & $44,440,000$ & $53,755,000$ \\
\hline Spain.............. & $34,207,000$ & $29,390,000$ & $23,843,000$ \\
\hline France............. & $242,912,000(a)$ & ) $299,610,000$ & $336,049.000$ \\
\hline \multicolumn{4}{|l|}{ Great Britain and } \\
\hline Ireland........... & $205,311,000$ & $189,618,000$ & $189,588,000$ \\
\hline Italy............... & $29,594,000$ & $25,249,000$ & $40,912,000$ \\
\hline Luxemburg. ......... & $2,000,000$ & $3,562,000$ & $3,425,000$ \\
\hline Norway............ & $8,777,000$ & $8,777,000$ & $12,870,000$ \\
\hline erlands.......... & $18,488,000$ & $18,784,000$ & $19,875,000$ \\
\hline Rumania........... & $28,172,000$ & $23,823,000$ & $35,756,000$ \\
\hline \multicolumn{4}{|l|}{ Russia in Europe } \\
\hline (54 Governments)... & $902,616,000$ & $680,017,000$ & $961,107,000$ \\
\hline Switzerland.......... & $5,220,000$ & $4,883,000$ & $4,792,000$ \\
\hline da............. & $520,103,000$ & $313,078,000$ & $404,669,000$ \\
\hline United States. . . . . . . & $1,540,362,000 \quad 1$ & $1,141,060,000$ & $1,121,768,000$ \\
\hline \multicolumn{4}{|l|}{ Russia in Asia } \\
\hline (10 Governments)... & 130,6 & $153,033,000$ & $113,966,000$ \\
\hline Algeria............. & $14,195,000$ & $12,877,000$ & $16,916,000$ \\
\hline Tunis............. & $3,242,000$ & 648,000 & $3,891,000$ \\
\hline Argentina........... & $71,000,000$ & $53,884,000$ & $47,983,000$ \\
\hline
\end{tabular}

(a) Not including the regions occupied by the enemy.

\section{HOW AUSTRALIA IS MARKETING ITS WHEAT}

As the 1915 wheat harvest drew near in Australia, the grain grower began to realize that he was in a very serious position. With the ocean freight situation governed by war conditions, and with the uncertainty as to wheat prices being maintained, no private firm or combination of firms dared to take the risk of large purchases, for, if unable to market while prices remained high, they might lose millions.

Under these circumstances, there was a strong probability that the bulk of the crop would remain unmarketed, and price demoralization threatened results that would be disastrous to the farmers, who needed the cash for their crop, and to the whole community.

On the other hand, the world was clamouring for wheat; there was no difficulty in finding buyers, and the country had a surplus of $150,000,000$ bushels for export. The Government recognized that the question was of national importance. It was vital not only to the Australian farmer, but to the Empire, that the crop should be profitably marketed: Some means must be found for disposing of it.

The scarcity of ocean vessels was at the root of the difficulty. Therefore, the first step was to secure all vessels controlled by the Commonwealth, in order to supplement those placed at the Government's disposal by the British Admiralty. Assuming 
that this would provide sufficient transportation, the problem was still only half solved. No guarantee could be given that ships would not be requisitioned for war purposes. Grain buyers declared "We will not buy a single bushel of wheat more than we have ships to fill, and those ships must be allotted to us absolutely,"-something that even the Government could not guarantee.

The Government therefore decided to assume the responsibility. The risk involved many millions. Only the Government with the resources of the country behind it could shoulder the responsibility of handling the entire crop and face the risk of lack of vessels and a falling market.

The scheme was a "pool" in which every farmer became a shareholder. First, the Government took complete control of the crop and of its disposal. No one could sell except to the Government; no one could buy except from the Government.

It was then decided that the farmer should be advanced $75 \mathrm{c}$. per bushel on his wheat, less freight from his station to principal shipping points. Arrangements were made with the Associated Banks to finance the undertaking. Farmers were to deliver their grain to the mills or railway stations, receiving the usual certificate, and on presenting same at the bank, were paid the sum called for.

For the money provided by the banks, amounting to millions of pounds sterling, a charge of $5 \%$ is made, which is a much lower rate than could have been secured by independent buyers.

Through agents, the Government undertakes to receive, forward and market the wheat. When the crop is finally disposed of, the balance, if any, over and above the $\mathbf{7 5}$ cents advanced, will be paid the farmer. He will thus receive all that the wheat realizes, less cost of handling, ocean transportation, marketing, and the 5 per cent. charged by the banks on the inoney advanced. Should the crop realize $\$ 1.14$ net per bushel, there will be a dividend of 39 cents payable on each bushel. Not only will he get full parity price for the wheat shipped out of the country, but also for every bushel used in internal trade, provision having been made for supplying millers at a price to be approximately the London parity. All will receive the same equitable treatment.

In normal seasons, ocean freight rates average from 16 to 24 cents per bushel. In December last the rate was quoted at 60 to 70 cents per bushel. Such tonnage as was available cost, including insurance, about 70 cents. According to the Journal of the Victoria, Australia, Department of Agriculture, the farmers were receiving the benefit of a reduction of from six to twelve cents per bushel in ocean freight, as a result of doing away with competition between dealers for vessel space.

The undertaking may be defined as a co-operative realization of the harvest, with the State acting as manager. Had it not been for this scheme, more than half the farmers of Australia would have faced ruin, with disastrous results to the whole community, a situation which, it is conceded, justified the Grovernment in taking action looking to its control.

Will it work out? It will, provided the Government can get the shipping. That is the risk the Government, or rather the country at large, must take.

\section{THE WHEAT CROP IN RUSSIA}

\section{KotChetkov, Assist. Agricultural Commissioner from Russia to the United States}

Wheat is cultivated in almost every part of the Russian empire, but the principal regions of this crop are the provinces of black soils (tchernozem) of European Russia. The distribution of the area under wheat crop in different parts of the Empire is shown in the following table, according to the data of the Yearbook of the Russian Department of Agriculture for 1912: 
I. Region of black soils:

1. Central agricultural provinces (Voronesh, Kursk, Orel,

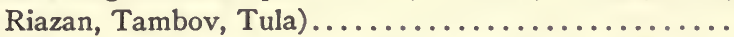

2. Middle Volga (Kazan, Nizhny-Novgorod, Penza, Saratov,

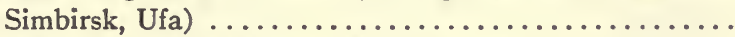

3. Low Volga (Astrakhan, Orenburg, Samara)............

4. Novorussia (Bessarabie, Cossacks of Don, Ekaterinoslav,

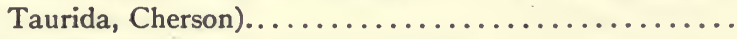

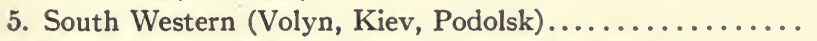

6. Little Russia (Poltava, Charkov, Tchernigov)........ 207,913 1,275,624 Total for Region.................. $3,355,853, \overline{14,150,024}$

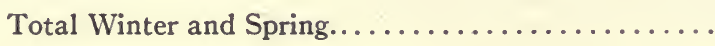

$17,505,877$

II. Region of other soils:

1. Industrial provinces (Vladimir, Kaluga, Kostrome, Moscow,

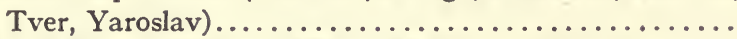

2. White Russia (Vitebsk, Minsk, Mohilev, Smolensk).....

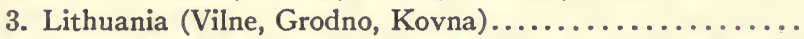

156,634

663,945

$6,658 \quad 1,644,659$

$10,491 \quad 3,991,897$

\begin{tabular}{|c|c|}
\hline $1,870,149$ & $6,461,593$ \\
\hline $1,104,008$ & 112,306 \\
\hline 207,913 & $1,275,624$ \\
\hline $3,355,853$ & $14,150,024$ \\
\hline
\end{tabular}

$1,417 \quad 31,569$

$24,005 \quad 27,149$

$77,993 \quad 16,316$

$4,072 \quad 1,744$

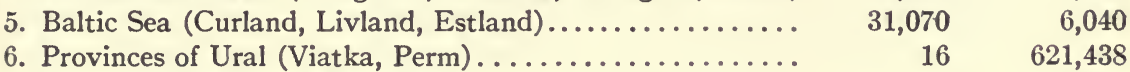

7. Northern (Archangel, Vologda)................ 16,586

Total for Region..................

Total Winter and Spring.............. 859,416

$* 1$ desiatin $=2.7$ acres.

III. Provinces of Vistula. (Warsaw, Kalish, Keltze, Lomzha, Lublin, Petrokov, Plotsk, Radom, Suvalki, Sedlets)

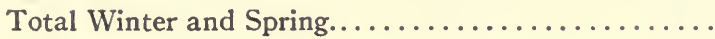

459,292

2,817

462,109

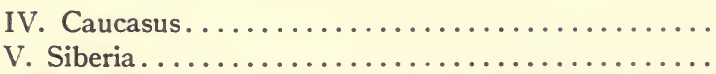

$3,134,965 \quad 1,518,428$

$4,704 \quad 2,598,109$

VI. Middle Asia (Akmolinsk, Semipalatinsk, Semiretchensk, Turgai, Ural, Syr-Daria, Samarkand,

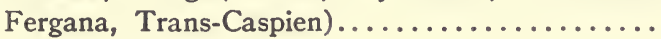

Total for the Empire.

$7,537,268$

$21,395,078$

Total Winter and Spring............... 28,932,346

It can be seen from this table that the area under winter and spring wheat in European Russia, with Poland (provinces of Vistula) but not including Caucasus, was in 1912:

$18,827,402$ desiatins $=50,833,985$ acres; and in Asiatic Russia and Caucasus:

$10,104,944$ desiatins $=27,283,349$ acres.

In the sixty-three governments (provinces) of European Russia 92.9 per cent. of the total area $(17,505,877$ of $18,827,402$ desiatins) under wheat cultivation is in the region of black soils. 
The total yield of wheat is increasing, as shown by the following table:

TABLE II.

Total net yield of wheat in

Year

63 governments of European Russia

Thousands of Poods*

$1890-1 \ldots \ldots \ldots$

$1895-6 \ldots \ldots \ldots$

$1900-1 \ldots \ldots \ldots$

$1903-4 \ldots . . .$.

265,957
520,773
525,981
771,757

Table II shows rapidly than the export. consumption per inhabitant, while it increased during the period 1892-1904 from 1.5 poods ( 54 pounds) to 4.5 poods (162 pounds), may seem very low, but it is not to be forgotten that the principal bread stuff in Russia is rye, the total yield of which in the Empire was, in $1912,1,602,263,000$ poods as against $1,331,655,400$ poods of wheat.

The total yield of wheat in 1912 was distributed in different parts of the country as follows, in poods:

\section{TABLE III.}

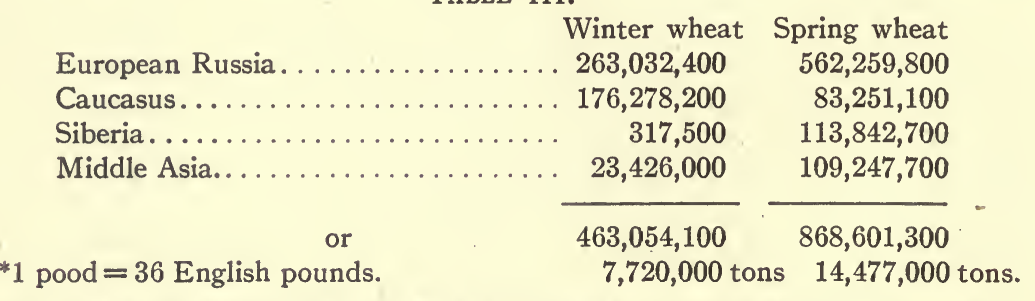

The export of wheat in 1912 was $240,545,000$ poods of grain, for the sum of $258,824,000$ rubles, and $7,352,000$ poods of wheat flour, for the sum of $12,637,000$ rubles.

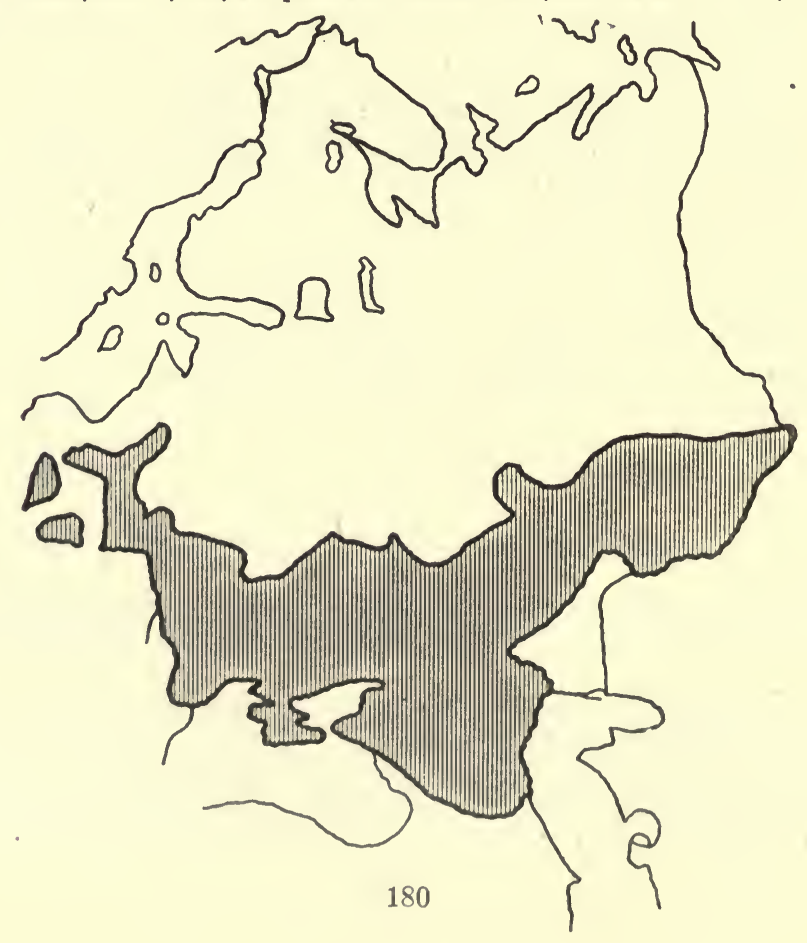


We have seen that most of the wheat is produced in the region of black soils in Southern Russia. On the map is shown (shaded with black lines) the region exporting wheat abroad or to other parts of the country. The following table (IV) gives the figures of transportation of wheat on the railroads from the region producing an excess of wheat to other parts of the country and abroad:

TABLE IV.

\begin{tabular}{|c|c|c|}
\hline \multirow[t]{2}{*}{ Year } & For Domestic Consumption & \multirow{2}{*}{$\begin{array}{l}\text { For Export } \\
\text { Poods }\end{array}$} \\
\hline & Thous & \\
\hline 1895 & 47,546 & 109,229 \\
\hline 1900 & 80,097 & 59,015 \\
\hline 1905 . & 87,205 & 147,686 \\
\hline 1909. & 115,804 & 248,129 \\
\hline
\end{tabular}

In addition to the railways, the rivers form an important means of transportation, connected as they are by a system of canals, for example, the Volga River is connected with Petrograd. We are sorry not to be able to give you any figures concerning this means of transportation. On the railroads the grain is transported in sacks; on the rivers, in bulk in large barges (200 to 280 feet in length on the Volga) towed by steamers.

\section{Methods of Growing Wheat}

Table III shows that about two-thirds of the wheat produced in European Russia is spring wheat. The methods of its culture are different in different parts. The best varieties of durum wheat are produced, up to the present time, on the lands which periodically are left for several years ( 5 to 15 ) for pastures and prairies, after having produced four or five different crops (wheat or flax, rye, oats, buckwheat). However, this kind of system is becoming more and more rare and can be found practically only in the extreme eastern parts of the region of black soils. As a rule the spring wheat is grown in the regular rotation of three years (fallows, rye, spring crops, such as wheat, oats, barley). The use of the farm manure is not yet general on the black soils, but its use is growing. There is no doubt that many virgin black soils are so rich in organic matter and nitrates that the use of manure is even harmful, especially in the dry years, causing the "burning" of the crop because of the excess of salts in the soil moisture. Experiments show that phosphates (acid phosphate, Thomas slag) give usually very good results on black soils, but its use in this region is only in the experimental stage. Practically, fertilizers are used on a large scale only in southwestern and western Russia for sugar beets.

The methods of tillage for spring wheat are usually very simple. In the "steppes" (prairies) of southern and southeastern Russia, the virgin soil is ploughed in the fall to a depth of six to nine inches, harrowed in the spring, and the sown seed is harrowed again.

Even now, in eastern and southern provinces, primitive ploughs ("Sabans") with a large flat iron share and wooden board, are used for the first deep ploughing, but this kind of an implement is becoming more and more exceptional, giving place to the modern ploughs of different kinds.

In the regular three year rotation (see above) the field, after rye, is usually ploughed in the fall to the full depth of five to seven inches, harrowed in the early spring, sometimes ploughed again, but shallow-four to five inches, and the sown seeds of wheat are harrowed or disced. The manuring, if any, always takes place in fallow, once for six or nine years, because of the lack of manure. In this case the spring wheat follows the manured rye.

The winter wheat is cultivated principally in western and southwestern provinces and in Caucasus. In the western part of Russia the methods of agriculture are more intensive and careful than in the East. The fallow preceding the wheat is always well manured. The peasants usually begin to plough the fallow late, at the end of June, but good farmers try to plough it for the first time in April or May, harrow several times 
during the summer, in order to destroy weeds and to keep the upper part of the soil pulverised, to keep the moisture in the soil. Six or, at the least, four weeks before the time of sowing, which takes place in the first days of September, the field is ploughed shallow or cultivated or disced.

The use of the modern ploughs (especially of German types Sack, or Eckert), discs, drills, harvesting machines, binders, horse rakes, etc., is very common at every middle sized or large farm, and the stores of Zemstvos (self-governing organs of the provinces or districts) and the co-operative stores are rapidly introducing modern implements among the peasants.

\section{Organization of Grain Elevators and other Grain Storehouses}

In Russia there is a network of grain elevators organized in many internal governments by the State Bank. We shall give below the description of these elevators. In addition to this network, the Ministry of Trade and Industry raised the question of systematic creation of elevators in seaports. The preliminary programme of the Minister of Trade was approved by the State Duma in the sessions of 1912 and 1913.

Below is data relative to the grain export trade of Russian ports and their need of grain elevators, according to the project of the Ministry of Trade and Industry.

Archangel-The average annual trade in grain being estimated at 125,000 tons, the project admitted the desirability of having at this place four floating elevators. At this time there is only one private floating elevator. The local Board of the Port expressed the necessity of one permanent elevator with a capacity of 17,000 tons.

Petrograd-The normal export of grain here is 900,000 tons, 350,000 tons of this arriving by railways and the remainder by waterways. In addition to the existing warehouses, a necessity was admitted for at least one elevator with a capacity of 35,000 tons.

Revel-Many of the private warehouses at this place are quite distant from the line of landing of the vessels, and it was admitted to be urgently necessary to have here an elevator with a capacity of 17,000 tons and, later, another of the same capacity, after the completion of the Moscow-Revel Railway.

Riga-It was proposed to build an elevator of 20,000 tons capacity and later another of 17,000 tons capacity.

Windava-At the normal export of 230,000 tons per year, it was admitted desirable to build here an elevator with a capacity of 17,000 tons.

Libau-The private grain dealers solicited in 1913 for an elevator of 70,000 tons capacity.

Odessa-Normal trade, $1,500,000$ tons yearly. Projected an elevator with a capacity of 70,000 tons and well equipped warehouses with a capacity of 60,000 tons, and, later, another elevator of 70,000 tons capacity.

Nicolaiev-The normal trade is estimated at 1,750,000 tons, more than $1,000,000$ tons of which needs storage. Estimating that an elevator will be filled six times during the season, the capacity of the necessary storage houses must be 185,000 tons. In addition to the existing elevator of 35,000 tons, it is necessary to have well equipped storage space for 150,000 tons. The Southern Railway Company planned to enlarge its existing elevator by the erection of a third building of a capacity of 25,000 tons.

Cherson-It is admitted desirable to build here an elevator of 50,000 tons and well equipped warehouses.

Eupatoria needs an elevator of 25,000 tons.

Theodosia needs an elevator with a capacity of 35,000 tons and well equipped warehouses for 17,000 tons. 
- Berdiansk-The normal grain export of this port is 400,000 tons yearly. About fifteen per cent. of this quantity is loaded from the cars directly to the steamers, and the total need of grain warehouses is estimated for this port at 60,000 tons. The existing storehouses are rather temporary, and, therefore, the port needs an elevator with a capacity of 35,000 tons, which could be enlarged later by an additional elevator of 25,000 tons.

Mariupol needs an elevator of 50,000 tons. Because of the planned improvements of this port its trade must grow, and it will soon need another elevator of the same capacity. With planned improvements of the port and building of the elevators, the export trade of Mariupol is expected to reach 800,000 tons of grain annually.

Taganrog-It is planned to build an elevator of 35,000 tons capacity and warehouses with capacity of 50,000 tons.

Rostov-The normal export trade of grain is about $1,600,000$ tons annually. About 340,000 tons, or sixty per cent. of the grain imported by river, and 170,000 tons, or twenty-five per cent. of the grain imported by railroad, are loaded directly from the barges and cars. There is in the port a private elevator, with a capacity of 13,500 tons, and warehouses with a capacity of about 115,000 tons. It is proposed to build on the new wharf two new elevators of 25,000 tons capacity each, and, in addition, two groups of well equipped warehouses with a total capacity of 50,000 tons. The project forsees also that, after the actual work of equipping the river Donets with locks is finished, it will be necessary to build here an additional elevator of 17,000 tons capacity.

Novorossiisk-The normal annual export of grain is more than 1,000,000 tons. Twenty-five per cent. of the exported grain is loaded directly from the cars. The remainder of the grain needs warehouses of 130,000 tons capacity. The capacity of the existing elevator (the largest in Russia) and other grain warehouses is about 90,000 tons. The remaining 40,000 tons will be more than covered by the obligatory building by the Vladicaucasus Railway of a second elevator with a capacity of 50,000 tons.

If we add the needs of the ports of Azov, Eisk, Temruk and Kertch, we may admit the total immediate need of our ports as

$$
\begin{aligned}
& \text { Elevators...................... 6,000,000 tons } \\
& \text { Well equipped warehouses............... 170,000 tons }
\end{aligned}
$$

The average cost of construction of elevators is estimated at $\$ 18.00$ per ton of capacity, and of well equipped warehouses $\$ 10.00$ per ton of capacity.

If we admit that the project overestimated the work of the elevators and that the elevators will be filled not six, but five times in a year, and the warehouses four times in a year, the quantity of grain served yearly by the present and proposed grain storehouses will be, in round numbers:

$$
\begin{aligned}
& \text { Proposed elevators. ................. 3,000,000 tons } \\
& \text { Proposed warehouses.................. 650,000 tons } \\
& \text { Present existing elevators............. 1,650,000 tons } \\
& \text { Total........................ 5,300,000 tons }
\end{aligned}
$$

or, approximately, five million tons, or more than one-half of the actual sea export.

The Ministry of Trade and Industry asked, for this purpose, a credit of $25,000,000$ Rubles $(\$ 12,500,000.00)$. We have no information at hand concerning the subsequent fate of the above mentioned project of the Ministry of Trade.

Actually the work of building a network of elevators in the country is in the hands of the State Bank, a Department of the Ministry of Finances. The latest information we have upon the activity of the State Bank in this direction we take from the "News 
of the Ministry of Agriculture," No. 10, February 10, 1913. In an article entitled "Elevators of the State Bank" we find that, in 1912 and 1913, the Bank constructed new elevators in the following points:

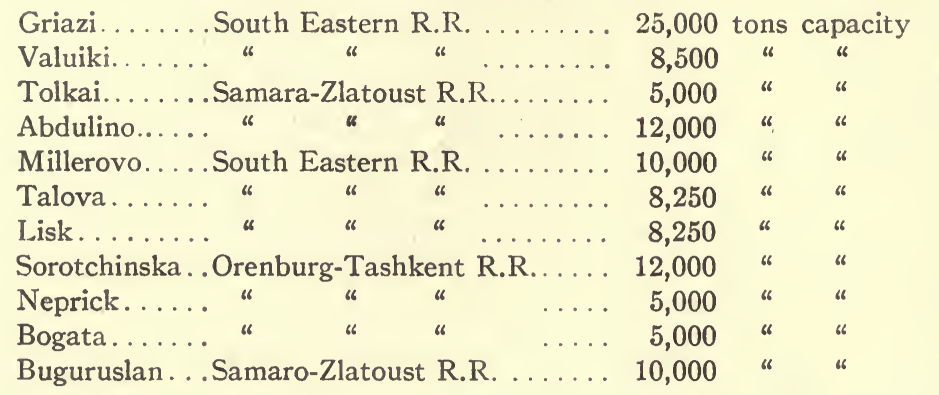

In 1914 the elevator in Samara, of 50,000 tons capacity, was opened. It was also planned to start in the spring of 1913 on the building of 19 elevators with a combined capacity of 185,700 tons.

The whole system of State Bank elevators, comprising eighty-four elevators, was to be completed in 1916. The network of all these elevators covers eight provinces, i.e. Samara, Saratov, Simbirsk, Voronesh, Tambov, Penza, Orenburg, and Ufa. Later it is planned to enlarge this scheme to the south and the southwest (provinces of Kiev, Kharkov, Poltava) and to the east to Siberia.

We find a description of the construction of State Bank elevators in an article by Mr. W. Alexandrov, in the "Agricultural Gazette" (the organ of the Russian Ministry of Agriculture) for 1914, No. 23.

The smallest size elevator is 5,000 tons. The capacity of the elevators in each case is determined in relationship to the grain trade of the place, usually twenty to thirty per cent. of the latter.

As a rule, the elevators are built upon the silo system; but, in some exceptional cases, in addition to the silo system, there are rooms for the storage of flour in sacks or oats in large bast sacks, prepared for shipment on the rivers Volga and Kama. Each silo has a capacity of from fifty to one hundred and seventy tons.

The elevators are equipped with conveyors, automatic scales, machines for cleaning the grain, etc. All the machinery is run by electricity from power station, which is placed in a separate brick building, near the elevator. The principal building materials used in the construction of the elevators are concrete, hollow concrete brick, iron and wood covered with iron.

\section{FARM STORAGE OF GRAIN}

\section{E. A. HOWES, Dean of Faculty of Agriculture, Edmonton, Alta.}

The question of greater production has been a live one in the Province of Alberta during the past year. There has been an unusually large crop, a record breaker in fact; and the very size of the crop and the great bulk of grain to be marketed has brought to light a condition in the West that must be fairly faced. Reference is made to the congestion in grain traffic that automatically follows a large harvest. Advice is cheap, also there are probably several factors to consider in discussing the amelioration of present conditions, but one factor well worthy of careful consideration is treated in the following paragraphs. 
That the crop last year was an unusually bountiful one was largely due to favourable climatic conditions. Nevertheless, the increased effort to make the land produce was partly accountable for it. This increased effort was called forth mainly by patriotic motives, but partly by a perfectly legitimate wish to profit by the unusual demand caused by war conditions. Part of the result is past history. Prices were undeniably good, but not as good as some expected. Probably prices could never go high enough to meet all expectations. However, the great trouble in this province lay in the fact that while yields were good and prices were good, most of the farmers, having no storage facilities of their own, wished to unload as early and as rapidly as possible. They could not always do this, and much dissatisfaction resulted, not to speak of definite loss caused by the delay. If, during the coming year, something could be done to mitigate this trouble, it would be a work well worth undertaking.

It is not intended to offer suggestions to railroads, because car shortage is to be expected after harvest; indeed it appears most unreasonable to blame the roads for failing to carry, the year round, cars sufficient to handle the grain rush at autumn. The roads, however, should be urged to make all possible provision in mobilizing cars for the jam that is sure to come, following a favourable summer. Nevertheless, it would seem that the farmer should shoulder a certain amount of the responsibility. Readymade granaries are not hard to procure, and while these cost money, and it is cheaper to haul direct to the elevator, it is better to provide them than to suffer loss from delay. Then, too, the man who can hold his grain for a time is bound, in the average of years, to command a higher price than the man who sells during the rush. The very large grain grower may feel that it is impossible to provide adequate storage for his own use, but with the average farmer-and he is in the vast majority-it is both practicable and advisable. Any person interested in granary construction should read Bulletin No. 8 issued by the Department of Lands, Victoria, British Columbia.

\section{BACKYARD AND VACANT LOT GARDENING}

\section{OTTAWA}

The vacant lot gardens in the City of Ottawa consisted of 128 plots, fifty by one hûndred feet, for which no less than 180 applications were received. There was great enthusiasm shown by the majority of the gardeners during the summer. It was no unusual sight to see one hundred persons busy at their gardens on a summer's evening. The season was favourable for most crops and in consequence the results, as a whole, were very satisfactory.

A number of persons told what they had grown on their plots, the following being some examples:

Plot No. $31-10$ bags of potatoes; 300 ears of corn; 1,200 cucumbers and 300 tomatoes.

Plot No. 13-12 bags of potatoes; a liberal supply of corn, pumpkins and squash.

Plot No. 20-9 bags of potatoes, a large crop of tomatoes, cucumbers and beets.

Plot No. 110-Potatoes, 6 bushels; carrots, 1 bushel; turnips $1 \frac{1}{2}$ bushels; beets, 2 bushels; cabbage, 36 heads; green beans, 16 gallons; peas, shelled, 10 quarts; onions, 2 gallons; corn, 13 dozen cobs; tomatoes, $314 \mathrm{lb}$. ripe, 2 bushels green.

Plot No. 121-For a family of seven, a constant supply of green beans, July 15 th to Oct. 1st., potatoes, 6 bags and sufficient carrots, turnips, parsnips, onions and cabbage for the summer, fall and winter supply. 


\section{NOTES FROM TORONTO BACKYARD GARDENERS}

"If someone started a plausible story about two million dollars being buried in the back yards of Toronto, it can readily be imagined with what eagerness the people would be up with the early bird and out in the yard digging for treasure. The treasure is there all right."

"I have kept no account of cash returns from my $40 \times 50$ foot garden, but at least $\$ 12$ or $\$ 15$ would have to be paid out for such supplies as it produced. But the point I wish to make is the advantage of having sound fresh fruit and vegetables and their more frequent appearance on the table."

"I never made any serious attempt at gardening till this year. The work has been such a pleasure and the results so satisfactory that, apart from the value of the crops, I have been well rewarded."

"We have been well supplied with fresh vegetables all summer, and hope to store a good supply of carrots, parsnips, celery, etc., for days to come."

"My garden of $60 \times 20$ will reduce household expenses by at least $\$ 25$." .

\section{WOODSTOCK}

- "Recently I made the final inspection of the backyard gardens at Woodstock, Ont., and found some splendid gardens. It was a surprise to me to see how much could be raised on a small plot of ground when properly worked. Places which were weeds last year, so I am told, are places of profit and beauty this year. Most of the contestants had flowers along with their vegetables, which added to the appearance. There was one garden $50 \times 100$ where over $\$ 100$ worth of vegetables were produced. Other gardens produced as much in proportion to their size. In some cases we found three crops of lettuce had been grown, two crops of radishes and two crops of beets. The contestants seemed well pleased with the effort they had made and I was pleased to have the benefit of doing the judging." -

I. B. Whale.

\section{HAMILTON}

The Garden Club of the city of Hamilton for the year 1915 has been a decided success. We had two hundred and twenty-five members and with one exception they diligently cultivated their lots with the result that their families are amply provided with potatoes and other vegetables for the coming winter and in many cases they have sold what they did not require for their own use.

We estimate that more than 5,000 bags of potatoes, besides large quantities of other vegetables, have been grown by the members of the club.

\section{MEDICINE HAT}

While only 78 lots were registered in the books of the Vacant Lot Garden club as being cultivated, there were perhaps five or six times that many which were actually cultivated, and most of these were the direct or indirect result of the Vacant Lot garden movement. 
Never before in the history of the city has there been such an abundance of vegetables, and never before has the cost of living been so low. For the first time Medicine Hat has exported potatoes. Previously a great many carloads of potatoes have been brought in, but this year several carloads have been shipped out, and there are more to follow.

A great deal of garden truck was grown on acreage, and many who entered in this way got their inspiration from the Vacant Lot Garden club campaign in the local papers, and distribution of literature, so that it created a sentiment in favour of gardening which produced wonderfully gratifying results.

\section{CALGARY}

The second year of the Calgary Vacant Lots Garden club proved a great advance upon the first. Last year the total number of lots under cultivation was 243; this year it was 976 , an increase of 733 . This would represent about 100 acres devoted to vegetables that were brought directly under control of the club. In his report the Secretary-Treasurer, Mr. H. G. Burrows, says:

"We cannot begin to estimate the value of this work to the community. Every family in this city has been benefited directly or indirectly through the work of this organization and what has been accomplished cannot be weighed by dollars and cents."

\section{THE BACKYARD GARDEN}

The war still goes on; the need for food stuff is becoming more urgent as the time passes; therefore, it is important that, not only should the farming communities be encouraged to furnish more produce, but all persons in the cities, towns, and villages who have sufficient ground for a garden should grow something and thus do what they can to assist production. In many of the cities of the United States, and in a few in Canada, Garden Clubs have been organized.

We have in Canada an untouched force, throbbing with vitality and anxious to help-the boys and girls-many of whom have received training in gardening along with other subjects taught in the schools. Organized into clubs, enlisted possibly through the aid of the schools, they would prove no small factor in solving the diffculties that may arise through shortage of labour. The food produced through these agencies would be at the doors of those who most require it. It would be fresh and crisp every day, and the quantity consumed would probably increase 100 per cent. or more, thus effecting a considerable saving in the expenditure for meat and bread. The outlay would be small, and the saving to the people as a whole would be great.

A campaign for more production, conducted along the lines above mentioned, would cheapen the cost of living for those taking part, would increase materially the supplies for export, and would mean more food for the warring nations of Europe.

-Milton J. Tinline.

\section{The Home Vegetable Garden and a Patriotic Gardening Competition -Pamphlet No. 13 by W. T. Macoun, Dominion Horticulturist.}

Additional information on vegetable growing, the use of hot beds and cold frames, etc., will be found in pamphlets issued by the Publication Branch, Dept. of Agriculture, Ottawa, Ont. Free on application. 


\title{
THRIFT
}

\section{THE NECESSITY FOR PUBLIC AND PRIVATE, ECONOMY}

\author{
"Extravagance, always a folly, in these days becomes a crime; thrift, \\ always a virtue, in these days becomes a national duty."
}

Germany's Example--In Germany, since the war began, strict economy has been the order of the day. The whole population has cut down its living expenses, and has stopped all unnecessary work, so as to devote the greatest possible part of its labour to supplying the fighting men with material. By the Allied command of the sea, German foreign trade has been mostly stopped. But the German people have managed to do without their imported luxuries. The absolute necessities they have managed to produce at home. At the same time the stoppage of imports has relieved Germany from the necessity of sending out exports to pay for them. This has set free a great mass of labour and produccive capacity, which has become available, firstly, to produce such goods as will replace the absolutely necessary imports; secondly, to produce war material. In consequence, after a year and a half of war, Germany is able to supply her people with the necessities of life out of the fruits of their own labour: and in addition, to keep her armies in the field plentifully supplied with munitions-and this while she has at least five or six million men in the fighting line.

Restricting Consumption in Britain-Until a few months ago, hardly any effort was made in Great Britain to restrict consumption to what was necessary, so as to have as large a surplus as possible left for the supply of the war. This was not through want of patriotism, but because people did not see the truth of the situation. Owing to war orders and to the rise of prices, all producers were making great profits, workmen were earning high wages, there was an appearance of prosperity and plenty of money in circulation. People could see no need for cutting down their expenditure-they could live as well or better than before.

Urging Economy-But the mistake was pointed out, and was soon brought home. People saw that no nation could carry on a war costing nearly half its national income, and at the same time go on living as before, without quickly coming to collapse and disaster. A campaign for economy was started all over Great Britain and is now going on. People are being taught that they must cut down their cost of living to its lowest point and restrict themselves to necessaries. It does not matter whether individuals can afford superfluities or not. Every superfluity consumed means that so much labour has been expended in producing it, which might have gone to producing the necessaries of life or supplies for the army. There is simply not enough labour in the country to produce the necessaries of life for the civil population, the supplies required for the army, and the superfluities as well. If superfluities continue to be consumed, it means that there will be a shortage of the other things. In the same way public bodies are being forced to abandon all work that is not absolutely necessary, whether they have the money for it or not. That is not the question. If they had the money ten times over, by spending it on unnecessary work they are diverting labour which should be employed in another way. 
The Crisis over in Canada-The situation has been recognized in Great Britain, but it has not been so fully recognized in Canada. When the war began we were forced by the shutting off of borrowed capital into a measure of public and private economy. That was so much to the good. But we were economical not because we recognized the need for it - that need was not recognized even in Great Britain at that time-but because we were forced to be. Now our situation has changed. Thanks to the tremendous harvest and enormous war orders, money is abundant, and we have nearly got over our local economic crisis. We have the same apparent prosperity as Great Britain. Do not let us repeat her mistake. We cannot afford it, if we are to do our share in the winning of this war.

A Better Situation-The question will be asked-Can we afford to supply goods. on credit, and to what extent? We could not afford it six months ago, because we had to meet our own current debts abroad. But that situation has now changed. We have cleared off our current obligations, and for the future we have only to meet our operating expenses. Everything above that will be profit, and we need not insist on immediate payment.

Canada's Opportunity-It will appear from the above that if we are willing to observe, during the remainder of the war, from choice, the same economy in public and private expenditure that we have observed during the past year from necessity, we shall be in a position to extend to Great Britain and to our Allies an assistance that will be even more valuable than sending our soldiers to Europe; and that this assistance will not only cost us nothing, except to abstain from the pleasure of spending our money as fast as we make it, but will turn to our own great advantage.

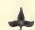

All money that is spent in these days on superfluous comforts and luxuries, whether in the shape of goods or in the shape of services, means the diversion of energy that can be better employed in the national interests, either in supplying the needs of our fighting forces in the field, or in making commodities for export which will go to reduce our indebtedness abroad. And, on the other hand, every saving we make by the curtailment and limitation of our productive expenditure increases the resources which can be put by our people at the disposal of the State for the triumphant vindication of our cause."-Mr. Asquith.

"To meet the costs of the war it is necessary that our savings should be doubled; and this will mean the exercise of economy to an extent which is not yet appreciated by the bulk of the people. The alternative to drastic economy is drastic taxation.

It is not yet clear that Local Authorities have realised the fundamental change that has taken place in their financial position and the pressing necessity that exists for retrenchment and economy. . . . The public must realise that the era of extravagance has passed away, and that for many years to come a policy of the strictest economy must characterize the administration of the local as well as the national government of this country."-QUARTERLY ReVIEW.

"The question of personal expenditure is a difficult and delicate one. It is easy to lecture other people, but what is more important is to make every man understand that he should examine his own expenditure, to see how much he can cut it down in the national interest. It is for the men who benefited from additional income derived from the war to show why this expenditure should not be postponed until the war is ended."

-Hon. A. J. Balfour. 
"As a representative of the army in the field, I want to appeal on their behalf to the civilian army at home to play their part strenuously. Whether the army in the field, who are entirely dependent on the civilian army for food, equipment and munitions, can get those things in sufficient quantities depends absolutely and entirely on whether every man and woman at home shows the utmost energy in production and the utmost economy in consumption. Any failure in this respect helps the enemy to win just as much as the soldier who refuses to do his utmost in the field of battle.

"The question is how we can take millions of men from their workshops and farms and yet provide for all the needs of the civil population and the army millions in the field. If those left behind only work as hard as they did before and all the consumers consume as they did before the war, our problem will be insoluble.

"Hitherto we have filled the gap by vast importations, but the Chancellor of the Exchequer and other financial authorities impress us with the vital necessity of reducing our imports. The dilemma is either that the civilians must go short of things that they are accustomed to in peace times or the armies must go short of munitions and other indispensable supplies. Which is it to be?"-LORD KITCHENER.

"Canada has been in the habit of doing as little as possible for herself and calling on the resources of the banks and lending companies, in the last few years. There has been a constant stream of money, millions and hundreds of millions, sums incalculable and beyond our simple conceptions. Credit has been too good, resources too great and optimism unbounded. We have unlocked the doors of the vaults and have revelled in 'loans."-Sir GeORge Foster.

Every penny saved helps You and your Country.

Every penny spent unnecessarily helps the enemy.

Save your money now; later it may save you.

Some can serve their country by fighting;

Some can serve their country by working;

All can serve their country by saving.

"There is, I believe, a call now-a most earnest and special one--for service and sacrifice by everyone in this Province and in every part of the Dominion, and every reasonable step should be taken at this time of stress and strain that will add to the strength of the country and conserve our resources in every way possible for the great task. It is surely a time for all of us to abstain from luxuries and extravagance in what we wear and what we eat as well as in what we drink."-PrEmier Hearst.

"As we all know, in 1915 there was an enormous contraction in the manufacturing and mercantile business of the country, although to a considerable extent this was replaced by orders for munitions - the phenomenal harvest also further assisted the recovery of trade. The necessity for practising economy has been impressed on all of us, but I am afraid that so far there is very little evidence that the advice has been taken seriously, either by individuals or municipalities-restrictions in expenditures must be, I think, brought about in both cases."-SIR EDMund OsLer.

"The United Kingdom has advanced large amounts to Canada for military expenditure, and the time may come when it will be desirable, if not necessary, for the Dominion to finance its own requirements. In any case, we must economize in every way possible so that we may bear our full measure of responsibility during the war and be prepared for the taxation that must follow."-Sir F. Williams-TAYLOR. 
"We have heard a great deal about the conservation of national resources. The war has proved the possibility of a wiser conservation of our individual resources, and we have realized our social responsibilities at this time of national crisis. We must now realize that we are the trustees of our own incomes and owe it as part of our contribution to the building-up of a greater Canada that useless extravagances be abandoned. This needs most careful consideration."-Department of Public Health, Toronto.

On every hand one sees evidences of waste throughout the country as well as in the cities. The farm home, the country hotel, the school child, the youth and maiden, all show the same disposition to regard food, clothing, furniture and books with carelessness and prodigality. A general thrift campaign, such as some of the speakers of the Women's Emergency Corps advocate, should be of inestimable value.

Thrift will help us to win the war, and the lessons we are receiving in thrift will do us no harm when the war is over. But there must be thrift all round. Thrift means a system under which all can thrive-not a system of senseless luxury and ostentation for some, and of grinding poverty and hardship for others.

Economy in Canada, to be effective, must divert labour and capital from catering to indulgence in luxuries to the production of food, clothing, munitions, and other essentials of national strength. Retrenchment in foreign-produced luxuries is most likely to meet this requirement. Under normal conditions imports make foreign markets. But we have in the consumption of war a market for all we can produce and more.

Economy that renders labour or capital idle is worse than useless. Only such economy as diverts labour and capital to more productive uses or to the production of more permanent results can be regarded as beneficial. Where results of that nature are not virtually assured it is better to avoid all disturbing departures from the ordinary patronage on which commerce and industry depend.

Thrift is not cheese-paring, but an intelligent use of food and other resources, the habit of sacrificing personal interests to the nation's.

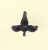

Produce more and consume or destroy less is a simple, effective, and unassailable formula, but economies that cause unemployment without the certainty of resultant greater production should be avoided as worse than useless.

If you want to have some one working for you, put some money in the bank. 


\section{Campaign of Thrift}

In Great Britain a campaign has been inaugurated by direction of the Board of Education, to promote thrift among the schoolchildren. A circular has been issued by the Board explaining that facilities are to be provided and the pupils are to be told of the desirability of subscribing to the war loan. "Teachers, should make clear," says the circular, "that everyone who can save even so small a sum as five shillings has an opportunity to contribute to the loans. Reginald McKenna, Chancellor of the Exchequer, speaking at a meeting to urge economy and to promote the loan, said "The people of this country have got to learn that in our present circumstances parsimony becomes the highest virtue. A lump of sugar not consumed, bread not wasted, and a cigar or cigarette not smoked means so much less imported foreign goods which we can pay for only by sending gold out of the country or borrowing it. We must economize if we are to endure."

\section{Saving in the United States. Campaign Inaugurated}

The American Bankers' Association has now inaugurated a country-wide campaign for the promotion of savings, and invites the co-operation of bankers, business men, school authorities and the public generally, in making it as influential as possible.

Movements of this kind have an unusual dignity and effectiveness when carried on by a nation-wide organization for a large public purpose, and afford a special opportunity for every well-disposed person to give help.

A campaign for savings is deserving of support at any time, but now more than ever it should appeal to public favour. An especial effort will be made to enlist the cooperation of the public schools, and teach the children the principles and habits of thrift. The campaign will be ably and enthusiastically led and if proper co-operation is given there will be results worth while.-The National City Bank of New York, January, 1916.

\section{PLAIN LIVING AND HIGH THINKING}

"We have found to our surprise that the plainer living imposed by the losses of the war is not by any means so great a hardship as we feared. We now realize that many of our supposed luxuries, some even of our presumed necessities, were so merely because we thought them so, or rather because our neighbours thought them so. We have discovered practically, what our sages have long tried to teach us, that a very large proportion of our expenditure has served no end of real comfort, but simply the lust of the eye and the pride of life. The simplest, easiest, and most comfortable mode of living is, on the whole, that of conformity with our environment; and now that we have all gone down a peg or two together, we really are scarcely aware that the general level has been lowered. It is astonishing how many things we can do without and not miss them-provided they are not rudely recalled to our consciousness by gloating possessors next door. On the more positive side we are equally astonished to find how quickly we become used to little actual discomforts that at first seem intolerable. Just as many of our gilded youth have had, in the trenches, to accommodate themselves to an intimate association with vermin, so we find it easy to ignore, in a high cause, numbers of little irritants that would once have raised intolerable blisters. Grumbling has almost wholly ceased. We are all so busy that we have no time to think of inconvenience. 'Slackers' and 'grousers' have become almost synonymous terms; and the group they embrace is a very small one."-James F. Muirhead, of London, England. 
"I doubt if the working classes of this country regard any more the aristocracy as an effete race of parasites battening on their labours. And, on the other hand, the aristocracy more than ever before realises the magnificent qualities of the British working man, and what the nation owes to him. I think the common sacrifice has brought all classes together in a manner that has not existed since the Napoleonic Wars. The common peril has reunited the country.

"Furthermore, all our standards of life are changing, and must continue to change. The nation must go back to the simple life, to the less luxurious method of our ancestors. I do not mean that I want the poor to suffer in any way. The more wages the working man earns to the extent that he can procure for himself and his family better food, better clothes, better housing, the better it will be for the country. But above this minimum standard of comfort, every class will have to alter its ways. We shall have to abolish all useless luxury; we must dispense with every form of extravagance.

"This war is going to be the great leveller. Money must no longer be the criterion of power. Wealth must no longer be the proof of superiority. Henceforth the citizens of this country will have to pull together."

- Hon. Walter long, President local Government Board of England.

\section{ECONOMY IN THE HOME}

\section{Good Food, Well Cooked}

If it is true that half the cost of living is the cost of food, then with the whole world calling for economy, there never was a time when the need was greater for economy in domestic expenditure. Nor was there ever a time when there was a greater need for knowledge regarding food values and the preparation of nutritious food at small cost.

This is essentially woman's work, and those who complain of the drudgery of preparing three meals a day often fail to realize how important that work is in the affairs of life. The usefulness, happiness and efficiency of the individual depend largely upon health, which to a great extent is governed by the suitability of food and its proper preparation. That the world should have wholesome meals at reasonable cost is far more vital to national welfare than the question of a career for women. The architecture of the house we live in, the fashion of our clothing and many other things that enter so largely into the make-up of our lives are non-essential. What is far more important is that men and women should be strong physically and efficient mentally. The ranks of the world's strong men are being sadly thinned, and the vigour of those who will grow up to take their place depends so much on the work of the women in the home that the importance of the subject needs strong emphasis.

When the importance of food in relation to human welfare is borne in mind, it is pitiful when we consider how little sensible thought is given to the subject, and how many women, particularly in cities, are brought up without any real knowledge of this important office, and sometimes actually to despise a knowledge of domestic affairs.

\section{What makes the Food Bill large}

Very often the food bill of a household is excessive for the following reasons:

1. Poor cooking. This sometimes results in the waste of about one-third of the food used. Under this heading may be included badly constructed ovens, and lack of knowledge as to the temperature at which food should be cooked. Generally too much heat is used.

2. Loss through cooking excessive quantities.

3. Buying materials that are of small nutritive value.

4. Buying foods that are out of season, and consequently high-priced. Select native products. 
"There is food enough in flesh and vegetables wasted in Canada every year to feed every hungry mouth, if conserved and saved. Authorities in Britain state that the majority of people should save 10 per cent. more than usual and the more wealthy, 20 or 25 per cent. Are we doing it?"-MONETARy Times.

\section{$+$}

"It has been said that more is wasted in a Canadian home in one week than would keep a French family for two weeks, and there can be little doubt that there is much truth in this statement. Nearly every day in very many homes enough is thrown away to make most valuable soups, and garbage cans far too often reveal most deplorable waste." -Dept. of Public Health, Toronto.

\section{Meat Consumption}

Based on the Census returns of 1910, the per capita consumption in Canada works out to $61 \mathrm{lbs}$. of beef, $9 \mathrm{lbs}$. of mutton, and $663 / 4 \mathrm{lbs}$. of pork, or $1363 / 4 \mathrm{lbs}$. of all kinds of meat.

An estimate of the per capita consumption of meat in the United States was given as 172 lbs. for 1909, and from the information to hand it appears that Canada's neighbor is the greatest consumer of meats per capita. Other countries are given as follows: United Kingdom, 119 lbs.; France, 80 lbs.; Germany, 113 lbs.; Argentina, 140 lbs.; Denmark, 76 lbs.; Norway and Sweden, 74 lbs.; Belgium, 70 lbs.; Austria-Hungary, 64 lbs.; Russia, 50 lbs., and Spain, 49 lbs.

\section{ECONOMY IN FOOD}

The following appeal is made in the September issue of the Journal of the Board of Agriculture of Great Britain: Everyone who lives in the country or has a garden can produce something to eat-the more the better; vegetables, fruit, poultry, eggs, rabbits, milk, cheese.

\section{Every Plant in your Garden may Save You Money.}

Produce all you can; buy as little as possible! Cultivate thoroughly! Destroy insect pests and weeds! Prepare manure!

\section{Preserve and Store Your Crops With the Greatest Care.}

The finest harvesting may be rendered useless by bad storing. Protect from the weather! Destroy vermin! Store your own vegetables! Bottle your fruit or make jam or pulp of it! Preserve your eggs when abundant? Cure your own bacon.

\section{Eat Little Meat}

Replace meat by milk, cheese, peas, beans and lentils, which are as rich in fleshformers as meat, and much cheaper. Use more vegetables! Eat more fruit! Bake your own bread; it will be cheaper and better.

\section{Cook Vegetables by Steaming}

Boiling in water reduces their food value! Cook potatoes in their skins! Use the hay-box cooker; it will save coal.

\section{WASTE Nothing}

Buy nothing from abroad that can be produced at home. 
In England the National Union of Women's Suffrage Societies has been conducting a very successful campaign throughout the country in national economy. Patriotic housekeeping and child welfare exhibitions have been organized in many towns, at which lectures have been given by experts on the best use of food, the use of money, civic wealth, etc., and exhibits have been shown of fuel economizers, economical cooking utensils (such as hay-box cookers), simplified furniture and all sorts of labour-saving devices.

A model patriotic housekeeping exhibition was held at the N.U. Shop in London in November and December, which was very much appreciated. The kitchen was literally packed during the demonstrations, and visitors came from Leeds, Devon, Carlisle and Hants, and many, not connected with the N.U., stated that the information given by the exhibition was exactly what they needed for thrift campaigns contemplated by themselves at home.

\section{WHAT KIND OF APPLES TO BUY}

\section{POINTERS FOR THE CONSUMER}

\section{JOHNSON, Fruit COMMISSIONer, OtTAWA.}

Do not buy the Ben Davis for use in the fall nor the Ribston Pippin late in the winter. Such errors have done much to turn the public from a most delicious food.

Like the gardener who plants flowers to give a succession of bloom from early spring till late fall, our apples should be chosen to give us the best quality, both for dessert and cooking, from fall until the spring.

The average consumer appears to think that there are only one or two high grade varieties of apples produced in Canada. He has heard of the Spy, the McIntosh Red and the Fameuse, and thinks he must have these, no matter how much he has to pay for them, whereas other apples, quite as good in quality, are practically unknown. The Spy is undoubtedly an apple of fine flavour and texture, but, like other apples, it has its season and it's off-season. In the early part of the year, say the latter part of August and the first of September, the Yellow Transparent, Autumn Strawberry, Gravenstein and St. Lawrence are just as much to be desired as the Spy during the winter months. In September the Spy will not compare with such varieties as the Ribston Pippin, a medium sized, streaked apple of most delicious acid flavour, a splendid cooker, and particularly delightful when baked and served with cream; but it, too, has its season and, if kept too late in October, it grows mealy and is not a desirable apple to buy. Other apples that may be purchased at this time with the assurance of getting something equal in quality to the Spy, are Wealthy, Fall Pippin and Blenheim Orange. These are succeeded in the latter part of October and in November by such varieties as the King, an apple well known to all commercial fruit dealers as being unusually beautiful, large in size, red in cqlour, full of juice and of a flavour unexcelled by any other apple produced on the Continent. The King is a difficult apple to grow as the tree is not productive, and on that account is it not as well known to the public as it should be, but I should consider my supply of apples incomplete without a good quantity of Kings each year. But the King has not the monopoly of fine flavour for this season. The R.I. Greening is then at its prime. This variety is so well known that it is unnecessary to enlarge upon its qualities. It is one of our best dessert and cooking apples and, as it is produced in large quantities in the various provinces, it is usually sold at a low price in comparison with some of the more showy apples. I have often thought that if the Greening had the colour of the Spy, it would displace it in public favour, and it is my conviction that no household should be without a good supply of this variety at the beginning of the winter. It holds its flavour and keeps well on into the winter. 
For January and February we have many varieties of splendid quality, such as the Steele Red, Spitzenburg, Grimes Golden, Yellow Bellflower, Jonathan, Tolman Sweet and Hubbardston. These are all dessert apples of the highest quality, and for my own use I would just as soon have them as the Spy, and I am sure that no one will question but that they are quite as good as the Spy for cooking purposes. As winter advances, I would suggest for dessert such varieties as the Golden Russet, which at this season surpasses all other varieties in richness of flavour. For cooking, even the much despised Ben Davis, Stark and Gano, if properly prepared, will then be found very acceptable, and may be depended upon to keep, without showing material waste, right on into the late spring.

As my life has been devoted to the fruit growing industry, I think I may safely claim familiarity with all the standard varieties grown in Canada. It may therefore be of interest to state the varieties I selected for our own use during the present winter, after we had exhausted our supply of Ribston Pippin and Gravenstein. Since the family is not a large one, we secure our apples in boxes. The list was as follows:Snow, McIntosh Red, King, Greening, Bellflower, Jonathan, Steele Red, Spy, Golden Russet, Ben Davis.

"Perhaps the item most to be condemned, as usually it is positively dangerous, is the patent medicine, which is found in such alarming quantities in so many homes."-Toronto Dept. of Public Health.

\section{THE FOOD VALUE OF CHEESE}

\section{Dairy Department O.A.C.}

Cheese at $17 \mathrm{c}$. a pound furnishes, for one dollar, more than twice as much human energy as is obtained from one dollar's worth of beef sirloin at 18c. per pound. There is more than twice as much muscle building food in a pound of cheese as in a dozen eggs. The more general use of cheese as a food will help to reduce the cost of living.

Note the following points about cheese.

(1) Cheese furnishes energy and muscle.

(2) It can be eaten without cooking, or made into a variety of cooked dishes.

(3) Well prepared cheese is practically pre-digested and can be eaten by any one.

(4) There is less water about dairy products than any other class of foods.

Ask your grocer for Canadian Cheese and insist that it be of good quality. Make up your mind to eat it at least once a day. The Dairy Department at the Ontario Agricultural College, Guelph, has issued a leaflet containing receipts for cheese dishes which will be sent on aplication.

\section{THE CANNING OF POULTRY}

\section{DR. R. Barnes, Chief of Meat and Canned Food Division, Ottawa.}

Since the bringing into operation of the Meat and Canned Foods Act eight years ago, the effect has been to eliminate veal as a constituent of the products labelled and sold as "Chicken" and "Turkey."

It may not be out of place to state that at the time the Act came into force there was not one single plant in Canada engaged exclusively in the canning of chicken. Several had tried and were losing ventures, due solely to the fact that they could not place on the market an honest product at the price for which so-called "Canned Poultry" could be purchased, and of this counterfeit there were thousands of cases. 
It may be asked how the Meat and Canned Foods Act produced such a wonderful change. First, by prohibiting the movement of canned poultry from one province to another, or out of the Dominion, unless it had been inspected and marked. Secondly, by requiring a true and correct description on the label. These two requirements can only be met by the examination of the raw material by a qualified veterinarian who passes only what is fit for food, who controls sanitary conditions and supervises the product from the time it enters the plant until it is shipped out to the trade.

The official markings are the words "Canada Approved," the Crown and the establishment number. This mark on any tin or package indicates that the article within was at the time of marking sound, healthy and fit for food, and that in the case of products, the process of manufacture was conducted under proper sanitary conditions. Purchasers of canned poultry should buy only such as bear this mark, otherwise they have no assurance as to the soundness of the product.

\section{THE BEN DAVIS APPLE}

\section{BY PETER MCARTHUR}

To-day I was tricked into praising the Ben Davis and I culled my choicest adjectives in an attempt to do it justice. And now that I know it was the Ben Davis I was praising I am not going to take back a word. Instead I am going to add to them.

My change of heart is due to Charles M. MacFie, of Appin, Secretary of the Glencoe Apple Growers' Association. When I was calling on him he invited me to sample a new preserve his wife had been putting up. He.went to the pantry and brought out a sealer filled with something faintly ambertinted and delicately translucent. It looked like citron or like especially successful pear preserves. While he was getting me a dish of it, my mouth watered in anticipation, for it certainly appealed to the eye. I tasted it. Superb. I thought it was pear preserves, though it was better. Instead of the flat taste often noticed in pears it had a faint sub-acid flavour that made it perfect.

When I had finished my eulogy he told me as gently as possible, so as to avoid shock, that what I was eating was preserved Ben Davis apple. It seems that this apple has been masquerading all these years. Instead of arousing contempt as an eating apple, it should be ranking with the pear as a preserving fruit. He gave me a sample from another sealer which contained the same kind of preserves, except that the apples were not peeled. The choicest flavours are just beneath the skin and it was even better than the first, though not so attractive in appearance, and the skin was so tough that it had to be rejected. But it was fit for a king of the canners. I naturally asked Mrs. $\mathrm{MacFie}$ for the recipe, and here it is:

Peel and core the apples and cut each into about twelve slices. Place in a preserving kettle and add two cups of sugar for each quart of preserves. Cover with boiling water and then let the preserves boil in the covered kettle until the apples become transparent. Then seal away while hot.

\section{HOUSEHOLD EFFICIENCY}

\section{MisS M. U. WATSON, Director Macdonald Institute, Guelph.}

The daughters of Canada should not be sent to homes of their own 'without the training necessary for intelligent buying and satisfactory preparation. They should either receive it at home, or be sent to school and be given opportunity to learn it before marriage.

The best milk at any price for the babies. Their lives depend upon it. 
Buy skimmed milk for milk soups and desserts, because it is a substitute for meat and costs about quarter the money.

Eliminate meat from the diet of small children. The normal child will thrive better on milk, cereals and eggs in place of meat. A child's appetite is what the parents make it. Do not feel sorry for the child whose breakfast is oatmeal and milk, and whose supper is bread and milk with a bit of biscuit and jam; the child is well fed.

The housewife who prevents a dollar's worth of waste has earned that dollar, iust as surely as did her husband in office, workshop or farm.

An ignorant and untrained servant wastes more than an intelligent buyer can save.

Constant watchfulness and the careful training of helpers are the only safeguards.

The untrained mistress cannot be expected to prevent waste. Her ignorance is as costly as that of ignorant servants.

\section{AVOID WASTE}

\section{Miss B. M. Philp, Lecturer, Macdonald College, Quebec.}

We women have responded well in providing necessities for the men at the front, but there is an equally urgent duty before us in seeing to it that the resources of our country are husbanded and conserved in order that we may stand the heavy drain and strain upon us. The women of France have given us a wonderful example of what can be done by thrift and resourcefulness. The women of England are learning the lesson, but we in Canada scarcely know the rudiments of economy. Life has been too easy for us. Nevertheless we have shown what we were capable of in Patriotic work, and if we will we can prove equally successful in the checking of extravagance, in increased productiveness and in the conservation of resources.

Let every woman begin at once to examine the channels through which her money goes. How much is spent on necessities, how much on luxuries? Let her learn to do without the latter by stopping them at once or by degrees. Study the amounts spent for the necessaries of life. Are they wisely spent? Do we secure value for our money? If not, let us not rest until we do. The physical necessities of life may be grouped under the headings: shelter, food, clothing. Shelter includes rent or its equivalent and the running expenses of a home, such as light, fuel, taxes, laundry, repairs, wages, telephone, etc. Study each of these outlays carefully and see if there is waste anywhere. Learn to economize in light by switching off the electricity when not in use and doing with fewer lights. In the matter of fuel much is often wasted by not understanding the furnace or range and burning much more coal than one gets return for in heat. Learn to run the furnace economically. If we can make a ton of coal last a few days or a week longer than before we have accomplished something in the way of economy. Turn off the gas directly instead of leaving it a minute or so after the food is cooked, and make use of the simmerer more frequently. Repairs are often made necessary by carelessness in handling. Learn to take care of furniture and equipment and insist that the other members of the family do likewise. Even the boisterous small boy will respond to the appeal when he realizes that he is thus helping to win the Empire's battles. Dry out the bars of soap so that there may be less wastage, and do not leave it lying in the pan of water you are using. Utilize the soap scraps in making melted soap for laundry or other purposes. These are just a few of the ways in which leakages occur in the running expenses of a home.

In the matter of food the chief causes of waste are (1) Poor cooking, resulting in a loss of food value or rendering the food unpalatable so that much is left on the plates; (2) Buying more of some commodities than can be used before spoiling; (3) Buying staple goods in too small quantities and losing the reduction in price for quantity; (4) Buying 
things out of season; (5) Buying cooked foods that could be more cheaply prepared at home; (6) Not making use of leftovers, water in which vegetables are cooked, etc. (7) Buying things that could be produced at home. Even an apartment can have a window box for parsley and cress, and many a city home has a bit of ground which could be made to produce vegetables for the home table.

Clothing is perhaps one of the most difficult lines in which to avoid extravagance since the desire for personal adornment is inborn in every one of us. The shops present so many alluring accessories of dress that our expenditure for these of ten exceeds, that for the actual clothing of the body. Still even here we can be stern with ourselves, in the light of the present need. It must be not "What can I buy?" but "What can I do without?" Let us limit ourselves to real necessities and in the purchase of these let us see that we get value for our money. Buy only suitable materials. Learn to recognize quality and insist on getting it. Garments made of good material, though more expensive at the outset than shoddy, wear many times as long, keep their shape and look well long after the poorer article has gone to the rag man.

In the matter of production the women of rural communities have many opportunities for helping that are denied to their urban sisters. Every extra dozen eggs they can secure from their poultry yards, every additonal peck of vegetables or fruit they can produce and take to market will help the cause. In the lack of adequate help in the fields due to enlistment they can supply much of the need since with the introduction of machinery the necessity for physical strength has been much lessened and any woman can learn to drive a gang plow, a harrow, mower or binder. The opportunity is ours to see that the output from Canadian farms for 1916 does not fall below that of 1915, but, if possible, exceeds it.

\section{HOUSEHOLD ACCOUNTS}

\section{Miss B. M. Philp, Lecturer, Macdonald College, Quebec.}

Keep accounts in order that you may see where your money has gone and what proportion your respective expenditures bear to the whole outlay and to each other. This need not be done in an elaborate and burdensome way, but as simply as possible. Below is given a form which is easy enough to be kept by any woman and which may be adapted to suit her special circumstances.

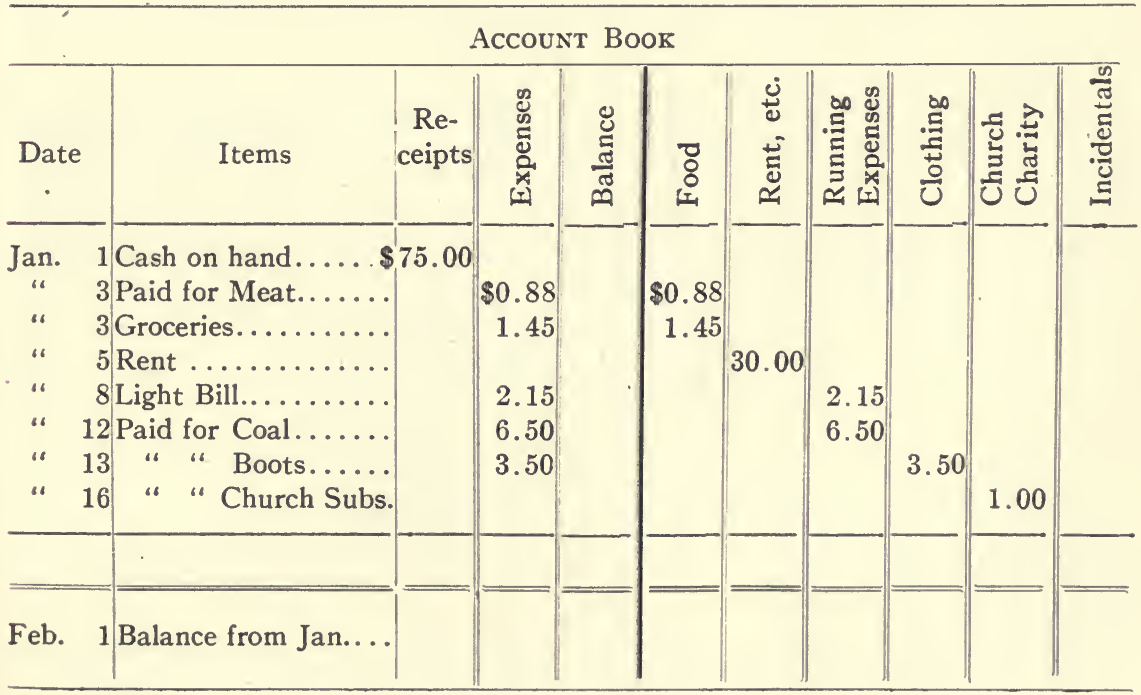


Any blank book may be ruled and used for this purpose. A form such as the above shows the date and nature of each transaction. Receipts and expenses are clearly shown and the balance may be found daily or weekly as preferred. The remaining columns are added to enable the housekeeper to see what amounts are spent on each department and may be added to at her discretion. For instance, she may wish to subdivide her food account in order to show the relative amounts of the butcher's, baker's and grocer's accounts, or she may wish to keep her light and fuel accounts separate in Running Expenses, or to keep separate clothing or personal accounts for different members of the family. She may add a column for Education, or Recreation, or Investments. Each account form should meet the needs of the household for which it is kept. Statistics such as these enable the housewife to see where her heaviest expenses are and if any seem disproportionate to the size of her income she can investigate and find out the reason. It also enables her to determine where she can best retrench if retrenchment becomes necessary. Extra demands can be met by the saving of a few cents here and there. Figures obtained from the study of the expenditures of many thousands of families show that for an average family of five the division of income in percentages should be about as follows:

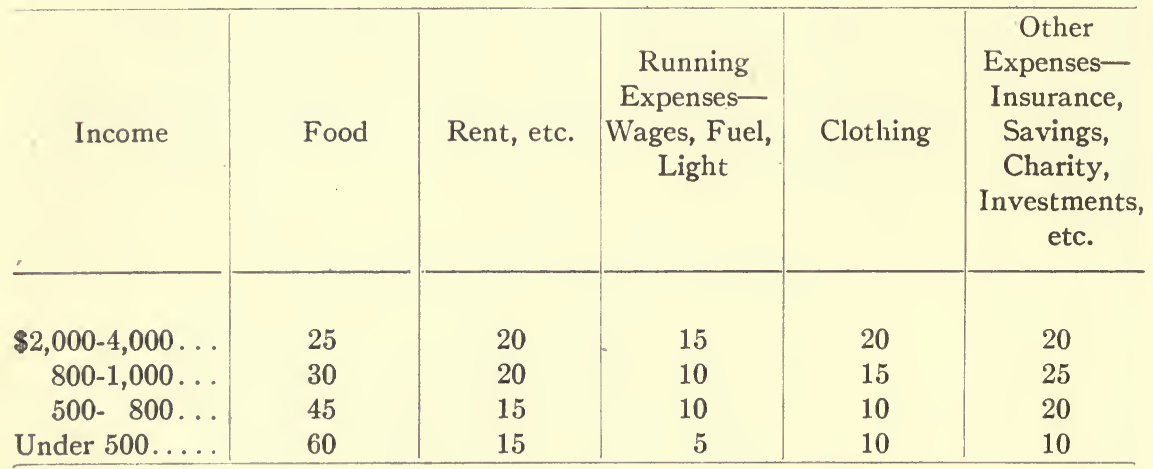

The less the amount of the income the larger the percentage which must be spent for food, leaving less for the other expenses of the family. These figures furnish a standard by which one may judge whether one's own income is apportioned to the best advantage.

In addition to the daily account sheet it is well to have a similarly ruled sheet in which to enter the monthly totals, viz., total Receipts and Expenses and monthly balance as well as the amounts spent each month on the several divisions. This furnishes a record for comparison from month to month, and the idea may be carried still further and a yearly account sheet made out showing the totals for the year.

Monthly Account Sheet

\begin{tabular}{l||l||}
\multicolumn{1}{c|}{1,16} & Rec. Exp.
\end{tabular}


Where credit accounts are carried it would be necessary to have a column for credit expenses as well as cash and this might be subdivided to show the different persons for whom a credit account was carried.

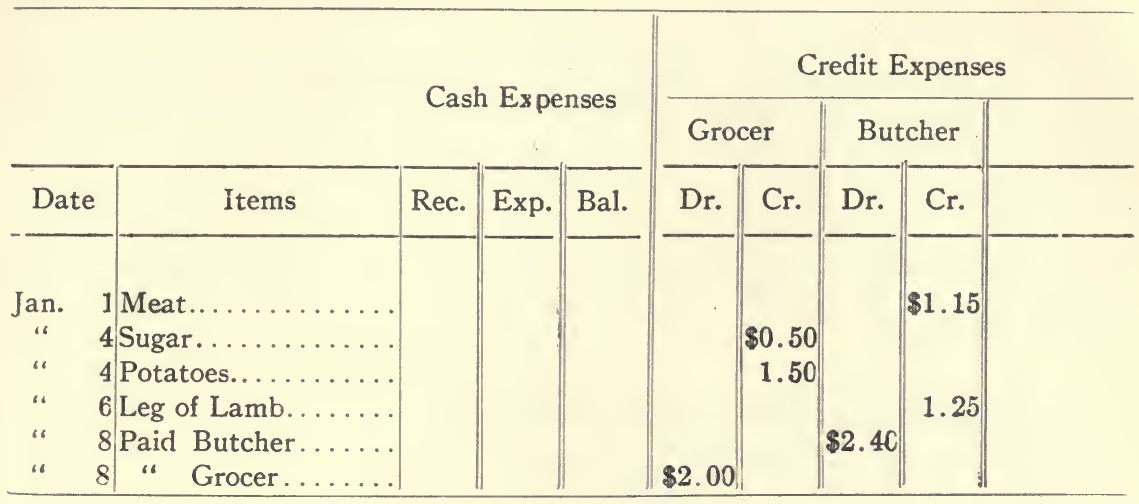

Applying a system such as this to one's household expenditure places the running of the home on a business basis and only by recognizing it as a business and treating it as such can the best results be secured. The method outlined is by no means the only one that may be employed, but it is simple and effective and if put into practice by every woman at the head of a home and a similar system for personal accounts taught by her to the boys and girls of her family the effect on the well-being and prosperity of our country would be inestimable.

\section{PATRIOTIC PURCHASING}

\section{"New occasions teach new duties."}

You can help win the War! Keep your money circulating in Canada by buying Canadian Products-products of Canadian farms, orchards and factories.

Your money is needed at home, where it will continue to work for you. Every dollar sent out of the country unnecessarily is a dollar lost.

If Canada cannot supply your needs, give your preference to the products of the Empire-Great Britain and Ireland, Australia, New Zealand, South Africa, India, Ceylon, British West Indies. There are few, if any, essential articles that are not or cannot be produced within the Empire. Buy them in preference to goods from any other country. Keep your money within the Empire.

Next to the countries of the British Empire, give your preference to goods that come from the countries of the allied nations-France, Russia, Italy, Japan. Make the dollars fight for us.

This is not a matter of spite; it is a matter of war finance. 
Germany is spending practically nothing in foreign countries, not only because of the British Navy, but because she realizes the importance of keeping money at home.

It is illegal to import from enemy countries during the war, either direct or by way of a neutral country. Products that were brought in before the war started may legally be purchased.

You are not assisting Canada or the Cause by purchasing goods that come from Neutral Countries. Do not do so, unless it is unavoidable. Remember, Canada first; the Empire next, Allied Countries third. Let our trade follow the Flag.

Where were these apples and vegetables grown?

Where was this cheese made?

Where was this article manufactured?

Where was the raw material for its manufacture produced?

These are the questions you should ask the dealer. We appeal to the women to be patriotic in their shopping.

Curtail as much as possible the purchase, particularly from foreign countries, of articles classed as luxuries. These are extravagancies in War time. All available shipping is needed for the transportation of food and other essentials of life. Room cannot be spared for articles of luxury.

Do you realize to what an extent foreign-made goods prevail in Canada? You will find them everywhere if you look around you.

On every hand you will see German and Austrian goods, ranging from lead pencils to kid gloves.

Germany and Austria will make every effort to seize the World's Markets after the War is over. They are preparing now. They will endeavour to flood this country with the output of their factories, and will succeed just to the extent that you consent to buy them. Nationalized business, not individualized business is their aim.

Help to build up Canadian industries while the war is still on, so that they may be better able to withstand the pressure afterwards. Keep Canadian workmen employed. Demand Canadian products.

Here are some of the articles that we have been accustomed to import from Germany and Austria:

Lace, Toys, Artificial flowers, fruit and leaves, Socks and stockings, Gloves and mitts, Dress fabrics and trimmings, Woollens and cottons, Chinaware, Glassware, Cutlery, Combs, Buttons, Fancy Goods, Lead pencils, Drugs, dyes and chemicals, Tobacco, pipes, pouches and other smoker's requisites, Binder twine, Musical instruments and parts, Electrical apparatus.

Great Britain is taking steps to give the preference to Canadian goods. 


\section{A Call to Women for Aid}

“As a result of the work done through the Consumers' League, assisted by the Department of Agriculture, stores that are featuring United States produce when they can get local produce, are being to a certain extent ostracized and are beginning to see that it is to their own advantage to secure home grown produce."

"During the coming year we should have a united campaign throughout the whole Dominion with regard to the matter. The way to success is to get the women interested.

- Wm. E. Scott, Deputy Minister of Agriculture, British Columbia.

\section{GIVE PREFERENCE TO CANADIAN GROWN FRUIT}

\section{JOHNSON, Fruit Commissioner, Ottawa}

It is a matter of surprise that Canada should import some ten million dollars' worth of fruit each year, when it is well known among fruit experts that the fruit produced within her own borders surpasses, in quality and flavour, that grown in any other part of the world.

It will be remembered that in the year 1914 large quantities of apples went to waste in the fruit producing sections of the Dominion, while the same year 269,359 barrels (imported chiefly in boxes and reckoned at three to a barrel) of apples were imported from the States. The greater quantity of apples imported are brought into the Prairie markets, where they come in competition with British Columbia, Ontario and Nova Scotia fruit. How can this be explained? The claim is sometimes made that the packing of the imported fruit is superior to our own. This may have been true some years ago when we were beginners in the art of box packing; but now that British Columbia has sufficient quantities of large, beautifully finished apples of the type produced in the Western States, to impress the market, and since Ontario and Nova Scotia have also adopted the box for their high class apples, I maintain that Canadian apples of just as fine quality and as well packed as any imported stock, may be obtained at prices not so high as those asked for the imported fruit. As far as the barreled apples are concerned, our experience goes to show that the Canadian pack is superior to the American; a fact undoubtedly due to the effect of the Fruit Marks Act, which has established uniform grades for the whole Dominion.

One of the great difficulties I believe in replacing imported fruit with our domestic fruit is that the public are not alive to the values of the different varieties. This is particularly true in the case of peaches and apples. In 1913, for example, Canada imported $12,137,029$ pounds of peaches (valued at $\$ 353,459$ ). These were produced mainly in the Northwestern States, and were picked when perfectly hard and before they had shown any sign of ripening, with the result that our markets are filled with imported peaches of fine appearance but of very poor quality. This fruit in many cases is taken from the boxes in which it is shipped, unwrapped and placed in baskets, leading the public to believe that the peaches are Canadian grown. I am convinced that in this way many people are prejudiced against peaches simply because they do not realize that the woody, tasteless fruit which they buy early in the season is an imported product and not the luscious peach as grown in Canadian orchards. Every consumer should make sure that the peaches he buys are Canadian grown, fresh from our own Canadian orchards, where the peach is fully matured before being shipped, and consequently possesses the delicious flavour and juicy texture that only properly matured peaches can have. Ask for Canadian peaches and be satisfied with nothing else. 


\section{USE CANADIAN FRUIT}

\section{R. M. WinSlOW, Provincial Horticulturist, Victoria, B.C.}

The people of Canada as purchasers and consumers have a partiotic and practical duty with respect to Canadian products. Our producers, fruit-growers included, are doing their share in increased production. Their efforts, in considerable measure, will be vain, unless the consumer does his part and co-operates in the great movement by demanding Canadian products.

In nothing is this more true than in respect to fruits. This country has an important fruit industry, and our fruits are of high quality. The industry is not nearly as large and as prosperous as it should be, however, because consumers, by failing to insist on Canadian fruit, are paying each year from $\$ 3.000,000$ to $\$ 4,000,000$ for imported fruits, of kinds produced in Canada. The following table shows the quantities, and value (including duty paid, but not including freight or distributing costs), imported in 1913 and 1914:

\begin{tabular}{|c|c|c|c|c|}
\hline & \multicolumn{2}{|c|}{1913} & \multicolumn{2}{|c|}{1914} \\
\hline & & Value incl. & & Value incl. \\
\hline & Quantity & $\begin{array}{l}\text { Duty but } \\
\text { not Freight }\end{array}$ & Quantity & $\begin{array}{l}\text { Duty but } \\
\text { not Freight }\end{array}$ \\
\hline & lbs. & $\$$ & lbs. & $\$$ \\
\hline lackberries, gooseberries, rasp- & & & & \\
\hline berries and strawberries.... & $6,939,470$ & $712,789.00$ & $7,104,745$ & $816,955.80$ \\
\hline Cherries................ & 971,619 & $122,470.38$ & $1,084,797$ & $142,092.94$ \\
\hline Currants................. & 30,071 & $2,726.42$ & 19,214 & $1,825.28$ \\
\hline Peaches................ & $\begin{array}{c}14,579,147 \\
\text { bu. }\end{array}$ & $476,390.33$ & $12,137,209$ & $474,854.50$ \\
\hline Plums... & $\begin{array}{l}151,650 \\
\text { lbs. }\end{array}$ & $313,074.80$ & $\begin{array}{l}123,531 \\
\text { lbs. }\end{array}$ & $353,610.10$ \\
\hline $\begin{array}{l}\text { Quinces, apricots, pears, } \\
\text { nectarines, etc........... }\end{array}$ & $\begin{array}{c}13,445,837 \\
\text { bbls. }\end{array}$ & $441,601.90$ & $\begin{array}{l}11,040,871 \\
\text { bbls. }\end{array}$ & $502,137.51$ \\
\hline Apples.................. & $\begin{array}{l}320,325 \\
\text { lbs. }\end{array}$ & $957,174.75$ & $\begin{array}{l}330,907 \\
\text { lbs. }\end{array}$ & $1,236,664.80$ \\
\hline Grapes.................. & $6,247,527$ & $505,743.29$ & $7,712,447$ & $644,326.24$ \\
\hline & & .87 & & $\$ 4,15$ \\
\hline
\end{tabular}

All the above fruits are produced in large quantities in Canada. It rests entirely with the consumers to diminish the imports and to establish a bigger outlet for fruit growers by preferring the home grown products.

Anything that reduces imports is just as effective in restoring a proper balance to Canada's foreign trade as an increase in exports. It is impracticable, with respect to most fruits, to develop a considerable export trade, and the consumer's co-operation is essential in enlarging the domestic market for Canadian fruits.

The purchaser of fruit can be guided by a few general rules:

1. The grading, packing, grade-marks, and the sizes of fruit packages in Canada are governed by a Dominion law, enforced by the fruit inspection service. The requirements of the law are very generally observed by fruit growers. In consequence, the consumer has the maximum of protection in buying Canadian fruit.

2. Canadian summer fruits are usually later in maturing than imported fruits, owing to our cooler season. When southern fruits of any kind are on sale, Canadian fruits will follow shortly.

3. The retailer usually knows in advance when Canadian fruits are to be had. 
4. The retailer likes to meet the customer's wishes. fruits.

5. It will particularly help if consumers will wait for Canadian-grown preserving

6. Canada produces each year far more apples than are imported. It is sound practical patriotism to always demand Canadian apples.

7. Look on the package for the address of the grower. Insist that it be Canadian.

8. The year 1916 promises large crops of fruit of all kinds in Canada. It is a good year for a good resolution-Buy Canadian fruit.

Ask your dealer whether the fruit he is offering is Canadian. Insist on being supplied with Canadian-grown fruit. Be patriotic consumers of Canadian fruits and vegetables.

\section{PRICES OF FOOD PRODUCTS STEADILY RISING}

The United Kingdom Board of Trade Labour Gazette reports that in December 1915 , prices in that country had advanced on an average 24 per cent. over December 1914. The prices of the following articles had advanced from 40 to 15 per cent. in the order given: beef, tea, mutton, flour, bread, butter, eggs, milk, cheese, bacon, sugar and potatoes. Fresh fish was 50 per cent. higher, but margarine only 3 per cent.

Prices in Berlin in November were 82 per cent. above July 1914, having fallen 6.6 in the previous month, due, it is said, to government regulation.

It is not to be assumed that this increase in prices is an accurate measure of the German food shortage. Food articles that can be stored have been stored in large quantities, so as to provide for future emergencies. Organization has been effected to regulate the placing of food in storage and its withdrawal and distribution as the needs of the community warrant.

\section{Food Prices as indicated by Index Numbers}

\begin{tabular}{|c|c|c|c|}
\hline & 1915 & 1914 & 1913 \\
\hline \multicolumn{4}{|l|}{ Canada } \\
\hline 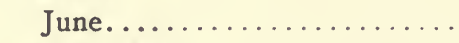 & 148.6 & 135.3 & 136.4 \\
\hline December ............... & 162.14 & 137.6 & 137.1 \\
\hline \multicolumn{4}{|l|}{ Great Britain } \\
\hline June.......... & 147.7 & 115.9 & 121.3 \\
\hline November............... & 159.1 & 125.5 & 120.7 \\
\hline \multicolumn{4}{|l|}{ United States } \\
\hline June.................. & 125.992 & 121.096 & 120.050 \\
\hline December.................. & 133.146 & 124.183 & 125.734 \\
\hline \multicolumn{4}{|l|}{ Italy } \\
\hline 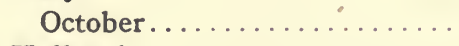 & 120. & 97.6 & $\ldots \ldots$ \\
\hline \multicolumn{4}{|l|}{ Holland } \\
\hline 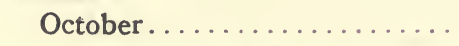 & 145. & 117. & ear's average) \\
\hline
\end{tabular}

At the end of January the Canadian index number stood at 172 as compared with 139 for January 1915. As a result the cost per week for food for the average working man's family is now $\$ 8.28$ or 31 cents per week more than a year ago. The chief advances were in lard, eggs, butter, cheese, sugar, tea, coffee and potatoes.

In Great Britain there was an advance of 5 per cent. during December, making a total advance since the war began of 46 per cent.

In the United States in January the index number rose from 133 to 137.

The latest Austrian figures show that the general level of prices is 117 per cent. above the prices current a year ago. 
Percentage increases in Food Prices in England, Germany and Austria, between July, 1914, and August, 1915

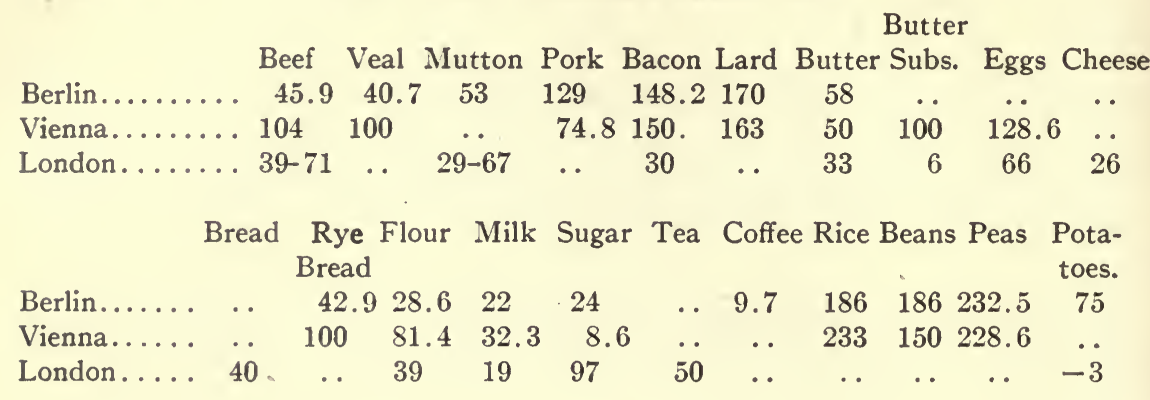

\section{Food in Germany}

The Socialist paper "Vorwaerts," published in Berlin, estimated in July, 1914, the total amount to be paid per month for the unavoidable necessities of food for a family of four persons at 25 marks, 12 pfennige, or about $\$ 6.25$ per week. This was the minimum. This minimum advanced in succeeding months as follows:

\begin{tabular}{|c|c|c|c|c|c|}
\hline 1914 & Marks & $\$$ & 1915 & Marks & $\$$ \\
\hline August........ & 22.44 & 5.00 & January....... & 29.65 & 7.12 \\
\hline September..... & 26.74 & 6.42 & February...... & 31.49 & 7.56 \\
\hline October........ & 27.09 & 6.50 & $\mathrm{Ma}$ & 32.90 & 7.90 \\
\hline November..... & 27.86 & 6.70 & April... & 24.91 & 8.38 \\
\hline December.... . & 28.74 & 6.90 & May............. & 26.49 & 8.76 \\
\hline
\end{tabular}

In October, 1915 , it had advanced to probably 50 marks, or $\$ 12.00$.

Not only was there a lessened quantity but the lessening of quality was perhaps a greater evil. "Vorwaerts" states:

Meat less and poor; breadstuffs, including cheese, not to be enjoyed; about half the normal quantity of butter and eggs used; vegetables of the poorest sort in use; sugar much reduced; cocoa, tea and marmalade have almost disappeared from the table, even fresh fruit, so necessary to the nourishment of children; potatoes and war bread have become the principal means of nourishment. The result is general under-nourishment - . This means not only bad nourishment, but hunger, permanent hunger!

(Following the publication of the above statement came the temporary suppression of the German paper.)

\section{GERMANY'S FOOD}

Germany has been able to keep up her struggle against the Allies because of her wonderful national organization. She had trained and organized her people, organized her industries and organized her agriculture. Her financial institutions, schools and universitites, and her churches also apparently had been organized to contribute their share in the maintenance and strengthening of the nation. Had she been unable to feed herself, she would, long ere this, have succumbed. How has she been able to do it?

Immediately upon the outbreak of the war a Commission of sixteen experts was formed to advise and direct the Government along the lines of the production and the consumption of food. On this Commission were eight representatives from the most important agricultural colleges; there were also two Imperial Statisticians. Prof. Paul Eltzbacher, Rector of the Commercial College, Berlin, was Chairman. The first 
conclusion that strikes one is that Germany had ready a corps of trained experts able to handle this question. These men had available a mass of statistical material dealing most thoroughly with the resources and products of the Empire and with their distribution. They were able to start work at once-in fact, so promptly were their conclusions arrived at that one suspects they were more or less ready at the time of the outbreak of the war.

The question that they put to themselves was- "If Germany were cut off so that she could neither import food nor export, what lines of production should be followed, and what restrictions should be put upon the consumption of food?" Their general conclusion was that with certain changes in their lines of production, certain modifications in the handling of their food, possible extensions in the use of vacant land, and the strictest economy in consumption, the German people could feed themselves. From time to time they advised the Government, and on their advice public enactments were made. In December of 1914 their complete report was pubished. An English translation of this report was issued in June, 1915, by the University of London Press-"Germany's Food-Can it Last?" edited by Dr. S. Russell Wells, with an introduction by Dr. A. D. Waller. The report is one of intense interest, and is very suggestive for the people of Canada.

The Commission started out with this recognition of the importance of their investigation. "The problem is not only of theoretical interest, but of the very greatest practical importance, for it concerns nothing less than the outcome of the war. The efficiency of our army, our transport service and our finances has been brilliantly proved. If we wish to win, the organization of food supplies must not be lacking."

First, as to producers-No food must be fed to live stock that can be used as human food. As a consequnce the number of swine must be reduced by nine million and the number of milch cows by one million. Potatoes were to be grown as extensively as possible, replacing some of the acreage of sugar beets. The reduction in the number of milch cows would produce less milk, but this milk was to be consumed as far as possible either as whole milk or as cheese. Butter was to be eliminated as much as possible from the national diet, being considered a luxury. This, of course, has hit the German housewife very severely, and will explain to some extent the so-called "fat riots." The extension of the potato acreage was to provide a cheap flour which could be used to supplement wheat, but particularly rye flour.

Beet sugar has been one of the products on which the whole agricultural industry of Germany was based. How was the question of their large surplus to be handled? First of all, encouragement was to be given to the increased home consumption of sugar; secondly, the acreage of sugar beets was to be reduced; and, third, the sugar factories were to change their plans whereby a larger portion of the sugar would be retained in the by-product, thus decreasing the output of sugar and increasing the sugar in the by-product for stock food.

In this manner the Commission went over the entire range of food products. No wheat was to be used for making starch and the people were to be instructed not to starch their clothes, thereby economizing and also improving sanitary conditions; health and economy were to be considered of more importance than fashion.

"One thing is, of course, needful if the requisite measures are to succeed, that each shall sink his personal interests unreservedly in the common weal to-day. It does not matter whether a farmer or a manufacturer prospers, or whether a company pays dividends, but we have all got to live. It is not a question of money at all but of bread, meat and potatoes."

Having fully considered the question of production, the Commission turned their attention to that of the consumption of food. The result of their suggestions was the setting out of what has been known as The Ten Commandments. These were printed on placards which were posted in every public building, railway coach and street car. 
Following up the work of this Commission the Government appointed special committees or commissions for the storing and distribution of food products, and appointed another committee closely to follow the working out of their recommendations and to submit from time to time suggestions for variations in the regulations or the making of new enactments.

\section{The Ten Commandments}

(1). Don't eat more than necessary. Don't eat between meals.

(2). Consider bread sacred. Use every little piece. Dry bread makes good soup.

(3). Be economical with butter and fat. Use jam instead of butter. Most of the fat we get from abroad.

(4). Use milk and cheese.

(5). Use much sugar. Sugar is nourishing.

(6). Boil potatoes with the skins on; then nothing is lost in peeling.

(7). Drink less beer and alcohol; then the supply of rye from which these are made will be greater.

(8). Eat vegetables and fruit. Plant vegetables in every little piece of earth. Be economical with preserved vegetables.

(9). Gather all you don't eat for the animals.

(10). Cook with gas and coke. The ashes from coke make good fertilizer.

Moral-Obey these ten commandments and economize for the Fatherland. The rich must also follow these commandments.

\section{A DUTCHMAN WITH THE ENEMY}

\section{The London Trmes Weekly, January 21st, 1916.}

"In Munich things are dear and bad. The sausages and the ingredients with which the food is prepared are not made more palatable by the frequent employment of substitutes. This is noticeable not only in the case of ordinary dishes, but also, and more particularly, in the various confectioners' shops. The pastry evidently contains a very large amount of potato meal. As for prices, I paid $4 \mathrm{~s}$. for one hors d'oeuvre, consisting of a herring, a couple of radishes, a small piece of celery, half an egg with a sausage, and a couple of shrimps, which would certainly not cost more than $1 \mathrm{~s}$. in Holland. The price of beer has gone up more than 40 per cent., while the quality has gone down very much. Eggs cost $2 \frac{1}{2} \mathrm{~d}$. to $3 \mathrm{~d}$. each. Here we made our first acquaintance with the breadcards. We got breadcards from the head waiter at breakfast ( 175 grammes of bread each). This gave us a right to five miniature loaves. The small German loaves are well known, but these were extra small. The bottom was hardly larger than a five-mark piece. It has frequently been proved that even this small quantity of bread is not entirely unmixed with substitutes. Whether the quantity of bread people get is sufficient is a matter of doubt."

"Much female labour is employed in Vienna. I saw women doing the hardest navvies' work and busy as street cleaners and tram conductors. Public life, speaking generally, seems to go on in the usual way. The theatres are crowded. Naturally the feminine element is far and away predominant. One does not see much mourning worn, and to go by externals one would think, sitting in a theatre, that there was no war at all. There is something inexplicable in the psychological attitude of the people. 
"Food is dear and scarce. Butter costs 4s. 2d. a lb.; lard, 7s. 6d.; and goose fat 5s. 10d. Dinner for two at the hotel, with a bottle of ordinary Rhine wine, costs $14 \mathrm{~s}$. $6 \mathrm{~d}$; yet so little did we get that two hours later we were very hungry and paid 4s.2d. for some small pieces of bread and butter, with salmon and ham upon them, and two cups of coffee."

"We stopped in Berlin for some four days. Private motor-cars no longer run there. In Wertheim's stores you see two notices. One of them states that on account of want of string, packets cannot be tied up, and the other that small parcels cannot be sent home owing to lack of employees. Women work as conductors on tramways and on the underground railway, and I saw 20 or 30 women with spades and other implements digging at the works connected with the new railway tunnel under the Friedrichstrasse."

\section{"K." Bread}

Five per cent. of potato meal must be added to rye bread. A larger addition is permitted, but in this case the bread must be distinguished by the letter $\mathrm{K},{ }^{*}$ and if more than 20 per cent. is added the amount of addition must also be marked on the bread.

The making of potato bread is not due to a lack of grain, for, owing to the prohibition of its use as fodder, we have quite enough for our requirements without the wheat hitherto imported, but to the fact that the greater durability of grain in contrast to the perishable potato makes it particularly suitable for storing as provision for the future. The use of potatoes in bread-making increases the consumption of potatoes instead of grain and so makes a saving of grain possible."

-German Report.

*K here stands for Kartoffel (potato), but the bread is often called Kriegskot (war bread).

\section{Great Loss of Men Will Defeat Germany}

Paris, Feb. 8.-In an interview published in La Liberte, a well-known manufacturer who has just returned from internment in Germany throws new light on the economic situation in the Empire. He says:

"Germany has never lacked a supply of copper. She found a two-year supply in the invaded regions of France. In order to hoard up her own resources she stopped the exploitation of her own iron mines, and is working the French mines exclusively. From these she has withdrawn a vast stock equalling the amount ordinarily dug up in ten years under French methods in peace times.

"Wheat is very scarce in Germany, but potatoes and other vegetables are very abundant and cheap. Meat is extremely scarce, but coal is plentiful and relatively cheap.

"It must not be expected that Germany will succumb to economic pressure. She will be defeated only by the loss of untold thousands of men, a loss which is already acutely felt throughout the nation. 


\title{
WOMEN AND THE WAR
}

\author{
"To brave hearts nothing is impossible."-JoAN of ARc.
}

"In this tragic hour my message to every woman in Britain is:-Be brave!-sure in the victory that awaits my brave countrymen and their Allies. Men must fight, but this is not the time for women to weep. They must be strong in faith, active in war-work, inspiring as ever by their love and patriotism the magnificent courage of their countrymen. France will never forget what Britain has done and is doing-French women and British women join hands in a bond of mutual sympathy and affection, rejoicing together in the renewed hope of our glorious future and of our eternal friendship cemented in the war."

-SARAH BERnHARDT.

\section{$\downarrow$}

"Our women-they are superb."--General Joffre.

\section{THE APPEAL OF AN ENGLISH SCHOOLGIRL}

"Night after night the big ships sail out into the starlit darkness, carrying men, and yet more men, away from the peaceful shores of Britain to the reddened fields of France, or the sandy beaches of Gallipoli. Cheerful and confident, the men go forth to battle for us, and we women are left at home, face to face, many of us for the first time in our lives, with anxiety, sorrow, and dire need. Few men are left, and they are needed in the arsenals and munition factories; therefore on the women of the nation falls the burden of producing the food supplies. No longer is it true true that "men must work and women must weep"-all must put their shoulders to the wheel, and answer the country's call in this her hour of need. Now that the highways of the ocean are less safe than of yore, it is imperative that more food should be produced in the country itself, so that the Army, the Navy, the wounded, and, above all, the children, who will be the future men and women of the Empire, may be adequately supplied. At a time when the nation is being called upon to bear a tremendous strain morally, physically and financially, it is of the utmost importance that the food supply should be well maintained. But how can this be unless the women lend their help? Women of England! here lies your great opportunity, which may not come again! For years you have claimed equal rights with men, show now that you are worthy of them, and can fill a man's place."

\section{-Eilidh Hay Forbes, in The Journal of Agriculture.}

\section{BRITISH WOMEN AND THE WAR}

"Two hundred and fifty thousand women are working in the War Munitions Factories of Great Britain."

Apart from these everyday occupations, British women have swarmed into the factories of the big centres for war work, and a large proportion of them are women who never before have had anything to do with factory life. At a Coventry shell-making 
works all the production is done by women drawn from the leisured classes. They are under the supervision of a few trained foremen, and work ten hours a day. The women are not only doing the work well, but seem to be thoroughly interested in it.

The London Chronicle correspondent says: "In all the armament areas thousands of women, sometimes tens of thousands, are at work in the big towns. Under one roof in Birmingham I saw three thousand girls engaged in making fuses for British and Russian shells-and Birmingham is ringed with factories. At Newcastle a single munition firm alone employs six thousand women. The point that has to be remembered is that these hosts of women war workers have volunteered from widely varied conditions of life. It is a democratic army, like our army in the field. There are well-to-do women in the ranks, as well as domestic servants; there are school teachers and shop girls, the daughters of professional men as well as the wives of soldiers at the front. The uniform of overalls raises them all to the same level."

\section{THE WOMEN OF AUSTRALIA}

Resolved: that this meeting of the National Council of Women of Victoria urges all women to be steadfast in this time of suffering, and to use every effort, no matter at what personal cost, to secure final victory; in order that their children may succeed to the heritage of their fathers, the freedom of the British Empire.

Such was the resolution drawn up at a meeting of the Australian National Council of Women.

Surely it is a strong bond of union amongst the wide flung Dominions of our Empire that women in the British Isles, in Australia, in New Zealand, and women in Canada, are all resolved on one thing, that no sacrifice is too great to make, which will help to serve the Empire in the time of its dire need.

How loyally women there have already given of their best, we all know. We Canadians who cannot think of Ypres, of St. Julien and Langemarck without a thrill of pain as well as of glory, can understand the feeling of the mothers and wives of the Australian heroes of Anzac. Australia may previously have meant little to us. Henceforth it must mean a land of heroic men and women.

Every Canadian woman worthy of the name will join with the women of Australia in the resolution which came from their National Council of Women.

\section{GIVES ALL HER BOYS TO CAUSE OF FRANCE}

Speaking of his experiences at the front, Baron Malaussene, adjutant-lieutenant, in a recent interview, said:

"The Canadians fought like lions; they are great fighters. We in France are grateful to every mother in Canada who has sent her son, and for the blood of Canada that has been spilt on the battlefields of France. We will not forget, but we pray that it may cement a more lasting friendship in the years to come between this country and that across the seas."

\section{Spirit of the Women}

"Yet there are still many in your country who have not yet felt that there is a war-who feel no duty upon them to serve at this time. We in France realize that we are fighting for the lives and the honour of our wives and little children and our national freedom. Ah! it is because you are so far away that men do not realize the need of England, the cry of France and her allies, for help. Behind the splendid heroism of the fighting men of France there is the spirit of the women. Ah! the brave, courageous women. There is not a woman in France today who is thinking of her own comfort or pleasure before the cause. It is the grand spirit of the women of France that is helping her through these terrible times. 
"I will tell you a story:

"In a little hospital not far from the firing line, where Dr. Williams was tending the wounded, there was a poor French lad badly wounded. It seemed as if nothing would rally his spirits but a sight of some one from home, so the doctor asked if he had a mother. Yes, he had, and the light came into his eyes at her name, but she lived too far away, and they were very poor. Never mind, there was a way, and in two days the doctor had that mother by the bedside of her boy. There was never a cry or a tear, only brave words of cheer and encouragement. She sat with him through one night and told him how he would soon be well enough again to fight. Once outside the ward this brave woman broke down for an instant. She said, 'I have sent six boys to the front; he is the only one left, and tomorrow, my baby, my last one, goes to the war. $\mathrm{Ah}$ ! it is hard!' 'But,' said a soldier nearby, 'your boys have done bravely, mother, for their country; would you have it different in the hour of France's need?'. She drew herself up. 'No!' she exclaimed, 'had I all my boys at my side again, I would gladly' send them to fight for their country.'

\section{HE SAW A WOMAN PLOUGHING}

\section{President of Britain's Agricultural Board tells Shrewsbury Audience of Singular Sight}

The necessity of replacing men's labour by that of women in agricultural occupations is engaging the attention of most people in England at the present moment.

Lord Selborne, president of the Board of Agriculture, is a keen advocate of women taking the place of men on the land wherever possible. In an address which he gave a few weeks ago at Shrewsbury, he said he had seen what he believed nobody had ever seen in England-"a woman ploughing." "Women of every class," he declared "must assist. The squire's wife and the farmer's, and the parsons' wife, the wife and the daughter of the labourer, each in turn could make a contribution to agriculture in this year of war, and so work for victory just as husband, son or brother, in the fleet or in the trenches. I would make a special appeal to the wives and daughters of men who are fighting, because they are well cared for by the nation. They have not been left in grinding poverty as are the German women whilst the men are fighting the battles.

It was not right that a woman in this country should live in greater luxury than she did before her husband or son went away to fight; she should do her part just as the men. She must go on to the land if the farmer asked her at a fair wage for a fair day's work. This is a moment when each man and woman of every class must put forward that unselfishness and patriotism on which depends the fate of England."

\section{THE WOMEN OF MONTENEGRO}

The Montenegrins themselves do not understand so much about artillery as about other arms, in the employment of which they are past masters. Their specialty is not the complicated modern war, but the partisan warfare in the mountains, the real Indian war. One hears them shouting something to one another on the bare, black mountains; then they glide down into the valley in groups of two or three, jump in their soft felt shoes from stone to stone, conceal themselves in the holes which are hidden by the evergreen bushes, and suddenly they all collect at one spot in the rear or at the flank of our patrols. Woe to these patrols if they allow themselves to be surprised! The Montenegrins give no quarter to anybody, not even to the wounded. On the other hand, it is next to impossible to capture Montenegrin soldiers. Wherever a warrior goes or stands there also is his wife, and when he falls she jumps to his side and drags him away. No dead or wounded are found after a battle. 


\section{ITALIAN PEASANT WOMEN AS FARM HELPERS!}

In the midst of mobilization, in the summer, in spite of various classes having been recalled, the harvest was gathered in without great difficulty, and was generally abundant; when the men were wanting, the women were ready to work, those wonderful Italian peasant-women, prodigal of children, and desirous of taking the place of their husbands in all the labours of the field. The Valley of Aosta, scantily populated, has given all its valid men to the $A l p i n i$; the women have reaped, threshed, and garnered the grain; they have attended to the vintage, and now are digging and ploughing the earth.

\section{EDITH CAVELL-TWO OPINIONS}

The Official Defence by Dr. Alfred F. M. Zimmermann, German Under Secretary for Foreign Affairs, Oct. 24th, 1915

"I see from the English and American Press that the shooting of an Englishwoman and the condemnation of several other women in Brussels for treason has caused a sensation, and capital against us is being made out of the fact. It is undoubtedly a terrible thing that the woman has been executed; but consider what would happen to a State, particularly in war, if it left crimes aimed at the safety of its armies to go. unpunished because committed by women. No criminal code in the worldleast of all the laws of war-make such a distinction; and the feminine sex has but one preference, according to legal usages, namely, that women in a delicate condition may not be executed. Otherwise man and woman are equal before the law, and only the degree of guilt makes a difference in the sentence for the crime and its consequences."

"It was a pity that Miss Cavell had to be executed, but it was necessary. She was judged justly. We hope it will not be necessary to have any more executions."

The Opinion of James M. Beck, Late Assistant Attorney General of the United STATES

"And you, women of America! Will you not honour the memory of this martyr of your sex, who for all time will be mourned as was the noblest Greek maiden, Antigone, who also gave her life that her brother might have the rites of sepulture? Will you not carry on in her name and for her memory those sacred ministrations of mercy which were her lifework? Make her cause-the cause of mercy-your own!" 


\section{THE CALL TO THE COLOURS}

Not having been invaded, England has been' long in awakening to the reality of the war, but an old Oriental proverb says "Beware of the man who is slow to wrath." The great majority of the British people to-day, especially the women-the people of England, Scotland, Ireland, Canada, Australia, New Zealand and South Africa, finally realize fully that to preserve their own liberty and that of the world the teeth and claws of the Prussian tiger must be torn out.

-LORD NORTHCLIFFE.

\section{PROVISIONS OF THE CANADIAN MILITIA ACT}

The provisions of the Canadian Militia Act according to which all male subjects between the ages of eighteen and sixty may be called upon are worth studying in this connection. They may be placed on "active service anywhere in Canada and also beyond Canada for the defense thereof, at any time when it appears advisable to do so by reason of an emergency." They are divided into four classes, which are to be called to the colours in order:

First class: Eighteen years and upwards, but under thirty years, who are unmarried or widowers without children.

Second class: Thirty years and upwards, but under forty-five, unmarried or widowers without children.

Third class: Eighteen years and upwards, but under forty-five, married or widowers with children.

Fourth class: All those of the age of forty-five years and upwards, but under sixty years.

\section{FACTS REGARDING ENLISTMENT FOR SERVICE OVERSEAS}

Enlistment is for the war, and six months after, if required.

Remuneration:

The following are the rates of pay in the C.E.F.

Rank

Colonel........................\$6.00

Lt.-Colonel.....................5.00

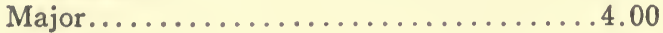

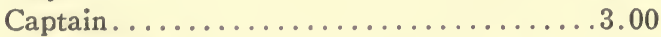

Lieutenant........................ 2.00

Adjutants in addition to pay of rank $\$ 0.50$

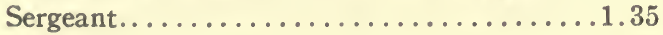

Corporal.........................1.10

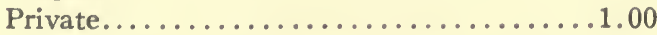

Field

allowance

$\$ 1.50$

1.25

1.00

.75

.60

.15

.10

.10

Privates and Non-commissioned officers are provided with clothing, equipment and subsistence. 
Separation Allowance-Soldiers' dependents (wives, children of a widower, or widowed mothers, if son is unmarried and sole support) are paid the following monthly allowance by the Canadian Government:

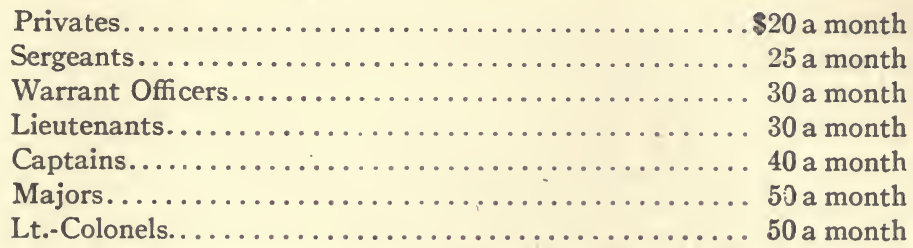

If a soldier has dependents, a portion of his pay is made to them direct.

In cases where the separation allowance and pay are insufficient, further assistance may be given by the Canadian Patriotic Fund.

Sick, Wounded and Prisoners-Sick and wounded are cared for and their pay continued until discharged.

\section{THE PATH OF FIRE}

No nobler call to Canadians has been sounded than that of the Chief of the Mohawks last week in the Council Chamber of the Six Nations at the Indian reserve near Brantford (Ontario). Some dissatisfaction had been expressed by a Chief present at the restrictions imposed upon Indians in the exercise of their fishing and shooting rights under the treaties with the pale faces. It was a tense moment when the Chief of the Mohawks rose to urge the duty of responding to the call of the King for men-and yet more men. In quiet tones he recalled his own sacrifices. His eldest lad, working on the farm, hitched his horses to the fence one day and followed the recruiting sergeant. Later he sailed with the First Canadian Contingent. That year the area under crops on the farm had to be cut down. Then a second son and later a third boy joined the King's colours, and the Chief and his squaw were left alone to till the land, restricting further the acreage under crops. It was a simple story of duty and sacrifice simply told, and it carried its own message. Drawing himself up proudly, the Chief reminded his hearers of an old Indian legend. An Iroquois who had been captured by an enemy tribe was given two alternatives; to seek freedom by passing through a path of fire which his captors had made or remain behind with the women and children. The Iroquois prisoner never hesitated-he preferred the path of fire, with the honour and freedom it held out, to the ignominy and disgrace of remaining with the women. Seizing the psychological moment, the Chief of the Mohawks gave the war cry of his tribe and sat down.

It was a thrilling moment for the palefaces who were privileged to witness the scene. That war cry of the Mohawk Chief was the answering challenge to German tyranny of one who had tasted of British freedom. It was a call to every Canadian eligible for military service. For every man capable of serving King and country at the front the choice now comes - the path of fire, which is the path of honour, or - !

"Not once or twice in our rough Island story

The path of duty was the way to glory".

-The Globe, Toronto.

The Old Serb.- "Fighting with the Bulgarians against the Turks I lost my brother; my sons fell fighting with the Greeks against the Bulgarians; but only when the Germans came were my wife and my grandchildren killed." 


\section{THE BOYS AT THE FRONT}

\section{The "Listening Post"}

The following contribution appeared in The Listening Post, a Canadian newspaper published in the trenches in France.

"Think of the Listening Post! Far out in front of the trench, nearer Berlin than anyone else. All alone, but for his wire. Watchful, alert, peering through the dark, analysing every sound, dissecting every vision, investigating every smell. An epicure, a critic, a reporter rolled in one. A rising bank of mist that may be gas; a footfall out in front that may be our own patrols or it may not. The safety of the trench depends upon him, and on the safety of the trench depends-yes, what?

"On a fine night, with a full moon, dry ground and a good view. Fine! A regular picnic. All the universe and the myriad stars to remind you of your future happiness. But on a wet night, a thin drizzling, slush of a night, your knees a sponge, your elbows a marsh, your tummy a morass, nothing to be seen, heard or smelt, but wet, damp and misery. Then's time you think of your past sins.

"Flare lights may show up your position, but it is the bullets-and machine guns that actually ascertain whether a listening post is a post or merely a prostrate piece of timber.

"There is a diversity of opinion among Listening Posts, as to whether they run more risk from the bullets of those in front or their friends behind. But that, like the Welsh coal strike and compulsory service, is a controversial matter, and the Editor says it is 'spot barred.'

"One day I'll write a poem about a listening post, and then the world will know the dull depths of the dreary, damp, despondent, despairing, dangerous drudgery of this devastating duty.

"Yet many of them like it, ask to be sent out. Go and go again. If the aeroplanes are our eyes by day, the listening posts are certainly our night lights."

\section{A LETTER FROM FRANCE}

The following letter from a prominent Scotch Agriculturist, who knows Canada well, is of more than usual interest.

$$
\text { "B.E.F., France, }
$$

January 28, 1916.

"I was very glad to have your letter of December 12 th, which reached me a few days ago in an old French Chateau, of the 11th Century."

"The response of Canada has been mangificent, but the details you give bring out the facts better than any paper. At this part of the line we have a lot of Canadians near us, and some Australians not so far away, both fine-I don't know which to admire more. But our own chaps are grand. How they stand the mud and water, cold and dirt, monotony and danger and wounds so well is a constant wonder. The indifference to danger or rather to the.possibility of sudden extinction is very strange."

"This part of the country was overrun by the Germans and the burned churches are abundant evidence. Nearer the line there are of course no undamaged houses and the villages are heaps of ruins quite uninhabited. These guns have such a deuced long range nowadays that one must be a long way back to be clear of them. I suppose we are at this moment six or seven miles from their guns but they can pip us when they like. 
Two aeroplanes came over today and dropped a couple of bombs in the garden next doortotal casualties, one bird killed by flying glass. It is remarkable how much ammunition must be expended to get any result. The other day they gave us 2,000 shells, any amount of machine gun and rifle fire and lots of bombs and other horrors for several hours and the casualties were two killed and half a dozen wounded on our section. I am glad to say we gave them two shells to their one and knocked them about a good deal. We are gaining on them in ammunition and men and it seems to me that we only need inflexible determination for say two years more to finish them off for keeps."

"You may think from what our papers say that we are making a muddle of things, and no doubt many mistakes have been made by those in high places, but I question if any other nation could have done what we have done in the time. I am sure Germany could not. As to the organization, it is wonderful. My brigade. of which I am a Staff Officer, was moving lately-say 4,500 men and 300 horses and waggons. We halted each night in a new place and within an hour every man had a hot meal, had received or posted his letters, and even bought postal orders-the office was in full swing with a typewriter clicking away and telegrams and motor cyclists coming and going. Next morning shortly after dawn and a hot breakfast, the whole outfit would be marching again. Men who had fallen sick in the night would be flying in motor ambulances to base or field hospitals, lame horses would be picked up by the Mobile Veterinary Section, and the vouchers for the payment of billeting money for the whole 4,500 men and 400 horses in perhaps 150 different billets properly made out and certified would be in the hands of the village 'Maire.' If you remember that Brigades have been recruited, trained, equipped and organised so that they can move like this in a foreign country all in eighteen months you can see that we have worked miracles. And remember that three hot meals a day have got to come from somewhere every day and they never fail to come. All the stuff comes across the Channel, even our coal, which is served out to us every day even on the move. And eighteen months ago there were not - Brigades that could move and fight in the British Army. There is nothing wrong with our organization, but we are fighting the best professional soldiers in the world, and even if the war lasts ten years we shall still be amateurs fighting professionals. You cannot train civilians like me to their pitch of efficiency in a year or so, but every month the war lasts reduces the number of their professionals and brings us nearer the same level of quality. Already we are nearing them, soon we shall dominate them.

"The spirit of our men is grand. The other night one of our men, wounded in both arms, was pulled off the top of the parapet which he was climbing in order 'to get at the chap that did it.' I suppose he was going to bite him, as he could not carry a rifle. All they hope for is that the enemy will come out of his holes so that they can get at him."

"The German methods are, of course, despicable and we are much handicapped by them. For instance this town, which is quite large, and of which you would know the the name quite well, is within easy range and is full of French women and children. Whenever we have given the Huns a specially hot time they turn their guns on this town. It has no military effect whatever beyond this, that, as we know they will kill women and children if we bombard them hotly, it rather cools our ardour. It is all of a piece with their favourite game of advancing behind a screen of women, driven forward by their bayonets. Nothing that you have ever read about the German atrocities is exaggerated. If some particular act is not true you may be certain that another of equal barbarism has been perpetrated. It is difficult to imagine anything worse than spitting babies and carrying them alive on their bayonets over their shoulders, and we know they have done this. Again and again in the advance from the Aisne it was found that in houses occupied by German officers a favourite habit was to open the grand piano and use it as a closet, filling it with human ordure. This is a small thing but it shows the "mark of the beast'." 


\section{IN THE TRENCHES}

"For breakfast, about seven o'clock, we have tea or cocoa, bacon and bread. Our dinners consist of a pound of good fresh beef, potatoes, and bread, or steak, potatoes and bread and onions. For tea again we don't fare at all badly. We usually get bread and jam, biscuits and tea or cocoa, and on top of all that we get as many smokes as we can very well manage. Generally, we do our own cooking on our trench fires, but when there is a shortage of cooks, our rations are brought to us already prepared. In addition to the four packets of cigarettes that are included in our regular rations each week, we receive quite a lot from private sources."-A Canadian Soldier.

Tommy Atkins in the trenches well fed is a great fighter; well fed he will stand to the last. John Bull at home over-fed might become overconfident. The Canadian who does not deny himself in some way does not know that he is in the war. The Canadian farmer is pushing production not for the epicure and gourmand, but for the boys at the front. Beef, bacon, flour, cheese and eggs from Canadian farms are for the Front, not for overloading our home tables. Let us economise and keep the supply waggons moving. Remember what the "Distressed Pessimist" said in Punch (Dec. 8, 1915) after a too hearty meal.

"It's odd-very odd! But somehow, fresh after dinner, I never can get myself to feel as though the Germans would win."

\section{Jam replaces Butter}

The value of jam as a food lies in its richness in sugar, in the minerals which are present in the skins of the fruit, in its laxative character and its mechanical aid to digestion, writes Prof. James Long in The London Evening News. Its "toothsomeness," too, is not to be despised, for it appeals to that relish and appetite which go so far in the maintenance of health.

Five pounds of jam cost no more than one pound of butter, but what of its relative value as food? One pound of butter provides 3,600 calories, whereas five pounds of jam provide 5,250. Practically the energy value of three and a half pounds of jam is equal to that of one pound of butter, and at a good deal less cost.

Sugar present in fruit has a remarkable effect on nutrition.

Jam contains a large proportion of "invert" sugar, which is more freely digested than raw sugar and can be eaten with greater impunity.

Honey is an excellent example of invert sugar, of which it contains nearly twelve ounces to the pound, and is well known as a delightful, nutritious and easily digestible dainty, although as with everything else, too much can be eaten at once.

An officer of the Royal Field Artillery sings the praises of jam: "Money is not much use here where there's little to buy, and when a rich country feeds its soldiers so well. When I say well fed, I mean bacon, steak, bread, and jam every day, varied by bully and 'Maconochie.' I think jam will never have to bow to wheat while there's an army to be fed in the field. It is the staple out here; many a muddy loaf, or a loaf that has had a brush of the oil barrel, is made eatable by jam. Goodness knows where all the plums and apples come from. Then jam comes in tins, and tins are useful for making paths. Bread comes in nothing - that's where jam scores; also jam is equivalent to vegetables." 


\section{SUGAR FOR THE SOLDIERS}

\section{A German Report states:}

"The consumption of sugar must be much increased. Last year we exported more than one million tons of sugar; now this sugar can serve as a substitute for other food stuffs. Such an increase in the consumption of sugar is quite possible. In England and America the sugar consumption per head of the population is nearly twice as big as ours. There, to a much greater extent than with us, jam of all kinds is eaten together with or instead of butter, and many sweet dishes of simple composition are used for dessert.

"Sugar is also suitable as a food in its ordinary form. For some years it has been tried as an invigorator in fatiguing marches or in sports. Exact inquiries show that by eating about 12 to 15 grams of sugar at intervals of half an hour the feeling of tiredness can be overcome most effectually. We have been rightly urged, therefore, not to forget sugar of various kinds in sending gifts to our troops in the field."

Canadians would do well to keep this in mind in sending gifts to our soldiers-a small box of lump sugar will be most acceptable and helpful.

\section{A Hint}

"By the way," interjected one of the men, "if you are writing to Canada about us, would you mind telling those good people out there who send us these nice things not to put chocolates and cigars in the socks they knit and send out to us. We don't like to write ourselves for fear they might misunderstand us, and think us ungrateful. But when they reach us out here the chocolates are usually dissolved away, and the cigars are unusable."

\section{Newspapers for the Front}

Canadians Over Seas like to read Canadian papers. Newspapers from home are the next best thing to letters. Here is a suggestion: Wrap up some every week and address them as follows:

$$
\begin{aligned}
& \text { Lady Drummond, } \\
& \qquad \begin{array}{l}
14 \text { Cockspur St., } \\
\text { London, S.W., England. }
\end{array}
\end{aligned}
$$

Write on the outside the place of publication. Tie them up carefully. The postage is one cent for four ounces. Lady Drummond's clerks will then forward them to the boys in camp, hospital, or in the trenches.

\section{Magazines for the Soldiers}

"A Carload a Month" is the slogan adopted by a group of Toronto men interested in helping to meet the great demand for reading matter from the boys in khaki who are overseas. That this is one of the big needs of the lads, who are in training in England and who are fighting at the front, is evident from the statement of one of the Y.M.C.A. secretaries that at least 100,000 unused magazines should go forward periodically. $\mathrm{He}$ says these do much to relieve the strain and monotony of the camp and trench life. 


\section{PATRIOTIC AND RELIEF WORK}

"In providing comforts for the soldiers, in all the activities that we associate with the Red Cross, in ministering to the wounded, Canadian women have revealed the divinity that lies in the heart of woman everywhere and always appears at the call of sorrow and suffering. Their work has been incalculable, their courage sublime, their self sacrifice touching and inspiring."-SIR JOHN WILLıSON."

No man ever begins to give until he has deprived himself of something that he feels the need of having. That is to say; most of our giving, what is taken from our abundance and our superfluities, is not giving at all in any real sense.

What you do not feel the need of is not a gift. This is what lies behind the fact that it is not the large sums that are the greatest sacrifice, although they are useful, of course, according to their value. But the good that the giver gets out of his gift is to be measured only by the degree of sacrifice he has made in determining the size of his gift. This is the philosophy of the widow's mite. She out of her poverty gave all that she had. Most of us give only out of our abundance, and do not make very deep inroads upon that.

There is much in this to encourage the man or woman who is able to do only a little. The little so given may be greater in spirit and influence than the splendid gifts of the wealthy. But it has a word for the wealthy also, and each man has to consider his gift not according to its actual value, but according to its value relatively to his fortune. A man with a million does not feel his gifts in any sense at all until they begin to pinch his own life and habits.-THE TORONTO WORLD.

\section{CANADIAN PATRIOTIC FUND}

Object-The Canadian Patriotic Fund is organized for the purpose of rendering financial aid, in case of need, to the dependent relatives living in Canada or Newfoundland, of men fighting in the ranks of the Allies, no matter of what nationality they may be or in which army or navy they are serving. It may also assist, should necessity arise, soldiers or sailors discharged from the forces by reason of wounds or sickness.

The head office of the Fund is at Ottawa, the Honourary Secretary being Sir Herbert Ames, Kt., LL.D., M.P., the Honourary Treasurer, Sir Thomas White, M.P., and the Assistant Secretary, Mr. Philip H. Morris.

\section{Donations by Provinces to March 1st, 1916}

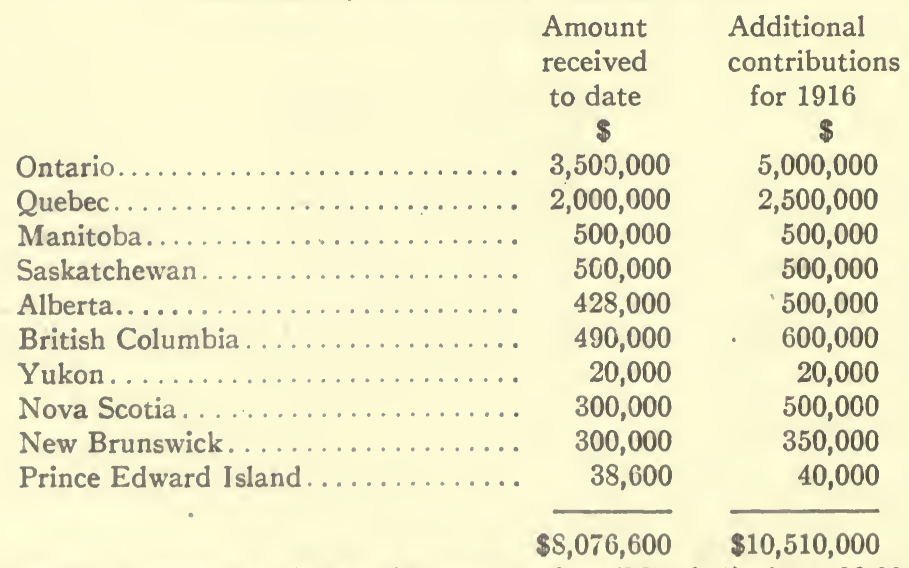

Sir Herbert Ames states that at the present time (March 1) about 30,000 families are receiving assistance from the fund. 


\section{County Council Grants}

The following statement of what the County Councils of Ontario have voted for 1916 to the Canadian Patriotic Fund is a splendid evidence of the generosity of the rural districts as exhibited toward this Fund. These contributions do not include what the townships are giving, nor the voluntary contributions coming from rural parts of the Province, but only what has been voted through the county councils. The record is described by Sir Herbert Ames, Hon. Secretary of the Canadian Patriotic Fund, as being "a triumph quite equal to that scored by Montreal or Toronto."

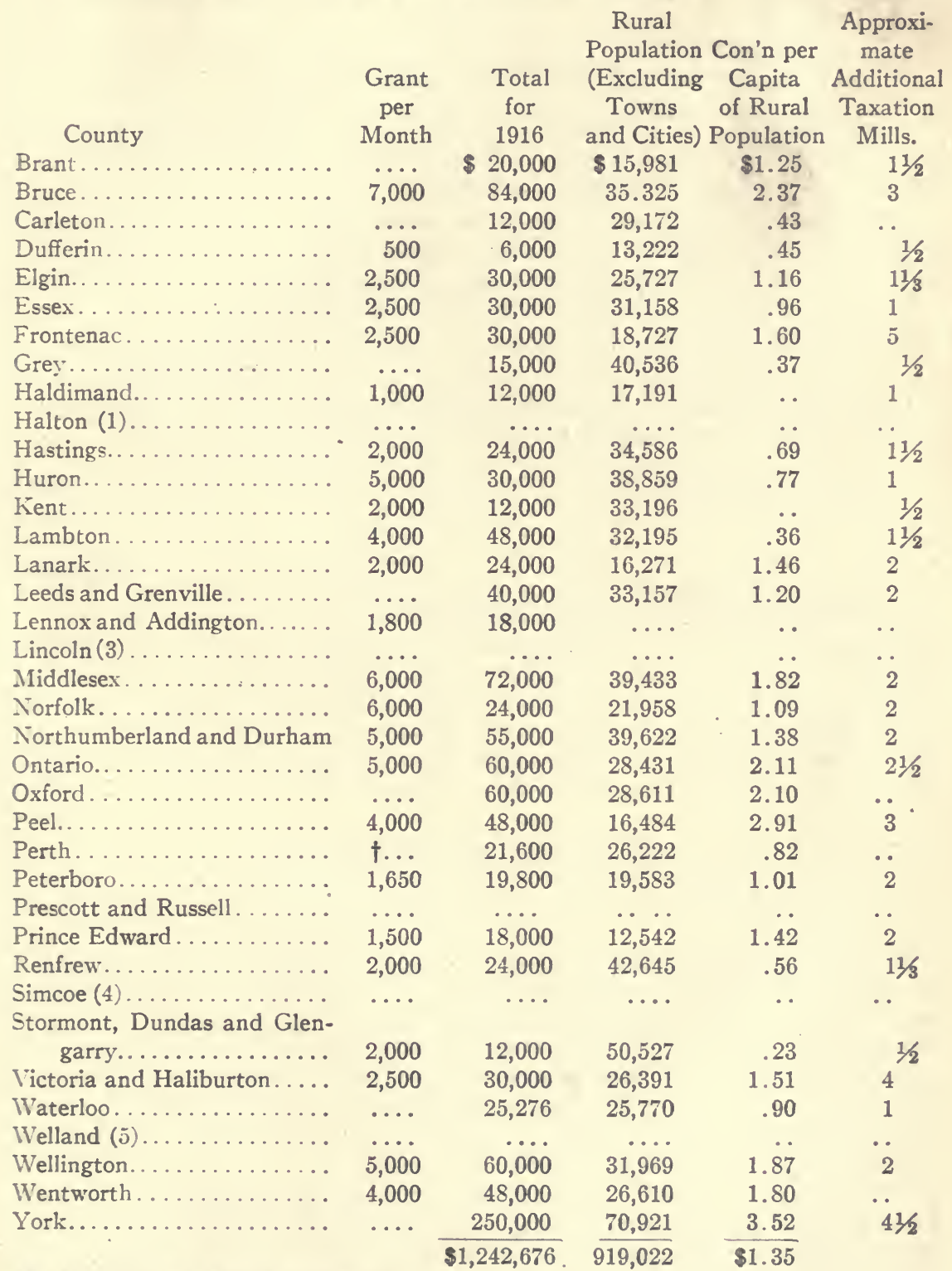

$\uparrow \$ 1,400$ till April, $\$ 2,000$ afterward.

(1) The Council of Halton raised $\$ 16,403$ by assessment in 1915.

(3) Lincoln County Council expended \$45,095 in 1915.

(4) Simcoe County granted $\$ 25,000$ in 1915 . Action for 1916 not yet taken.

(5) Welland County granted food stuffs valued at $\$ 7,003$ in 1915. 


\section{Patriotic Acre Fund, Saskatchewan}

Number of acres promised........................... 6,000

Contributions paid (Jan. 24), in grain or cash, equivalent in flour to...3,000,000 lbs.

A nominal charge is made by the Milling Companies and the flour put up in bags bearing the Association's emblem.

\section{CANADIAN RED CROSS SOCIETY}

Chairman of Executive Committee, Lt.-Col. Noel G. L. Marshall. Hon Treasurer, Brig.-Gen. The Hon. James Mason. Commissioner in England-Colonel Hodgetts, C.A.M.C. Head Office: 77 King St. E., Toronto.

The Canadian Red Cross Society is the representative in Canada of the International Red Cross Society with its Executive Committee in Geneva, Switzerland.

The work of the Red Cross Society is to co-operate with the Medical Services of the Navy and Army in the relief of sick and wounded sailors and soldiers.

To this duty is added that of ministering to the needs of prisoners of war.

In a report to the Press, made by the Chairman of the Society in February last, it was stated that the people of the Dominion had contributed in cash and goods since the beginning of the war until the end of 1915 , over $\$ 4,100,000$, as follows:

Value of Supplies, estimated. . . . . . . . . . . . . . . . . $\$ 3,000,000$

Cash........................................... 108,473

$\$ 4,108,473$

The cash contributed was as follows, by provinces:

Ontario...............\$707,204

Manitoba.............. 89,034

Quebec.................. 78,886

Saskatchewan............ 72,606

British Columbia........... 54,596

Alberta............... 40,792
Nova Scotia............\$23,744

Prince Edward Island....... 18,734

New Brunswick............. 17,307

Yukon................. 3,429

United States............ 2,200

\section{Waste Paper for the Red Cross}

Do not waste old papers; you can make money out of them for the Patriotic Fund or the Red Cross.

Several Women's Institutes have raised money in this way. Elizabeth Dolman Watson, President of the Women's Institute at Ayr, Ont., states that the Institute shipped a 12 ton carload which realized $\$ 74.07$, or $\$ 58.47$ net, after deducting $\$ 15.60$ freight. Newspapers brought $\$ 5$ per ton and magazines of a higher grade of paper $\$ 10$. "We rented a store, where we received paper one day a week for six weeks. The bulk of the paper was brought in by the people themselves. To facilitate handling, the papers were sorted and tied up in bundles of a size. We announced the collection through the Institute and the issue of the local paper."

What Ottawa is doing: The Daughters of the Empire inaugurated a system in Ottawa for the collection of waste paper, which is meeting with excellent success. As much as $\$ 300$ a month has been realized. Mr. E. C. Grant, of 24 Blackburn Ave., who is managing the undertaking, states that twenty boxes placed at different points in the city are bringing in over a ton a day. He writes, "We shall be pleased to give all information to any town or city undertaking the work, and also have them ship to us as we have an excellent contract for all the paper we can produce until the war is over." 


\section{THE BRITISH RED CROSS}

Collections in Canada for the British Red Cross Fund, so far as can be ascertained, are as follows:-

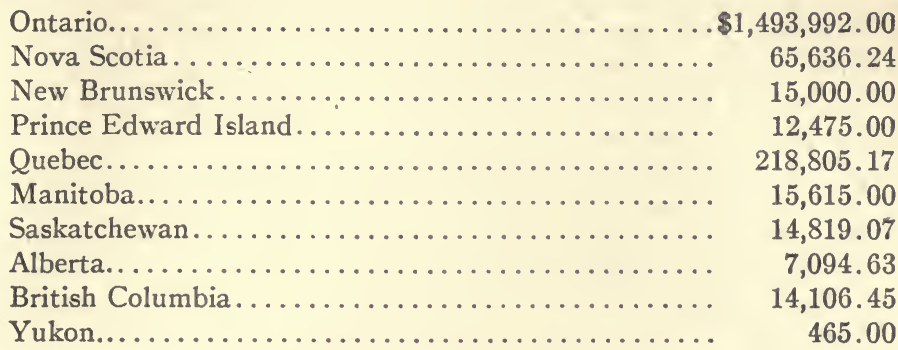

Of the amount contributed by Ontario, the City of Toronto's share was $\$ 542,607.00$.

\section{BELGIAN RELIEF FUND}

Secretary-Treasurer of Fund for Canada: Mons. Hector Prud'homme, 59 St. Peter Street, Montreal, P.Q.

Object-To relieve destitute Belgians behind the German lines in Belgium.

Total subscriptions in Canada for Belgian Relief received by the Central Executive Committee to January 18,1916 , cash and goods..........\$2,192,948.93

\section{BELGIAN RELIEF WORK}

When the war began, Belgium was the most densely populated and highly industralized state in Europe. Three-quarters of her 7,000,000 people supported themselves by commerce. Her exports and imports were nearly three times as great per capita as those of France and Germany. Her principal industries were dependent almost entirely on imported raw material and her principal markets lay outside her borders.

The immediate result of German aggression was that millions of Belgians were reduced to the verge of starvation. That they were saved from such a fate was due primarily to a group of Americans in Brussels, headed by Brand Whitlock, the American Minister.

The outcome of their efforts was the organization of a commission for the relief of Belgium. The Commission was a voluntary organization with a membership of something less than one hundred, chiefly Americans. With Herbert C. Hoover at its head, the work has been a marvel of efficiency and economy.

The undertaking involved the handling of huge sums of money and colossal shipments of clothes and provisions. Not only had enormous quantities of wheat, flour, bacon, rice, maize, etc., to be purchased and transported to Europe, but after it had been landed in Holland (through which country it had to go) it was necessary to prepare it for distribution, and finally to distribute it systematically among the people.

In the thirteen months prior to December,1915, one million tons of food and clothing were delivered in Belgium and northern France. Some idea of what this means may be realized from the statement that it would take about 20,000 miles of ten-ton capacity freight cars to transport this amount of merchandise.

To date, $\$ 60,000,000$ has been expended by the Commission, at a cost of less than half of one per cent., which constitutes a record for work of this kind. As by far the greater portion of the labour involved in distribution has been given gratuitously, the half of one per cent. may be said to represent the cost of conveyance, milling, and incidental business expenses. 
To-day the Commission is feeding close to ten million people in Belgium and northern France. This is more than the Commissariat of any one of the belligerents is supplying, and half as many as all of them together. The ration allowed to each individual is ten ounces of food per day, which is about one quarter of the average consumption in this country. No matter how much money a man may have, he cannot purchase more. All receive alike whether they have means or are entirely destitute. At the present time in Belgium alone there are 2,000,000 people who are unable to pay anything at all for the food they receive.

It has been very generally assumed that the 9,500,000 Belgians and French within the German lines of occupation are being fed largely at the expense of the people of the United States. Such is not by any means the case. Mr. Hoover is responsible for the statement that of the sixty million dollars expended to date, only ten millions have been derived from charitable sources. The other fifty millions have come from the Belgians themselves.

An article in a recent number of the Outlook (New York) states that as a result of the appeal made throughout the United States, 71,000 tons of food and clothing valued at $\$ 5,600,000$ and $\$ 312,000$ in money (total $\$ 5,912,000$ ) were contributed, while, the British Empire had given $\$ 8,000,000$ in cash. According to the Commission's figures, the United States has given 7c. per capita, while Australia has given 70 cents, and New Zealand $\$ 1.25$ per capita. It is also pointed out that Great Britain is supporting 200,000 Belgian refugees on her own soil, and has done a large part towards clothing the people within the lines of German occupation. Holland has, for upwards of one year, been caring for hundreds of thousands of refugees who fled across the frontier to escape the terrorism which the Prussian hosts were scattering broadcast through the land. Tons and tons of foodstuffs have been sent into the prostrate kingdom in an effort to appease the hunger of its people. It is further noted that the French have paid for all the provisions distributed among their countrymen. At the suggestion of the Commission the Germans agreed to allow sufficient from the Belgian harvest to meet derhands for one month.

From all these sources, and allowing for the number who are able to pay for their food, the Commission has been enabled to provide the bare minimum of sustenance necessary to keep $9,500,000$ Belgians and French who are captives within their own countries. It was estimated that with the stores and funds in sight, the people could be fed until the beginning of 1916, when further assistance would be necessary.

The proportion of the load which the Belgians are themselves carrying has increased, but the time when they will be able to carry the whole of it is not yet in sight, as hitherto the Germans have not allowed them to manufacture goods to be sold in neutral countries. Indeed another crisis is now impending. Three million men, women and children are in direct need of warm clothing. This calls for an outlay of $\$ 4,000,000$ in money or new clothing, for the rigid regulations in force prevent the bringing in of second-hand wearing apparel.

The Central Committee for Belgian Relief, 59 St. Peter Street, Montreal, will accept contributions and supply any information required.

\section{FRENCH RELIEF (SECOURS NATIONAL)}

Object-To relieve the impoverished civilians of Northern France and collect materials for French Hospitals (in co-operation with the Canadian Red Cross Society). Needs-(a) Money; (b) Clothing of all kinds in good condition; (c) Hospital Supplies.

Address-Local Branches in Ottawa, Montreal, Toronto, Hamilton, Winnipeg.

When the Germans invaded Northern France they captured more than 200,000 men, women and children, who were found in the village streets or working in the fields. The unfortunate people were seized and driven on foot into Germany in the 
clothes in which they stood. Children were separated from their parents and husbands from their wives. These people were kept at various concentration camps in Germany in the most miserable condition, without additional clothing being furnished to them and with scarcely food enough to keep them alive.

After a time large numbers of them were sent back to France via Switzerland in an absolutely destitute condition. The Swiss people were most generous in contributing clothing and money. Two and a quarter million French inhabitants still remain in the territory of the North and East occupied by the Germans.

Money and clothing are given to those who have fled from the devastated districts. Agents visit the war zone to ptevent black misery for those who have been unable to escape from the scene of conflict and are forced to remain near their ruined homes.

No request has come for aid from the French people. This organization is entirely voluntary and aims to be a tangible expression of Canadian appreciation for the heroic conduct of our great ally.

While much has been done by the French Government and by the French people for their fellow countrymen the need for relief in money and in supplies of clothing is great and will continue during the war, and while the contributions which have been made by the people in the United States and Canada have undoubtedly been large, such contributions are small in proportion to the amounts contributed by the French people themselves.

The "Secours National" has received in donation of money the sum of $10,500,000 \mathrm{f}$. Of this amount the French people have given about nine-tenths, or 9,000,000f;; there has been received from the United States about 400,000f. and from Canada about 350,000 . England, Spain and other countries have also contributed. Most of the donations of clothing have come from the United States and Canada.

- The Ontario Branch at its annual meeting held in Toronto on February 29th, reported the following contributions:

Cash to February 11 th.............................. $\$ 22,405.00$

Estimated value of goods actually despatched, including clothing, hospital

supplies, and twelve motor cars.................. $74,011.00$

Total........................... $\overline{\$ 96,416.00}$

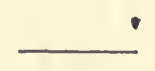

\section{POLAND}

Devastated Poland has no less than 1,500,000 refugees, mostly Jews, who have endured all the innumerable miseries of war. Over 120 Jewish Relief Boards are operating to-day in Russia with the authority and sympathy of the Russian Government, and their needs, merely for feeding the impoverished Polish Jews, are fully $\$ 3,000,000$ a month. Without immediate help many thousands of men, women and children will go to certain death by exposure, pestilence and starvation. It is the tragedy of the centuries. Any of the members of the Committee will thankfully receive contributions. An appeal to the Jews of the British Empire for the help of their brothers has been made by Lord Swaythling and Leopold de Rothschild, C.V.O., and the Jewish colony of Toronto has opened a fund. The committee consists of Rabbi S. Jacobs, Jacob Cohen, J.P., Leo Frankel, Harry Samuel (of M. \& L. Samuel, Benjamin \& Co.), and Edmund Scheuer.

"An area three times larger than Belgium is entirely laid waste. Cities and towns have been destroyed, and thousands of villages burned down. All horses and cattle have been taken. There is no corn; no potatoes are left. There are millions of sufferers, mostly homeless, all lacking food."-PADEREWSRI. 
"All the world was in haste to help Belgium. My country now appeals for help. The War, with its iron tramp, has crushed Poland, a country seven times as large as the Kingdom of the heroic Albert. The sword has filled the rivers of this unfortunate country with blood; her sons are compelled to fight in three hostile armies.

"The War has ruined towns and villages. The spectre of hunger has stretched its arms over the vast land between the Niemen and the Carpathians. Workmen have lost their work, for all the workshops and factories are shut. The plough is rusting from the want of use, for the labourer has been robbed of tools and seed. Tradesmen in towns have no trade, for no one has money to buy their goods. Old men and women in the midst of the hard winter have lost the roofs over their heads. Epidemics spread through the country. The domestic hearth is extinguished, and when children stretch out their thin arms begging for a piece of bread, their mothers can only answer with tears. . . . In such hunger and need are millions."-Henry Senkiewicz.

\section{SERBIAN RELIEF}

The Serbian minister in London announces that several relief funds in Serbia are sending through him their appeal to all benevolent men and women, fathers and mothers and all philanthropic institutions, painting the suffering of the Serbian refugees, the starvation of the population staying at home in Serbia, the painful scenes of the desperate mothers and frozen children. Many thousands of refugees are dispersed in the villages of Greece, in the Albanian desert or in the rocky hollows of Montenegro, without home, without food. The life of these refugees is now nothing else than a slow dying out. This help will be a real help only if it comes as quickly as possible.

Contributions for this F und will be received by the Treasurer of the National Service Committee (Mrs. John Bruce, of Toronto), and forwarded to the London Branch of the Serbian Relief Committee.

No supplies of food or clothing will be received.

\section{NATIONAL COMMITTEE OF WOMEN FOR PATRIOTIC SERVICE}

\section{(Commonly known as the National Service Committee)}

The officers for 1916 are President, Mrs. A. E. Gooderham, "Deancroft," Toronto; Vice-President Mrs. Torrington; Treasurer Mrs. Bruce, 37 Bleecker Street, Toronto; Secretary, Mrs. Plumptre, 77 Kińg Street East, Toronto.

The National Service Committee is the channel recognized by the National Relief Committee for the collection and transmission of funds and supplies for "Comforts" for the Canadian Expeditionary Force.

By courtesy of the Canadian Red Cross Society, and in consideration of a contribution to office and warehouse expenses, these gifts, generally known as "Field Comforts," are collected in the Society's warehouses and forwarded by its packing staff, but these goods are not reckoned as Red Cross goods nor included in its returns; as the Red Cross Society deals only with sick, wounded and prisoners, while "Field Comfort's" go to fighting men.

\section{CANADIAN INDIANS; "PATRIOTISM AND PRODUCTION"}

The Indian population of Canada continue to give evidence of their loyalty by enlisting and contributing liberally to the patriotic or other funds. To the end of $\mathbf{1 9 1 5}$ their contributions for patriotic purposes amounted to $\$ 16,969.00$, and an equally good response is being made to this year's call.

The total Indian population, exclusive of Eskimos, was 103,531 in 1915, and the total income derived from all pursuits was $\$ 5,927,595$ or $\$ 60.48$ per capita. The chief 
sources of income are agriculture, wages earned, fishing, hunting, other occupations and industries, trust funds and land rentals.

In 1915 the land under crop was estimated at 65,257 acres, grain roots and hay being the leading crops, estimated to be worth $\$ 1,813,619$. In addition the beef sold and consumed during the year was valued at $\$ 309,506$.

In many localities where industries such as lumbering, hunting and fishing, on which the Indians relied for a livelihood, are no longer active, attention is now being turned to the soil. Many are beginning to realize how valuable an asset they possess in their farm lands. The Department of Indian Affairs is giving special attention to this phase of the work, and it is hoped that, with capable oversight and guidance, better methods of farming will be adopted and good use made of much land that has hitherto remained uncultivated.

\section{THE BLUE CROSS}

This organization has sent veterinary requisites, medicaments, and other comforts for horses engaged in war to nearly 300 regiments. These supplies have included such things as humane pocket killers, portable forges, clippers, waterproof rugs of a special design, many thousands of calico bandages, also flannel bandages and wither pads, wound syringes, pocket cases of surgical instruments and a very large number of fly nets.

In many cases regiments are receiving weekly, fortnightly and monthly supplies of necessaries for their horses.

In the early days of the war the Blue Cross offered its services to the French government, which has no official veterinary hospital equipment as have the British, which gratefully accepted and officially recognized them.

It has now four splendid depots in France divided into twelve hospitals, and a very excellent and valuable work is being done, 2,118 horses having been cured since the hospitals were opened.

\section{AN APPEAL}

I'm only a cavalry charger,

And I'm dying as fast as I can

(For my body is riddled with bullets-

They've potted both me and my man);

And though I've no words to express it,

I'm trying this message to tell

To kind folks who work for the Red Cross-

$\mathrm{Oh}$, please help the Blue one as well!

My master was one in a thousand,

And I loved him with all this poor heart

(For horses are built just like humans,

Be kind to them-they'll do their part):

So please send out help for our wounded,

And give us a word in your prayers-

This isn't so strange as you'd fancy,

The Russians do it in theirs.

I'm only a cavalry charger,

And my eyes are becoming quite dim

(I really don't mind, though I'm "done for,"

So long as I'm going to him):

But first I would plead for my comrades,

Who're dying and suffering, too-

Oh, please help the poor wouncled horses:

I'm sure that you would-if you knew.-SCOTS GREYS. 


\section{EDUCATION AND THE WAR}

\section{"Agricultural and vocational training is the big topic in educational circles to-day."}

\section{A REVOLUTION NECESSARY IN EDUCATION}

"If we are to face the future with any confidence after this exhausting war, we must face it as an educated people. We shall not be able to afford to waste the efficiency of a single English child. On all sides we hear the cry, though we see little enough of the practice, for economy. Now economy means one or both of two things-less expense, greater production. It is said by materialistic economists that lack of capital will render greater productiveness impossible. They !orget the only capital that has permanent significance-the men and women of the nation. Our national business is to eliminate waste in human beings and to make each human being capable of realizing to the full his or her potential capacity for creative work, whether such work be material or moral or spiritual. Those ends can only be reached by the best training of childhood in the homes and in the schools. Something, of course, can be done among adults; but in the aggregate it is, comparatively speaking, very little. The bulk of humanity is made or marred in youth. Now there is no more appalling fact in our national economy than the waste of that supreme national product-the child. We do not refer particularly to the waste of infant life, for that is merely one of many by-products of ignorance. We refer to the waste of efficiency among the children who survive. Consider the children of the people, how they live, after the experience of half a century of compulsory primary education. There are nearly half a million children between the ages of twelve and fourteen years who are receiving no education, or no education worth having. Some of these are at school, but all are at work, work leading no-whither, at the very age when moral and physical development are at stake. In addition to these there are at least a million and a half of children between the ages of fourteen and seventeen years who are receiving in the week no school education of any kind. The Consultative Committee in its report of 1909 asserted that 'at the most critical period in their lives a very large majority of the boys and girls in England and Wales are left without any sufficient guidance and care. . This neglect results in great waste of early promise, an injury to character, in the lessening of industrial efficiency, and in the lowering of ideals of personal and civic duty'."-"The WeEkLy TrMes, London, Eng."

\section{A CREED FOR COUNTRY BOYS AND GIRLS}

\section{G. C. CREelman,'B.S.A., Ll.D., President Ontario Agricultural College}

\section{The Boy's Creed}

1. I believe that life in the Country can be made just as pleasant and profitable as life in the City.

2. I believe that father and I can form a partnership that will suit both of us. 
3. I believe that if I kill every weed on my father's farm we shall be well paid by the increased crop alone, to say noching of the benefit to our neighbours.

4. I believe that by careful selection of our chickens I can double the output of the flock.

5. I believe that by introducing Alfalfa on our farm we can keep twice as many domestic animals as at present.

6. I believe that by keeping twice as many animals, we shall be able to grow much larger crops of Alfalfa and other things.

7. I believe that by planting shade trees, growing flowers, and shrubs and by keeping a tidy homestead, we shall be better contented and happier in every way, and our farm will increase in value.

8. I believe not in luck, but in pluck.

9. I believe that farming is a most honourable calling, and having decided to stay on the farm, it is my duty to make the best use of my time, now, in school, that I may be the better farmer in the days that are to come.

10. I believe in working when I work and playing when I play, and in giving and receiving a square deal in every act of life.

\section{The Girl's Creed}

1. I believe that I have a right to be happy every day.

2. I believe that God's blue sky and God's green earth are a part of my inheritance.

3. I believe that I have a right to love little chickens and ducks and lambs and puppies as well as dolls and ribbons.

4. I believe that I could take care of these things as well as my brother, who does not love them as much as I do.

5. I believe that I should love to keep house better than anything else and I only wish they taught housework at school.

6. I believe that keeping a garden "all my own" would be great fun, and I believe that I could be very happy in giving away the flowers and in cooking the vegetables that I raised myself.

7. I believe that I could study real hard at my Grammar and Geography and Arithmetic and Spelling if I could do cooking or sewing with the other gir!s in the afternoon.

8. I don't want to go to town and leave my father and mother and my brothers and sisters to live in the country, for I know I should miss them all, and the trees and the creek and the green grass and the old woods and everything, but oh! I don't want to stay at home and do nothing but wash dishes and carry water and do the chores and grow old like Auntie. I want to laugh and love and live.

9. I believe I can learn to sew and cook and do laundry work and do them well. And I want to learn them and I want to do them well.

10. I believe in the square deal for girls as well as for boys, and I want everybody to be happy all the time-the old as well as the young.

\section{GOOD ROADS ONE OF CANADA'S GREATEST NEEDS}

\section{W. A. Mclean, Deputy Minister of Highways, Ontario.}

Rural roads are the primary channel of traffic. Along them, production, industry and commerce have their origin. Let the common roads be closed, and railways will decay in idleness; ocean liners will rust at their moorings. Nations have prospered without railways; but common roads, "Goods Road," have always been vital to national progress and development. 
The lessening of the cost of transportation is a measure of economy, of national thrift, which will produce a large return on the expenditure. On this continent, the cost of team haulage is rarely less than 25 cents per ton-mile and is sometimes twice that amount. Under the favourable conditions of good roads in Europe, the cost is reduced to between 8 and 12 cents a ton-mile.

The tonnage carried over the country roads of Canada is not readily estimated; but railway statistics show that the total amount of freight carried by the railways and originating in Canada, is about $60,000,000$ tons. This, for the most part, at one or both ends of the railway journey, must pass over the waggon road. And a considerable additional amount, consumed locally, passes over the waggon road without railway transportation. The average waggon haul for farm and natural produce is estimated at between seven and eight miles. It is probably a moderate assumption for Canada that a total of not less than $100,000,000$ tons passes over the roads of the country with an average haul of five miles.

Compared with European costs, good roads would effect a saving of not less than ten cents per ton-mile. Putting the amount saved at only five cents a ton-mile, or 25 cents per ton for the average haul of five miles, an adequate system of improved roads would create a profit of $\$ 25,000,000$ annually on the produce and merchandise now passing over the roads of Canada.

The time lost in travelling over bad roads is very great. It has been estimated that bad roads occasion a loss of a man and team for two weeks (12 working days) annually to the average farm.

Bad roads limit the output of farms to the kind and quality of produce that can be drawn to market. Good roads permit the farmer to take advantage to the utmost of the location and fertility of his land. In other words, it may be broadly said that with bad roads the production is restricted to the produce that can be hauled over the roads; whereas with good roads it is restricted only to the amount and quality that can be grown and sold on the market.

If the nation and the city are to reap the advantage of increased farm population and production, rural conditions must be made to compete with city, by making them profitable and agreeable.

Road-building is clearly one of the most important public works remaining for Canada to undertake. When the War is ended and our armies return, with a large additional influx of immigration, it will be well if we are so organized that roads can be built on an adequate scale, not only to aid in the development of Canada, but, temporarily, to assist in giving employment during what will probably be a trying period of industrial readjustment.

Only a very wealthy country, improvident of its resources, can progress under the handicap of bad roads. Those who have bad roads consider good roads an expensive luxury. But those who have the advantages of good roads, know that Good Roads are a necessity.

Road-building is a slow process in part, because it is expensive. And because the work is expensive, it must be distributed over a term of years and among various administrative organizations. But so distributed, and looked at from the standpoint of annual ability, the undertaking becomes less difficult. The total twenty-year cost of maintaining a household does not worry the average man-if his annual income is sufficient for the annual outlay. Road-building is a continuous work; if properly carried on, is cumulative in its growth, and is a question of annual expenditure available to meet direct outlay, plus sinking fund, interest and cost of maintenance.

In the Dominion of Canada there are about 250,000 miles of graded roads. The immediate objective in Canada should be to substantially improve about $16 \%$ of the total, or 40,000 miles, which would carry the more concentrated market or farm traffic; while about $2 \%$ additional, or 5,000 miles, should be treated on a trunk road basis. The total cost might be approximately estimated at $\$ 250,000,000$, of which about $\$ 50,000,000$ has been spent. 


\section{SHIPPING AND THE WAR}

Now that the New Year has fairly started, it is possible to look round the world of shipping and consider not only the trend of business in the year that has passed, but also prospects for the future. The history of shipping has never seen anything to approach the increases in freights of the past six months. The primary cause has been the needs of the Admiralty, in fulfilment of which they have freely requisitioned British tonnage. The result has been a chronic shortage of the means of transport in every market in the world. The keen competition among foreign shippers has forced upon the shipowner the embarrassing choice of freights which soared ever upwards against his own volition. A careful study of all the prospects cannot but reveal the absolute assurance that there is nothing, which can be humanly foreseen, to depress freight markets for a very considerable time to come; on the contrary, everything points to continued rises in every direction unless maximum rates of freight are fixed to Allied countries by Governmental intervention.-London Morning Post.

\section{THE OCEAN FREIGHT QUESTION}

\section{As Viewed by the English Miller}

The most serious feature of the corn (wheat) trade at the present moment is the enormous freight rates that have to be paid for the carriage of grain to this country. In normal times the cost of carrying a bushel of wheat from New York to a British port was about $2 \mathrm{~d}$. ( 4 cents); often it was a little less. Now it is $1 \mathrm{~s} .8 \mathrm{~d}$. ( 40 cents), an increase of $12 \mathrm{~s}$. ( $\$ 2.88$ ) a quarter (8 bushels).

North America has harvested the largest crop in the history of that continent. Not only is it the largest, but very much the largest ever grown there. The United States has reaped a crop of over a billion bushels, 112 million bushels more than her previous best. Canada has a still greater relative increase, her harvest having yielded 336 million bushels, 100 million bushels, or nearly 50 per cent., more than the previous record of the Dominion, and yet, thanks to the shipowners, we in England, are paying much more for wheat to-day than we were a year ago, although the commodity is much cheaper now both in Chicago and Winnipeg. A year ago October wheat was selling in Winnipeg at 115 cents a bushel. At the moment of writing it is just under a dollar, or 15 cents a bushel, i.e., 5s. a quarter cheaper than at the same date in 1914. On the other hand, a year ago, 12 weeks after the outbreak of war, No. 1 Northern Manitoba October shipment was sold in London at $44 \mathrm{~s} .6 \mathrm{~d}$. per $480 \mathrm{lbs}$., c.i.f. (cost, insurance, freight), the ocean rate being $33 / 4 \mathrm{~d}$. To-day the same grade of wheat in the same position is selling at $54 \mathrm{~s}$. per qr., c.i.f. True the rate of exchange is against this country to about the extent of the equivalent of $1 \mathrm{~s}$. 6d. per qr. of wheat at the present price of the cereal. We will deduct that sum from the present c.i.f. value of the grain, and call it 52s. 6d. The c.i.f. cost of No. 1 Northern Manitoba is then 8s. a qr. dearer here than a year ago. Adding to the $8 \mathrm{~s}$. the $5 \mathrm{~s}$. lower cost of the grain in Winnipeg, we have $13 \mathrm{~s}$., which is about the actual amount transport charges are costing us more than this time last year.

That this is a serious extra charge we think no one will deny. The British Government are carrying the war risk insurance at almost a nominal rate, call it $6 \mathrm{~d}$. a qr., and then reckoning 70 per cent. of flour from the wheat and 924 -lb. loaves to the sack of flour, we find that the extra profits-war profits-that the shipowners are making is imposing a bread tax on the British public of 11/3d. per 4-lb. loaf. These are figures that can be verified by the "man in the street." We do not ask any layman to take our figures. If he chooses to obtain a year-old London daily and compare American and Canadian market prices of wheat and Baltic sales then with those now current, he can soon verify them for himself, as can also his Britannic Majesty's Government. What the shipping companies' increased working costs are we cannot tell exactly, but suppose we allow them the odd one-third of a penny a loaf for increased working expenses, that would mean a full $4 \mathrm{~d}$. a bushel more, and we doubt if working expenses have increased 
to anything like that amount. However, that is a question we can leave to the shipowners to settle. What concerns the nation at large is that we are paying ten times as much for trans-Atlantic carriage on American wheat as we were doing before the war.

Two years ago the dfference between the price of wheat at Winnipeg and c.i.f. London and Liverpool was little more than $5 \mathrm{~s}$., now it is round about $20 \mathrm{~s}$. The Canadian and United States transport companies may be making a little extra out of carrying it to the seaboard, but if so the amount is very small. It might be interesting to know what our Government is paying for the ships they have requisitioned for carrying military supplies. This requisition has resulted in a considerable shortage of tonnage for ordinary commerce, and it is a question of supply and demand which is being answered in favour of the suppliers at the expense of the public.

The excessive freights amount in any case to a tax on breadstuffs, but if the Chancellor of the Exchequer could annex the whole of it we should not so very much object, though the knowledge that he will obtain a share of it is something. If all the shipping concerns were British the remedy would be simpler, but a considerable portion of the tonnage employed in the grain trade does not fly the Union Jack, and so is not within the control of our Board of Trade. The matter is further complicated by the fact that more than half of the grain is being carried to continental states.

We quite agree with Mr. Runciman that it is difficult to find a solution that will not do more harm than good, but whatever the difficulty, it should not be insurmountable.

\section{CANADA'S OCEAN FREIGHT}

Sir Robert Borden said in the House recently that he had taken up with the British authorities the question of transportation. More than a year ago the Government had arranged for the services of A. H. Harriss, of the C.P.R., to organize the transportation of supplies. Mr. Harriss in a recent report said that there had been an uninterrupted outlet for orders. The regular service established had proved to be of great advantage to the export trade. Between August, 1914, and April, 1915, 144,913 gross tons had been shipped. In the next seven months this had been increased to more than 400,000 tons. In February last arrangements had been made to secure the service of eighteen transports from the Admiralty. During the last seven months this had been increased to forty transports, twenty plying from Halifax and twenty from St. John. Representations had been made to the Admiralty for more, it being pointed out that a larger portion of ships had been taken from the North Atlantic services than from any other. It had to be borne in mind, however, that the paramount necessity of the Admiralty is for vessels for the transport of troops and munitions.

\section{WORLD'S MERCANTILE MARINE}

Upon the outbreak of war the merchant shipping of the world, according to the figures of "Lloyd's Register of Shipping," which includes only vessels of 100 tons and upwards, consisted of 30,836 vessels, of $49,089,552$ tons, of which 24,444 of $45,403,877$ tons gross were steamers and 6,392 of $3,685,675$ tons net were sailing vessels.

The shipping owned by belligerent countries on that date was:-

\begin{tabular}{|c|c|c|}
\hline - & Steamers & Gross Tons. \\
\hline Great Britain and Colonies............. & 10,123 & $20,523,706$ \\
\hline 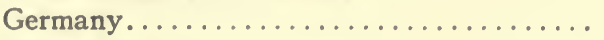 & 2,090 & $5,134,720$ \\
\hline 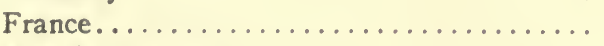 & 1,025 & $1,922,286$ \\
\hline 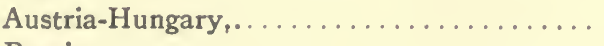 & 433 & $1,052,346$ \\
\hline 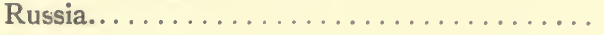 & 747 & 851,949 \\
\hline 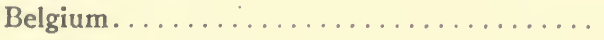 & 173 & 341,025 \\
\hline 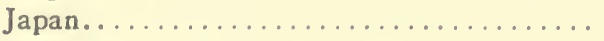 & 1,103 & $1,078,386$ \\
\hline Italy $\ldots \ldots \ldots \ldots \ldots \ldots \ldots \ldots \ldots \ldots \ldots \ldots \ldots \ldots \ldots \ldots \ldots \ldots$ & 637 & $1,480,475$ \\
\hline & 16,331 & 32,3 \\
\hline
\end{tabular}


As the total number of steamers in the world was but 24,444 of $45,403,877$ tons gross upon the outbreak of war, it will be seen that the steam tonnage owned in the countries at war represents 71 per cent. of the total steam fleet of the world.

The declaration of war was immediately followed by the complete immobilization of German and Austrian steam shipping, aggregating some 6,187,066 tons. It has been estimated that since the war began 1,200,000 tons gross of German shipping seized at sea or detained in port by the Allies have been restored to traffic. About 1,000,000 tons of Allied and neutral shipping have been sunk by the German navy, so that, after making the proper allowances, the total loss of tonnage to navigation since the war began may be put at 5,000,000 tons, or about 11 per cent. of the gross tonnage afloat at the beginning of the war.-Bulletin of DePt. OF TRADE aNd CoMmerce.

\section{RUSSIA'S AGRICULTURE}

The following statistics of Russia's agricultural production, and facts as to future development were published in an article in "Logging," by the Hon. William P.Anderson, Agricultural Commissioner for the Russian Government in the United States.

\section{Acreage and Yield of Farm Products in 1912}

\begin{tabular}{|c|c|}
\hline $\begin{array}{cc}\text { Acres } \\
1912\end{array}$ & $\begin{array}{c}\text { Yield } \\
\text { Poods }=36 \text { lbss. }\end{array}$ \\
\hline Winter wheat, rye and barley........93,672,644 & $2,085,114,000$ \\
\hline $\begin{array}{l}\text { Spring wheat, rye, barley, buckwheat, } \\
\text { millet and beans.............159,520,128 }\end{array}$ & $2,986,989,000$ \\
\hline Potatoes................ 11,544,852 & $2,318,767,000$ \\
\hline $3,832,056\{$ & $\left\{\begin{array}{l}45,807,200 \text { fibre } \\
37,972,000 \text { seed }\end{array}\right.$ \\
\hline 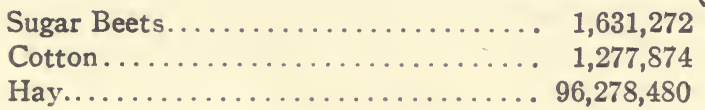 & $\begin{array}{r}7,995,672,000 \\
26,515,000 \\
3,678,470,600\end{array}$ \\
\hline
\end{tabular}

Enormous quantities of hemp are grown for fibre and seed, and of sunflowers for seed.

Live Stock in 1912

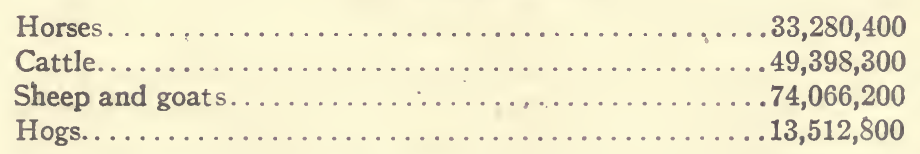

With $8,950,000$ spinning spindles operating in the country in 1913 , only $46 \%$ of the raw cotton requirements was imported, the balance being raised at home.

Enormous though her present crops may seem, they give but a faint idea of Russia's potential productiveness, which will be realized only as her millions of virgin acres are brought under cultivation. These enormous resources are being carefully developed through the Departments of Lands and Agriculture.

Schools of Agriculture have been founded in many parts of the country. Their graduates act as farm advisers or as workers at the Experiment Stations and Fields, 214 in number in 1912.

The Russian Government has placed an agricultural commissioner in the United States with a staff of trained workers, who study American methods of agriculture, and keep.in touch with the work being carried on at Experiment Stations. 


\section{INDIA}

"It may not be generally known in America that out of the population of 315 millions which make up the Indian Empire, there are in my native land, India, exclusive of male adults of unwarlike races, about sixty million male adults of the fighting racesa number not far short of the total population of Japan and her dependencies-out of which a choice of recruits for this war might be made. If this is going to be a war of attrition, it may be worth remembering thac the above figure of sixty millions represents more than double the total number of male adults in the German Empire, and about twice the total number of white male adults in the British Empire. It is not difficult, therefore, to see whether Germany or England is capable of the longer endurance so far as fighting men are concerned, and which part of the British Empire can supply the largest number of soldiers for the longest period, to preserve the prestige of the Union Jack. The native soldier of Hindustan has already stood the rigors of a European winter, has fought with valour side by side with the British soldier in the trenches in Flanders, in France, at the Dardanelles, and elsewhere, has won several Victoria Crosses and Military Crosses, and has often been mentioned in dispatches."

-S. M. Mitra, in The Nation, London.

\section{AGRICULTURE IN FRANCE}

\section{Compulsory Cultivation of all Fallow Land}

In order to obtain a maximum amount of agricultural production, Mr. Méline, the French Minister of Agriculture, has prepared a law under which proprietors of fallow lands will be invited within two weeks after notice is served upon them by a registered letter, to have these parcels of land ploughed and under cultivation. If the invitation is not complied with, the law will provide that the mayors of the "communes" or towns will have a right to commandeer the land in question and order its cultivation, which will be done under the direction of the municipalities which shall provide the funds necessary to the proper carrying out of the work. The same law provides for the creation of a municipal or farming committee in charge of the superintendents of these parcels of land to be cultivated until harvesting time, when the crops will be sold by auction by the same committee.

Mr. Méline in the reasons set forth in the preamble to the law, says that the 1915 crops were $10 \%$ short of what they were in 1914 .

The Minister insists upon the importance of not losing a minute if France is to avoid being taken unawares by events and left subject to the possibility of being too late in the field of economic exigencies. Farm hands will be provided, under special arrangements, by the military authorities from the minor services and from the incapacitated soldiers.

\section{SCHEMES TO DEFRAUD FARMERS}

Speaking before the Commission of Conservation lately, Mgr. Choquette, of St. Hyacinthe, Que., drew attention to the uncurbed activities of those who victimize farmers by selling them stock in worthless or fraudulent enterprises.

"Hardly a day passes," he said, "when farmers, young and old, are not invited to share in some financial operation, in some great speculation, dazzling their sight with the hope of immense gains. The agents are persuasive and insistent. They know a 
thousand tricks. City lots, mining lots, gas, oil, patents, everything is made the object of tempting solicitations under the name of some master of finance or with the help of an advertisement, skilfully inserted in a prominent place in a paper with a wide circulation. It is a real plague, a pest. One must live in the country and hear the complaints of the victims to realize the magnitude of these operations. In the single county of St. Hyacinthe, over one hundred thousand dollars have been extracted from the farmers' pocket, and the whole amount is lost. Some of these farmers, seized with a real frenzy, did not hesitate to sell the splendid farms that had come down to them from their ancestors and exchange them for worthless paper, which did not confer the title to an inch of ground or a milligram of metal."

"Cannot this evil be suppressed? Should the farmer be left to gain experience at his own expense by becoming a prey to these rapacious thieves? I think we should follow the example of the Old Country and decree that no person or syndicate shall be authorized to solicit funds unless they have an official certificate, attesting that the undertaking for which they are collecting money is of public utility. Such a law would remove a great many snares."

One good thing about investing your money at home is the fact that before you invest you can investigate.

\section{LOSSES TO CATTLE THROUGH BRUISES IN SHIPMENT}

A conservative estimate places the loss sustained through bruises on cattle handled by the Stock Yards at Toronto, in 1915 , at $\$ 750,000$.

The loss is greatest among cattle, and for the most part is attributable to hooks by horns, which might be entirely prevented if farmers would go to the trouble of applying a little caustic potash when calves' horns start to grow. This will stop their growth entirely and painlessly.

Part of the loss is, however, attributable to rough handling and the consequent bruising of lambs, sheep and hogs, and occurs between the time they leave the farm and their arrival at the yards.

Employees are warned by notices posted at the markets, railway sidings and packing houses, not to use sticks in such a manner as to cause bruising, and so far as the packing houses are concerned, the abuse of live stock is not tolerated.

At the loading stations, however, accommodation is often insufficient, there not being enough pens to keep strange cattle separated before loading. When the cattle present in one or two pens are made up from a number of different herds, and are strange to each other, they naturally become restless, jumping and hooking and causing great damage. This state of affairs the railways are seeking so far as possible to remedy.

The Union Stock Yards, when unloading stock, use a buffer on each side of the car door, thus preventing crowding against the sides of the doorway. They also inspect for old nails and spikes. Men loading stock at country points are urged to have the sides of the car doors protected by buffers.

Buyers figure against losses incurred in this way, so that the loss is borne by the farmer. Buyers at the Toronto markets for sometime deducted two dollars per head for horned cattle. This arrangement, while it lasted, showed good results, both as to dehorning and as regards handling. The practice now is to buy gored cattle at a price that will cover the depreciation. -John TAYLOR, GunNs Limited. 


\section{CANADIAN EQUIVALENTS}

\section{For Measures and Weights expressed according to the Metric System}

1 Metre..................40 inches (very nearly)

1 Kilometre................ 1,000 metres $-\frac{8}{5}$ mile.

1 Are........................ 120 sq. yards.

1 Hectare.................. 2.47 acres (nearly $21 / 2$ acres).

1 Kilogramme...............2.2 lbs.

1 Quintal................. 100 Kilogrammes-220 lbs.

1 Quarter................. 8 bushels.

1 Pood (Russian)................. 36 lbs.

1 Litre.................. $13 / 4$ pints (gallon-about $41 / 2$ litres).

1 Hectolitre................ 100 litres, or very nearly 22 gallons.

1 Gram................. $151 / 2$ grains.

1 Kilogram. . . . . . . . . . .

Ton $=2,000 \mathrm{lbs}$; Long Ton $=2,240 \mathrm{lbs}$; Metric Ton $=2,200 \mathrm{lbs}$.

\section{ADMISSION TO CANADA OF FARM LABOURERS AND DOMESTICS}

The Immigration Act provides for the admission without hindrance of agriculturists and domestic servants. The money regulation is not enforced in the case of persons coming to assured farm employment, or to domestic service. It is required, however, that every person entering Canada shall be in good health and of good character and shall have transportation to destination, and either assurance of employment when they arrive at destination or sufficient funds to look after themselves for a short time in case of need.

For the duration of the War, the authorities will not enforce the provision requiring continuous journey from country of birth, as regards bona fide farm labourers.

"As to" Britain's ability to pay the bills, there will be no diminution in that cruse of oil. So long as Britain's name on a scrap of paper is made good by her blood land treasure before the world, you can put no commercial value or limit on the Empire of Great Britain."-C. W. BARRON, The Wall St. Journal. 


\section{CURRENCIES OF LEADING COUNTRIES}

Approximate value at standard rate of exchange.

\section{Great Britain and Ireland}

1 Penny................... $=2$ cents.

1 Shilling (twelve pence).......... $=24$ cents.

1 Pound (20 Shillings)........... $=\$ 4.86$

Note-On January 4, 1915, demand sterling was quoted in New York at $4.743 / 8$, a depreciation of little more than $2 \%$ from normal.

Australia, New Zealand, South Africa, British West Indies, etc., employ the same system as Great Britain.

\section{France}

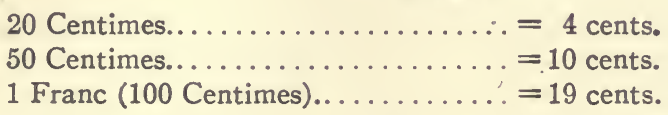

\section{Russia}

5 Kopecks................. 3 cents.

20 Kopecks................ $=10$ cents.

1 Rouble (100 Kopecks)......... $=51$ cents.

1 Imperial (10 Roubles) $\ldots \ldots \ldots \ldots=\$ 5.10$

\section{Germany}

20 Pfennige................. $=5$ cents.

50 Pfennige................. $=12$ cents.

1 Mark (100 Pfennige).......... $=24$ cents.

Note-On January 4, 1915, the Mark was valued at $187 / 8$ cents in New York. This was the lowest quotation to that date since the outbreak of the war.

\section{Austria-Hungary}

10 Heller.................. $=2$ cents:

1 Krone $(100$ Heller $) . \ldots \ldots \ldots \ldots \ldots$ cents.

5 Kronen.................. $=\$ 1.00$

Note- On Jan. 4, 1915, the rate of exchange was $35 \%$ below par.

\section{Turkey}

1 Piastre................... $=4$ cents.

10 Piastres.................. $=44$ cents.

1 Medjidie (100 Piastres) $\ldots \ldots \ldots \ldots=\$ 4.40$

\section{Denmark}

10 Ore....................

1 Crown (100 Ore).............

\section{Netherlands (Holland)}

5 Cents..................... $=2$ cents.

25 Cents.................. $=10$ cents.

1 Guilder or Florin (100 Cents)..... $=40$ cents.

Note-In. Norway and Sweden the same system is in use as in Denmark.

In countries of the Latin Union the following coins have the same value as the French Franc (19 cents)-

Belgium and Switzerland "Franc"; Italy "Lira"; Greece "Drachme"; Rumania "Lei"; Serbia "Dinar"; Spain "Peseta." 


\section{LIST OF BULLETINS AVAILABLE FOR DISTRIBUTION ISSUED BY THE DOMINION DEPARTMENT OF AGRICULTURE}

As long as the supply lasts, copies of the following will be sent on application to The Publications Branch, Department of Agriculture, Ottawa. No postage is necessary.

\section{Field Crops}

TITLE

Agrostology, Summary of Results, Division of

Alfalfa or Lucerne.

Alfalfa Growing in Alberta.

Cereals, Summary of Results, 1914.

Clover, Sweet-The Truth.

Corn for Ensilage, Growing and Using.

Corn for Ensilage and the Silo.

Corn Growing in Manitoba.

Crop Rotation and Soil Cultivation.

Crop Rotations for Central and Eastern Ontario.

V Crop Rotations for the Dry Farming Districts of Canada.

Drainage on the Farm, Tile

Emmer and Spelt.

$\checkmark$ Field Husbandry, Summary of Results, 1914.

Field Root, Profitable Varieties for Ontario and adjacent Parts of Quebec.

Field Root, Profitable Varieties for Maritime Provinces and Eastern Quebec.

Flax Plant, The

Flax Fibre.

Fodder and Pasture Plants (coloured plates). For sale by single copies only, at the office of the King's Printer, Government Printing Bureau. (Price 50 cents.)

Forage Crops and Pasture Grasses.

Forage Crops, Summary of Results, 1914.

Grain Crops on the Prairies, Preparing Land for

Grain recommended by the Dominion Cerealist for British Columbia, Varieties of

\section{Live Stock}

Abortion, Bulletin on Contagious

Anthrax and Blackleg.

Bacon Pigs in Canada.

Beef Raising in Canada.

Ewe and the Lamb, Care of the

Farm Buildings, Ventilation of

Fly, Cattle Horn

Health of Domestic Animals, Conservation of
TITLE

Grain Recommended by the Dominion Cerealist for Quebec and Ontario, Varieties of

Grain recommended by the Dominion Cerealist for the Maritime Provinces, Varieties of

Grain Crops, How the Ripening of may be hastened.

Grass, Awnless Brome versus Western Rye.

Legumes, Inoculation for the Growth of

Plant Breeding in Scandinavia. For sale at the office, Secretary, Canadian Seed Growers' Association, Ottawa.-Price $\$ 1.00$

Rape Plant, The

Seed Growers' Assocation and Its Work, The Canadian

Seed Control Act, with Regulations, The

Seeds, Growing Field Root, Vegetable, and Flower in Canada.

Seed Oats.

Seed, Inquiry regarding the Wheat, Oats, Barley, Flax, and Ensilage Corn used for in Canada.

Smut, Seed Treatment for Grain

Tobacco Experiment Stations in Quebec.

Tobacco Culture in Canada.

Tobacco Seed Bed.

Weeds, Do you know your

Weeds.

Weed, Orange Hawk

Weeds and Weed Seeds.

Wheat, Quality in
Hog Cholera.

Horse, The French-Canadian

Horse Breeding and Rearing of Colts.

Horses and Cattle, Mange in

Maladie du Coit.

Meat Inspection Service, The Canadian

Rabies.

Ram and Ewes, Care of during the Breeding Season. 


\section{Live Stock-Continued}

TITLE

Sheep-Breeding Stock, Advice to the Beginner in the Selection of

Sheep-Castration and Docking.

Sheep-Dipping, Advantages of

Sheep Husbandry in Canada.

Silo, The Stave

Steer Feeding in Manitoba, Experiments in

Stock in Winter, The Feeding of

Swine Husbandry in Canada.
TITLE

Tuberculosis: a plain statement of facts regarding the disease, prepared especially for farmers and others interested in Live Stock.

Warble Flies-the economic aspect and a contribution on the biology.

Wool and Its Manufacture.

Wool for Market, Preparing

Wool Growers, Practical Assistance to in the Marketing of their Wool Clips.

\section{Poultry}

Chicks, Brooding and Rearing

Duck Raising.

Eggs, The Care of Market

Eggs, The Candling of

Eggs, The Payment of According to Quality.

Eggs, Rules for the Production and Marketing of New Laid

Eggs, Lime Water for the Preservation of

Egg and Poultry Situation in Canada, The

Eggs in the House, The preserving of

Eggs, Standards for Canadian

Egg Production, Winter

Egg Circle Members, Suggestions for

Egg Circles, The Organization of Cooperative

\section{Dairy}

Butter, Some of the Factors that Control the Water Content of

Butter, Sweet Cream

Buttermaking on the Farm, 2nd edition.

Cheese, Coulommier-some notes on its manufacture.

Cheese Making, Cooling of Milk for

Cheese, Cream

Cheesemakers, Notes for Factory

Cheese, Island of Orleans

Cheese, Coulommier

Cheese and Butter, Cream

Cheese Factory and Creamery Plans, with Specifications.

Cold Storage Act, 1907, as amended in 1909 , and Regulations.
Flock, The Farm

Geese, The Management of

Hens and Pigeons, How to tell the Age of

Incubation, Artificial

Incubation, Natural

Nests, Trap

Poultry, The Crate Fattening of

Poultry House, The Farmer's

Poultry, Plan of Permanent Laying House for

Removal of Male Birds after the Breeding Season, Importance of the

Turkeys, The Management of
Cow Testing, Good Reasons for

Cows, Profits from Dairy

Cow Testing, with some Notes on the Sampling and Testing of Milk.

Cow Testing, Notes on

Creamery Cold Storage Bonuses.

Cream, Care of for Buttermaking.

Creameries, Cold Storage for

Dairy Legislation.

Dairy Industry Act and Regulations, The

Dairying and Cold Storage.

Dairying in Canada, Progress of

Ice, The Use of on the Farm.

Milk Test Act, The

Milk Production in Canada.

Milk, Cream.

\section{Orchard and Garden}

Apples for the Canadian Northwest, Progress in the Breeding of Hardy

Apple Dealers in Manitoba, Saskatchewan and Alberta, and also in Kenora and Keewatin: A List of Wholesale and Retail
Cabbage and Cauliflower Culture.

Co-operation and Fruit Growing.

Fruits, Small

Fruit Industry, The

Fruits, The Preservation of for Exhibition Purposes. 


\section{Orchard and Garden-Continued}

TITLE

Fruit Trees, Protection of from Mice and Rabbits, and Care of Injured Trees.

Fruits, Vegetables, and Ornamental Plants. How to protect from Insects and Fungous Diseases.

Garden, The Vegetable

Grapes, Growing for Home Use.

Garden, Home Vegetable, and a Patriotic Garden Competition.

Hot Beds and Cold Frames, How to make and use

Home Lot, Planning the

Homes, Beautiful, and How the Farmer may make them.

Horticulture, Division of, Summary of Results, 1913.

Horticulture, 1914, Summary of Results.
TITLE

Inspection and Sale Act, Amendment to', 1913, as affecting Fruit, and regulations thereunder.

Medicinal Plants and their Cultivation in Canada.

Orchards, Renovation of Neglected

Perennials tested in the Arboretum and Botanic Garden at the Exp. Farm, Ottawa: List of Herbaceous

Plum Culture.

Potato Growing in the Maritime Provinces. Potato, The

Roses, Hardy-Their Culture in Canada.

Strawberry Culture.

Tomatoes, The Outlook for Canadian in Great Britain.

Tomato Culture.

Top-Grafting.

\section{Insects and Plant Diseases}

Apple Scab.

Army-Worm, The

Chinch Bug in Ontario, The

Cutworms and their Control.

Flea Beetles and their Control.

Fly, The Large Larch Saw

Fly, The Hessian, and the Western Wheatstem Saw-fly.

Insects, Pests, and Diseases Destructive to Vegetation-Legislation in Canada to prevent the Introduction and Spread of, with Regulations regarding the Importation of Vegetation into Canada.

Insect and Pest Act, Regulations under the Destructive, governing the Importation, Sale, Shipment, and Exportation of the Common or Irish Potato.
Insect Conditions in British Columbia, Preliminary Survey of

Locusts, Control of in Eastern Canada.

Plant Diseases of Southern Ontario.

Potato Diseases Transmitted by the Use of Unsound Seed Potatoes.

Potato Canker.

Potato Scab.

Potatoes, Powdery Scab of

Potato Diseases, Control of

Smut Diseases of Cultivated Plants.

Strawberry Root Weevil in B.C., The

Tent Caterpillars.

Trees, Plants, and other Nursery Stock, Instructions to Importers of into Canada.

\section{Miscellaneous}

Agricultural Instruction Act and Explanatory Speech by the Minister of Agriculture.

Bee-Keeping in Canada.

Bees, Facts about

Bulletin of Foreign Agricultural Intelligence (Monthly).

Experimental Farms, The Work of the

Experimental Farms and Stations, A Guide to

Farms, Dominion Experimental, A Review 1886-1912.
Farm Products: Food and Clothing Materials, their formation and composition.

Farmers! Watch your Balance in Nature's Bank.

Gazette, The Agricultural, of Canada. (Monthly, \$1.00 per year.)

Hints, No. 1, Seasonable, March.

Hints, No. 2, Seasonable, July.

Lime in Agriculture.

Manures and Fertilizers.

Maple Sugar Industry in Canada, The 


\title{
Miscellaneous-Continued
}

Plants, Poisonous

TITLE

Potash in Agriculture.

Publications available for Distribution, List of

Soils, Western Prairie: Their Nature and Composition.
TITLE

Soils: Their Origin and Nature. Fertility: its Maintenance and Increase.

Trees, the Planting and Care of Shade

Well, The Farm

World's Sole Manufactures of Protein, Fats, Carbohydrates, and Cloth Fibres, The.

\section{ONTARIO DEPARTMENT OF AGRICULTURE, TORONTO}

\section{Field Crops}

No. 228 Farm Crops; Experiments at No. 232 Field Beans.

O.A.C.

\section{Live Stock}

No. 214 Sheep Raising in Ontario: Does No. 225 Swine. it Pay?

\section{Poultry}

No. 208 Farm Poultry and Egg Market- No. 217 Farm Poultry.

ing Conditions in Ontario " 193 Tuberculosis of Fowls.

County.

\section{Dairy}

No. 205 Dairy School Bulletin.

“ 206 Dairy School Bulletin.

No. 221 Food Value of Milk and its

“ 207 Ice-Cold Storage on the Farm.

\author{
Products.
}

\section{Orchard and Garden}

No. 194 Apple Orcharding.

“ 216 Box Packing of Apples.

“ 222 Currants and Gooseberries.

“ 211 Fruits Recommended for Ontario

Planters.

“ 226 Plum Culture in Ontario.
No. 210 Strawberry Culture and the Red Raspberry.

“ 230 The Cherry in Ontario.

“ 231 Vegetable Growing.

“ 184 Uses of Vegetables, Fruits and Honey.

\section{Insects and Plant Diseases}

No. 227 Cherry Fruit-Flies.

“ 229 Smutsand Rusts of Grain Crops.

“ 187 The Codling Moth.
No. 219 The San Josè and Oyster-Shell Scales.

“ 158 Insects and Fungus Diseases Affecting Fruit Trees.

\section{Miscellaneous}

No. 174 Farm Underdrainage, does it No. 234 Pay?

“ 175 Farm Drainage operations.

“ 178 Character and Treatment of Swamp or Muck soils.

“ 188 Weeds of Ontario.

“ 213 Bee Diseases in Ontario.

“ 218 Birds of Ontario.
“ 208 Farm Forestry.

“ 223 Fertilizers.

“ 224 Greenhouse Construction.

“ 220 Lightning Rods.

“ 233 Natural Swarming of Bees. 


\section{MANITOBA DEPARTMENT OF AGRICULTURE, WINNIPEG}

\section{Field Crops}

TITLE

Alfalfa in Manitoba.

Alfalfa Inoculation.

Barley Growing.

Cultivation After Harvest for

Weed Control.
TITLE

Fodder Corn in Manitoba.

No. 16 Hay and Pasture Crops in Manitoba.

\section{Live Stock}

Beef Cattle Situation.

No. 7 Hog Raising in Manitoba.

“ 1 Horses.

Manitoba's Hog Market.
Pork Making on the Farm.

Some Facts about Sheep.

The Farmers' Beef Ring.

\section{Poultry}

No. 6 Farm Poultry in Manitoba.

No. 12 The Farm Flock.

Improving the Farm Egg.

\section{Dairy}

A Few Dairy Facts.

No. 14 Care of Cream for Creameries.

“ 3 Care of Milk and Cream.
No. 8 Cow Testing.

Cream for Creameries.

\section{Orchard and Garden}

Growing Cherries in Manitoba. No. 5 The Farm Garden.

Growing Plums in Manitoba.

\section{Insects and Plant Diseases}

Control of Insect Pests.

Spray Mixtures.

Tree Pests and Cutworms.

\section{Miscellaneous}

A Plea for Bird Houses.

No. 18 Bee-Keeping in Manitoba.

" 11 Canning and Preserving. Our Friends, the Birds.

“ 10 Plans for Farm Buildings.

“ 9 Repairing Farm Equipment and Roads.
Rye as a Weed Eradicator.

No. 2 Twelve Noxious Weeds.

" 17. Silo Construction and Ensilage Production.

“ 19 Soil Drainage.

Treatment of Alkali Soils.

\section{SASKATCHEWAN DEPARTMENT OF AGRICULTURE, REGINA}

Growing Profitable Crops on the Drier Lands of Saskatchewan.

Summerfallow.

Tillage of Prairie Land.

Tillage of Stubble Land.

Corn Growing in Saskatchewan.
Seed Grain, Seed Treatment and Seeding. Hints to Flax Growers. Varieties of Small Grains. Alfalfa in Saskatchewan. Alfalfa Seed Production.

Winter Rye. 
ALBERTA DEPARTMENT OF AGRICULTURE, EDMONTON

Vegetable Bulletin.

TITLE

Potato Bulletin.

Successful Poultry Raising.

Bulletins No. 1 to 5 on Swine.

Meat Curing on the Farm.

Weeds of Alberta.

Sheep Bulletin.
TITLE

Successful Farmers in Alberta.

Live Stock and Mixed Farming.

Co-operative Marketing of Eggs.

Land and Colonization in Alberta.

Opportunities in Alberta.

Guide to Peace River Country.

BRITISH COLUMBIA DEPARTMENT OF AGRICULTURE, VICTORIA Field Crops

No. 40 Alfalfa.

Clover Fodder.

Corn.
No. 61 Field-crop Competitions, 1914-15

“ 62 Field-crop Competitions, 1914-15: Boys' and Girls'

\section{Live Stock}

No. 64 Angora and Milch Goats.

“ 32 Control of Tuberculosis:

“ 67 Feeding and Management of

Dairy Cattle (ready shortly).

No. 60 Hog Raising.

Stock Breeders' Directory.

\section{Poultry}

British Columbia Poultry No. 49 Market Poultry. Breeders' Directory.

“ 39 Natural and Artificial Brooding and Incubating.

No. 55 Care and Marketing of Eggs.

Construction of Fresh-air Brooders.

“ 63 Poultry-house Construction.

Poultry-keeping on a City Lot.

Keeping Poultry Free from Lice. “ 26 Practical Poultry-raising.

Management of Geese.

Management of Turkeys.

\section{Dairy}

The Care of Milk and Cream.

\section{Orchard and Garden}

Cabbage, Celery and Tomato Production.

Commercial Onion Culture.

Commercial Potato Culture.

Culture of Small Fruits in the Coast Sections.

Farm Storages for Fruits and Vegetables.

Fertilizers for Fruits and Vegetables.

No. 33 Fruit Growing Possibilities, Skeena River.

The Home Vegetable Garden for Interior Sections.

Methods of Fruit Picking and Handling.

Orchard Cultivation and Cover Crops.
Orchard Intercrops.

Packing Orchard Fruits.

Planting Plans and Distances.

Practical Irrigation.

Progress and Prospects in Fruit and Vegetable Growing.

Propagation and Selection of Nursery Stock.

Potato Recipe Book.

Pruning Fruit Trees.

Selection of Orchard Sites and Soils.

Spray Calendar.

Sprays and Spraying.

Thinning Tree-fruits.

Varieties of Fruit recommended for Commercial Planting. 


\section{Insects and Plant Diseases}

TITLE

No. 68 Diseases and Pests of Cultivated Plants (ready shortly).

Fire-blight (Bacillus amylovorus, Burrill).

\section{Miscellaneous}

No. 42 Apiculture.

" 54 British ColumbiaWomen's Handbook (1913-14).

Gardening on a City Lot.

" 30 Guide to Bee-keeping.

“ 44 Irrigation.

“ 35 Place and Purpose of Family Life.

“ 36 Preparation of Food.
TITLE

Fungous Diseases of Orchard and Garden.

Insects Injurious to Orchard.

\section{QUEBEC DEPARTMENT OF AGRICULTURE, QUEBEC}

The following are published in English:-

By the Department:

Plans of Cheese and Butter Factories.

List of Cheese and Butter Factories.

The Production and Preparation of Pork

for Market.

Drainage Plans for Farmers.

Culture of Fruit Trees.
Seed Improvement.

Root-seed Growing.

The Use of Agricultural Lime.

Women's Institute Quarterly, 1916.

Wild Oats.

No. 66 Silos and Silage.

Report of Markets Commissioner.

\section{NOVA SCOTIA DEPARTMENT OF AGRICULTURE, TRURO}

1. Articles on Soils, Soil Cultivation and Crops of Nova Scotia.

2. Articles on Sheep Raising in Nova Scotia.

3. Articles on Dairying in Nova Scotia.

4. Articles on Swine Breeding in Nova Scotia.
By Macdonald College:-

The Farmer's Vegetable Garden.

Farm Poultry.

The Milk Supply of Montreal.

5. Articles on Gardening in Nova Scotia.

6. Articles on Horse Breeding in Nova Scotia.

7. Articles on Poultry Raising in Nova Scotia.

\section{NEW BRUNSWICK DEPARTMENT OF AGRICULTURE, FREDERICTON}

\section{Field Crops}

Field Crops and Soil Management.

\section{Live Stock}

Improvement of Live Stock. 


\section{Poultry}

Fattening and Marketing of Poultry.

Poultry House Construction.

Opportunities in Poultry Culture in N.B. The Baby Chick.

\section{Orchard and Garden}

Establishment of Apple Orchards and their Care up to the Tenth Year.
The Renovation and Top-Grafting of Old Trees and Orchard Spraying Campaign. Spraying the Apple Orchard.

\section{Insects and Plant Diseases}

Apple Tree Borers.

Brown-tail and Gypsy Moths.

Chief Insecticides and Fungicides for

Orchard and Garden Crops.
The Forest-Tent Caterpillar.

Powdery Scab of the Potato.

\section{Miscellaneous}

Home-mixed Fertilizers.

Agricultural Education, Suggestions for Teachers.

A Little Talk with the Baby's Mother.

An Appeal to School Garden Teachers.

Call of The Land.

Circular No. 1-Arbor Day Observance.

Education for Agriculture.

Food and Diet.

Homes and How to Make Them Attractive.
Home Economics as Applied to the Choice and Preparation of Foods.

Nature Study and Agricultural Course for Public Schools.

Notes on Bee-Keeping.

Schools Gardens, Instructions to Teachers. The School Garden-Its Purposes-Its Care during Vacation.

The Preservation and Care of Food.

Uses of Fruits in the Household. 


\section{INDEX}

To the Farmers of Canada, Hon. Martin Burrell, Minister of Agriculture. Page

Thanksgiving in England for Canadian Crops........................ 4

\section{THE WAR AND FINANCE:}

Extracts from the Budget Speech of Sir Thomas White, Minister of Finance

The National Income and Expenditure of the United Kingdom...........

The Capital and Income of the British Empire................... 8

The Nation's Need, British Bankers' Manifesto. . . . . . . . . . . . . . . . . . . 10

Cost of the War..................................... 12

Belligerents' Borrowings.................................. 12

Produce More; Save More, Sir Thomas White..................... 13

Trade of Canada; Summary for 1914, 1915 and $1916 \ldots \ldots \ldots \ldots \ldots \ldots \ldots 13$

Canada's Foreign Indebtedness................................ 14

\section{PRODUCTION IN 1915:}

The Farmers' Response, C. C. James........................ 15

How the Provinces Responded . . . . . . . . . . . . . . . . . . . . . . 16

Saskatchewan's Big Year. . . . . . . . . . . . . . . . . . . . . . . . . 17

Alberta's Big Wheat Crop . . . . . . . . . . . . . . . . . . . . . . . . . . . . 18

A Great Change.......................................... 18

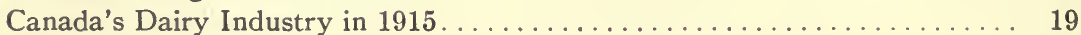

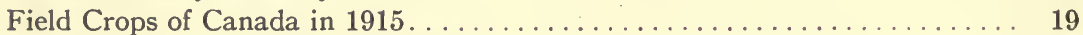

Wheat Crops of Canada, 1910-15 . . . . . . . . . . . . . . . . . . . 21

Wheat Exportable Surplus, 1915.......................... 21

Field Crops of the United States, $1915 \ldots \ldots \ldots \ldots \ldots \ldots \ldots \ldots \ldots \ldots \ldots \ldots . \ldots \ldots 22$

Field Crops of England and Wales, 1915..................... 23

PRODUCTION IS CANADA'S DUTY WHILE EMPIRE IS AT WAR:

Extracts from Addresses by Sir Thomas White................. 24

Our Country's Need, C. C. James........................ 25

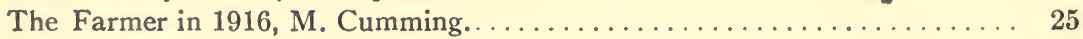

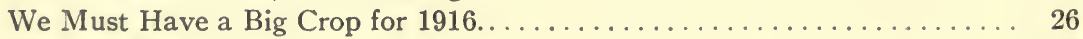

Patriotic Production. .............................. 27

The Situation in Manitoba, George Batho................... 28

The Call of 1916, W. E. Scott. . . . . . . . . . . . . . . . . . . . 29

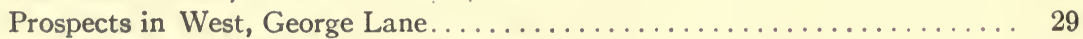

Fall Wheat and Fall Ploughing, acreage of ................ 30

FOOD SUPPLIES OF THE UNITED KINGDOM . . . . . . . . . . . . 31

Meat Consumption in............................... 32

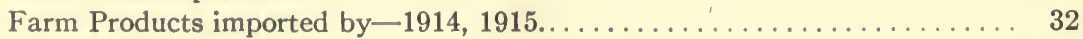

Increase in Values of Foods imported by, $-1914,1915 \ldots \ldots \ldots \ldots \ldots \ldots . . \ldots 4$

Britain's Food Imports in War Time. . . . . . . . . . . . . . . . . . . 35

Big Purchases in United States. . . . . . . . . . . . . . . . . . . . . . . 35

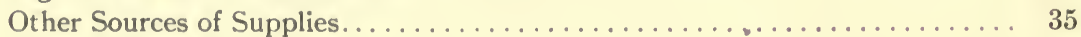

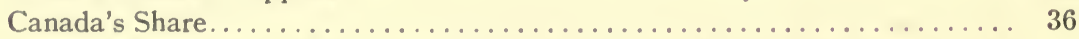

Values of Canadian Agricultural Exports to United Kingdom and United

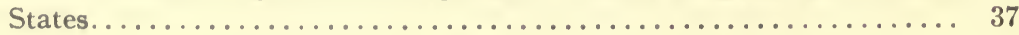


Soil Cultivation, J. H. Grisdale. . . . . . . . . . . . . . . . . . 38

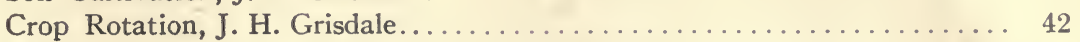

Winter Preparation on the Prairies, J. H. Grisdale................ 45

Seed Time Suggestions for the Prairies, J. H. Grisdale... . . . . . . . . . . 46

Field Crops in Manitoba, T. J. Harrison.................... 48

Some Timely Hints, S. A. Bedford....................... 50

Saskatchewan Crop-Growers' Plans in War Time, John Bracken......... 51

Preparation of Seed Bed for Oats in Saskatchewan, M. J. Tinline... . . . . . 52

Rate of Seeding in Alberta, G. H. Hutton...................... 53

Instances of What Good Cultivation will do................. 53

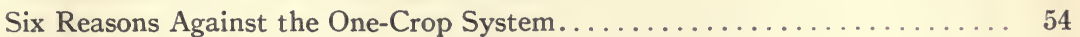

Just Once More, M. Cumming............................ 54

Growing Potatoes on Sandy Soils, A. L. Gibson................. 55

War Against Insect Pests, C. Gordon Hewitt.................... 57

Methods of Insect Control, C. Gordon Hewitt.................. 58

What Gocd Rotation Will Do......................... 59

Acre Profit Competitions in Ontario, C. F. Bailey................ 59

\section{GOOD SEED:}

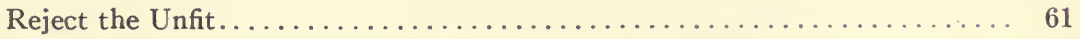

The Seed Situation, Geo. H. Clark........................ 61

The Production of High Class Seed in Canada, L. H. Newman.......... 64

Cereals; Recommended Varieties and Their Characteristics, Chas. E.

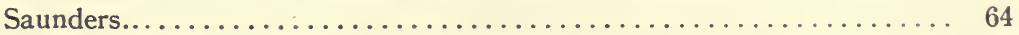

What Varieties Shall I Sow, results of Co-operative Experiments in Ontario 66

Rot-resistant Varieties of Potatoes......................... 67

How Saskatchewan Grain-Growers may do their "Bit" in 1916, G. H. Cutler...................................... 67

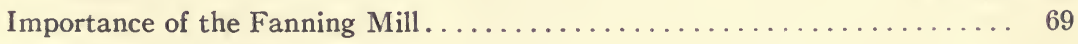

Loss from Grain Smut............................... 70

Money in Alsike.................................. 70

\section{FERTILITY AND FERTILIZERS:}

The Importance of Humus, from Dr. F. T. Shutt before the Committee

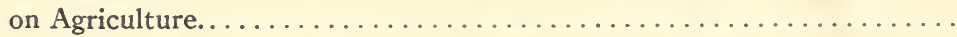

The Value of Manure, from Dr. F. T. Shutt before the Committee on

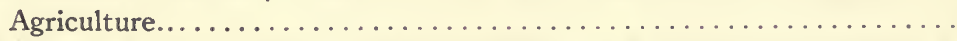

The Value of Clover, from Dr. F. T. Shutt, before the Committee on

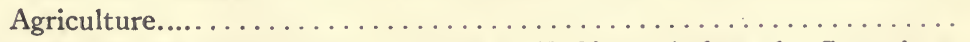

The Profitable Use of Fertilizers, from Dr. F. T. Shutt, before the Committee

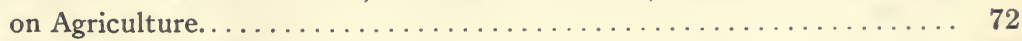

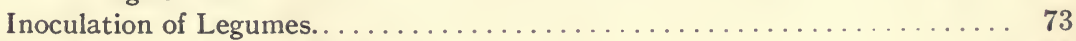

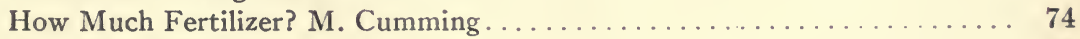

Lime, R. Harcourt............................. 74

Experiments with Lime in Nova Scotia, J. M. Trueman............. 76

The War and Fertilizers. . . . . . . . . . . . . . . . . . . . . 77

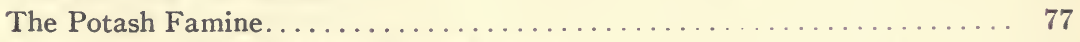

Fluctuations in Cost of Fertilizer Materials....................... 78

Canadian Fertilizer Exports and Imports . . . . . . . . . . . . . 79

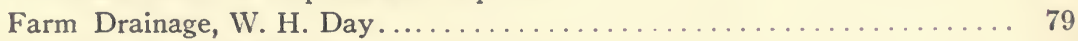

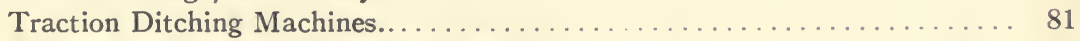

The Cost of Tile Drainage, W. W. Hubbard.................. 81 
The Live Stock Industry, H. S. Arkell. . . . . . . . . . . . . . . . . . 83

The Empire's Share in the Meat Trade...................... 91

The Present Opportunity for Canadian Stockmen, John Bright....... . . . 92

The Horse Industry, John Bright........................ 94

Legislation Affecting Horse Breeding.................... 97

The Necessity for Increasing our Herds and Flocks, James Audley ......... 98

Special Assistance to the Live Stock Industry, John Bright. . . . . . . . . 100

The Swine Industry and the British Market, G. E. Day... . . . . . . . . . . 102

Live Stock in Manitoba, F. S. Jacobs. . . . . . . . . . . . . . . . . 103

Quality in Live Stock, Wm. A. Munro. . . . . . . . . . . . . . . . . . 104

Reducing Cost of Production-Grain Crops; Pork, G. H. Hutton. . . . . . . . 105

The Swine Industry in Quebec, H. Nagant.................. 106

The Production of Veal, H. Nagant........................ 107

Mutual Confidence as a Factor in Increased Production of Live Stock,

A. P. Westervelt................................ 107

Beef Cattle, numbers of, by Provinces...................... 108

Live Stock, numbers of, Ontario........................ 109

Live Stock, numbers of, Manitoba, Saskatchewan and Alberta... . . . . . . 109

Mixed Farming in the West........................... 110

Prices realized in United States for Beef Cattle from Saskatchewan and

Alberta....................................... 110

Breeding and Beef Profíts.............................. 110

\section{THE DAIRYING INDUSTRY:}

The Dairying Industry, J. A. Ruddick.................... 112

Cheese and Butter Prices at Montreal 1914-1916................. 117

A Message to Ontario Dairymen, H. H. Dean........ . . . . . . . . . . 118

Notes on Dairying in Eastern Ontario, G. G. Publow. . . . . . . . . . . . . . . 119

Dairying in Ontario in 1915, Frank Herns . . . . . . . . . . . . . . . 120

Manitoba Dairy Products, F. S. Jacobs. . . . . . . . . . . . . . . . . . 120

Canadian Dairy Records, Chas. F. Whitley...................... 121

Assistance in Cow Testing. . . . . . . . . . . . . . . . . . . . . 123

What One Farmer has Done. . . . . . . . . . . . . . . . . . . . . . . . . 123

A Great Cheese Year... . . . . . . . . . . . . . . . . . . . . . . . . . . . . . . 124

\section{THE POULTRY INDUSTRY:}

The Egg and Poultry Situation in Canada, W. A. Brown ............ 125

The Profit-Making Hen............................ 127

Improving Ontario's Egg Production, W. R. Graham............... 127

Quebec's Opportunity in Poultry Raising, M. A. Jull................. 128

Selecting Poultry for Efficiency, M. A. Jull..................... 129

Prospects for Poultry in Manitoba, F. S. Jacobs... . . . . . . . . . . . . . . 130

Poultry in Western Canada; B.C. Laying Contest.................. 131

\section{SPECIAL CROPS:}

Canadian Sugar Statistics... . . . . . . . . . . . . . . . . . . . 133

From Sugar Beet to White Granulated Sugar, Dr. Michael Potvliet. . . . . . . . 133

Sugar, a Canadian Product, C. H. Houson... . . . . . . . . . . . . . . . . . . 134

Statistics of World's Sugar Production and Consumption . . . . . . . . . . . . 136

Honey Production, F. W. L. Sladen... . . . . . . . . . . . . . . . . . . . . . . . 137

The Maple Sugar Industry, Jos. H. Lefebvre. . . . . . . . . . . . . . . . . . . . . . 138

The Flax Shortage, James A. McCracken... . . . . . . . . . . . . . . . . . . . . 140

Production of Flax in Ontario . . . . . . . . . . . . . . . . . . . . . . . . 141 
Flaxseed or Linseed; Imports and Exports . . . . . . . . . . . . . . . 142

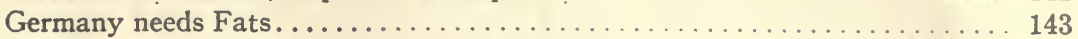

Fruit Production during the War, F. H. Grindley . . . . . . . . . . . . 143

Fruit Losses from Insects in Ontario. . . . . . . . . . . . . . . . . . . . . . . . 144

Beans, J. O. Laird..................................... 145

Beans, British Imports of............................ 146

Beans, A Cash Crop. . . . . . . . . . . . . . . . . . . . . . . 147

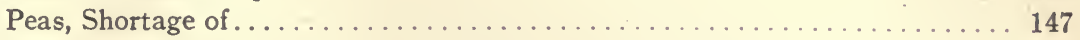

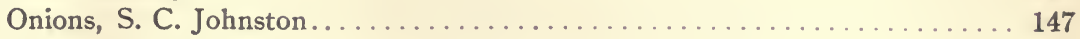

Tobacco; the 1915 Crop................................. 149

Dried Vegetables.................................. 150

O.P.V. Silage for the Maritime Provinces, John M. Trueman .......... . 151

Root House Construction in Alberta, S. G. Carlyle... . . . . . . . . . . . 151

\section{WHEAT AND THE WAR:}

The Course of Events-Ocean Freights and Prices-Statistical Position-

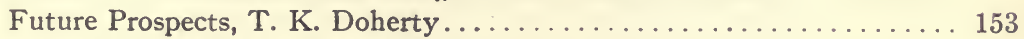

How Australia is Marketing its Wheat...................... 177

The Wheat Crop in Russia, W. Kotchetkov..................... 178

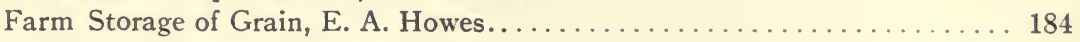

BACKYARD AND VACANT-LOT GARDENING............... 185

THRIFT-THE NECESSITY FOR PUBLIC AND PRIVATE ECONOMY . . 188

Economy in the Home... . . . . . . . . . . . . . . . . . . . . 193

What Kind of Apples to Buy, D. Johnson.................... 195

Cheese, The Food Value of............................ 196

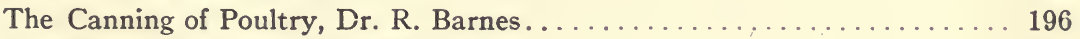

The Ben Davis Apple, Peter McArthur... . . . . . . . . . . . . . . . . 197

Household Efficiency, Miss M. U. Watson. . . . . . . . . . . . . . . . 197

Avoid Waste, Miss M. B. Philp.......................... 198

Household Accounts, Miss M. B. Philp... . . . . . . . . . . . . . . . . . 199

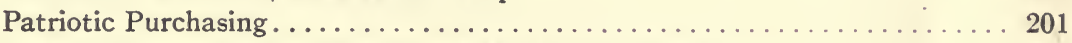

Give Preference to Canadian-Grown Fruit, D. Johnson... . . . . . . . . . 203

Use Canadian Fruit, R. M. Winslow...................... 204

Prices of Food Products-Canada, Great Britain, United States, Germany, Austria...................................... 205

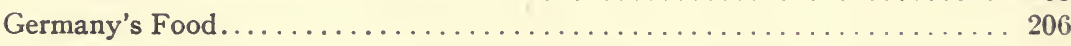

\section{WOMEN AND THE WAR:}

Appeal of an English School-girl; British Women and the War; The Women of Australia; Gives all her Boys to the Cause; He saw a Woman Ploughing; Women of Montenegro; Italian Peasant Women; Edith Cavell-Two Opinions

\section{THE CALL TO THE COLOURS:}

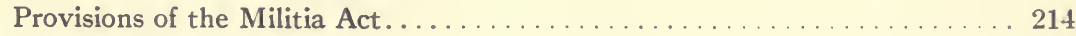

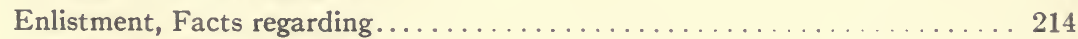

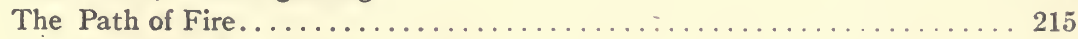

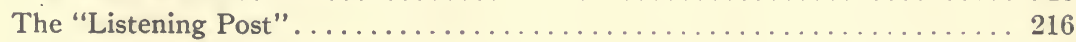

A Letter from France. . . . . . . . . . . . . . . . . . . . . . 216

In the Trenches; Jam replaces Butter, Sugar for Soldiers; Newspapers and

Magazines for the Front..................... 218-219 
Canadian Patriotic Fund. ............................ 220

Canadian Red Cross Society . . . . . . . . . . . . . . . . . . . . . . . 222

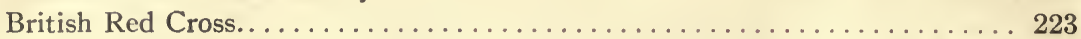

Belgian Relief Fund.................................. 223

Belgian Relief Work................................. 223

French Relief (Secours National) . . . . . . . . . . . . . . . . . . . . 224

Poland........................................... 225

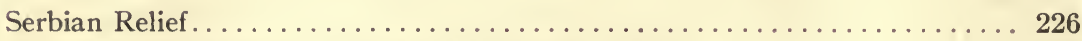

National Committee of Women for Patriotic Service. . . . . . . . . . . . 226

Canadian Indians: Patriotism and Production................... 226

The Blue Cross..................................... 227

\section{MISCELLANEOUS:}

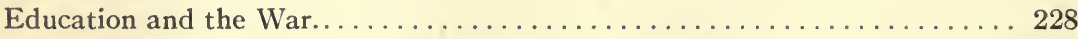

A Creed for Country Boys and Girls, G. C. Creelman.............. 228

Good Roads, One of Canada's Greatest Needs, W. A. McLean . . . . . . . . . . 229

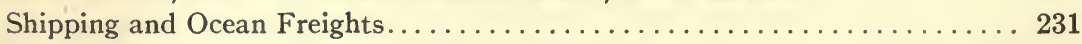

Russia's Agriculture; Agriculture in France; India.............. . 233-234

Schemes to Defraud Farmers.......................... 234

Losses to Cattle through Bruises.......................... 235

Equivalents for the Metric System ...................... 236

Farm Labourers and Domestics, Admission to Canada of . . . . . . . . . . 236

Currencies of Leading Countries....................... 237

List of Bulletins available for distribution-Dominion and Provincial Departments of Agriculture...................... 238-245 





\section{UNIVERSITY OF CALIFORNIA LIBRARY,}

BERKELEY

THIS BOOK IS DUE ON THE LAST DATE STAMPED BELOW

Books not returned on time are subject to a fine of $50 \mathrm{c}$ per volume after the third day overdue, increasing to $\$ 1.00$ per volume after the sixth day. demand may be renewed if expiration of loan period.

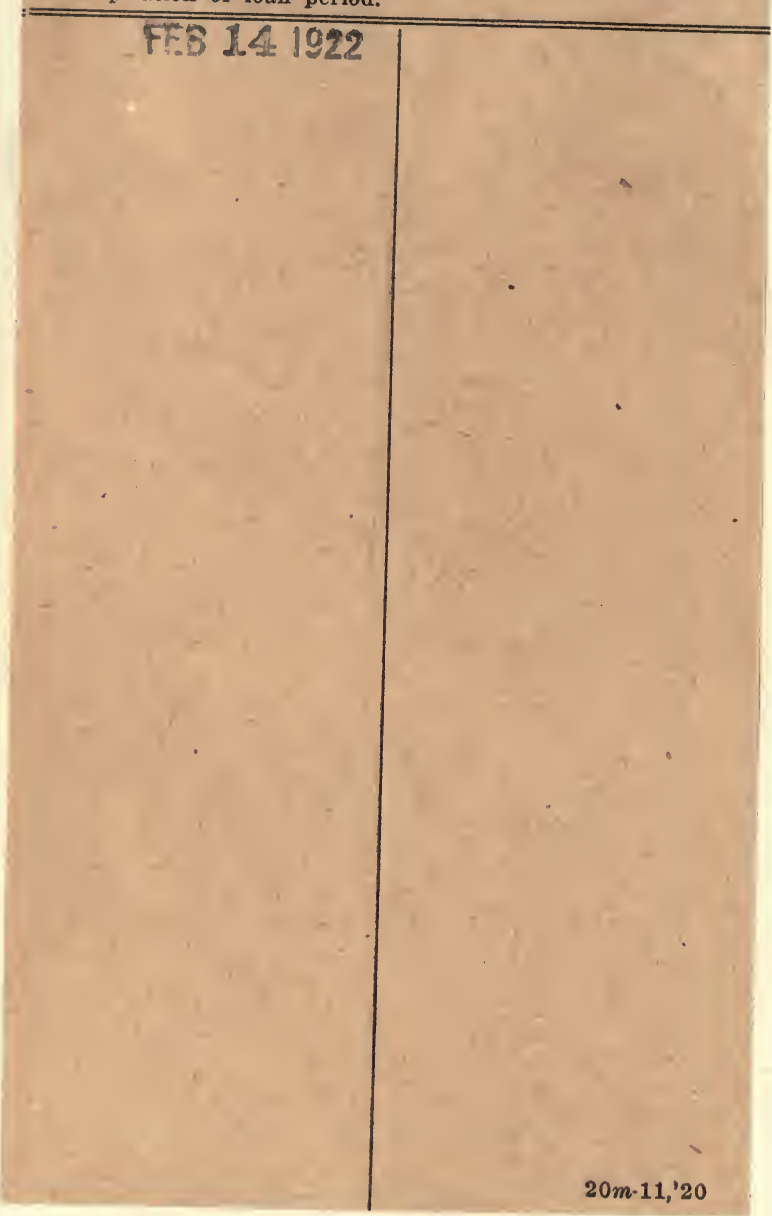




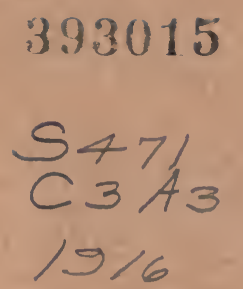

UNIVERSITY OF CALIFORNIA LIBRARY 
